U.S. Industrial Competitiveness: A Comparison of Steel, Electronics, and Automobiles

$$
\text { July } 1981
$$

NTIS order \#PB81-235749

\section{U.S. Industrial Competitiveness} \section{A Comparison of Steel,} Electronics, and Automobiles

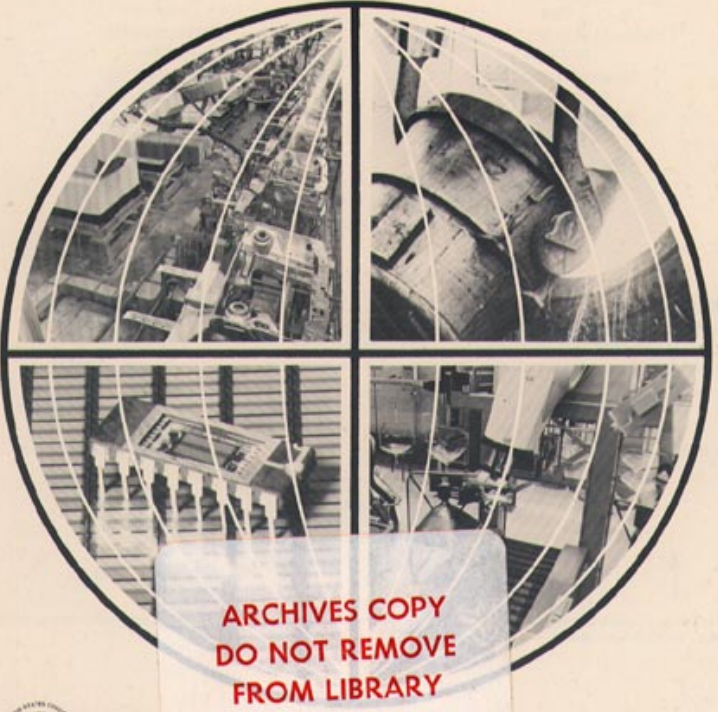

Cowaress of
Once of fect 


\section{Foreword}

This assessment builds on past and ongoing work by OTA requested by the Senate Committee on Commerce, Science, and Transportation and several other congressional committees. OTA'S study of the role of technology in the competitiveness of the American steel industry appeared in June 1980. An assessment of international competitiveness in electronics is now in progress. The report that follows draws upon both of those assessments, as well as past work at OTA on the automobile industry. It compares the international competitiveness of the U.S. steel, electronics, and automobile industries and evaluates prospects for better integration of policies affecting industries in the United States.

A variety of factors that influence industrial competitiveness are identified, and the current status and future prospects of the three industries-all critically important to the American economy-are evaluated and compared. The report also reviews past policies toward these industries in the United States, examines possibilities for industrial policy in the American context, and outlines options for policymakers.

OTA is grateful for the assistance of the advisory panel for this study, as well as for that provided by many individuals in the executive and legislative branches of the Government. OTA assumes full responsibility for the report.

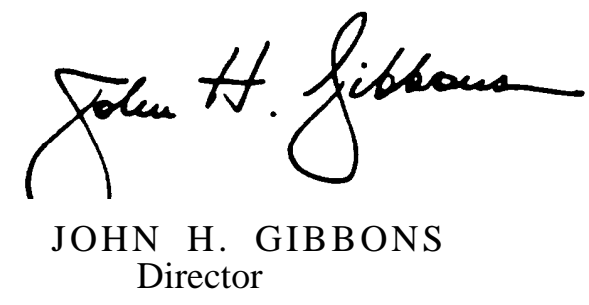




\title{
Advisory Panel
}

\section{Alan K. McAdams, Chairman \\ Cornell University}

\author{
Steve Beckman \\ International Union of Electrical, Radio, \& \\ Machine Workers \\ Milton Deaner \\ McLouth Steel Corp. \\ William E. Dennis \\ American Iron \& Steel Institute \\ John Holden \\ Ford Motor Co. \\ Robert R. Johnson \\ Burroughs Corp. \\ Maryann N. Keller \\ Paine Webber Mitchell Hutchins Inc.
}

\author{
E. Floyd Kvamme \\ National Semiconductor Corp. \\ Daniel Luria \\ United Auto Workers \\ Thomas P. Rohlen \\ Stanford East Asian Forum \\ H. Paul Root \\ General Motors Corp. \\ Gary R. Saxonhouse \\ University of Michigan \\ Caroline Ware \\ National Consumers League
}

NOTE: The advisory panel provided advice and critique throughout the assessment, but does not necessarily approve, disapprove, or endorse the report, for which OTA assumes full responsibility. 


\title{
Project Staff
}

Lionel S. Johns, Assistant Director, OTA

Energy, Materials, and International Security Division

Peter Sharfman, Program Manager

International Security and Commerce Program

John Alic, Project Director

$\begin{gathered}\text { Martha Caldwell } \\ \text { Robert R. Miller* }\end{gathered} \begin{gathered}\text { Ethan Arbisser* } \\ \text { Philip Mundo* } \quad \begin{array}{c}\text { Eric Davis* } \\ \text { Robert Rarog* }\end{array}\end{gathered}$
$\begin{gathered}\text { Administrative Staff } \\ \text { Sven Steinmo* }\end{gathered}$
Helena Hassell $\quad \begin{gathered}\text { Disher* } \\ \text { Dorothy Richroath Jacqueline Robinson }\end{gathered}$
Contributors
Marjorie Blumenthal, * Transportation Program
Joel Hirschhorn, Materials Program
Larry Jenney, Transportation Program
Philip Robinson, Materials Program
Con tractors
Robert B. Cohen \& associates
Lallra D'Andrea Tyson
Weil, Gotshal \& Manges
John Zysman

\section{OTA Publishing Staff}

\author{
John Bergling Kathie S. Boss Debra M. Datcher Joe Henson
}

*OTA contract personnel. 


\section{Contents}

Chapter $\quad$ Page

Glossary .. . . . . . . . . . . . . . . . . . . . . . . . viii

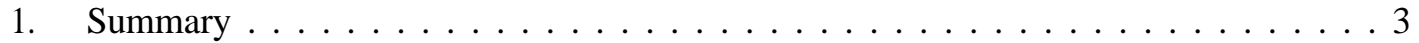

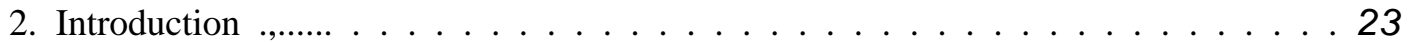

3. Steel, Electronics, and Automobiles: Industrial Structure . . . . . . 31

4. Measures of Competitiveness in the Three Industries . . . . . . . . . . 49

5. Industry-Specific Competitiveness . . . . . . . . . . . . . . . . . . . 69

6. Government Policy Effects on the Three Industries...............109

7, Prospective Competitive Futures, . . . ..., ., . . . . . . . . . . ..., ...127

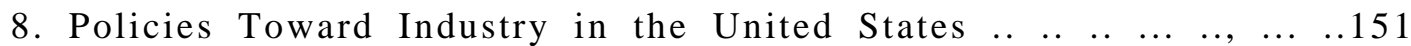
Appendixes:

A. Defining International Competitiveness . . . . . . . . . . . . . 169

B. The Economics of Industrial Policy . . . . . . . . . . . . . . . . . . ...175

C. The Legal Environment for Industrial Policy. . . . . . . . . . . . . 183

D. Foreign Industrial Policies. ., .. . . . . . . . . . . . . . . . . . . . 190

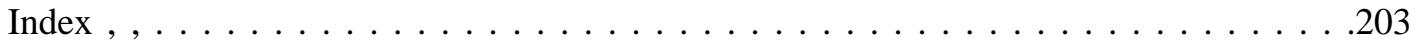




\section{Glossary}

Bit. A unit of information consisting of a binary digit that can have one of two values-e,g., "O" or "l, " " + " or " - ". Digital circuits operate by manipulating bits which are represented by voltage levels.

CAFE - Corporate Average Fuel Economy. Fleetweighted miles per gallon ratings for a manufacturer's automobile production, Standards through 1985 for all cars sold in the United States have been set under the Energy Policy and Conservation Act,

Chip. A small piece of a semiconductor material such as silicon on which an integrated circuit has been fabricated.

Competitiveness. The relative ability of firms located in a particular country to develop, produce, and market goods or services of a particular type in competition with firms in other countries. As used in this report, costs of production are the most important single factor in determining competitiveness.

Continuous casting. A process for solidifying steel or other material in the form of a continuous strand rather than individual ingots.

Digital. Refers to electronic circuits or devices, the inputs and outputs of which are nominally discrete voltage levels. Analog or linear circuits, in contrast, have inputs and outputs that vary continuously over a range of voltages, Virtually all computers process informat ion in digital form.

Dumping. The sale of exported goods at less than the price charged by the manufacturer in his home market, or in some cases at less than cost. Dumping is restricted under the GATT as an ' 'unfair' trade practice.

DR-direct reduction. A family of processes for making iron from ore without exceeding the melting temperature. No blast furnace is needed.

Emissions. The most important contributors to air pollution from the crankcase and exhaust of automobile engines are carbon monoxide, hydrocarbons, and nitrogen oxides, The latter two can combine to produce photochemical smog.

EPCA-Energy Policy and Conservation Act. Passed in 1975, it set fuel economy standards for automobiles and also contained provisions for controlling oil prices.

Escape clause. Section 201 of the Trade Act of $1 ! 374$, which permits temporary restrictions on imports, in the absence of prohibited practices such as dumping, if sudden surges of these imports substantially injure a domestic industry.

Full costs. 'Fixed plus variable costs. A full cost pricing strategy aims to cover all costs-those independent of the volume of production (fixed), as well as those depending on volume (variable costs).

GATT-General Agreement on Tariffs and Trade. An international organization, based in Geneva, that provides a forum for trade negotiations. Member countries are committed to reducing the barriers to world trade, and expanding its volume.

GDP-gross domestic product. The total value of goods and services produced by an economy over a given period, usually 1 year.

GNP-gross national product. GDP, plus the income accruing from foreign investment, less payments made to investors in foreign countries.

Hardware. The physical components of a computer system, such as the processor itself, input/output devices, and storage units,

IC-integrated circuit. An electronic circuit made by fabricating components such as resistors, capacitors, and transistors on a single piece of a semiconductor material, usually silicon.

Integration. See vertical integration.

ITC-International Trade Commission. An independent agency of the U.S. Government which investigates and rules on trade-related matters, primarily concerned with imports.

Lithography. Processes similar to printing used in fabricating integrated circuits, Lithography is used to expose chemical resists as part of the process of laying out circuit patterns. Light, Xrays, or electron beams can be used. All present commercial processes use light. The resists are analogous to the light-sensitive emulsions of photographic film,

Mainframe computer. One that typically costs over $\$ 100,000$ and requires trained operators, special facilities, and permanent installation,

Marginal costs. The incremental costs associated with an increase in volume of production.

Market promotion policy. A public policy directed at a specific market - as for labor or capital. Generally intended to improve the operation of that market,

Microcomputer. A computer based on a microprocessor and using other integrated circuits 
for support functions, or, alternatively, containing all functions on one chip (single chip microcornputer).

Microprocessor. An integrated circuit that can serve as the processing unit for a digital computer. Also used to provide particular digital logic functions as an alternative to customdesigned integrated circuits. Microprocessors vary in their word lengths - the number of bits in the words they manipulate-hence, 4-bit, 8bit, etc.

Minicomputer. A computer that typically costs under $\$ 100,000$ and does not need specially trained operators or special facilities.

Minimill, A small nonintegrated steel mill, typicalIy scrap-based and using electric furnaces to produce a limited range of products.

MITI-Ministry of International Trade and Industry, Japan.

MOS - metal oxide semiconductor. Refers to both transistors and integrated circuits. MOS ICS are unipolar as opposed to bipolar; they are denser and dissipate less power than bipolar ICS, but are usually slower. The most widely used RAhfl's and microprocessors are MOS devices.

MTA-Multilateral Trade Agreement. The MTA represents the outcome of the most recent GATT negotiations on reducing trade barriers, known as the Tokyo Round.

Nonintegrated. Steelmaking firms that do not reduce iron from ore, but typically make finished products starting with steel scrap.

OECD-Organization for Economic Cooperation and Development. An international organization composed of industrial countries. Its aims are to encourage economic growth and employment and to promote the development of industrializing countries.

Offshore manufacture. The production of parts and components, and/or their assembly, in plants located in foreign countries, followed by shipment back to the home market or to third country markets.

OMA - orderly marketing agreement. A negotia ted limit on imports from a particular country, such as currently exists for color televi$\mathrm{s}$ ion receivers from Taiwan and South Korea.

Peripherals. Computer hardware other than the processing unit itself. Typical peripherals are terminals, card readers, and auxiliary storage units.

plug compatible. Computer equipment-both processors and peripherals-that can be plugged directly into an IBM system.

Processor. The portion of a computer system that executes the program.
Productivity. Output per unit of input-used in this report exclusively to mean labor productivity, the physical quantity or value of goods produced per unit of labor input. Labor input is usually measured in worker-hours.

Quality. A statistical measure of the extent to which devices, products. or systems meet design specifications. For electronic components, quality can be expressed as defect fraction, For steel or automobiles, quality has a more complex meaning. For steel it might be expressed in terms of surface characteristics, physical properties, or chemical composition. For automobiles, quality could be measured by the number of defects present after final assembl y-e.,g., runs or orange peel in the paint, loose or missing parts, operating defects, misalined trim.

RAM-random access memory. An integrated circuit which functions as read/write memory for a digital processor. Each memory location can be addressed directly (random access) and its contents read and/or changed (written).

Reliability. A statistical measure of the extent to which devices, products, or systems perform satisfactorily in service-i.e., without failures. Reliability can be measured as mean time between failures-commonly used for electronic components such as ICS or systems such as computers. An essentially equivalent measure of reliability is the average number of failures over time or over some other measure of usage - for automobiles, reliability might be measured as failures per 10,000 miles. In a complex system such as a computer or an automobile, failures would often be further classified by type. For example, failures that prevented operation could be distinguished from those that only impaired operation,

Semiconductor. Electronic devices such as transistors or integrated circuits based on silicon or other materials that have electrical conductivities intermediate between insulators such as glass and conductors such as metals (the term semiconductor also refers to the materials-e.g., silicon-themselves).

Software. Computer program. Can also refer to other carriers of information such as books, film, phonograph records,

Solomon Plan. A program for revitalizing the American steel industry prepared by a commission headed by Anthony Solomon. The commission's report was issued in 1977.

Spark ignition engine. The conventional type of internal combustion engine used in most automobiles. 
Teletext. A system for sending graphic messages (pictures and/or text) over hard-wired lines (telephone or cable) to home television receivers. Similar to videotext, which uses a broadcast signal.

Tonne. A metric ton, $1,000 \mathrm{~kg}$ or $2204.6 \mathrm{lb}$.

TPM - trigger-price mechanism. Sets a floor price for steel imports into the United States. The price is based on the production costs of the low cost producer (Japan), plus transportation charges, adjusted for currency fluctuations. Steel imports entering the United States below this price automatically "trigger" an accelerated antidumping investigation.

Transistor. An active semiconductor device that can function, for example, as an amplifier. Transistors have replaced vacuum tubes in many applications.

VCR-video-cassette recorder.

Vertical integration. An indication of the extent to which a given firm produces the materials, components, or subsystems that are inputs to its end products. A highly integrated automobile firm might produce its own glass, steel, spark plugs, radios, An integrated steel firm begins by making iron from ore, then converts the iron to steel.

VHSIC - Very High-Speed Integrated Circuit. Name given to a U.S. Department of Defense $\mathrm{R} \& \mathrm{D}$ program aimed at military needs for very large-scale integrated circuits. The designation refers to the high speed required for applications such as signal processing.

Video disk. Refers to systems for playing back video pictures from information mechanically encoded on a spinning disk. Analogous to a phonograph record.

Videotext. A system for broadcasting graphic messages (pictures and/or text) to home television receivers. Similar to teletext which is hard-wired.

VLSI-very large-scale integration. Refers to integrated circuits with of the order of 100,000 circuit elements.

VRA-voluntary restraint agreement. A negotiated limit on imports similar to an OMA. VRAS on steel negotiated by the United States with the EEC and Japan were in effect from 1969 to 1974, They limited steel imports to specific tonnages plus 5 percent annual growth, 


\section{CHAPTER}

S $u$ m $m$ a $\quad r \quad y$ 


\section{Contents}

Page
Principal

Principal Findings. ............................. ..... 3

$\begin{array}{lllllllllllllllllll}\text { Competitiveness } & \ldots & \ldots & \ldots & \ldots & \ldots & \ldots & . & \ldots & \ldots & \ldots & \ldots & \ldots & \ldots & \ldots & \ldots & \ldots & & \end{array}$

Effects of Public Policies on Industry $\ldots \ldots \ldots \ldots \ldots \ldots \ldots \ldots \ldots \ldots \ldots \ldots \ldots \ldots \ldots \ldots \ldots$

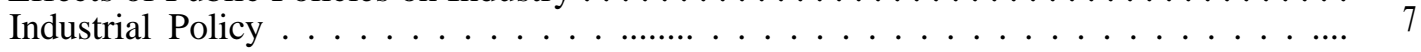

The Steel Industry. . . . . . . . . . . . . . . . . . . . . . . ...... . 9

The Electronics Industry. . . . . . . . . . . . . . . . . . . . . . . . ... 12

The Automobile Industry . . . . . . . . . . . . . . . . . . . . . . ..... . 14

Policies Toward Industry . . . . . . . . . . . . . . . . . . . . . .... 17 
This study of international competitiveness compares three U.S. industries-steel, electronics, and automobiles-and also discusses "industrial policy" and the prospects for better integration of policies affecting industry in the United States. It does not address specific policy measures for the three industries in detail.
The report draws heavily on recently completed and ongoing work at OTA: the study of the steel industry recently published as Technology and Steel Industry Competitiveness; a complementary effort on international competitiveness in electronics that is still in progress: and several studies related to the automobile industry.

\section{Principal Findings}

\section{Competitiveness}

1. The steel, electronics, and automobile industries are all increasingly pressed by international competition-as are many other sectors of the American economy. The United States must accept the reality of a highly competitive global marketplace-one that this country can no longer expect to dominate as in the 1950's. Markets in the United States are the largest in the world-this is a strength for domestic industries, but makes an attractive target for other countries. In semiconductors and computers, American firms have prospered by treating domestic markets as only a part of the larger world market-as have Japan's automobile and consumer electronics producers. Where a global market exists, firms operating on a worldwide basis may have advantages over those that restrict themselves to a domestic market even as large as that of the United States.

2. Public perceptions that U.S. competitiveness has been slipping in manufacturing industries such as steel, electronics, and automobiles are basically correct. At the same time, both the magnitude of the problems and their consequences can be overdrawn. On the average, American steelworkers have labor productivity as high as any in the world; the industry remains more profitable than its foreign rivals. The automobile industry has suffered as much from recession and escalating fuel prices as from declining competitiveness. The high-technology sectors of the U.S. electronics industry continue to be world leaders. In absolute terms, much of American industry remains efficient and innovative, although in relative terms it may have declined with respect to other countries.

3. Helping to improve the competitiveness of American industry - both the ability to export and the ability to compete with imports in U.S. markets-is a feasible objective for Congress. Both causes and effects of shifts in international competitiveness are influenced in significant ways by public policies, Among the causes are relative rates of productivity growth and relative technological capabilities-which depend on investment incentives and R\&D stimuli, among other factors, Effects of shifts in competitiveness include changes in standards of living and in employment levels. In the past, public policies have seldom directly addressed the sources of competitiveness and economic efficiency. Congress could decide that the time has come for a more focused and consistent approach.

4. While the United States retains technological superiority in many industries, it has no across-the-board advantage. In some technologies and in some sectors, U.S. firms are behind in the installation and use of available technologies. Where the 

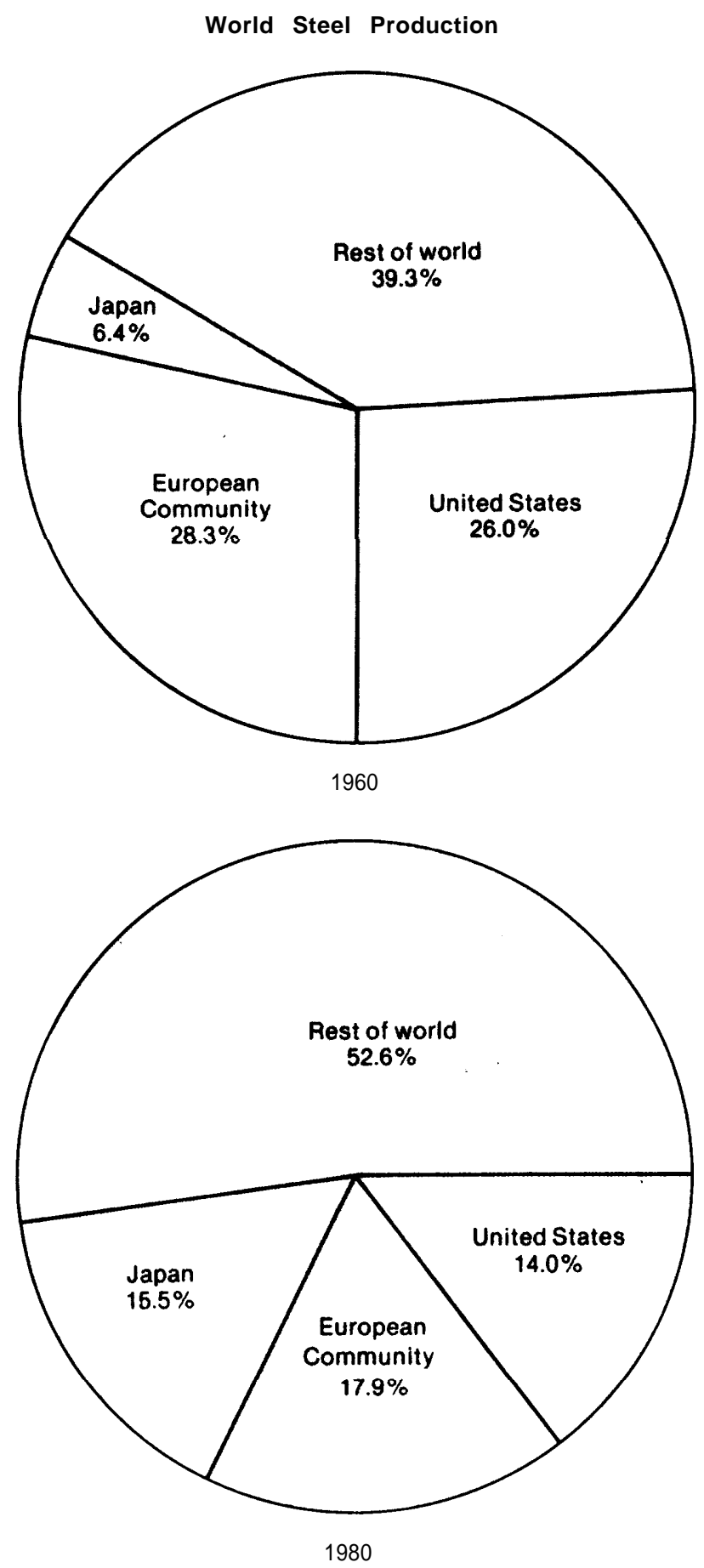

Totals: $1960-346.1$ million tonnes 1980 - 7177 million tonnes

SOURCES 1960- Technology and Steel Industry Competitiveness (Washing. Ion D C Off Ice of Technology Assessment June 1980\} p. 116. 1980- World Crude Steel Output Drops ASM News. February 1981 p 1
United States continues to be technologically preeminent, this superiority remains a vital competitive tool; but American industry can only stay ahead by continuing to innovate-in product and process technologies, as well as marketing, sales, and service. This requires continuing investment in R\&D and in new plant and equipment, plus aggressive, market-oriented commercialization of new technologies.

5. Long-term decreases in domestic employment opportunities are occurring in mature industries such as steel, consumer electronics, and automobiles. Maintaining or enhancing competitiveness generally requires raising productivity. Improvements in labor productivity in the absence of a growing market can result in falling employment. In industries facing stagnant or slowly growing markets, the United States may have to choose between maintaining competitiveness at the sacrifice of employment opportunities or maintaining employment at the sacrifice of competitiveness.

6. A commonplace observation that nevertheless deserves reiteration is that American firms and industries compete among themselves as well as with foreign concerns. Entirely apart from competition between firms within an industry, different industries vie for resources such as investment capital-which goes to those sectors that appear to offer the best returns. Firms and industries seek from Government policies and regulations (or the absence of policies and regulations) that will give them advantages over their competitors. They also compete for the best people-on the shop floor, in the R\&D laboratory, and in executive ranks.

\section{Effects of Public Policies on Industry}

1. In the United States, public policies affecting industry are typically formulated, legislated, and implemented on an ad hoc basis. One result is that they are sometimes contradictory and may lack continuity, Often the conflicts-e.g., between protecting the 


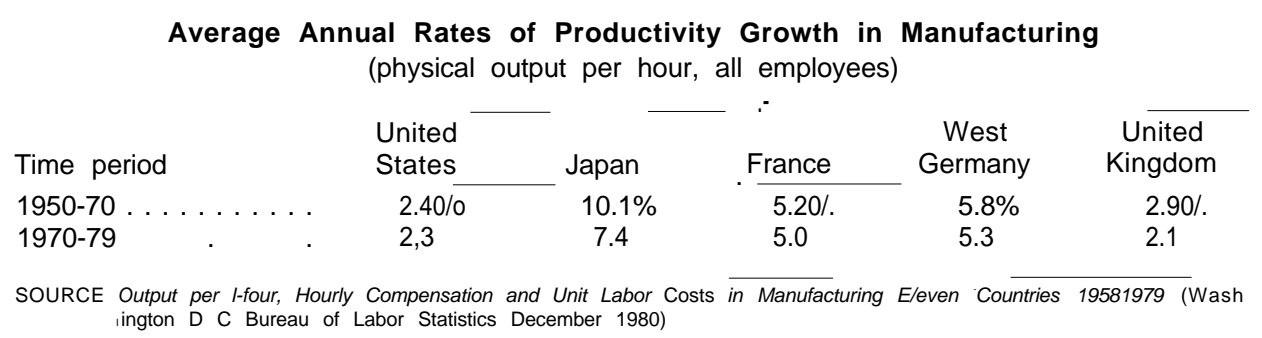

environment and encouraging energy production-contribute to a lack of national consensus on priorities. Industry in the United States is therefore sometimes faced with rapid shifts in Government policy, In contrast, industrial policies in other countries often rely rather effectively on consistent sets of signals or projections to guide and encourage industry. International competitiveness has seldom been treated as a major policy goal by either
Congress or the executive branch; as a result, inconsistency and lack of continuity in public policies have sometimes harmed U.S. competitiveness.

2. The objectives of public policies affecting U.S. industries are seldom well-integrated and not always well-defined. Such policies include regulatory measures directed at all industry (such as workplace safety and some environmental standards), regula-

Real Gross Domestic Product (GDP) per Employed Person Relative to the United States as 100

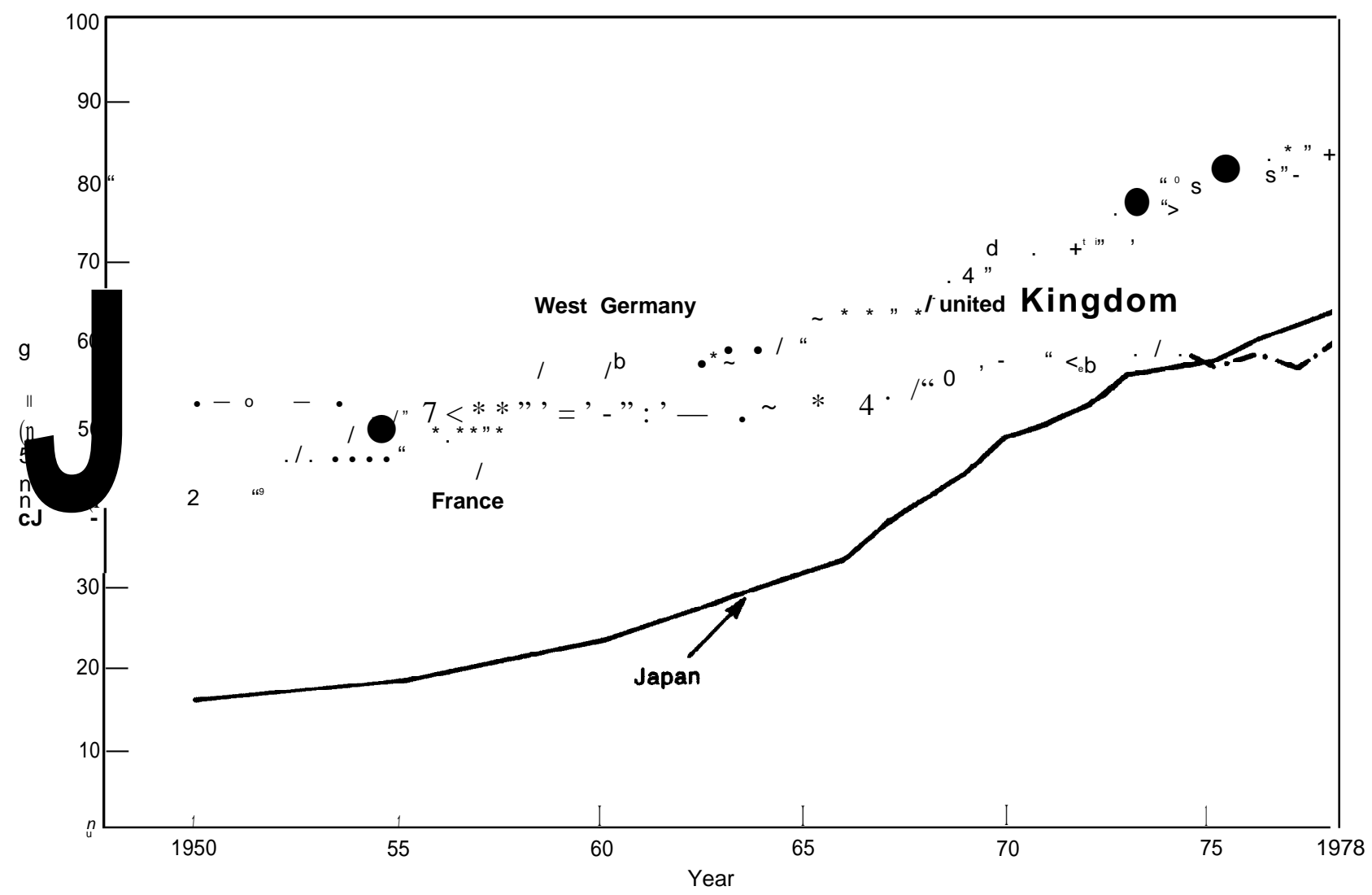

SOURCE M E Mogee Technology and Trade Some Indicators of the Sfate of U.S. Industrial Innovation (Washington D C Subcommittee on Trade Committee on Ways and Means U S House of Representatives Apr. 21 1980\}, p 25 From BLS data 
tions that apply only to specific industrial sectors (such as automobile fuel economy standards), tax policies that encourage particular kinds of investment, emergency measures such as the Chrysler loan guarantee, and a substantial degree of "jawboning" (directed at targets as various as steel prices and Japanese automobile imports). There is little coordination among such policies. Nor are macroeconomic policies formulated with much attention to effects on particular industrial sectors.

3. Despite the undoubted importance of public policies in setting the conditions under which firms and industries compete -both domestically and internationallymany Government actions have only indirect and secondary effects on competitive behavior. The wide range of performance exhibited over the years by American firms within a given industrial sector-e.g., steel or computers-and the fluctuations from year to year, show that Government is only one influence among many in determining competitive position. A well-developed appreciation for the often subtle and indirect ways in which Government influences industry would be an important step toward a more coherent industrial policy.

4, The fragmented industrial policy of the United States is also a potential strength. Our pluralistic system, which is responsible for much of the ad hoc character of U.S. policies toward industry, creates an environment where flexible and innovative responses are sometimes possible. Each industry interacts with a variety of public agencies; there are many avenues for seeking changes in response to new or growing problems, or to new opportunities. With policy made throughout the system, inter-

BLS Productivity Indexes (physical output per hour-all employees, 1967=100)

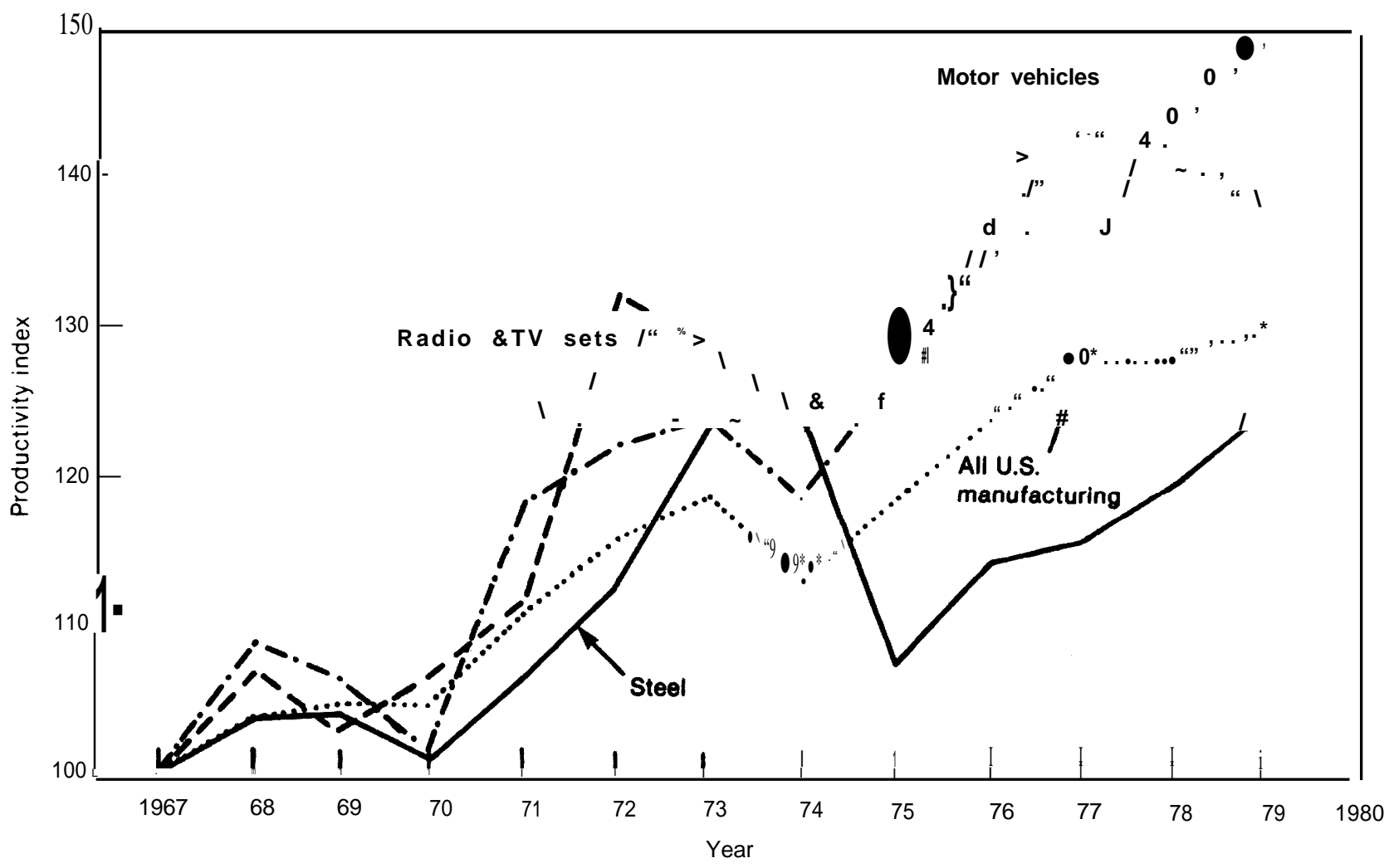

SOURCE Productivity Indexes for Selected Industries (Washington D C Bureau of Labor Statistics) 
ested parties can generally find a hearing, and often an advocate. Genuine conflicts of interest and genuine disagreements about priorities are illuminated rather than suppressed.

5. American industry has often responded to evidence of declines in competitiveness by arguing that Government has become too concerned with regulating industry, insufficiently concerned with supporting it. Many in the business community contend that they need reductions in effective corporate tax rates (e.g., liberalized depreciation allowances), modifications to environmental and safety regulations, and more vigorous enforcement of laws governing "unfair" trade practices such as dumping. Policy changes of these sorts might in some cases be appropriate, but in the three industries studied would by themselves be insufficient to ensure future U.S. competitiveness.

\section{Industrial Policy}

1., OTA'S study of competitiveness suggests that Congress consider developing a more coherent and explicit policy toward industry. The ad hoc approach to industrial policy followed in years past may not suffice in the current context. Today the United States no longer enjoys the overwhelming technological lead or relative

Average U.S. Wage Rates for Production Workers in Constant 1967 Dollars per Hour

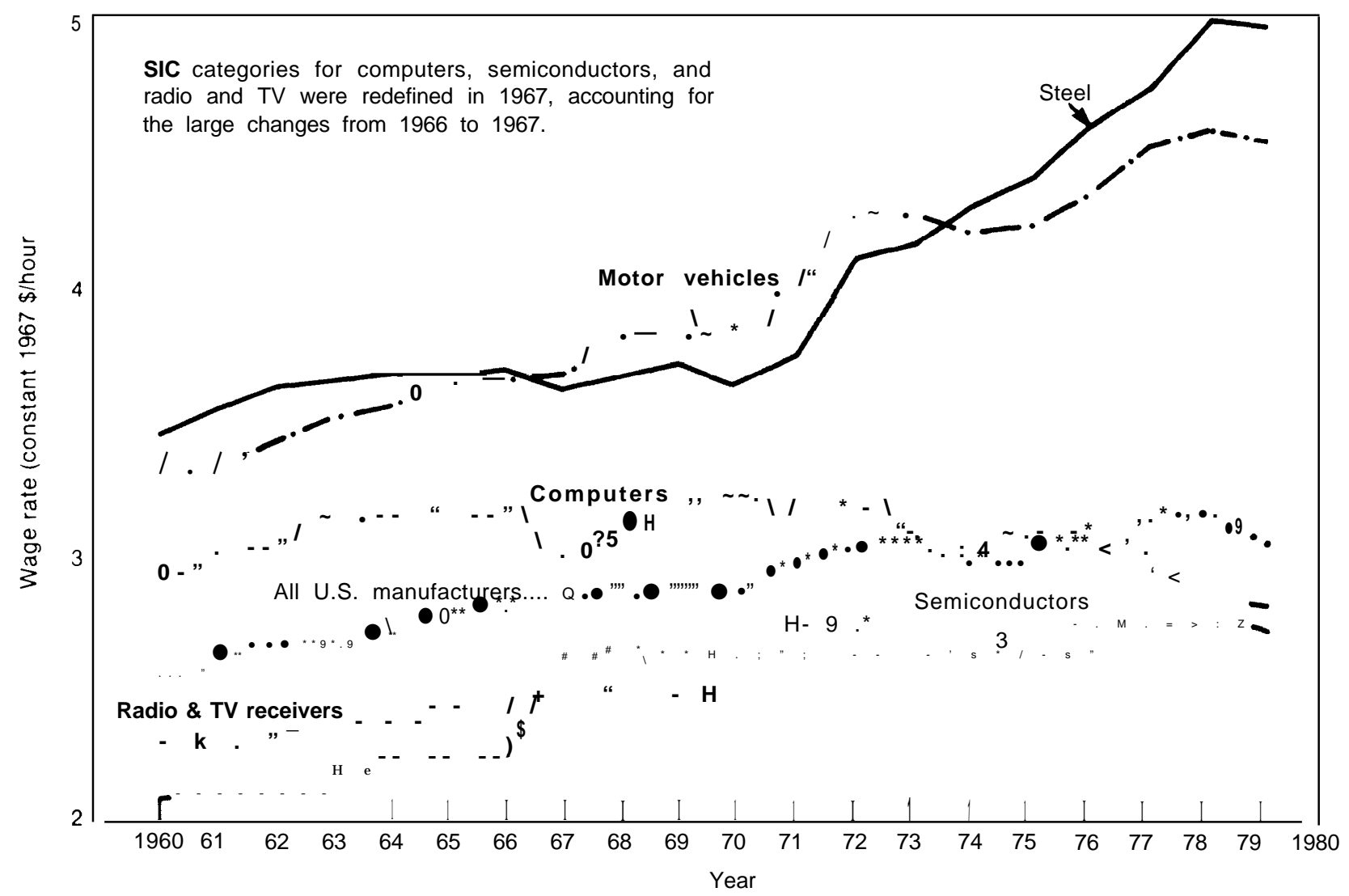

SOURCES AllU.S. manutacturing-Emplovment and Earnings. $909-1979$ washongton. D C Bureau of Labor Stalıstirs. Junn 1980 ?

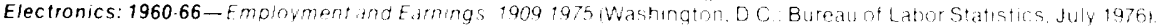

1967.71-US Census of Manutacturers 1972.

1972.79-Emptovment and Earnings. 19091979 W Washmgton. D C Bureau of Labor Statistirs. June 1980)

Steel-Annut Statstical Report Washington. DC American Iron and Steel Institute June 1979 ?

Motor vehicles-Emplovment and Farnings, 19091979 washington. D.C. Bureau of Labor Statistocs. June 1980 
economic strength it possessed two or three decades ago. A climate now exists within the United States that appears potentially receptive to new policy approaches and to a consciously developed industrial policy. While genuine cooperation among Government, industry, labor, and public interest groups is unlikely to spring up overnight, there is at least shared concern over U.S. competitiveness. This growing awareness could facilitate agreement on the objectives of industrial policy.

2. Two prerequisites for a coherent and effective industrial policy are: first, a set of objectives that can be broadly agreed on - the development of which is largely a political task; and second, enhanced analytical capability within Government. Analysis is needed not only for linking the overall goals of industrial policy with particular policy instruments-e.g., for determining differential effects of tax measures on various sectors - but also for evaluating competitiveness, and for relating sectors to one another and to the aggregate economy. Judgments concerning competitiveness and economic efficiency are complex and demanding. A practical, working knowledge of each industry, including its technology, is required.

3. Although analyses of competitiveness must begin by examining sectors individually, industrial policy itself need not be sectoral. To have an industrial policy does not necessarily mean targeting certain industries for promotion, or subsidizing industries in decline. Such measures will always be among the options and alternatives available, but are by no means essential characteristics of industrial policy. There is considerable doubt that such targeting has worked consistently well in the countries where it has been tried. (Industrial policy in Japan, for example, is much more complex than the notion of a target industry suggests. )

4. Industrial policy implies some perspective or framework for formulating and imple- menting policy measures. The analysis in this report suggests a framework that OTA calls "macroindustrial policy. " Macroindustrial policy would be based on sector-by-sector analyses of competitiveness, but rely where possible on market signals and policies with aggregate objectives in preference to sectoral measures. The first choice among tools would be macroeconomic policies. If the analysis indicates that these would not suffice, then the second choice would be other aggregate measures such as market promotion policies. (Market promotion policies are intended to enhance the workings of the market system; examples are job relocation and retraining programs, or science and technology policies, ) If these too seemed insufficient, policies specific to the particular industry or to individual firms might be developed.

5. One aim of macroindustrial policy could be to preserve the flexibility and adaptability of the American economic system while creating a stable climate for industrial growth and the enhancement of competitiveness. The following measures are among those that could improve competitiveness and might play a role in macroindustrial policy:

- policies to stimulate innovation, to strengthen the technology base for commercial (rather than exclusively military) applications, and to promote $R \& D$ (and the diffusion of its results) directed at commercial products and processes.

- policies, including tax and regulatory measures, to encourage capital formation and investment in new technologies -both product technologies and new, more productive manufacturing methods.

- support for education and training of the work force, including retraining of those displaced by technological change, and the encouragement of labor mobility. In general, the United States appears to have more low-skill manpower and less high-skill manpower than an industrial 
economy of the 1990's will require; an overall upgrading of the work force (engineers and managers as well as production workers) could directly improve productivity y and competitiveness.

- economic adjustment policies aimed at smoothing flows of capital and labor from declining firms or industries to those with strong prospects for future competitiveness, but leaving the market to identify sectors of growth and decline.

- measures designed to encourage competitive U.S. firms to export, together with policies to promote open world trade-including fully reciprocal treatment of U.S. industries that export or invest overseas-and protection against unfair competition in domestic markets.

6. The increasing concern in the United States with competitiveness and "reindustrialization" has not yet led to agreement on how to move toward a consciously formulated industrial policy. To lay groundwork for further development, Congress might consider steps of the following sorts:

Ž creating a central focus within Congress - such as a caucus, task force, or an ad hoc committee on industrial policy-for members and staff with responsibility for policies that affect industry.

- encouraging broadly based participation by consumer and other public interest groups, and labor, as well as representatives of Government and business, aimed at clarifying the goals and objectives of industrial policy and going beyond sectoral concerns,

- creating an analytical group with ongoing responsibilities for examining competitiveness and economic performance and their relationships to productivity; technology; and regulatory, tax, and trade policies-as well as the social and economic impacts of shifts in competitiveness. Such a group might include projections and forecasting among its responsibilities, as well as the dissemination of such projections to the private sector-including analyses of new technological developments and their prospective commercial impacts, both domestic and foreign. It could be located either in the executive or legislative branch.

\section{The Steel Industry}

The competitiveness of the integrated portion of the American steel industry has declined in part because wages have increased faster than productivity. Although the labor productivity of the industry is high compared to most of the rest of the world-as are profits, on the average - the industry's plant and equipment have not been modernized rapidly enough to give efficiency improvements that would keep pace with rising wages.

Steelmaking costs vary widely among American firms, tending to be higher in the integrated segment of the industry, which comprises 85 percent of U.S. production. (Integrated firms are those that start with ore and market finished steel products. ) Nonintegrated firms often have more modern equip- ment and lower costs, though producing only a limited range of products. Shifts in competitiveness will continue to increase the relative importance of nonintegrated and alloy/specialty steelmaker.

Costs in many portions of the U.S. industry are now high enough that domestic steelmaker are in a poor position to combat imports, particularly those "dumped" by foreign producers. Costs are also too high for exports of most types of steel to be competitive. Since the late 1960's, the U.S. Government has adopted a variety of policies intended to insulate American steel firms from foreign competition-and particularly from "unfair" trade practices (those prohibited by U.S. law or international obligations), At best, these 
Employment in the American Steel Industry (annual averages in thousands)

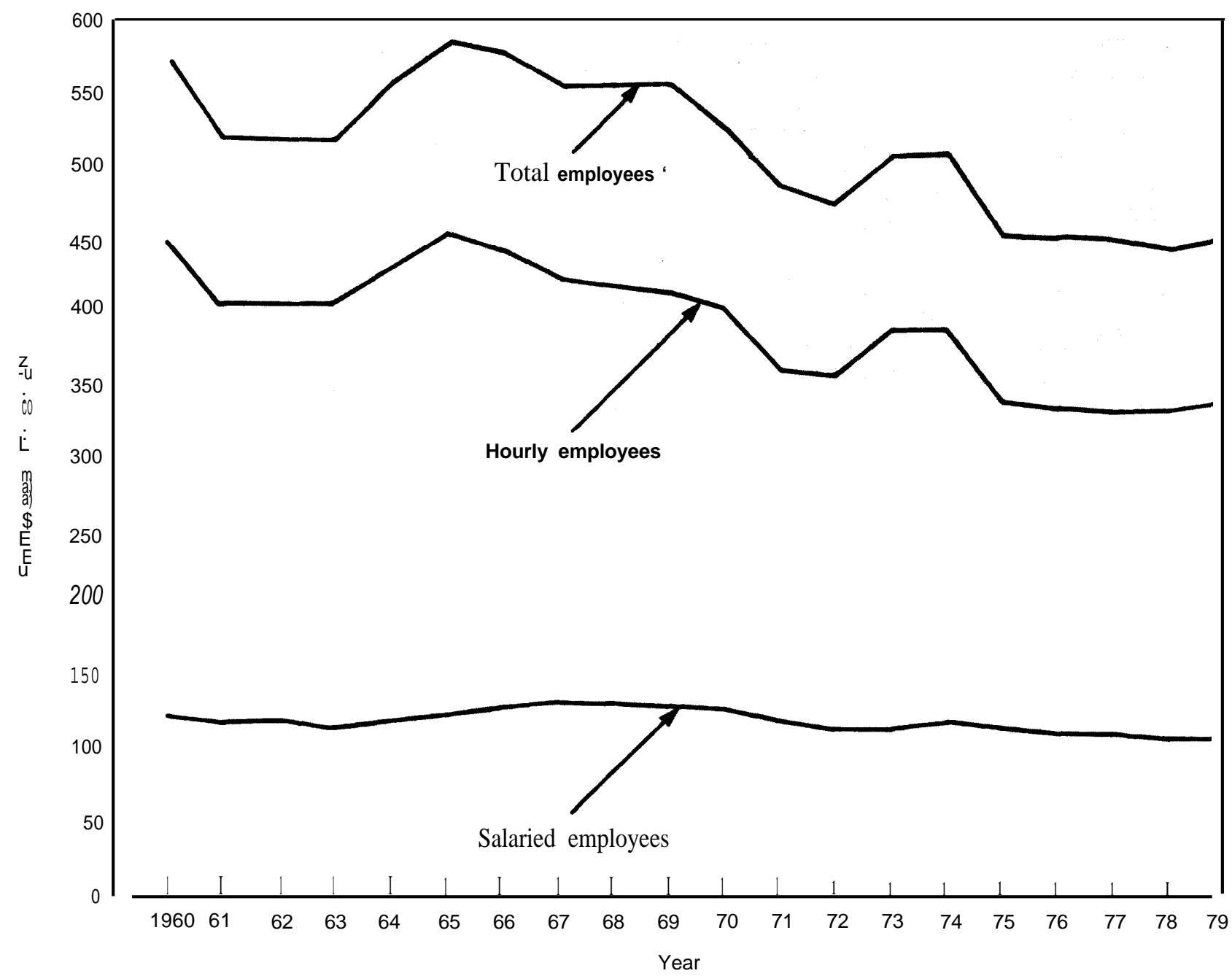

SOURCES Annual .Statistical Report, American Iron and Steel Institute, 1978, 1979

have had limited success; antidumping remedies, in particular, have often been ineffective. Positive measures to aid American steelmaker in modernizing, restructuring, or otherwise enhancing their competitiveness have been few in number and of little impact.

Government regulations, such as those dealing with environmental protection, have required significant capital expenditures by the industry. But the money spent in meeting regulatory standards would have been insufficient to maintain U.S. competitiveness even if directed entirely at modernization and productivity improvement. At the same time, the Federal Government has not attempted to offset such investments-as do several other countries with similar regulations-so that the industry could otherwise update its plant and equipment. This is one reason why most of the productivity growth in the American industry has come piecemeal through improvements to existing facilities. With the exception of minimills and other small producers, the U.S. industry is often unable to match the technology installed in foreign mills. To catch 


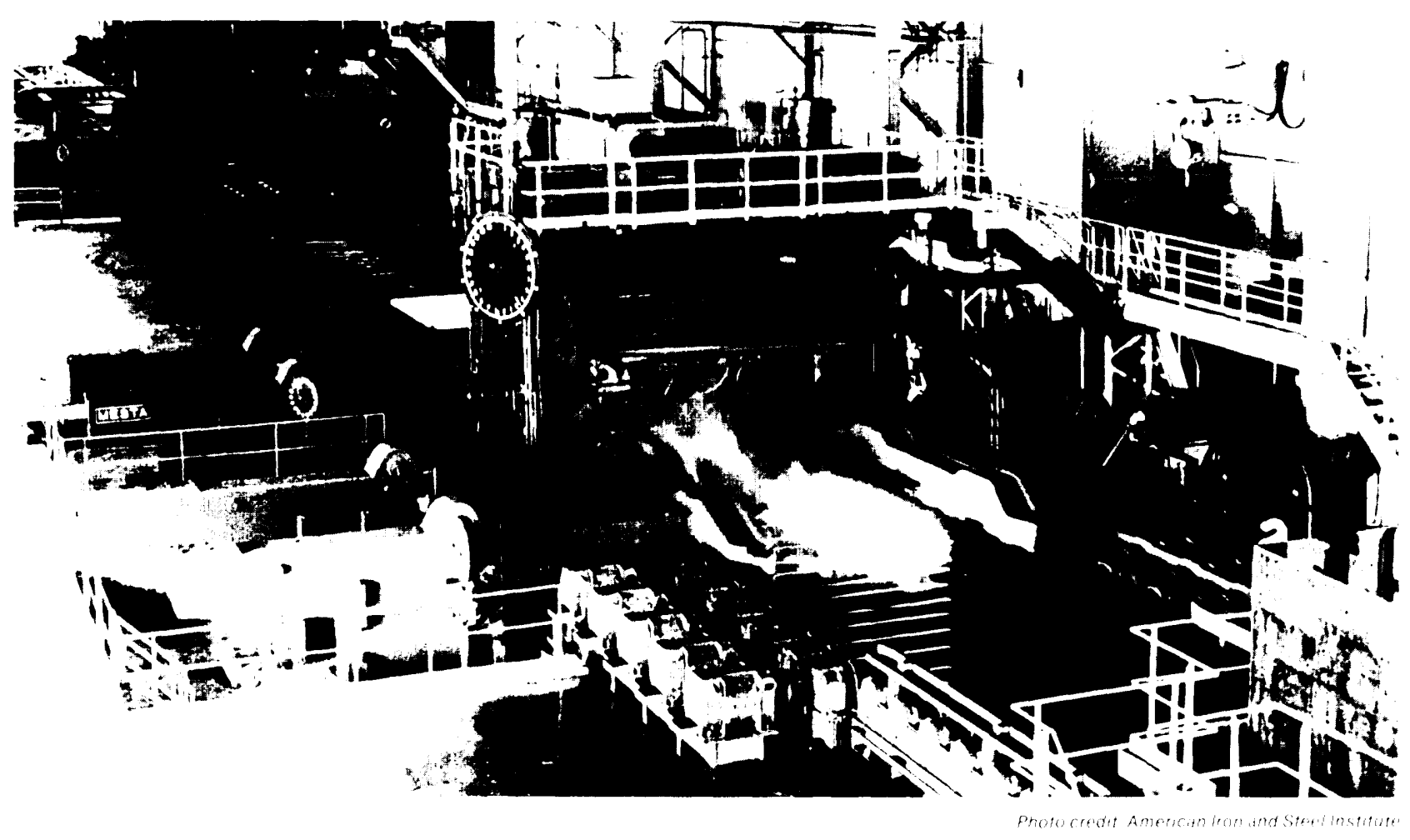

Slab casting machinery

up would require capital spending at rates approximately double those of the past few years,

There are nonetheless positive signs for American steelmaker. First, competition is transforming the U.S. industry, and obsolete, inefficient mills are being closed, Second, other countries have now achieved many of the immediate productivity increases available from new mills and new process technologies; they will have more difficulty making further gains. Finally, long-term trends in prices for material inputs used in making iron and steel should favor the United States.

At the same time, with current and probable prices for steel, and existing process technologies, new integrated mills based on existing technologies may no longer be economic in this country, Nor are they likely to be economic in any industrialized nation with high labor costs. In the future, developing countries with low labor costs such as South
Korea are likely to be among the stronger international competitors. During 1980, steel production decreased in the industrialized world, while increasing in the developing world.

Because growth in domestic consumption will be slow, because large export sales are unlikely, and because productivity advances will continue, employment in the American steel industry is unlikely to recover, If productivity grows more rapidly than the market, which is likely, employment will continue to decrease. As in other mature industries, the goal of increased competitiveness may conflict with the goal of increased employment, It may be impractical to maintain existing employment levels in such industries, The United States faces a fundamental dilemma in reconciling possible employment decreases in particular industries with the need to maintain competitiveness and employment across many industries. 


\section{The Electronics Industry}

U.S. competitiveness varies markedly across the diverse segments of the electronics industry; it is greatest in high-technology sectors such as semi-conductors and computers. Government policies could help maintain the present advantages.

OTA'S study focused on three sectors of electronics: consumer electronics (mainly radios and televisions), semiconductors, and computers. These sectors differ in their technologies, in their present competitive positions and future prospects, and in the ways in which public policies have affected them. Although the U.S. consumer electronics industry has declined in competitiveness, our semiconductor and computer sectors remain the strongest in the world.

In international terms, the U.S. consumer electronics industry is now rather small. American-owned firms retain the major share of the domestic color TV market, but much of their production has been relocated to foreign countries to reduce costs. Weaker U.S. manufacturers of TVs and other consumer electronics products have disappeared.

As the competitive positions of U.S. companies have declined, foreign firms-principally Japanese-have located assembly plants here. Negotiated quotas on imports of color TVs from Japan, Taiwan, and South Korea have hastened this trend. While em-

Import Penetration in Consumer Electronics, 1978

\begin{tabular}{|c|c|c|}
\hline Product & $\begin{array}{l}\text { Imp } \\
\text { U.S. }\end{array}$ & $\begin{array}{l}\text { orts as \% of } \\
\text { consumption }\end{array}$ \\
\hline Videotape players /recorders . . & & $1000 / 0$ \\
\hline Household radios . . . . . . . . . & $\ldots$ & 100 \\
\hline CB radios $\ldots \ldots \ldots \ldots \ldots \ldots$ & & $\ldots 90$ \\
\hline Black and white TVs ......... & & .85 \\
\hline Electronic watches . . . . . . . & & .68 \\
\hline High fidelity and stereo component & & . 64 \\
\hline Phonographs and compact stere & tems & . 43 \\
\hline Audio tape recorders. . . . . . . & . . & .35 \\
\hline Microwave ovens. . . . . . . . . & & .25 \\
\hline Color TVs . . . . . . . . . . . . . . . & & .18 \\
\hline
\end{tabular}

\footnotetext{
SOURCE "The U S Consumer Electronics industry and Foreign Competition, Executive Summary, " final report under EDA grant No 0626 Executive Summary, " final report under EDA grant No 0626.
07002.10 , Department of Commerce, Economic Development Admin. istration, May 1980, p 2
}

ployment has been maintained at levels higher than would otherwise have been the case, much of the value-added remains overseas, along with management control and many professional and skilled jobs.

The future of the U.S. consumer electronics sector depends on new generations of home entertainment products. If these products are designed, developed, and successfully marketed by American firms, and if advantages in either product or process technologies can be maintained, the United States could retain a substantial presence.

As is the case for steel, productivity gains in consumer electronics-e.g., resulting from automation -will work against maintaining employment. Only if new products with large markets are introduced (which remains a possibility), or if U.S. firms begin to compete aggressively and successfully in other parts of the world (which now seems unlikely), will it be possible to increase employment in this sector.

In the semiconductor and computer sectors, markets are growing rapidly; therefore employment is rising even while productivity increases. Although American firms retain more than half of world sales in both semiconductors and computers, there is still cause for concern. First, the U.S. share of the world

\section{Comparison of the United States and Japan} in Digital Integrated Circuit Technology

\footnotetext{
Process technologies

Electron-beam lithography $\ldots \ldots \ldots \ldots \ldots \ldots \ldots \ldots$

X-ray lithography . . . . . . . . . . . . . . . . . .

Deep ultraviolet lithography $\ldots \ldots \ldots \ldots \ldots \ldots \ldots$

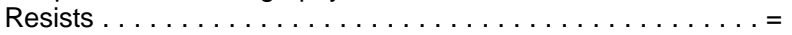
Quality control . . . . . . . . . . . . . . . . . . . . ?

Silicon materials . . . . . . . . . . . . . . . . . . Automated assembly. . . . . . . . . . . . . . . =

Product technologies

Computer-aided design capability. . . . . . . . . . . . . . +

Memory circuit designs. . . . . . . . . . . . . . . . .

Microprocessor designs . . . . . . . . . . . . . +

+ United States ahead

- United States behind

= Rough parity

$\sim$ See text (ch 5)

SOURCE. H C LIn for OTA electronics study
} 


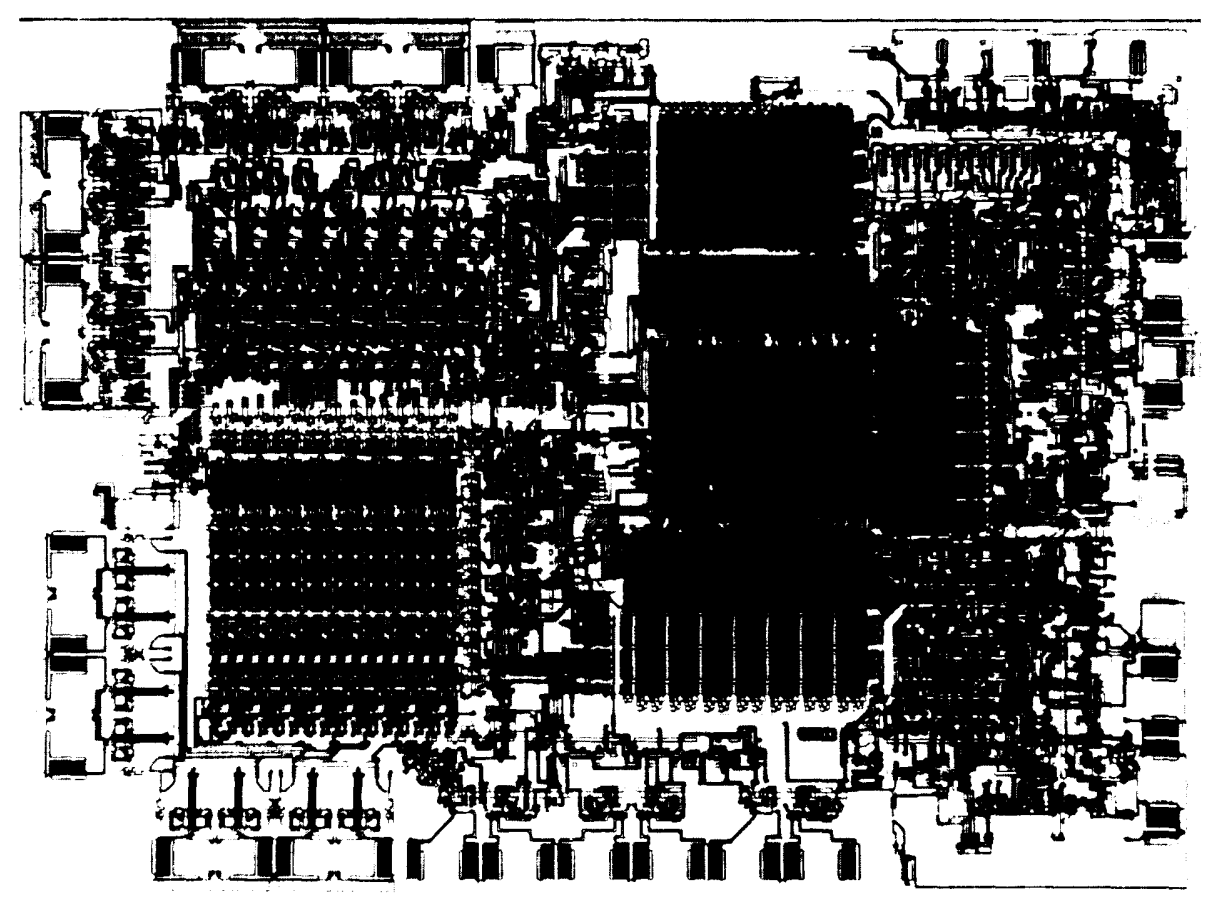

8-bit microprocessor circuit

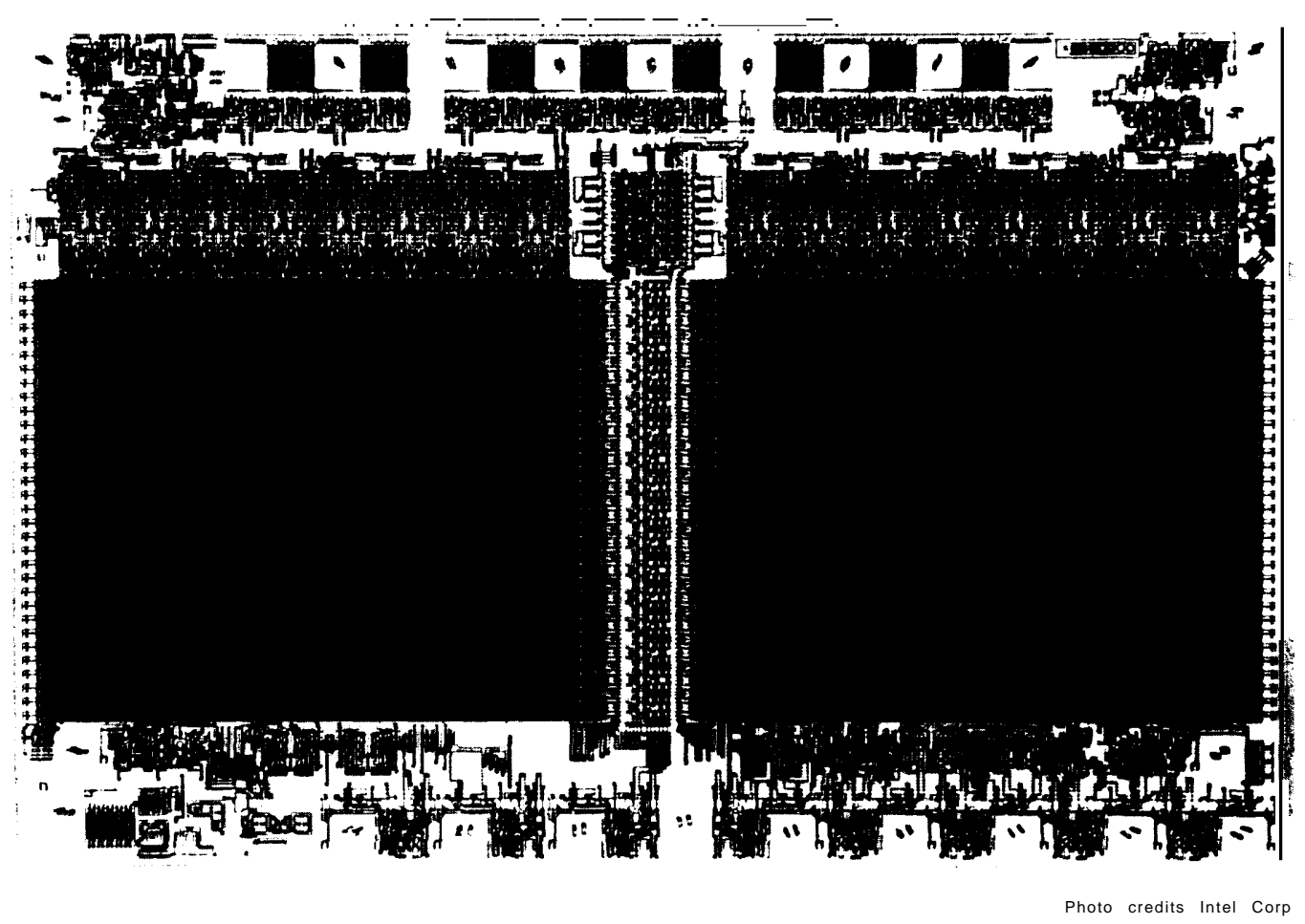

Integrated circuit memory chip that can store more than 32,000 bits of information 


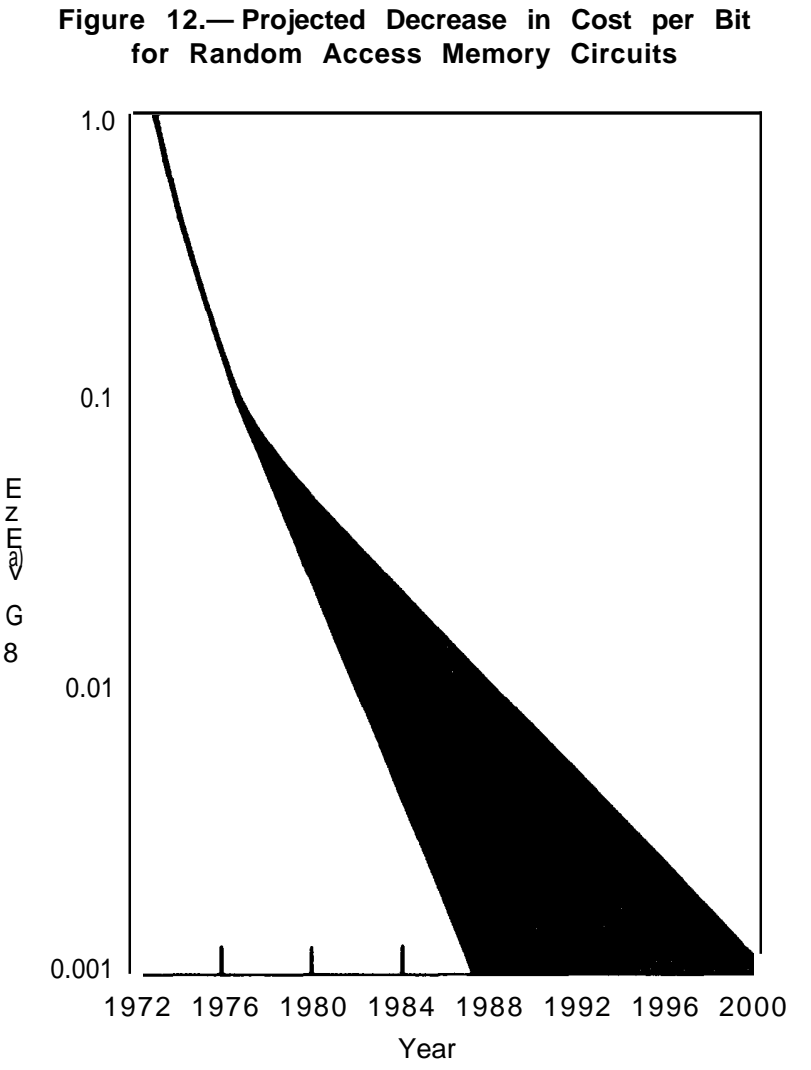

SOURCE K D Wise, $\mathrm{K}$ Chen, and R E Yokely, Microcomputers A Technology Forecast 10 the Year 2000 (New York John F Wiley \& Sons 1980). p 57

market is shrinking, more so for semiconductors than computers. Second, Japanese firms have made startling inroads into U.S. markets for several high-technology semiconductor products. Third, other governments are actively supporting and promoting their semiconductor and computer industries.

In both semiconductors and computers, the technology gap that American firms established in the 1960's has shrunk; in some cases it has vanished. The United States must continue to innovate in order to maintain the technological capabilities on which competitiveness depends. This is vital not only for the electronics industry, but for the many other portions of our society and economy that depend in some way on electronics technology and its applications-ranging from computerized control of steelmaking processes to biomedical implants such as cardiac pacemakers. Supportive Government policies toward R\&D and product development can help maintain a technological lead.

An important advantage of American semiconductor and computer firms is their demonstrated ability to compete on a global scale. In the 1980's, the health of these sectors will depend on their ability to generate and attract capital, on an adequate supply of welltrained engineers and scientists, on success at $R \& D$ and innovation, and on trade policies that protect American firms from unfair competition at home while seeking fully reciprocal access to foreign markets.

\section{The Automobile Industry}

The automobile industry is undergoing long-term international restructuring; superimposed are a series of difficult short-term problems for American manufacturers. Public policies toward this industry, as for the others, could ease the adjustment process.

Automotive technology, like that for steel, is well-diffused internationally; no one country has a technological advantage. Technical change in these industries is slow compared to electronics, major innovations infrequent.

Despite losses during 1980 totaling more than $\$ 4$ billion, the American automobile in- dustry is in many respects stronger relative to the rest of the world than our steel industry. For example, the U.S. automobile industry's productivity record compares more favorably with that of other countries, as well as with other domestic industries. But since 1978, decreased total demand for automobiles has combined with a shift in the market toward small cars to produce sharp declines in domestic production and employment, The decrease in demand is associated with a gradual change from a growth market to one which is more nearly a replacement market, and with a recession marked by tight credit. 


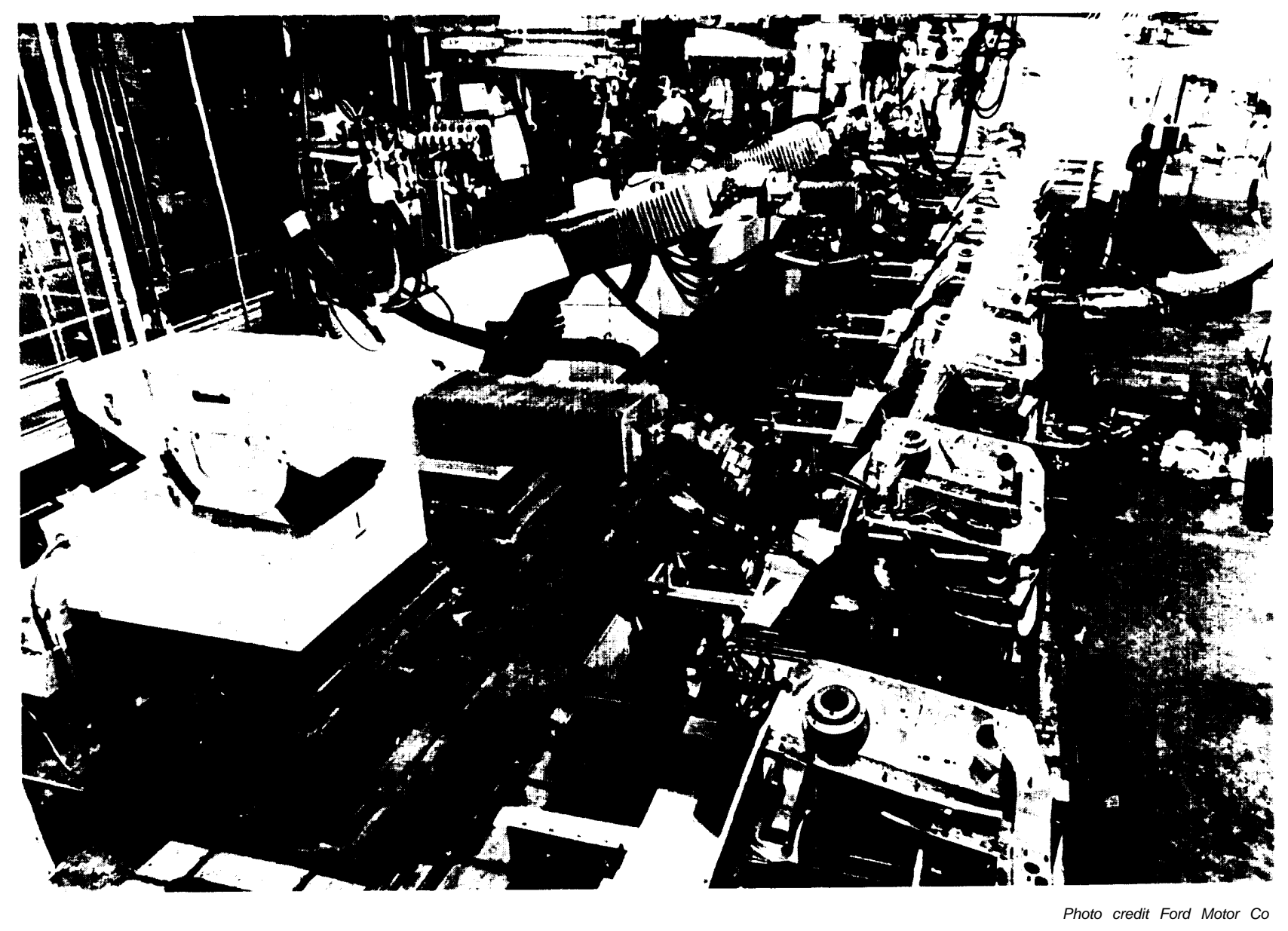

Robots welding automobile subframes

In marked contrast to previous periods of decline in total sales, sales of imports from Japan have continued to increase. Rising gasoline prices are an important cause of this shift in consumer demand. Redesign and retooling to produce new generations of small cars are straining the capital resources of U.S. automakers. In contrast, their competitors face substantially lower expenditures because they already build small cars almost exclusively-a legacy of markets which have been less affluent and of fuel prices which have historically been much higher.

For subcompact cars, Japanese firms appear to have production cost advantages over U.S. automakers that may be 20 percent or more-largely because of lower labor costs; this gives them flexibility but is only one reason for their current success. Using conventional designs, and engineering which is often clever but generally not particularly innovative, the larger Japanese automobile manufacturers have learned product differentiation from American firms and applied the lessons to the small-car segment of the market-where the product lines of American automakers are thinnest. Furthermore, they have established an image-largely justified-of high-quality and trouble-free service, which has combined with expanded and strengthened dealer organizations to give good resale value as well as wide coverage of markets. 
Motor Vehicle Production and Sales Figures (thousands of cars and trucks)

\begin{tabular}{|c|c|c|c|c|c|}
\hline \multirow[b]{2}{*}{ Year } & \multirow[b]{2}{*}{ U.S. production } & \multicolumn{3}{|c|}{ Sales } & \multirow[b]{2}{*}{ Import penetration } \\
\hline & & Domestics & Imports & Total & \\
\hline 1978. & 12,875 & 12,890 & 2,320 & 15,210 & $15.3 ? 40$ \\
\hline 1979 & 11,471 & 11,132 & 2,743 & 13,875 & 19.8 \\
\hline $1980 \ldots \ldots \ldots$ & 8,012 & 8,581 & 2,883 & 11,464 & 25.1 \\
\hline
\end{tabular}

SOURCE, Tables 5 and 6 in ch. 4.

Projected Sales of Passenger Cars in Major World Markets

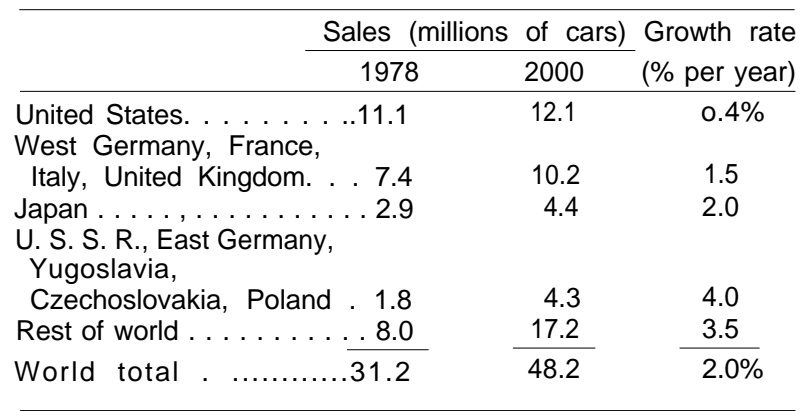

SOURCE the Changing World Automotive Industry Through 2000 (Cambridge, Mass Arthur D Little, Inc, January 1980).

Japanese automakers are now firmly established in the United States, and will not yield market share easily. Their competitiveness is demonstrated by recent sales increases in Europe as well as the United States. Japanese manufacturers are currently attempting to further broaden and strengthen their product lines to counter the new small cars American firms are introducing.

U.S. automobile manufacturers have been more directly affected by public policies than steel or electronics firms. At the same time, domestic regulations dealing with exhaust emissions, safety, and fuel economy also apply to foreign firms selling in the United States. The difference is that the Europeans and Japanese have been building small cars with good fuel economy for many years. When the market turned to small cars even more rapidly than regulations had pushed in this direction, imports reaped the benefits.
On a world scale, the automobile industry is going through a period of corporate consolidation but geographic dispersion. Some observers predict that as few as six translational producers could dominate world auto markets by the end of the century. Automobiles designed and produced in different parts of the world are becoming more similar. This and other forces are leading to the spread of production to developing countries with low labor costs and growing markets. Such changes will affect suppliers to the industry, as well as the automakers themselves. Sales growth in most parts of the developed world will be slow compared to the newly industrializing countries. Strength in developing country markets will be one of the factors determining future competitive success in the world automobile industry.

As in steel and consumer electronics, some of the current unemployment in the U.S. automobile industry seems irreversible. The domestic auto market is growing only slowly. Prospects for large export volumes are slight because, although some U.S. automakers have large sales overseas, they serve foreign markets primarily through local production. In any case, exports from the United States are generally not cost competitive after transportation charges. Given slow domestic market growth and productivity that must increase if American automakers are to remain competitive, employment will decrease. There is little alternative. 


\section{Policies Toward Industry}

The United States has many policies that affect industry - ranging from broad, macroeconomic fiscal, monetary, and tax policies to tightly defined regulations imposed on specific industrial sectors. But it cannot be said that the United States has a consciously designed or coherent industrial policy. In principle, fragmentation of policy can be a strength-providing interested parties with access to the Government at many points and contributing to flexible responses. But in recent years there have been few signs of this.

The three sectors examined by OTA have been influenced in different ways and to different degrees by Government actions. They are similarly dependent on a strong, stable economy, hence on effective macroeconomic policy. In the long term, sectoral remedies are unlikely to function effectively or efficiently in the absence of a healthy, growing aggregate economy; successful macroeconomic policies make sectoral problems easier to deal with.

Other policies with aggregate objectives also have important effects on the competitiveness of American industry. Often these work indirectly by influencing corporate strategy and decision-making; in the end, competitiveness depends on the success of many individual firms, each of which performs differently over time, Tax policies, for example, are an important part of the supply side linkage between macroeconomic policies and particular industrial sectors (and firms). Both development of new products and investment in new plant and equipment depend on cash flow, which is affected by direct taxes on corporate profits, investment tax credits, and depreciation allowances.

Taxes are but one example among many of aggregate policies with important and differential sector-specific effects, Government support for the construction of roads and highways has had a major, long-term impact on the American automobile industry, as have energy policies. In the past, national defense programs helped shape the U.S. electronics industry. All sectors are dependent on the quality of the educational system.

Regulatory policies have had significant impacts on the steel and automobile industries. However, regulation cannot be blamed for the majority of the problems these industries face. Expenditures for regulatory compliance in the steel industry have been large in absolute terms - as have expenditures for diversification out of steelmaking-but still represent only a small fraction of what would have been needed to maintain competitiveness. (Steelmaker in Japan have spent more in meeting environmental regulations than those in the United States. ) In the automotive industry, regulatory burdens have often affected imports, particularly from Europe, more heavily than domestic vehicles because American firms have been able to spread development costs over larger production volumes.

Trade policies have sometimes had unintended negative consequences. For example, protracted and unresolved dumping proceedings in sectors such as consumer electronics have harmed U.S. competitiveness by creating a climate of uncertainty and irresolution. The overall thrust of postwar American trade policy has also exposed U.S. industries to more intense competition. At the same time, the emphasis on opening and expanding international trade, as well as promoting economic development in other countries, has created new opportunities for many American firms,

Finally, the lack of effective policies for smoothing economic adjustment has added to 


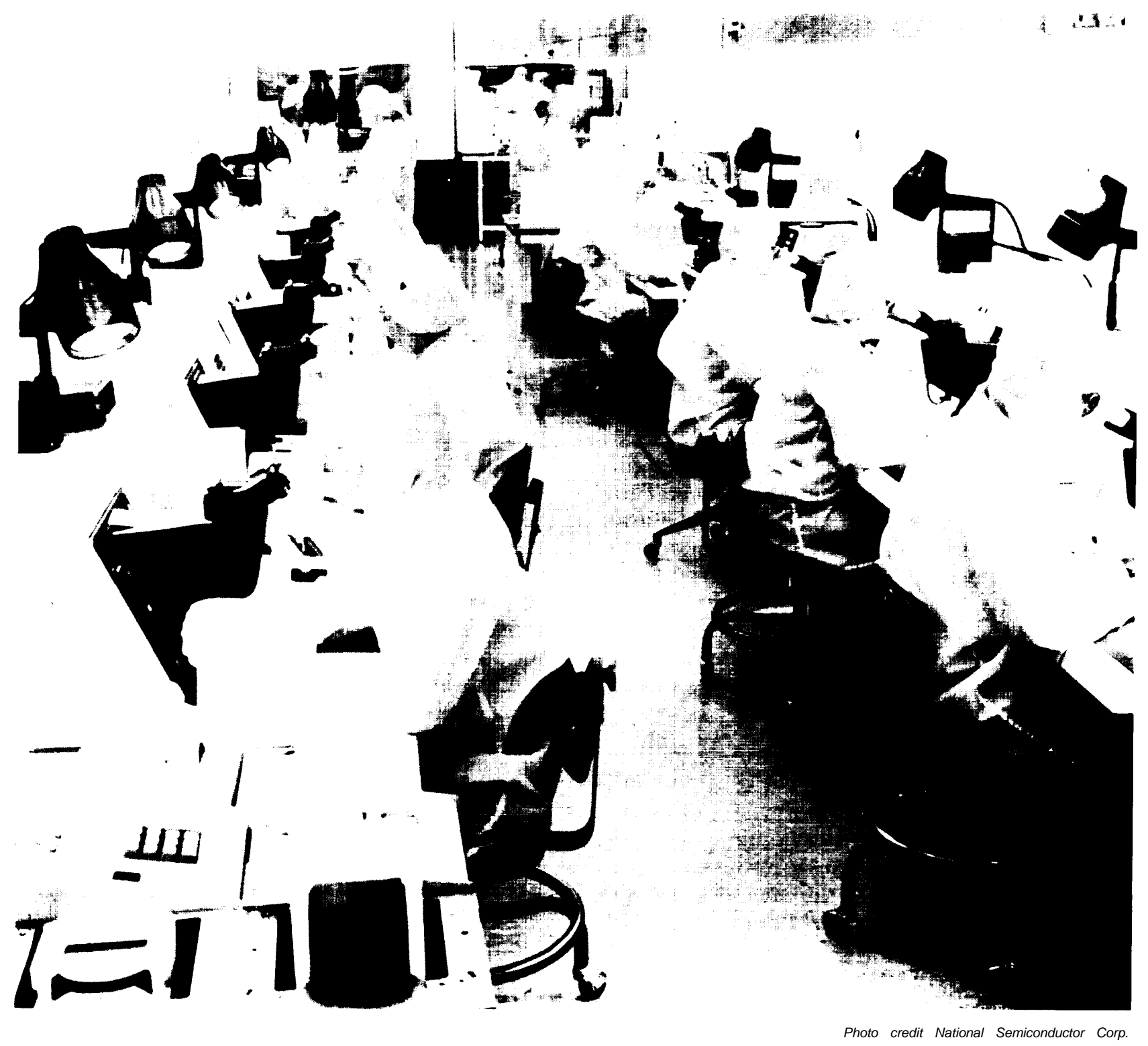

Workers in a clean room testing wafers for integrated circuits

the problems of many industries, aggravating the effects of unemployment and related dislocations.

Does the United States then need a better industrial policy? Clearly the Government intervenes in many ways in the activities of industry and will continue to do so. This is necessary in a complex industrial society. The issue is not intervention versus nonintervention. The issue is whether a more coherent industrial policy will function better than an ad hoc combination of macroeconomic and industry- or firm-specific measures. The answer is not obvious. The U.S. economy performed well for many years without a consciously developed industrial policy. During most of those years, the economy was growing rapidly; there was no apparent need for policies explicitly addressing competitiveness, productivity, or (nonmilitary) technology. 
OTA'S review of these three industries suggests several reasons why a consciously formulated industrial policy might produce better results.

- First, it could give the private sector clear signals about what the Government will do in the future-something the existing policy process often fails to accomplish. The creation of a relatively stable environment often seems among the most beneficial characteristics of industrial policies in other countries.

- A second potential advantage of industrial policy is simply improved effectiveness. Recent policies toward the consumer electronics and steel industries include several cases of initiatives that failed to achieve their purported objectives. Industrial policy could provide better and more consistent means for evaluation and refinement of policy tools.

- Third, a conscious industrial policy might reduce the risks of capture by firms or sectors in temporary distress or long-term decline. Industries and their employees seldom approach the Government while their competitive position is strong, Those firms and industries that find their position weakening have strong incentives to seek Government aid such as subsidies or trade protection. Furthermore, the greater their immediate problems, the greater the drive toward a short-term palliative. Industrial policy could provide improved mechanisms for evaluating the problems of distressed firms and sectors within the overall context of the U.S. economy, considering the claims of various parties, and responding to undesirable trends before they reach crisis proportions.

Thus far, in attempting to deal with sectoral problems within the economy, there has been little movement toward prospective rather than reactive policies because the former have had no real constituency. While it is easy to show, for example, that trade protection generally has costs that in the aggregate outweigh its benefits, the real issues are distributional: Who bears the costs and who receives the benefits? Is it a particular group of displaced workers? Is it the depressed local economy of the community where fading businesses are located? Or is it the nation as a whole, in which case costs and benefits are widely but thinly spread? When the costs but not the benefits of a policy are isolated and visible, the stage is set for a resolution on political grounds that may mask the problem rather than curing it.

The alternative is a more integrated and consistent industrial policy, But our current methods of making policy toward industry have deep historical roots and will not be quickly transformed. Industrial policy affects virtually every constituency, interest group, and public concern in the United States; those affected will want to be heard. The nature of the American political system virtually guarantees that policy toward industry will be to some extent fragmented and contradictory. This is not a bar to industrial policy, only a limitation on its form.

A consciously developed industrial policy does not imply centralized coordination or planning. Nonetheless, industrial policy would require relatively broad agreement on goals and objectives, together with a strengthened analytical capability within the Government for designing policy instruments to match these objectives, as well as for evaluating their effectiveness.

The Government has a variety of institutional mechanisms for formulating macroeconomic policies; by themselves these are insufficient, Industrial policy must be rooted in concrete, practical knowledge of the workings of industry and the sources of competitiveness. This demands an empirical appreciation of corporate decisionmaking and of the ways in which Government actions shape the behavior of firms in the private sector.

Any analysis of competitiveness, as well as any analysis of the effects of alternative policy measures, must proceed on a sector-bysector basis. This does not mean that policies based on such an analysis will necessarily or exclusively focus on particular sectors. 
Among the options will be both sector-specific and aggregate policy instruments. However, effective policies targeting particular sectors cannot be developed in isolation; rather they should be based on careful evaluation of costs and benefits throughout the economy. Sectoral policies of some types may aid a favored industry but carry high costs elsewhere.

Political and economic issues intersect in the design of industrial policy, elements of which will inevitably benefit some sectors at the expense of others. Distressed industries have the greatest incentives to exert political pressure for support and protection; over time an effective industrial policy must allow the efficient to thrive, the inefficient to decline. To do otherwise can be costly indeed; British taxpayers have recently been subsidizing their steel industry at the rate of $\$ 2$ million per day,

A suitable framework for industrial policy, one designed to fit the strengths of the American political and economic system, might be found in "macroindustrial policy." Macroindustrial policy would begin by providing a structure for integrating the various elements of public policies toward industry. It would be based on explicitly formulated objectives embracing economic efficiency and industrial competitiveness, as well as related social goals - e.g., employment opportunities. Competitiveness is important because it affects, among other things, national security and the standard of living.

The macroindustrial framework would stress the dependence of individual industrial sectors on macroeconomic and other aggregate policies, as well as emphasizing linkages among sectors. Macroindustrial policy might have sectoral components and include sector-specific policy instruments, but would prefer aggregate measures and reliance on market mechanisms where possible.

Elements of macroindustrial policy could include measures to promote economic adjustment, innovation and the technological base for manufacturing and service industries, fair trade and competition, manpower training and mobility, capital formation, and new productive investment. Policies would aim to complement the market system, providing a structure for easing adjustment and spreading the costs of change so that particular groups were not gravely disadvantaged.

In the near term, modified tax policies designed specifically to stimulate capital investment in U.S. industry could have significant positive effects on U.S. productivity and competitiveness. So could tax incentives for $R \& D$ and the development and diffusion of new commercial technologies. Policy measures to improve the environment for industrial innovation are related steps that could also have immediate effects. In the longer term, macroindustrial policy might assign a particularly high priority to the development of more effective mechanisms for economic adjustment and to improving the country's human resources through support for education and training of the work force at all levels,

The development of macroindustrial policy or any other coherent and consciously evolved industrial policy would be a long-term undertaking. Congress and the President will have to decide whether the time has come when maintaining and enhancing the competitiveness of the U.S. economy requires such a policy. 


\section{CHAPTER 2 \\ Introduction}




\section{Contents}

Objectives and Scope $. * * * \ldots . . . . . . . . . . * . * * . . . * * . . * * * * * * . * * . * * * * . * * \mathrm{C}^{*} . " 23$

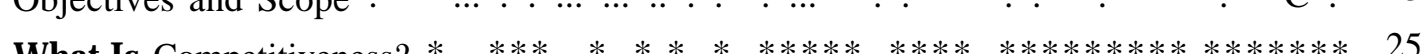

What Is Competitiveness? $* . * * * . . * . . * * . . * . . * * * * * . . * * * * . . * * * * * * * * * . * * * * * * * 25$

The Problem as Perceived... ... $* * * * \quad * . . * *_{0} . * \ldots * * * \ldots * . * * * * * * * * * * * * * * * * * * * * * 25$

The Role of Government .* . e.. o...**.* ......*****...**.*.@*..@***.*" 26 


\section{Objectives and Scope}

Concern over possible slippage in the competitiveness of U.S. industries mounted during the 1970's. Apparent symptoms included: a slowdown in economic growth; lagging rates of productivity advance; rapid inflation combined with unemployment; decreasing technological advantages in a variety of industries; mounting balance-of-payments problems, associated particularly with trade deficits in industrial sectors such as consumer electronics and automobiles; and a relative decline in U.S. military strength, Although these symptoms are not all directly related to industrial competitiveness, they have each contributed to a feeling current at the beginning of the 1980's that the United States and its industries have been reduced to muddling through, that the Nation is losing its position of leadership and preeminence in the world economy,

In fact, the United States has lost much of its preeminence, not only in specific industries such as steel, but in the relative size of its economy as a whole. Although the gross national product of the United States remains the largest in the world, on a per capita basis it was only ninth in the Organization for Economic Cooperation and Development in 1979, a little above that of France, and 17 percent greater than that of Japan. 'In particular industries, the United States has often only slipped in a relative sense; in absolute terms U.S. firms often remain world leaders.

Despite the concern such symptoms have raised, it has not been clear what, if anything, the U.S. Government can or should do. While changes in long-term comparative advantage might be considered inevitable, or at least beyond the ability of any one government to influence significantly, there are nu-

'For a typical account, see the Business Week issue on 'The Reindustrialization of America,' June 30, 1980.

Statistical Abstran t of the I Inited States (Department of Commerce, Bureau of the Census. 1980], p. 910 merous cases of apparent failures in public policy. These range from macroeconomic problems-difficulty in controlling inflation - to narrow issues such as the continuing debate over patent policies, unresolved after 30 years. The painfully slow evolution of energy policy is as good an example as any of the lack of consensus on complex problems.

Industrial competitiveness is only a subset of these general issues, but an important subset. Much of the recent discussion of reindustrialization and industrial policy has been based on a perception of slackening U.S. competitiveness-across the board or in specific industries such as automobiles, An examination of three industries-steel, electronics, and automobiles-permits only limited generalization about overall competitiveness, but is a useful starting point. Every industry is different; aggregate analysis cannot provide explanations for shifts in competitiveness adequate for guiding policy. Sector-specific policies-e.g., automobile fuel economy regulations-always require case-by-case analysis. Similarly, judgments of the net effects on competitiveness of policy changes such as tax cuts must be made on an industry-by-industry (or perhaps firm-by-firm) basis. Thus, examination and comparison of individual industrial sectors such as the three covered in this report is a necessary starting point for judgments of U.S. competitiveness and of the effectiveness of Government policies toward industry.

OTA'S work on the competitive position of U.S. industry began with a study of the steel industry, concentrating on the role of technology as a determining factor in competitiveness. ${ }^{\mathrm{q}}$ A parallel study of international com-

In a technical sense, the notion of an across-the-boardloss in compe $\mathrm{i}$ i $\mathrm{i}$ veness is not very mea $\mathrm{n}$ i ngful. The rea sons a re discussed in app. A.

'Techn ology and s teel Indus try Compe ti ti veness (Washington, D, C,: Of fice of Technology Assessment, U.S. Congress, June 1980), 
petitiveness in the electronics industry is scheduled for completion in 1981; that workin-progress provides much of the basis for the portions of this report which deal with electronics (primarily consumer electronics, semiconductors, and computers). While OTA has not explicitly studied the competitiveness of the U.S. automobile industry, several OTA programs have undertaken a variety of work in the past which has been brought to bear on such questions.

Competitiveness is an amorphous concept (discussed in detail in app. A). Because of this, a study of competitiveness can easily spread in a variety of directions to encompass the seemingly endless array of possible influences - by governments as well as private firms-on competitive position. To keep this particular study bounded, a number of constraints were imposed from the beginning. Beyond the fundamental restriction to only three industries, these constraints were:

1. To treat the industries primarily in their domestic context. - A major reason is that competitive strength in the home market is a prerequisite for international competitiveness, at least in the absence of significant government subsidies. Furthermore, many of the policy issues relate to domestic employment levels, Nonetheless, competitive success in some industries depends on marketing on a world scale; international competitiveness remains the focus of the report. (Geographic bounds of U.S. industry are discussed inch. 3.)

z. To compare the industries using an essentially economic framework.-While other perspectives can be useful, this one best unifies a comparison of dissimilar industries. The treatment of the three industries is comparative at the expense of detailed individual exploration.

3. To focus on the role of government policies, even though these often have only secondary influences on competitiveness.-Corporate decisions and strategies normally exert the most immediate effects on competitive performance. However, many of these decisions and strategies are shaped in important ways by governments. Public policies are, finally, the primary concerns of Congress, and hence of OTA. The more important policy influences on the three industries are discussed, along with the general framework of industrial policy in the United States. However, an exhaustive treatment of Government policies-either past or prospective-is beyond the scope of this study. Export promotion policies, for instance, are not examined in depths

4. To draw on foreign experience only selectively and narrowly.-Because the objective is to provide policy guidance for the United States, extensive discussions of industrial structure and performance in other countries, as well as the policies of foreign governments, have been avoided.

OTA'S objectives have thus been twofold: to examine and compare the competitiveness of the U.S. steel, electronics, and automobile industries within an economic framework, and to broadly discuss the policy avenues available to Government for dealing with shifts in competitiveness and their consequences. A basic question is: To what extent have government policies, here and in other countries, influenced shifts in international competitiveness? What role does technology play in such shifts? How have these effects differed between industries? If public policies in the United States, or those of its trading partners and competitors, place American industry at a disadvantage, what can and/or should the United States do?

\footnotetext{
'In the long term, government export policies probably have only marginal effects-certainly compared to import policies. Put simply, uncompetitive industries cannot export profitably. See C. P. Kindleberger, "Government Policies and Changing Shares in World Trade, " American Economic Review, vol. 70, May 1980 , p. 293 ,

"See app. D on foreign industrial policies.
} 


\section{What Is Competitiveness?}

Competitiveness is a term used in different ways by different people, as discussed at some length in appendix A. To economists, it has a precise though abstract meaning, This meaning, rooted in comparative advantage and ultimately based on relative costs, is used in most places in this report. In many cases, however, the comparative advantage framework, in which low production costs give competitive advantage, is an oversimplificatione.g., when governments subsidize industry, Nonetheless, comparative advantage remains a useful organizing device, one which can help sort out the likely effects of policy alternatives.

More broadly, competitiveness can refer to the strength of a particular industry as indicated by its international trade position, In a still more general way, competitiveness is sometimes used to convey a sense of economic health and vitality. This is a vague and imprecise use of the term; within a comparative advantage framework, individual firms or industries may become noncompetitive, but an entire country cannot. Given flexible exchange rates, a country can always export; the particular goods that it can export, and the prices they bring, depend on the relative competitive strengths of the various sectors of its economy. So does its standard of living.

The competitiveness of any one country in a particular industry such as computers or steel then hinges on its ability, relative to industries in other countries, to successfully develop, manufacture, and market the products of that industry. These activities are subject to a wide variety of influences, some of which are primarily under the control of individual firms, some not. One potential source of competitiveness is superior technology -e.g., a firm or a country might gain competitive advantage if it were able to market a more powerful computer at an attractive price. Otherwise, for commodities and products that are technologically similar, cost and price are primary determinants of competitiveness. Superior manufacturing or process technology-as opposed to product technology-is one way of achieving low costs. At the same time, public policies can confound simple cost/price measures of competitiveness. For example, governments can subsidize highcost producers, or protect markets with trade barriers so that domestic producers can charge higher prices.

In the end, however, it is the capability of individual firms in development, manufacturing, and marketing (including sales, servicing, and customer support) which determines a nation's competitiveness. The notion of competitiveness remains comparative, and competitiveness a dynamic concept, the indicators of which vary over time,

\section{The Problem as Perceived}

A number of generalized symptoms of what is commonly interpreted as slackening U.S. competitiveness were listed above-e. g., increasing trade deficits, and slow rates of productivity growth. When individual industries are examined, the symptoms become more specific: low profits, plant closings, and unemployment in steel; import penetration accompanied by foreign investment in consumer electronics; an increasing presence by
Japanese firms in semiconductor markets; a narrowing of the technological edge that the United States has held in computer systems; falling sales and low profits-or losses-by U.S. automakers, again accompanied by plant closings and layoffs,

Products in all three industries have been targets of foreign competition, past or present, especially from firms based in Japan: 
structural steel, color televisions, random access memory circuits for computers, and subcompact cars. Questions such as the following are asked: Are there generic problems with U.S. industry? Are the experiences of the steel, consumer electronics, and automobile industries harbingers of the future for all manufacturers? Does the United States need to increase its rate of capital investment in industry? If so, how should we proceed?

At the same time, the United States has not been alone in its recent economic difficulties. The decade of the 1970's was a difficult one, In most countries, rates of growth of output, employment, and productivity failed to achieve the levels of the earlier postwar period. Policy makers often found themselves with a poor choice between stagnation and inflation, and at risk of aggravating both.

These macroeconomic difficulties were compounded by significant structural problems within Western industrial nations and between them and the rest of the world. Most important were the problems caused by higher energy prices. Worldwide overcapacity in a number of important industries-including steel, shipbuilding, and textiles-also indicated the need for structural adjustment.

That other industrialized countries also have economic problems does little to alleviate U.S. concerns. For one thing, there is a perception that this country's difficulties may be more serious in the long term than those of West Germany or Japan. These nations, after all, still seem to be catching up to the United States. Some observers claim that declining competitiveness has already inflicted heavy costs on American society -e.g.,, the unemployment allegedly caused by rising imports. Such matters are easily oversimplified. Increases in productivity, which are necessary for maintaining competitiveness, also reduce employment opportunities unless markets grow rapidly. Whatever the cause, dislocations associated with shifts in competitiveness-either within the United States or internationally-are a serious concern, Regional unemployment, as in the industrial portions of the Midwest, or unemployment among particular segments of the population such as urban blacks, create particularly knotty problems.

\section{The Role of Government}

Public policies are closely tied to questions of competitiveness. Government policies affect competitiveness in many ways; the policies of the U.S. Government influence both American and foreign firms, So do the actions of foreign governments. Some policies have direct effects-e.g, those dealing with international trade, or regulations that increase costs for domestic industries compared to competitors overseas. Others are indirecti.e., policies dealing with education or manpower.

Macroeconomic policy has a central role. The health of individual industrial sectors is closely tied to that of the economy as a whole. A large share of the slump in sales by U.S. automobile firms during 1980 can be attrib- uted to recession (see ch. 5), Government policies targeting individual industrial sectors often depend for their effectiveness on a strong and growing economy, At the very least, designing such policies requires an understanding of the ways in which macroeconomic phenomena affect particular sectors. Rapid economic growth makes structural adjustment easier and would alleviate symptoms of problems in many industries.

While broad macroeconomic policymaking has always been seen as a legitimate governmental function in the United States, intervention past this point has been more controversial, though continuously evolving. Today Government loans and loan guarantees 
total almost $\$ 400$ billion. ${ }^{7}$ It is no longer realistic to say that Government should play no role at all.

The coincidence of depressed macroeconomic conditions and structural adjustment problems that developed in the 1970's has made economic policymaking more difficult. There appears to be growing agreement that the situation in the United States requires something beyond the Keynesian economic policies characteristic of the postwar period. Indeed, many observers blame just these policies for the inflationary tendencies that are part of the problem. Increasing difficulties in such politically and economically important industries as automobiles and steel have

'1', B.Clark. "The Public and Private Sectors-The Old Distinctions Grow Fuzz\}, "National Iournal, Jan, 19, 1980, p. 99. Onlvafraction of the $\$ 400$ billion total supports investment in industry. fanned interest in industrial policy and its relationship to macroeconomic, trade, and regulatory policies.

Much of the recent discussion of industrial policy has been concerned with the question of whether the United States should go beyond promotional measures directed at broadly accepted goals-such as support for science and technology aimed at military needs or the medical arts-to measures that support specific industrial sectors such as steel or electronics. Other governments target industries for development, promote exports, and restrict imports; should the United States do likewise? Decisions to support particular industries - whether to match the promotional measures adopted by other countries, to maintain employment, or for reasons of national security-necessarily deprive other industries, their employees, and localities, Hence the political concerns cannot be disentangled from the economic. 
CHAPTER 3

\section{Steel, Electronics, and Automobiles: Industrial Structure}




\section{Contents}

Page
Pag

Overview ........ $0 \ldots ., 0,0,0 \ldots, \ldots \ldots \ldots \ldots \ldots \ldots \ldots \ldots \ldots \ldots$

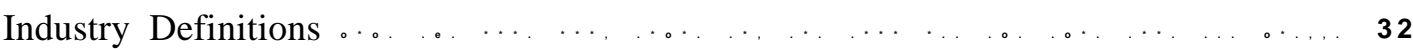

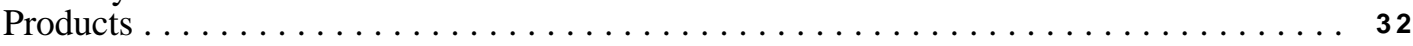

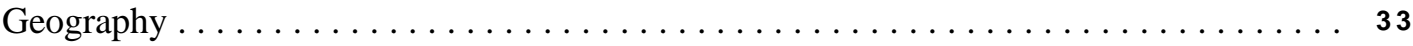

TheSteelIndustry .***.,., . . . . . . . . . *,,.*,,* .*.,***.. ..*.*.,,*.*.,.*.* . . 34

TheElectronicsIndustry. . . . . . . . . *... ...*.,. ...*..* . . . . . . . . .*..*, ,. 37

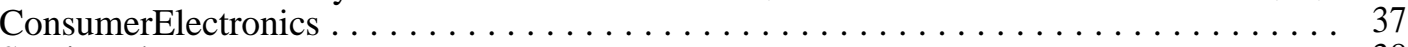

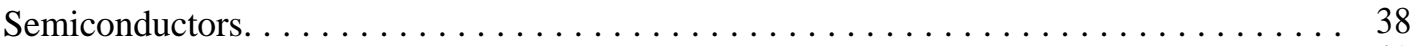

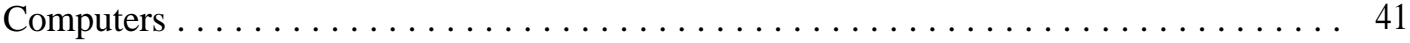

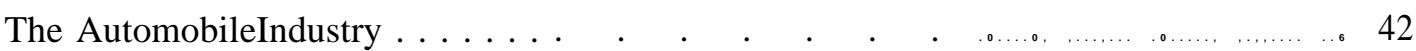

SummaryandConclusions .*..*** ..****. . . . . . . . .*.**, ...0.0 .**.*.. . 46

Table

TableNo. $\quad$ Page

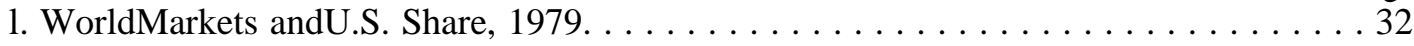




\section{Steel, Electronics, and} Automobiles: Industrial Structure

\section{Overview}

The many differences exhibited by the steel, electronics, and automobile industries illustrate the difficulties of attempting to generalize about the state of U.S. competitiveness. Together, these three sectors include much of the Nation's industrial base, providing employment for a substantial fraction of the work force. They cover a span of technological levels from low (some steel products, much of consumer electronics) to high (specialty steels, large-scale integrated circuits, computers), There are differences in competitiveness among the industries, among firms within each industry, and even among product lines within individual firms. Furthermore, all three industries are undergoing structural change.

Integrated steel firms in the United States are burdened by capital plant that is, on the average, older than that of most of their foreign competitors. While other countries, particularly Japan and several West European nations, rapidly expanded and modernized their steel capacities after the Second World War, U.S. capacity increased only slowly, Up to 25 percent of U.S. steel capacity now appears to be obsolete.' At the same time, the industry as a whole remains a reasonably efficient producer of steel, probably second in costs only to Japan - which has more modern, larger scale plants, as well as lower labor costs. The nonintegrated segment of the U.S. industry, in particular, is efficient and growing,

There is now excess capacity in world steel markets. One result of overcapacity is to create incentives for producers in many coun-

Technology and Steel Industry Competitiveness (Washington, D.C.: Office of Technology Assessment, U.S. Congress, June 1980). p. 129. tries to cut export prices and "dump" steel while attempting to maintain domestic price levels. Dumping and other unfair trade practices have been important concerns of the American steel industry,

The steel industry is not monolithic, but the typical disaggregation into integrated producers, nonintegrated firms, and alloy/specialty steelmaker is straightforward compared to the diversity exhibited in electronics. In many respects the three sectors of the electronics industry covered in this reportconsumer electronics, semiconductors, and computers - comprise three distinct industries. They exhibit different levels of technology, different levels of competitiveness, and different Government policy impacts.

Except for consumer electronics, most of the U.S. electronics industry remains strong; nonetheless, there is increasing concern because of shrinking U.S. technological advantages and the support other countries are providing their own industries, The Japanese, in particular, have targeted electronics as a cornerstone of future industrial expansion and are pursuing policies directed at that goal. Some observers feel that if the United States does not respond, its remaining competitive advantage may disappear.

During 1980, the automobile industry had the most visible set of problems, with imports taking more than 25 percent of the market and hundreds of thousands of workers unemployed. American automakers are going through a period of rapidly changing product mix, which is straining their capital resources. The domestic automobile firms differ markedly in their competitiveness, and in the resources which they can bring to meet- 
ing future needs-whether demanded by the market or by Government regulations.

As in the case of steel, the U.S. automobile market is now a smaller proportion of the total world market than in the early postwar period. The share of world auto sales accounted for by firms based in the United States has dropped from three-quarters in 1950 to less than one-third at present, despite their extensive foreign operations. But American firms have been and continue to be strong in some foreign markets; now they find themselves using knowledge (and sometimes profits) gained overseas in their home market.
In the remaining sections of this chapter, these industry sectors are described in more detail, together with aspects of their structure that affect competitiveness (many of these are amplified in ch. 5). This chapter is devoted primarily to understanding the diversity of the industries and its consequences. The approach is comparative, pointing out both similarities and differences. No attempt is made at complete descriptions, but factors that influence competitiveness are emphasized.

\section{Industry Definitions}

\section{Products}

An indication of market sizes, for the United States and the world, is given in table I. The industry subdivisions in the table are expanded on below.

The disaggregation for steel is that adopted in the OTA steel study; this divides the industry into producers that are primarily integrated steelmaker, nonintegrated firms, and manufacturers of alloy/specialty products. The basic distinctions are as follows. Integrated steelmaker begin with iron ore. They make iron, convert it to steel, and then to final products such as sheet, plate, and structural shapes. Nonintegrated firms typically begin with steel scrap and produce only a limited range of final product types-e. g., reinforcing bar. Alloy/specialty products have particular combinations of properties, such as high strength (aerospace alloy steels), high hardness and wear resistance (tool steels), or corrosion resistance (stainless steels); they typically sell for much higher prices than plain carbon steels. Most alloy/specialty firms use scrap as the main input.
Table 1.-World Markets and U.S. Share, 1979

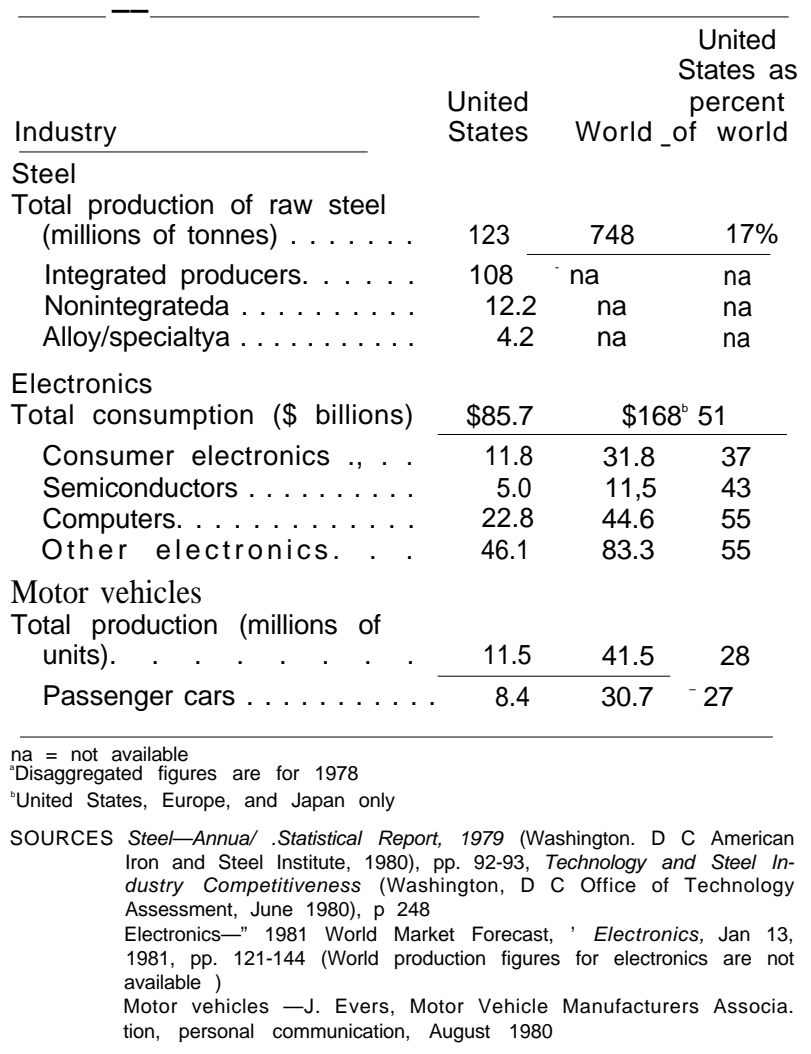


The three sectors of the electronics industry covered in this report-consumer electronics, semiconductors, and computerscontain only a fraction of the 5,000 to 7,000 firms in the U.S. electronics industry; however, they are among the most important.

Consumer electronics products include radios, televisions, audio equipment such as stereo receivers, electronic watches, and electronic toys and games. Home entertainment products such as TVs and video-cassette recorders receive the most attention in the following chapters.

Semiconductor devices can be discrete circuit elements such as transistors, or integrated circuits (ICS) containing several tens of thousands of circuit elements on a single monolithic "chip' of silicon a few millimeters on a side. ICS, and particularly digital ICS, are the most dynamic portion of the semiconductor industry, both in terms of technological advance and in terms of sales growth, ICS are used in a wide range of products made by many industries; an important current application is engine control electronics for automobiles, While the biggest single market for ICS is the computer industry, semiconductor technology is important to virtually the entire breadth of U.S. manufacturing and service industries.

The computer sector spans firms ranging from those that make mainframe machines selling for several million dollars to those that build microcomputers using a single IC chip as the processor. The computer industry is important not only in itself, but because of the rapidly expanding applications of dedicated computers in other products to make them "smart." Manufacturers of peripherals such as memory and terminals are included within the computer sector.

Communications ss the largest of the sectors omitted from this reportandfrom the full OTA electronics study. It was excluded prim:] rily to keep the $t$ wo s tudies more manageable.

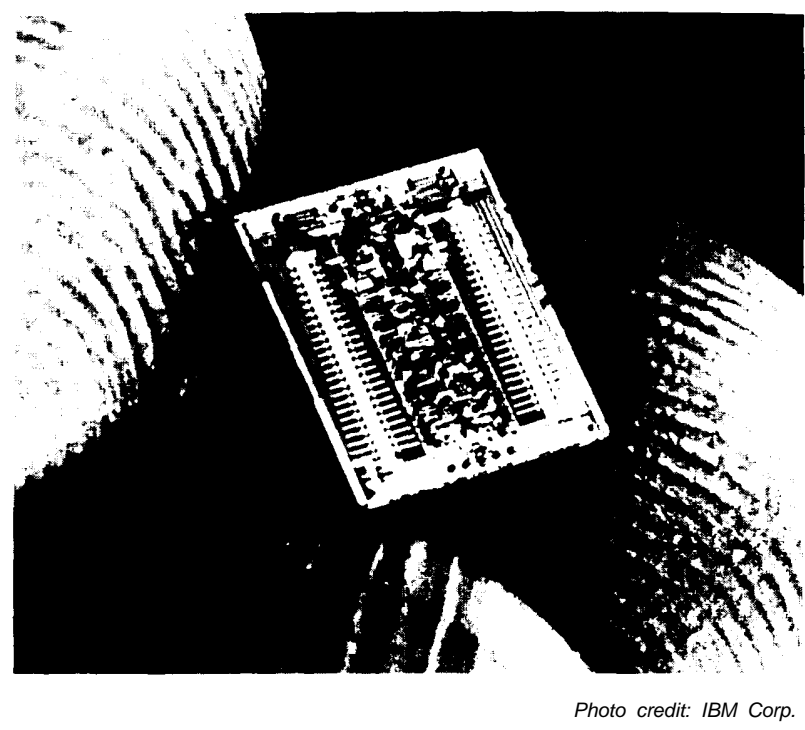

This IC-a 64K RAM memory chip-can hold 64,000 bits of information

The automobile industry as a whole embraces large numbers of sales and service firms, as well as suppliers of component parts. This report concentrates on manufacturers of passenger cars and light trucks, many of the latter being used interchangeably with passenger cars. Where the term "motor vehicles" is used, it refers to both cars and trucks,

\section{Geography}

The geographical boundaries of these industries must be defined before U.S. competitiveness can be assessed. Given the tendency toward internationalized production, what are the bounds of American industry and the limits of Government interest?

Many U.S. industries include firms that confront their foreign competitors not only through exports and imports, but also through manufacture and sales by overseas subsidiaries, This is common in electronics and automobiles, though rare for steel, There are several patterns of investment. In automobiles and computers, foreign subsidiaries 
sell mostly in foreign markets, This is also common in semiconductors; but in addition, many American semiconductor firms have overseas manufacturing facilities which reexport to the United States. Offshore assembly is also widespread in consumer electronics.

In one sense, these overseas subsidiaries are foreign firms, not a part of U.S. industry. On the other hand, they are often inextricably linked to the domestic operations of the parent company. Not only may these linkages be difficult to disentangle, but the subsidiaries may be profitable while the U.S. parent languishes-giving the parent more freedom in developing strategies to extricate itself from competitive difficulty, In 1979, for example, Ford was able to offset losses in the U.S. market with profits overseas. Further, one can ask if Japanese-owned TV plants in the United States-such as Quasar-should be viewed as domestic producers,

Some decision is needed to define the boundaries of U.S. industry and hence U.S. competitiveness. In general, this study has attempted to stay with convention (and convenience) by defining U.S. industries to be those operating within the geographic confines of the United States. Thus, in each of the three industries, U.S. firms are those employing U.S. workers; Quasar is an American firm, as is Volkswagen of America. Domestic manufacturing by Ford or IBM receives more attention than their overseas production. At many points, however, such distinctions break down, and overseas operations must be considered.

Major competition in each of these industries has recently come from Japan. This is not to say that other rivals are insignificant. Certainly West Germany and France are important factors in steel and automobiles, as are Korea and Taiwan in consumer electronics and steel, Nor is this meant to imply that Japan is the primary competitor in all industries. Japanese firms have not been successful in aircraft, and only about a third of U.S. imports of steel come from Japan, West Germany is a leader in machine tools (along with Japan), and other Far Eastern nations are major producers of apparel. Although attention has with reason focused on the Japanese, Japan does not constitute the rest of the industrial world.

\section{The Steel Industry ${ }^{3}$}

Steel has a unique combination of low cost and desirable physical characteristics that make it virtually the only material suitable for many applications. Among the most important of these are: automobiles (around 20 percent of domestic steel consumption), machinery and equipment (10 percent), and containers such as cans ( 7 percent). In addition, significant amounts of steel are used in construction, appliances, pipe, rail cars and locomotives, wire products, and military equipment, Industrial societies as they are known today could hardly exist without steel.

Almost all steel products are manufactured to standard specifications, There is lit-

Most of the information in this section is drawn from the OTA steel study. tle difference in the steel produced by various firms-a given type of sheet, plate, or structural shape will be much the same whether it comes from the United States or Korea. While there are specialty products and proprietary grades-e.g,, various tool-and-die steelssubstantial product differentiation as occurs in industries such as automobiles is seldom possible. Competition, therefore, is largely based on relative prices and customer service, Important elements of the latter are timely and dependable delivery, and technical advice, Such service is important and should not be minimized; it is not necessarily true that only prices determine sales. In fact, many customers maintain familiar and reliable sources of supply even when lower prices are available elsewhere. 


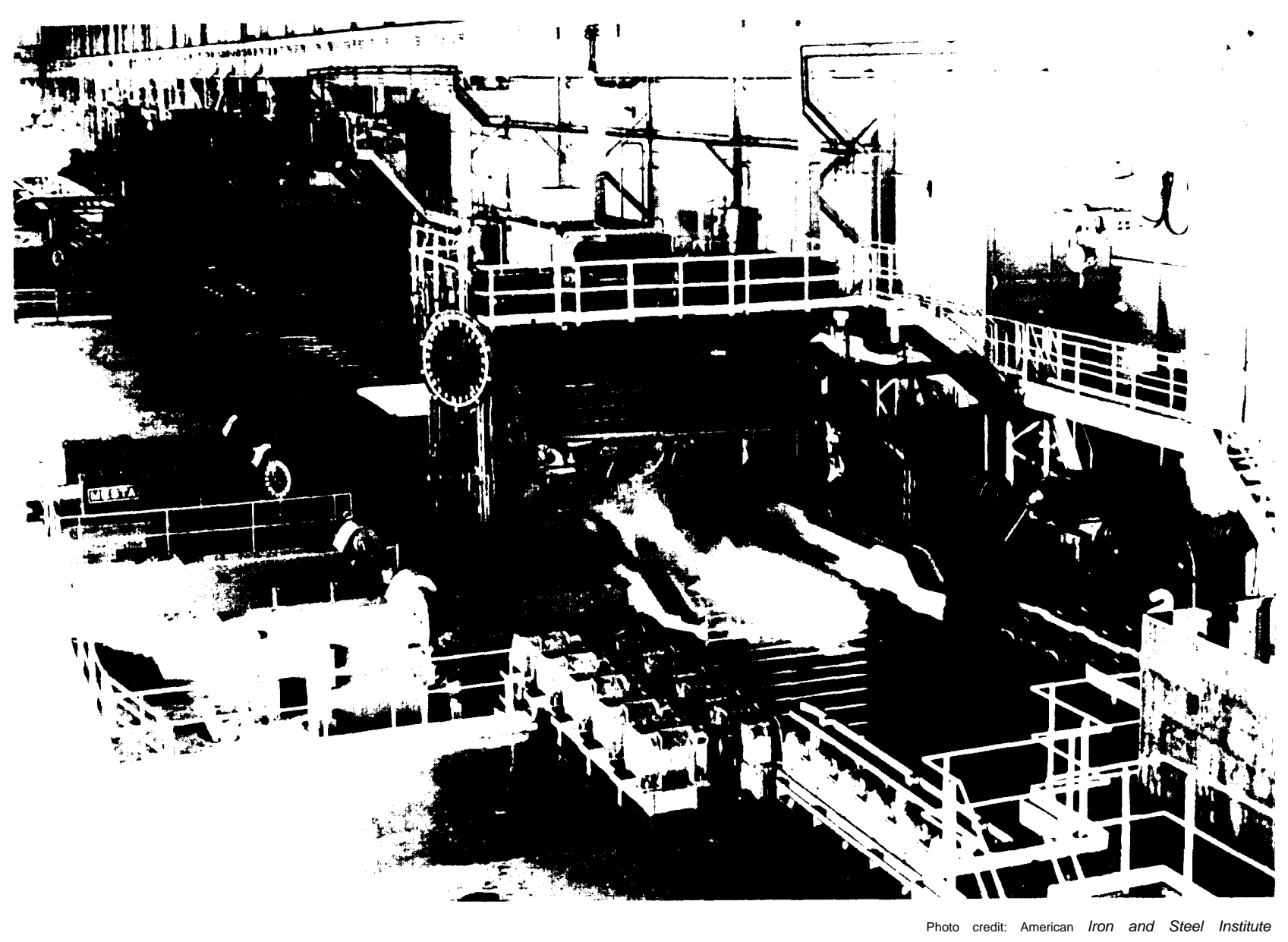

Slab casting of steel

From the standpoint of industry structure, steel has experienced a declining level of concentration over the years. U.S. Steel, still the largest producer, today accounts for barely more than one-fifth of the domestic industry's sales. Market share losses by the traditional leaders have been taken partly by imports but partly also by other domestic firms, including nonintegrated producers and specialty steelmaker. These companies occupy market niches for which the benefits of large-scale operation are less important.

Nonintegrated companies now account for some 15 percent of industry shipments. The OTA steel study estimates that such companies may account for as much as 25 percent of domestic production by the end of the dec- ade, provided adequate supplies of scrap and electricity are available at reasonable costs.

Price is a critical determinant of competitive ability in steel, particularly for sales to firms which themselves sell in highly competitive markets. Therefore, costs of production are also crucial. American steelmaker face both problems and opportunities in their efforts to achieve low costs. On the positive side is the close proximity of a large and diversified market. On the other hand, this country's technological advantages in steel have largely eroded. Technology for making iron and steel is now well-diffused internationally and available to all who can pay for it.

As might be expected for a commodity-like market, the industry engages in comparative- 
ly little R\&D. American firms tend to be more active in introducing product innovations such as dual-phase or microalloyed steels than in process innovations. In recent years, many of the latter have come from foreign firms. U.S. Steel, for instance, recently concluded an agreement with Sumitomo Metal Industries, a Japanese steelmaker, to purchase technology for computer-controlled production equipment.' The industry also relies on suppliers of machinery and equipment for many process developments.

The OTA steel study concluded that a number of significant innovations in making iron and steel might come into general use within the next 20 years. Moreover, many technologies already available and proven have not been as widely adopted in the United States as in some other countries. Not only computerized process control, but also continuous casting and a variety of improvements in basic oxygen steelmaking could raise yields and productivity, as well as save energy, if they were more pervasive in the American industry. Finding the capital required to implement new technologies or to modernize using existing technologies is a major hurdle for most portions of the American industry; the OTA steel study estimates capital needs for modernization and expansion at $\$ 3$ billion per year (in 1978 dollars) over the next 10 years, $\$ 5.3$ billion per year for total capital requirements,

There are factors beyond technology and investment capital which are important for the international production and sale of steel. Some work to the benefit of the U.S. industry, others to its detriment, An obvious benefit is the low value-to-weight ratio of steel, making it costly to ship, particularly overland; relatively little steel moves more than 300 miles from a domestic mill or port-of-entry. Imports must bear significant transportation costs.

On the other hand, the industry's large fixed capital requirements encourage "un-

".'Japanese Steel Maker to Computerize Production Lines of U.S Steel Mill, "Japun Report No. 97, Joint Publications Research Service 75611, May 11.1980, p. 48.

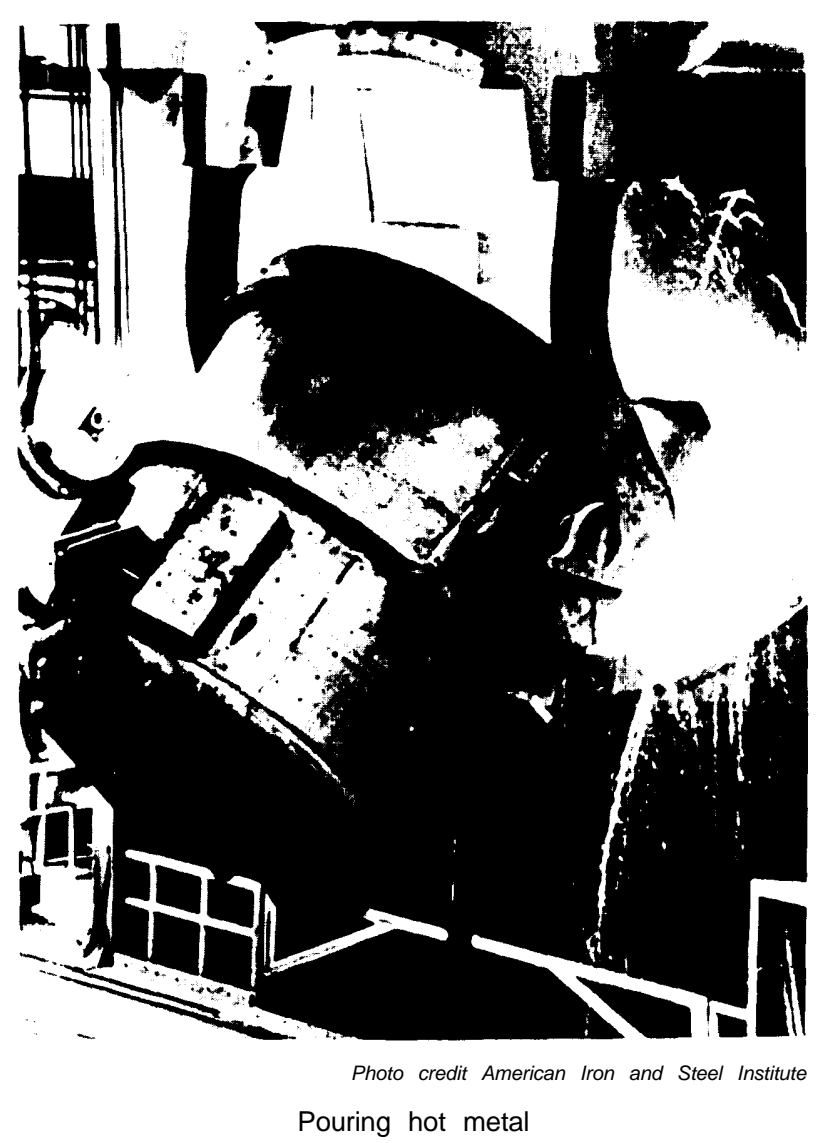

fair" pricing practices. Operating a mill below capacity results in high unit costs. Often the problem is worse abroad than in the United States because labor costs may be more nearly fixed in the short term. This can arise because of lifetime employment (Japan-although there is flexibility in Japanese labor costs because of the widespread use of contract workers and also the large fraction of wages paid as bonuses) or a social and political climate-often coupled with strong unions-that makes layoffs difficult (Europe). In any case, efforts of foreign firms to operate close to capacity without cutting prices at home may lead to dumping of excess production overseas.' This practice, together with the industry's cyclical demand pattern, has created difficult conditions for American steel firms, even though their average costs of

"Dumping refers to export sales at prices below those charged in the home market, or in some cases to sales at prices below cost. 
production may be fully competitive, There have been more dumping cases brought in the United States in steel than in any other industry. (The industry points out that other countries shield their steel industries from foreign competition and need not resort to antidumping measures. )

Despite intense price competition, the U.S. steel industry remains more profitable than other major national steel industries. But profits have suffered compared to other sectors of the American economy, Returns on equity for the steel industry in the United States have been significantly below the average for all manufacturing in every year but one since 1958.

Finally, it is noteworthy that the steel industry, in the United States and in other coun- tries, has faced increased costs because of government regulation, In the United States, environmental controls and workplace health and safety standards have raised costs of production. Ironmaking and steelmaking have been inherently polluting of both air and water; when Federal policy began to reflect environmental concerns, the burden of change fell heavily on this industry. The OTA steel study found that meeting environmental and workplace standards took about 17 percent of new investment in the industry during the 1970's. To the extent that such regulations do not apply abroad, the domestic industry is placed in a less competitive position by virtue of public policy alone.

\section{The Electronics Industry}

As pointed out previously, this study addresses only three sectors of the electronics industry: consumer electronics, semiconductors, and computers.

\section{Consumer Electronics}

Most of the products of this sector-e.g., radios, TVs-are sold through wholesale/retail distribution channels, mainly to households. A relatively high proportion of the consumer electronics products marketed in this country now originate in the Far East, Videocassette recorders (VCRs), for example, including those marketed under American brand names, are produced almost exclusively in Japan. Color TVs are assembled in the United States by both American and foreign firms; regardless of the home of the parent firm, many of the manufacturing operations are carried out in regions with low labor costs, primarily Mexico and the Far East. In the newest product categories, such as video disks and home computers, American firms are mounting strong efforts to maintain leadership. However, it is likely that in the long run, even if they are successful, the more labor-intensive production processes will move overseas,

Continuing competitive strength in consumer electronics depends, much as for steel, on maintaining low prices in mature products and staying abreast of technological developments that might have major impacts on the industry's future direction. The latter include the video disks and home computers mentioned above: in the future, such potential new products as flat screen TVs and integrated home entertainment centers may become large markets.

The Orderly Marketing Agreements for color TVs negotiated by the U.S. Government and beginning in 1977 function as import quotas. They have protected U.S. labor to some extent, and have also encouraged Japanese producers to locate plants here. In effect, the weaker U.S. firms that were driven from the market by import competition have been replaced by foreign firms manufacturing in the United States. The Japanese are being followed to the United States by companies based in Taiwan and South Korea. 


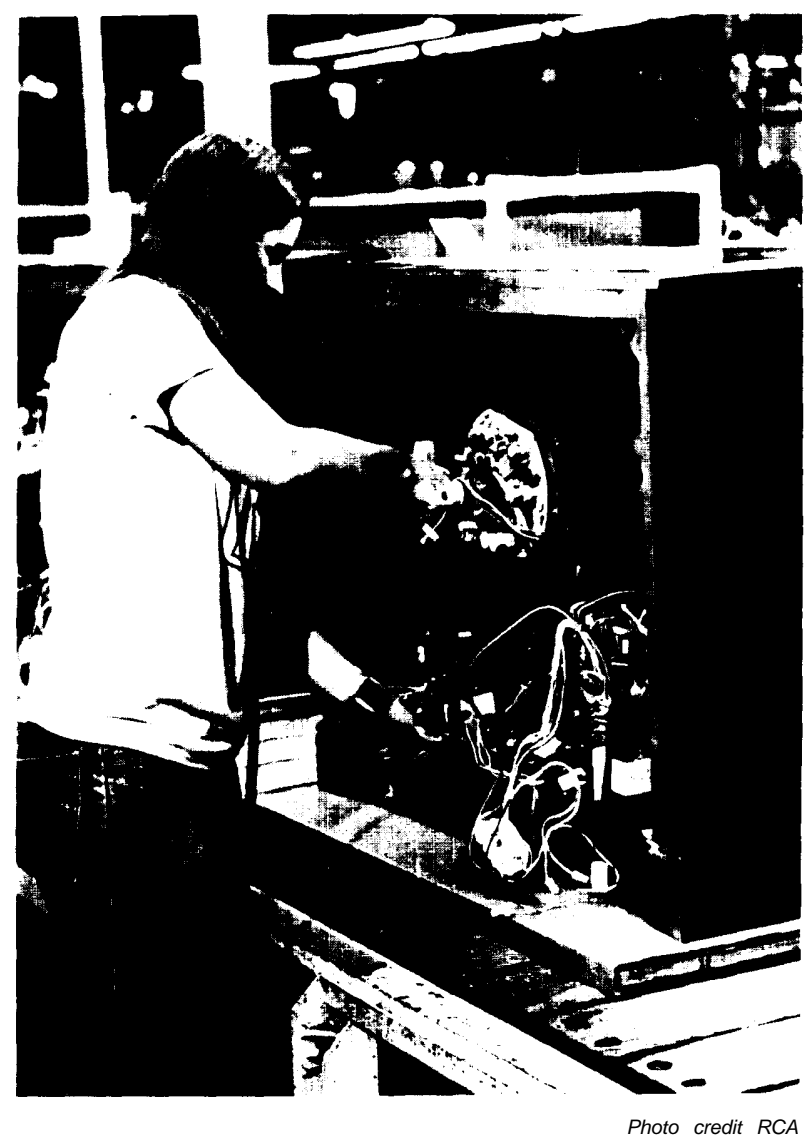

Final assembly of color TVs

While the largest U.S. firms have retained market share, the real questions deal with future products. Will these be developed and manufactured by American firms, or will foreign manufacturers capture the market as they did for VCRs? Will the United States become simply a site for assembly plants, with management control and $R \& D$ remaining overseas? Given the low profit margins in this sector, the high risks, and the past history of strong import competition in products based on U.S. technology, the domestic consumer electronics industry may, like the steel industry, have trouble finding the capital necessary to compete.

Retail distribution systems, and product quality and reliability, also affect competitiveness. Consumer electronics products are sold through a wide variety of retail outlets. Historically, this meant that manu- facturers attempting to establish and maintain recognized brand names paid close attention to distribution. Retailers not only were responsible for product sales, but also, and perhaps more importantly, for aftersales servicing.

This pattern has changed in recent years, partly as a result of imports, and partly because of improved product quality and reliability. Importers did not have extensive retail distribution networks. They countered by developing new marketing channels (e. g., discount stores) and-to avoid the need for frequent servicing-by emphasizing reliable, trouble-free products. As one result, product quality and reliability have also improved for domestic products. Higher reliability has diminished the role once played by retail servicing, and greatly expanded the number of possible retail outlets.

\section{Semiconductors}

Solid-state TVs are only one of the many near-revolutionary effects of semiconductor technology on the rest of the electronics industry. Many electronics products and systems now in widespread use would be quite impossible without semiconductors. Moreover, semiconductors are also having profound impacts on the products of many industries outside of electronics.

The semiconductor industry includes scores of firms, many specializing in narrow market segments; there are thousands of different types of semiconductors capable of performing many different circuit functions. Perhaps the most important feature for international competitiveness-impinging on all other aspects-is the technology itself, and its rate of change. Future applications of semiconductors in industries ranging from communications systems to home appliances will dwarf present accomplishments, if only because applications always lag the availability of technology; advances in semiconductor devices could stop now and the stream of new applications would continue basically unhindered for several years, Of course new applications also suggest new needs. The 


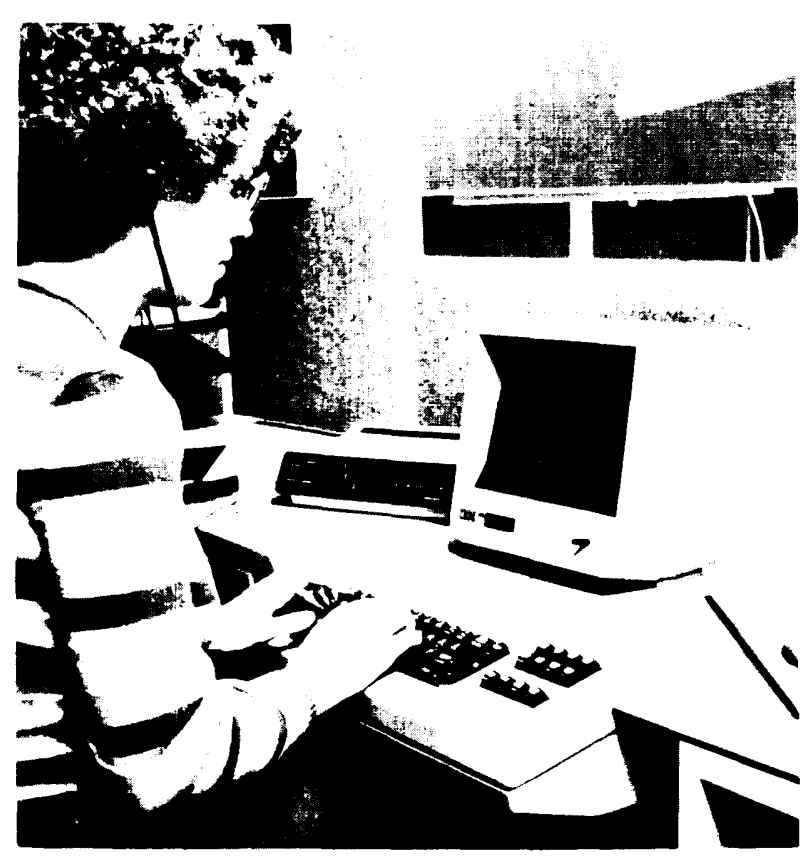

Photo credit Westinghouse Machine dictation/word processing center

microprocessor is a classic case-a product rapidly adapted to uses unforeseen by its developers, these new uses in turn spawning new microprocessor designs. (Microprocessors are ICS containing a complete computer processing unit on a single chip. )

Another important aspect of the semiconductor industry is the continuing decrease over time in manufacturing costs for equivalent circuit functions. These cost reductions have two basic causes. First, the ability to pack more and more circuit elements onto a single chip has dramatically reduced the cost per function-e.g., per logic gate or per bit of computer memory. As a result, the total cost of the circuitry for performing a given task has fallen rapidly. This has been a major cause of the decreases in the cost of computing power over the past 20 years-by a factor of more than a hundred since the mid-1950's. ${ }^{6}$ It has also made possible many applications that previously would have been impossible, impractical, or simply too expensive.

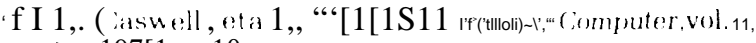
September 197[1, p. 10.
A second reason for cost decreases is the so-called learning curve phenomenon. The costs of the chips themselves drop as more of a given type are made, both from the experience gained in making them and because higher volumes justify more efficient processing equipment. As a firm's cumulative production of a given device goes up, the yieldthe percentage of chips that meet specifications-also tends to go up, and costs decline rapidly.

The promise of cost savings through experience is so well embedded in the industry's history that prices of new semiconductor devices have frequently been established with future savings in mind. That is, producers of a new device may set prices below their current manufacturing costs, confident that costs will fall as higher volumes are reached. One of the purposes of such a forward pricing strategy is to increase sales and achieve high production volumes as quickly

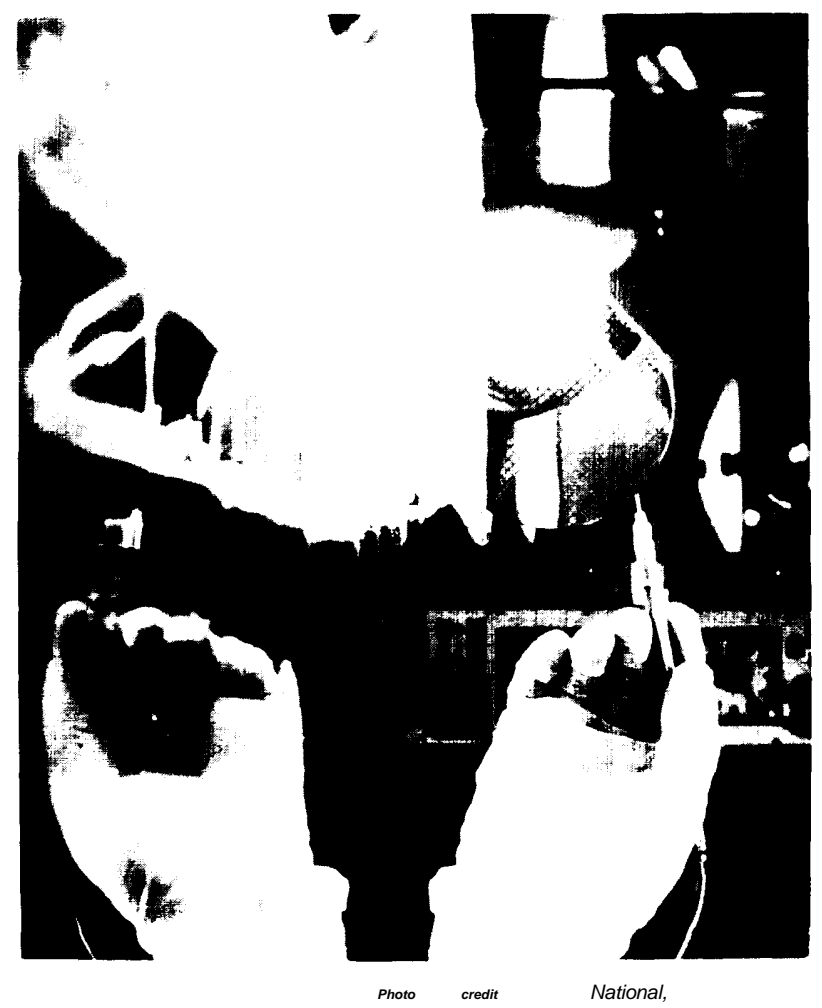

A silicon wafer for making ICS being handled with a vacuum pencil 
as possible. The advantages accruing to innovators first on the market with new products explain much of the emphasis the semiconductor industry places on $R \& D$.

In many firms, however, this $R \& D$ is confined almost exclusively to process engineering and circuit design. Basic research is limited to a few of the larger manufacturers, some of which-such as Western Electric (Bell Laboratories) and IBM-do not sell semiconductors on the open market, making them only for internal use.

Possibly because of its history of aggressive pricing combined with heavy $R \& D$ costs, the semiconductor industry has not been notably profitable, particularly in terms of return on sales. Nor does the dollar volume of sales keep pace with the level of physical output. As a result, internally generated cash flows have often been inadequate to finance the rapid plant expansions needed to serve growing markets. This problem has lately been exacerbated because the newest generations of ICS demand a considerably higher level of capital expenditure for design and manufacture. Capital requirements per dollar of sales are said to have risen 50 percent between 1970 and 1980, 'An upward shift in capital needs is common as industries mature, but in semiconductors the capital requirements are only partly for new production equipment. Additional funds are needed because of the higher level of technology itself-particularly the rapidly escalating costs of circuit design as ICS approach and exceed 100,000 elements per chip.

There is another feature of the industry worth exploring briefly, one common to industries early in their evolutionary histories. Semiconductor firms, especially the larger ones, are attempting to integrate forward into final products. Much of the incentive results from a natural desire to internalize more of the end-product value-added. Thus, semiconductor firms have, at various times, tried to

J. B. Brinton. . . Chip Makers to Shrug off Recession,"” E]ectronics, Apr. 10, 1980, p. 42. integrate forward into consumer products such as electronic watches and calculators, and also into computers.

There are strategic reasons for integration as well. End-product manufacture offers diversification and a measure of protection against the possibility of customers integrating backwards, In fact, backward integration-i, e., end-product manufacturers making their own semiconductors-has also been taking place quite rapidly, again primarily for strategic reasons. Firms whose products range from electronic toys and games to mainframe computers, as well as diversified industrial concerns, have been adding semiconductor capability, both to gain some measure of stability in supply, and to have the ability to design and produce unique devices which might be required for their own products but not in large enough quantities to attract merchant firms.

As a result, the structure of the sector is changing rapidly. Much of the spectacular success of the semiconductor industry in the United States has been built on innovative products and processes coming from independent firms-often small and entrepreneurial-serving the merchant market, This is just the type of firm that has seemed to be disappearing. It remains to be seen whether the structural changes taking place in the U.S. industry will result in a slackening of the pace of innovation and in competitiveness.

The major determinants of competitive ability in semiconductors are the capacity to innovate, and, as products mature, to manufacture at low cost. Neither of these demands will change in the foreseeable future, Maintaining competitiveness-interna tionally or domestically-will continue to require a much higher proportion of technically skilled personnel such as engineers than is true for most other industries, In addition to high-cost technical professionals, semiconductor firms need low-cost assembly labor to be competitive. As a result, virtually all the larger firms have transferred labor-intensive operations overseas. 
Beyond these two requirements-innovative capability and low-cost manufacture-is another factor important to competitiveness: product quality and reliability. In this, semiconductors are more like consumer electronics products than steel. While it is not quite true that all steel made to the same specification is the same, there are certainly larger variations in quality and reliability for semiconductors than for many other commoditylike products. Relative levels of quality and reliability y of Japanese and American ICS have been hotly debated. This issue, which depends on both process and product technologies - the latter because some ICS can be designed to tolerate flaws and partial failures-is discussed in more detail in chapter 5 ,

Quality and reliability are important because they affect costs to purchasers, Other cost factors which are important in some industries are only minor concerns for semiconductors. For example, the value-to-weight ratio of semiconductors is among the highest of all manufactured products, Consequently, transportation costs are insignificant. Moreover, the industry is environmentally clean so that, unlike the steel industry, costs of complying with environmental and workplace standards have not been burdensome.

\section{Computers}

While the mainframe and minicomputer segments of the computer industry seem at the moment structurally stable, other portions are changing rapidly. Microcomputer firms - those building machines based on microprocessors-have experienced a shakeout over the last few years associated with a transition from a hobbyist market to one dominated by small business applications. A number of pioneering microcomputer firms have disappeared through bankruptcy or acquisition. The peripherals sector-companies making auxiliary storage, terminals, and related equipment-is also volatile. Furthermore, software has become an important entrepreneurial area. Even in mainframes, the incius try structure has not been static, as plug-compatible manufacturers have entered the market-and in some cases, left it again. (Plug-compatible machines are interchangeable with equipment manufactured by IBM. but typically offer lower prices and/or higher performance. )

IBM is the largest manufacturer of mainframe computers-with manufacturing and sales operations around the world, It has a substantial market share in virtually every country in which it sells. Along with other American firms, IBM has dominated large computers worldwide since the inception of the industry in the 1950's, In fact, the computer industries of almost every country (Japan and Great Britain are the major exceptions) have had at their cores the overseas subsidiaries of American computer firms. over the years, the U.S. computer industry has become the archetype of the high-technology industry for which this country has been envied.

While some new entrants into the computer industry-namely the manufacturers of plug-compatible mainframes-have chosen to compete head-on with IBM, the manufacturers of micros and minis have, in effect, pioneered market niches left vacant by the mainframe companies, Increasingly, minicomputers are providing all the performance needed for particular applications. With markets for both plug-compatible and small machines being aggressively pursued by a varie!y of firms-including a number of successful semiconductor manufacturers-the structure of the computer industry will continue to change.

The market structure for computers remains simple compared with products such as consumer electronics or automobiles. Most computer manufacturers sell directly to final users, generally employing their own sales forces, Nonetheless, change is taking place here as well. Smaller computers intended for use in homes or businesses are now sold at the retail level. (Home computers can also be considered part of the consumer electronics sector. ) Regardless of the type of computer- 


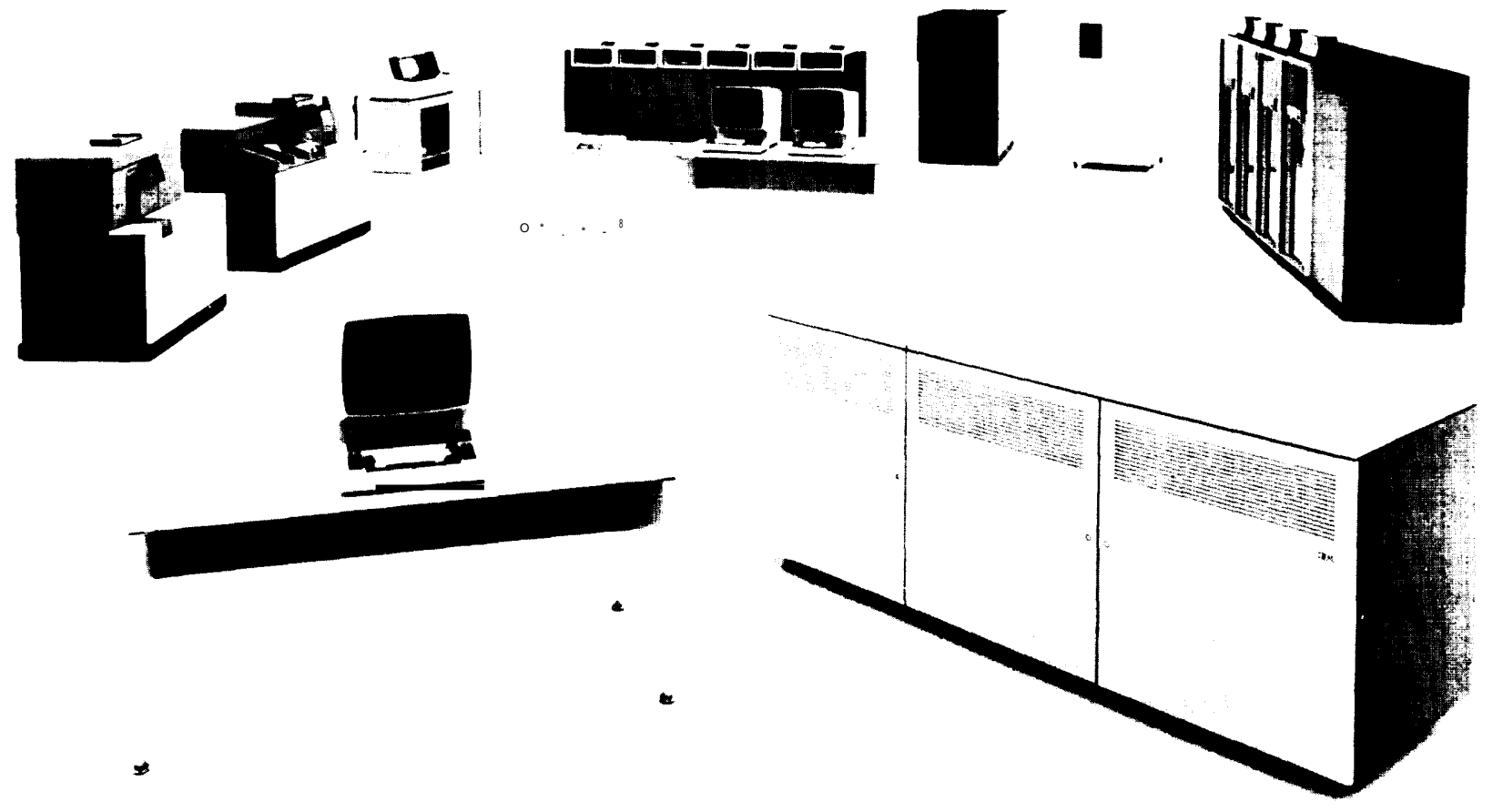

Photo cred(I IBM Corp

IBM 4341 Computer System

micro, mini, or mainframe-ancillary services such as software development, and maintenance of both hardware and software, are important for market acceptance. Sometimes the costs of such services are included in the price of the computer system, making direct price comparisons between competing products difficult.

\section{The Automobile Industry}

Because of its size alone, the motor vehicle industry occupies a unique position in the economy of the United States, and for that matter the world. The industry is responsible for the employment of more than 2 million people in this country in manufacturing alone, including supplier firms making component parts and accessories. Several million more are employed in sales and service activities.*

Despite its size, the industry is one of the Nation's (and the world's) more concen-

"The U.S. Automobile Industry. 1980: Report to the President from the Secretary of Transportation (Washington, D.C.: Department of Traneportation, I)OT-P-1O-8I-O2, January 1981), p. 84 . 
trated. One company, General Motors, manufactures over half of the cars and trucks produced in the United States; virtually all of the remainder are made by two other firms, Ford and Chrysler. Although a foreign competitor, Volkswagen, has recently begun assembly here, about 30 percent of its value-added is tied to imports of components from abroad; when its U.S. assembly plant is operating, Honda will probably also import major subassemblies such as engines.

Concentration in the automobile industry on a global basis is nonetheless decreasing, largely because of the rapid growth of Japanese automakers. These firms were insignificant in the early postwar period but have been gaining market share in many parts of the world. Imports have had the effect of reconcentrating the U.S. market.

Both Japanese and European automakers tend to have a greater share of their sales in markets outside their home countries than do U.S. firms. Whether through subsidiaries or exports, one-half or more of the sales of most foreign firms occur outside their domestic markets. For American automakers, the proportion is generally one-third or less. Therefore U.S. firms have a greater dependence on home market sales than do foreign manufacturers.

In the United States, most automobiles are purchased as replacements for vehicles already in the fleet, which now numbers well

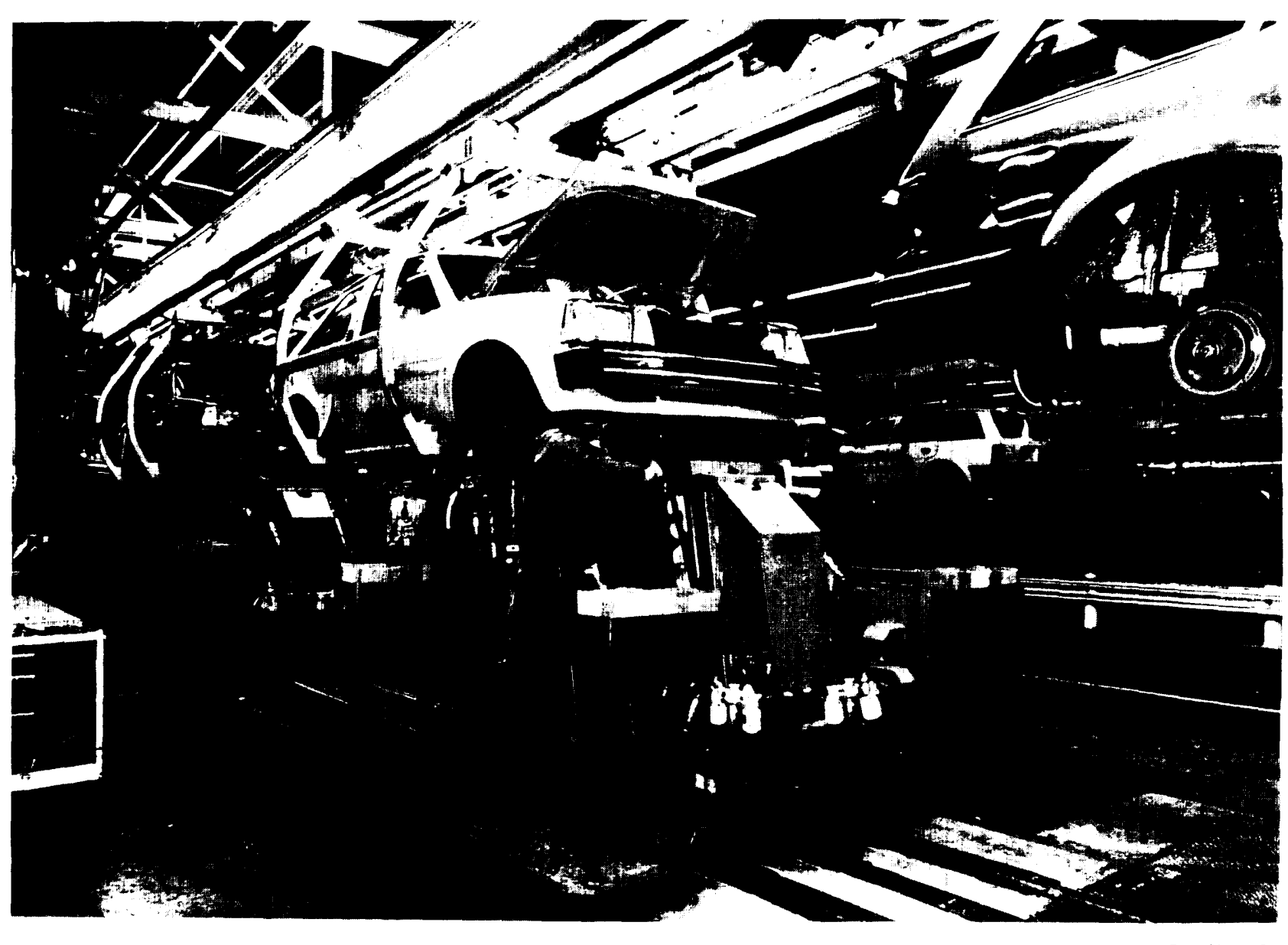

Engine installation on small-car assembly line 
over 100 million. For the typical purchaser, buying a car is a substantial outlay of funds; two-thirds buy on credit, Thus, the availability and cost of financing is an important factor in sales. Furthermore, most buyers can defer purchase of an automobile, new or used, simply by keeping the old one longer. Therefore, when economic conditions appear uncertain, and when interest rates are high, the market for automobiles is drastically affected, Much of the precipitous decline in sales of American-made cars during 1980 can be attributed to such factors. Returns on equity of U.S. automakers have generally been comparable to other U.S. manufacturing industries, but tend to drop more in recession years such as 1974-75 or 1980 ,

The producers of finished vehicles by no means constitute the entire industry. Autos are assembled from components-some made internally and some purchased from other firms, While all manufacturers make their own bodies, and most build the engines and drivetrains, American Motors buys its transmissions from Borg-Warner and Chrysler uses Volkswagen engines in some models. On rare occasions, manufacturers have integrated even further upstream: Ford operates a steel mill; Chrysler makes glass. For many other components, U.S. automobile companies rely on some 50,000 supplier firms. Often the automaker will produce only a certain fraction of its needs for a particular part, purchasing the rest outside. This "tapered vertical integration" allows the company to achieve scale economies while shifting the risk of variable demand to others. Value-added by the automakers is highest for GM -around 50 percent-lowest for Chrysler and $\mathrm{AMC}-3 \mathrm{O}$ percent or less. ${ }^{9}$

"R. A. Leone, W. J. Abernathy, S. P. Bradley, and ]. A. Hunker, *'Regulation and Technological Innovation in the Automobile Industry, " final report to O'TA, contract No. 933-3800,0, May 1980, p. 2-55.
Automobile manufacturers sell through extensive networks of independent franchised dealers. Financially sound and loyal dealers are of great importance to the automakers, who also depend on them to provide service and used car sales.

Market strategies of U.S. auto manufacturers have traditionally stressed upgrading of models and optional equipment, which offer opportunities to increase profits. Differentiating basic models through design features, and standard equipment, along with periodic styling changes, were cornerstones of industry marketing for decades, Recently, year-toyear styling changes have been deemphasized. Cars now remain in production for 10 years or more with little alteration. In the 1970 's, the variety of products represented in the marketplace nonetheless increased. Not only did domestic firms introduce new models, and imports proliferate, but light trucks and vans became more important as passenger vehicles.

Government regulations-concerned with safety, exhaust emissions, and fuel economy-have increasingly constrained the designs of vehicles sold in the U.S. market. The pace of technological change has accelerated in the industry - partly as a result of regulations, partly as a result of the demands of the marketplace. Automobiles built in the United States are evolving toward designs more like those in the rest of the world.

Regulatory uncertainty and demanding timetables for new standards have created difficult conditions for all automakers selling in the United States, Domestic firms have been affected much more heavily than foreign producers by regulatory and market demands for high fuel economy because most imports have been small cars with good gas mileage. Large investments are needed for U.S. automakers to redesign and retool their fleets to meet the new conditions. 


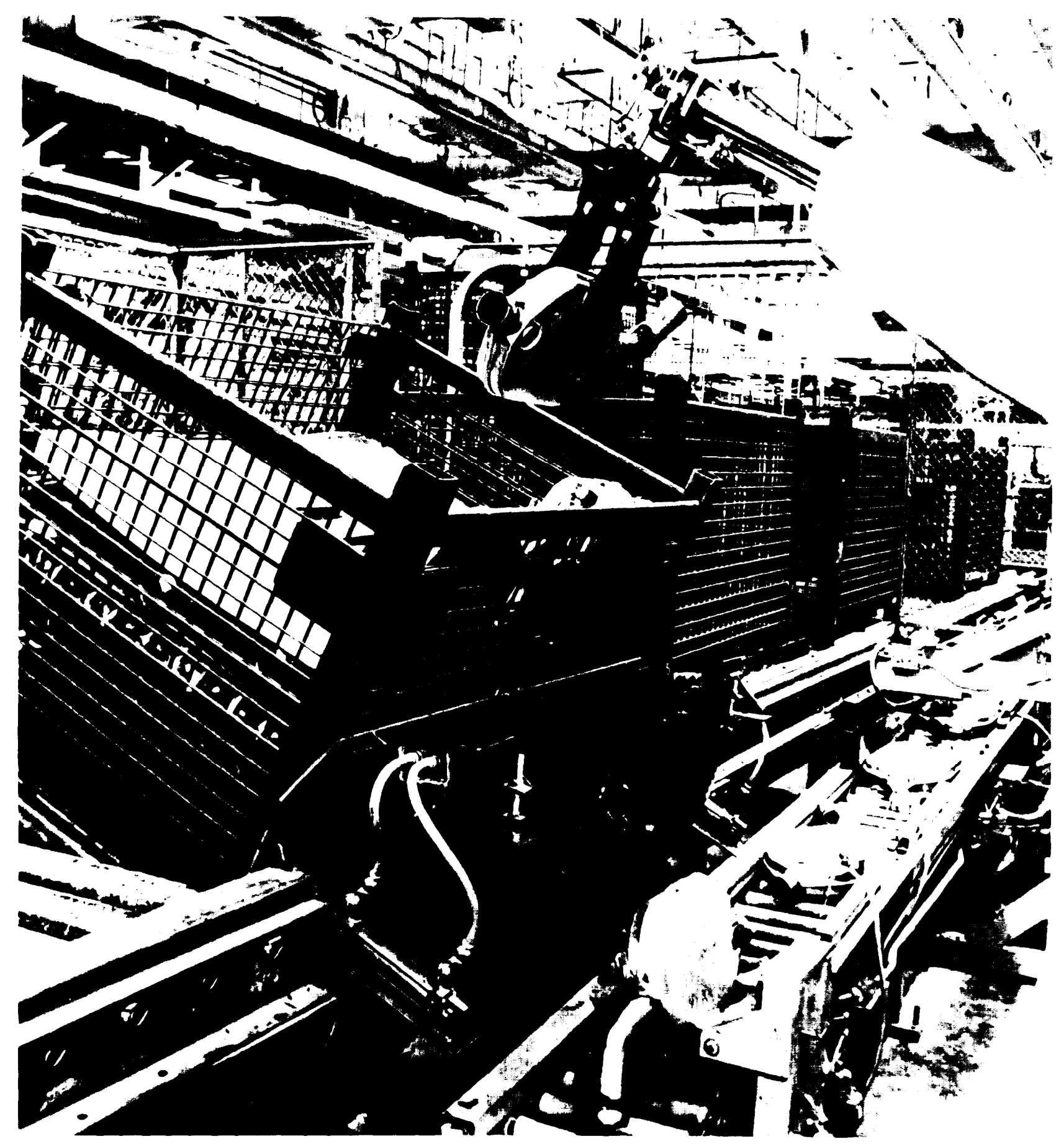




\section{Summary and Conclusions}

Steel, electronics, and automobiles differ in technological levels, markets, and industry structures. The more advanced process technologies in any of the industries can be quite demanding, and might well be called "high technology, "This is as true of computer-controlled rolling mills or integrated manufacturing systems for automatic transmissions as it is for the wafer fabrication lines used to make large-scale integrated circuits,

There is more variation in levels of product technologies. While most steel products are commodity items - and would be considered "low technology" compared to, for instance, aerospace alloys-electronics virtually defines the high-technology industry. Nevertheless, product technologies for TVs exhibit a pattern of relatively routine development and refinement which is quite different from the rapid advances characteristic of semiconductors or computers. For many years, technological change in automobiles was similar to that in TVs-a matter of continued refinement but few major innovations. In many respects, the turn to smaller cars making more efficient use of both fuel and interior space is no more than an acceleration of this process of refinement. At the same time, there is now much greater technological variety in the marketplace than in the recent past. Frontwheel drive, electronic engine controls, and diesel engines are examples. While not always new, these have certainly increased the diversity of technologies represented in the U.S. automobile fleet.

In all three industries, manufacturing costs are important. But for many electronics products, and for automobiles, product characteristics and consumer appeal-whether embracing real differences in performance (as indicated by computing power or fuel economy) or relatively superficial variations-are major determining factors of the competitiveness of individual firms, Such characteristics include product quality-both the reality and the perception-as well as design. Thus, the competitiveness of U.S. firms in all three industries depends on a complex of factors ranging from technological capability to marketing skills and management.

Structural change is taking place in all three industries, In steel, integrated firms are shutting down less efficient mills as nonintegrated firms increase their market share. In consumer electronics, the changes are directly associated with foreign competition. This competition came first from imports, then from foreign firms assembling their products in the United States, The semiconductor sector is experiencing acquisitions and vertical integration. Product mixes are changing in both computers and automobiles.

Structural change has been only one of the forces creating large capital needs in these industries, In steel, capital investment is required to meet environmental regulations, as well as workplace health and safety standards, and to replace outdated plant and equipment. In semiconductors, expansion of demand is outstripping the abilities of some firms to raise funds for $R \& D$ and new capital investment. Automobile companies are spending large sums both to develop new models and to purchase the plant and equipment to make them. The patterns and outcomes of these changes will have important effects on the competitive futures of all three U.S. industries, topics which are addressed in later chapters. 
CHAPTER 4 Measures of Competitiveness in the Three Industries 


\section{Contents}

International Trade Data $\ldots \ldots \ldots \ldots \ldots \ldots \ldots \ldots \ldots \ldots \ldots \ldots \ldots \ldots \ldots \ldots \ldots \ldots$

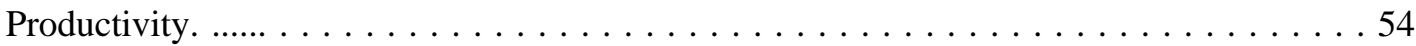

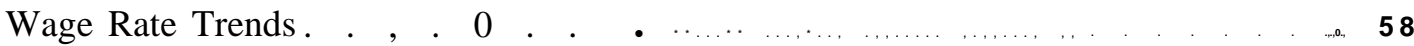

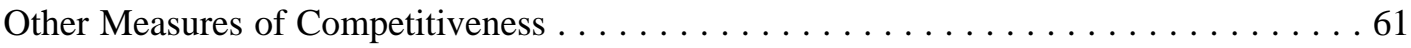

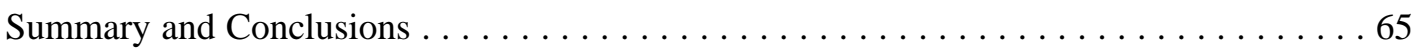

\section{List of Tables}

Table No.

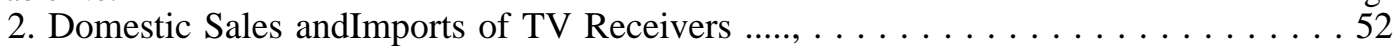

3. Domestic Consumption and Foreign Tradein Semiconductors . . . . . . . . . . . 52

4. Domestic Production and Exports of Electronic Computers, Parts, and Accessories 52

5. U.S. Automobile Production, Total Sales, and Import Sales. . . . . . . . . . . . . . . 53

6. U.S. Truck Production, Total Sales, and Import Sales. . . . . . . . . . . . . . . . . . . . . . . . . . . . . . . . . .

7. Value-Added per Production-Worker-Hour . . . . . . . . . . . . . . . . . 55

8. Productivity Growth for the United States and Japan, 1970-79 . . . . . . . . . . . . . 58

9. Average U.S. Wage Rates for ProductionWorkers in Current Dollars per Hour . . . 59

IO. Average Annual Rates of Productivity Growth in Manufacturing. . . . . . . . . . . . 61

11. R\&D Expenditures as a Percentage of Gross Domestic Product . . . . . . . . . . . 63

12. Percentage Allocation of Government-FundedR\&D by Objectives, 1975.,.. . . . 63

\section{List of Figures}

Figure No.

1. U.S. Consumption and Imports of Steel. . . . . . . . . . . . . . . . . . 50

2. U.S. Consumption and Imports ofRadio Receivers. . . . . . . . . . . . . . . 51

3. Value-Added Productivity of U.S. Industries as Percent

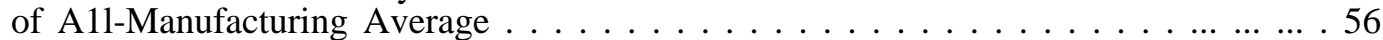

4. BLS Productivity Indexes . .......................00.. . . . . . . . . . 57

5. Average U.S. Wage Rates for Production Workers in Constant 1967 Dollars per Hour . . . . . . . . . . . . . . . . . . . . . . . . . . 60

6. Real Gross Domestic Product per Employed Person Relative to

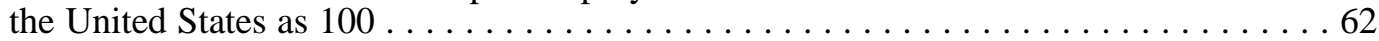

7. Royalty and License Payments and Receipts of U.S. Firms . . . . . . . . . . . . . . 64 


\section{Measures of Competitiveness in the Three Industries}

\section{Overview}

No single indicator suffices for comparisons of competitiveness across industries, for reasons discussed in appendix A. This chapter uses a number of indicators to examine the ways in which the American steel, electronics, and automobile industries differ in their competitive postures.

These industries compete with each other as well as with their foreign counterparts. They compete to generate capital, for the public policies they find desirable, and in their productivity improvements-because firms and industries that increase productivity faster than the national average can improve their competitive position. The following discussion addresses the competitive ability of each industry primarily in comparison with other domestic industries because of the primary role of domestic position as a determining factor in international competitiveness.

The first of the indicators used-international trade flows as measured by import penetration or exports as a percent of domestic production-shows that computers are the most competitive of these sectors, consumer electronics the least. Steel and automobiles are also lagging on this measure, while imports of semiconductor products exceeded exports for the first time in 1978,

Productivity data as indications of competitive ability are less straightforward; but, for most of these sectors lagging productivity does not appear to have been a major problem. The computer industry, which is very strong in terms of exports, shows unusually high labor productivity-despite a history of decreasing prices relative to technological capability. However, the consumer electronics sector, which has suffered severe import penetration, has increased its productivity about as fast as U.S. manufacturing in the aggregate-hence on this measure shows no real slackening of competitiveness. The situation is somewhat similar for steel, although here there is some evidence of lagging productivity. Automobiles exhibit productivity which is increasing significantly faster than for U.S. manufacturing as a whole. By themselves, productivity trends do not explain why the steel and automobile industries should be suffering on trade measures.

Insight into the problems of the American steel industry comes from comparing rates of increase in wages. Wage rate increases have outstripped productivity advance-in part because the industry has not modernized its plant and equipment rapidly enough for increases in productivity to keep up with those in wages. The automobile industry's current difficulties have other sources. Nonprice factors-such as the turn towards small cars with good fuel economy-are important causes of the recent increases in import penetration, Semiconductors and computers continue to look strong on all of the measures examined in this chapter,

The last section examines generalized indicators of competitive ability, including trends in R\&D spending. Such measures exhibit worrisome trends, but are not by themselves conclusive signs of competitive problems for American industry. 


\section{International Trade Data}

The trade balance in a particular sector is one of the fundamental indicators of competitiveness. During the 1970's, the U.S. share of world exports of manufactured goods fell from over 20 percent to about 17 percent. However, the U.S. dependence on exports is not as great as that of many other industrialized nations. Although the ratio of exports to gross national product (GNP) for the United States nearly doubled during the 1970'sfrom 4.3 percent in 1970 to 7.5 percent in 1979, this is still less than half the percentage characteristic of many Western European countries (though about half of all exports by

International Economic Indicators (Washington, D.C.: Department of Commerce, International Trade Administration, September 1980), p. 34.
European Community nations stay within the Common Market). Contrary to popular belief, Japan is not unusually dependent on exports; the ratio of exports to GNP in that country has remained at about 10 percent in recent years, ${ }^{2}$

Turning to the three U.S. industries, figures 1 and 2, along with tables 2 through 6 , show imports, exports, and production or sales (consumption). For simplicity, exports of steel, consumer electronics, and motor vehicles are omitted, as these are much smaller than imports. Imports of computers are likewise negligible compared to exports, and have not been included in table 4. (Motor vehicles exported to or imported from -Ibid.. p. 36.

Figure 1.- U.S. Consumption and Imports of Steel

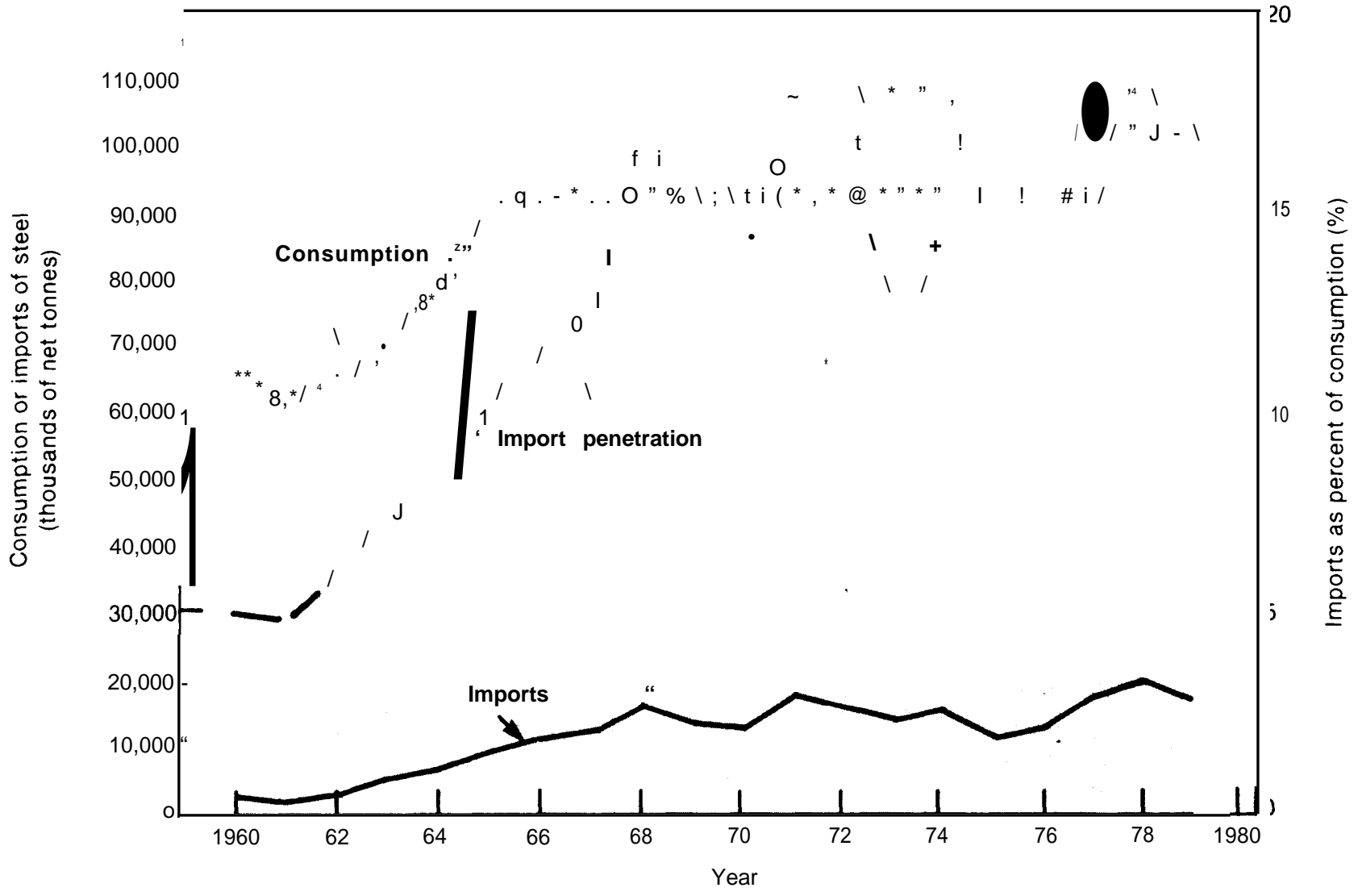

SOURCE Annual Stat/stcal Report, American Iron and Steel Institute, various years, steel only 
Canada have been excluded from the discussions of trade flows throughout this report because all production in Canada is by subsidiaries of U.S. firms and there is extensive trade both ways between parent firms and subsidiaries. )

The data show that these industries differ markedly in the extent to which imports have penetrated U.S. markets. In steel (figure 1), imports have taken a significant share of domestic markets for more than 15 years, although the percentage has fluctuated considerably, Substantial amounts of steel also enter the country embodied in imported cars and trucks.

Figure 2 and table 2 contain import data for two important consumer electronics products: radios and TV receivers. Most of the radios and black-and-white TVs sold in the United States are imports; the fraction ran well over half throughout the past decade. Color TV imports peaked in 1976, but were then discouraged by Orderly Marketing Agreements, negotiated first with Japan in 1977, then with Taiwan and Korea in 1979. Many components used in color TVs continue to come from abroad.

The pattern for semiconductors is shown in table 3, which includes exports as well as imports. Trade in both directions has grown, while the total market has been expanding rapidly. A great deal of this trade consists of interdivisional shipments between the domestic plants and foreign subsidiaries of U.S. firms. Semifinished devices are sent abroad for labor-intensive operations such as wire-

Figure 2.-U.S. Consumption and Imports of Radio Receivers

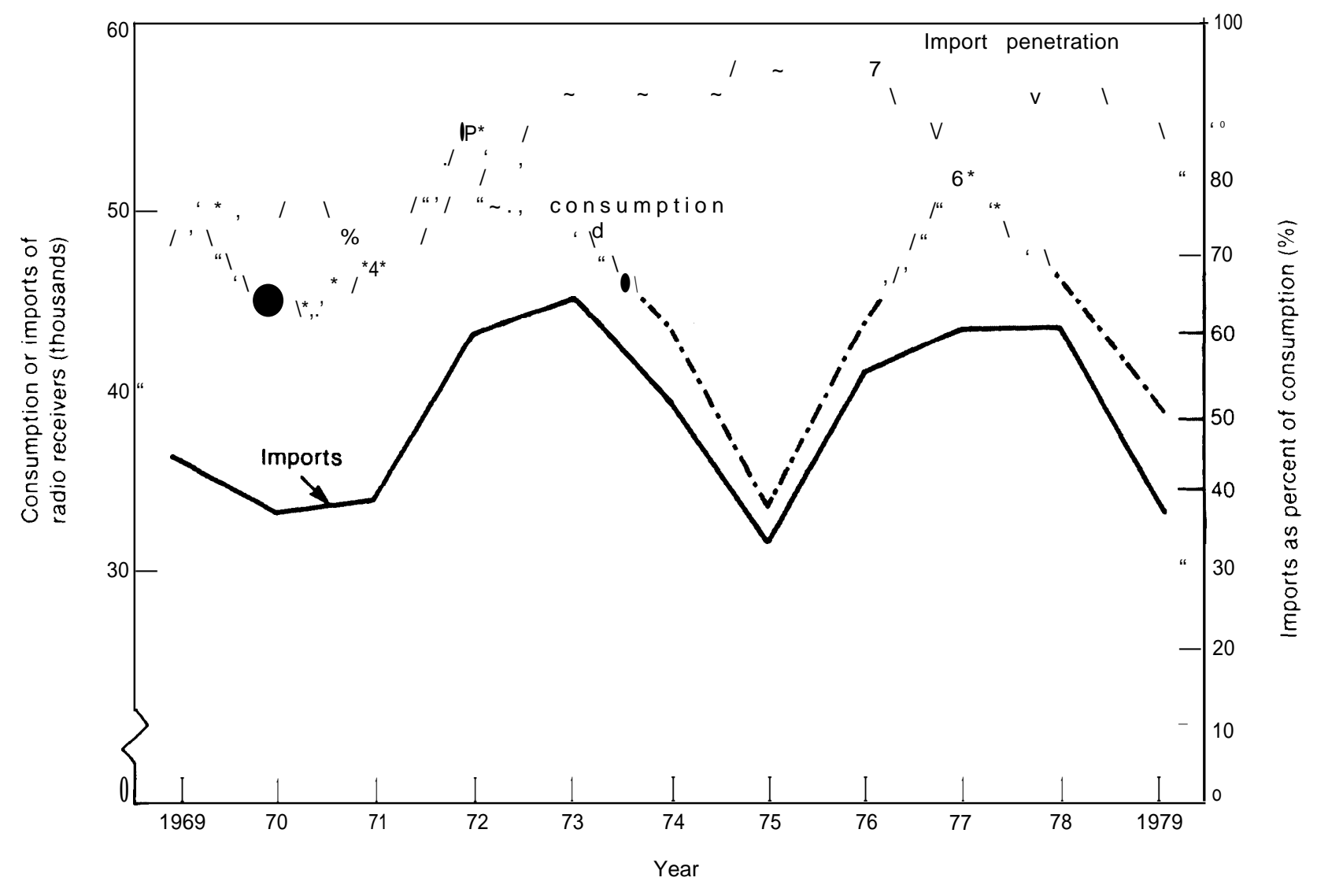


Table 2.-Domestic Sales and Imports of TV Receivers (thousands)

\begin{tabular}{|c|c|c|c|c|c|c|}
\hline \multirow[b]{2}{*}{ Year } & \multicolumn{2}{|c|}{ Total TV sales } & \multicolumn{2}{|c|}{ Imports } & \multicolumn{2}{|c|}{ Imports as $\mathrm{Y}$. of total sales } \\
\hline & Black \& white & Color & Black \& white & Color & Black \& white & Color \\
\hline 1968 & 5,551 & 6,032 & 2,043 & '666 & $36.80 / 0$ & $11.00 / 0$ \\
\hline $1970 \ldots \ldots \ldots \ldots$ & 4,546 & 4,822 & 3,596 & 914 & 79.1 & 18.9 \\
\hline $1972 \ldots \ldots \ldots \ldots$ & 8,145 & 8,378 & 5,056 & 1,318 & 62.0 & 15.7 \\
\hline $\begin{array}{l}1974 \ldots \ldots \\
1975 \ldots \ldots \\
1976 \ldots \ldots \\
1977 \ldots \ldots \\
1978 \ldots \ldots \ldots \\
1979 \ldots \ldots \ldots\end{array}$ & $\begin{array}{l}5,941 \\
4,968 \\
5,196 \\
5,664 \\
6,064 \\
6,254\end{array}$ & $\begin{array}{r}7,380 \\
6,485 \\
7,700 \\
9,107 \\
10,236 \\
9,846\end{array}$ & $\begin{array}{l}4,659 \\
2,975 \\
4,327 \\
4,908 \\
5,931 \\
5,874\end{array}$ & $\begin{array}{l}1,282 \\
1,215 \\
2,834 \\
2,539 \\
2,775 \\
1,369\end{array}$ & $\begin{array}{l}78.4 \\
59.8 \\
83.2 \\
86.6 \\
97.8 \\
93.9\end{array}$ & $\begin{array}{l}16.3 \\
18.7 \\
36.8 \\
27.8 \\
27.1 \\
13.9\end{array}$ \\
\hline
\end{tabular}

;OURCES Electronics Market Data Book 1980 (Washington, D C Electronics Industries Association. 1980) PP 10 and 33; Television Receivers, Color and Monochrome, Assembled or Not Assembled, Finished or Not Finished, and Subassemblies Thereof (Washington. D.C. U.S. International Trade Commission, pub. lication 808, March 1977), 1968 approximate

Table 3.-Domestic Consumption and Foreign Trade in Semiconductors (millions of dollars)

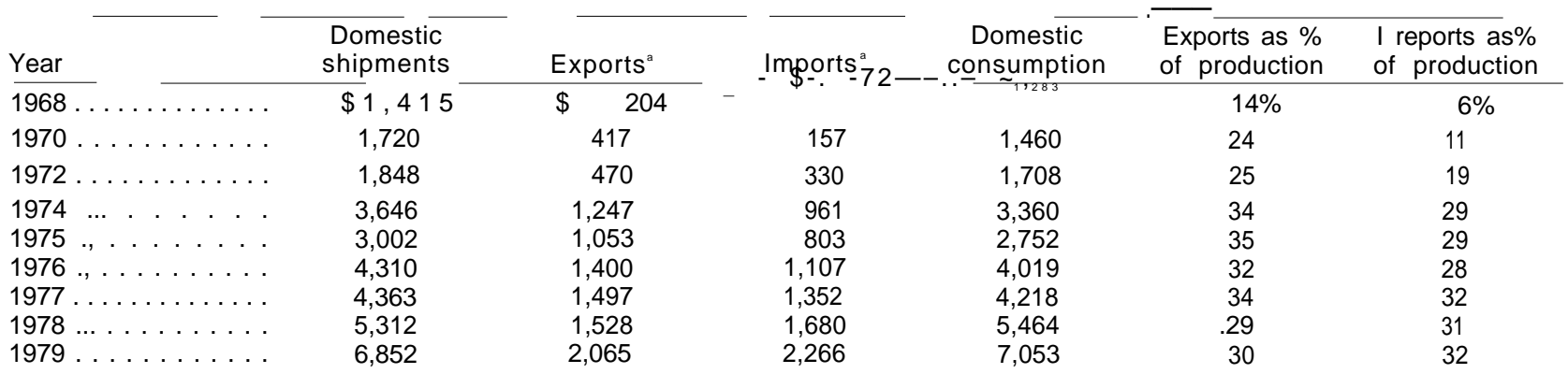

a Both exports and Imports include semiconductors exported for further processing and then reimported Such devices, usually shipped between divisions of the same company, appear both as exports and as Imports

SOURCES 1968.72-A Report on the Semiconductor Industry (Washington,D.C Department of Commerce Industry and Trade Administration, September 1979) 1974.79-Electronics Market Data Book 1980 (Washington, D C : Electronics Industries Association, 1980), PP 104 and 113

bonding, then reimported to the United States (or sold in other markets); of the $\$ 1.35$ billion in imports in 1977 , $\$ 1.12$ billion (83 percent) were intracorporate sales.

U.S. shipments plus exports of computers are given in table 4. The trade surplus of the United States in computers is greater than the deficit for all consumer electronics (which includes more than just radios and TVs and was about $\$ 3.6$ billion in 1979). In addition to exports from the United States, American computer manufacturers have large sales through foreign subsidiaries. Over two-thirds of all the computers that have been installed in Europe originated with American-owned firms. In contrast, virtually none of the computers in the United States have been designed and/or built by foreign firms. As for the steel that enters the United States incorporated in imports such as
Table 4.-Domestic Production and Exports of Electronic Computers, Parts, and Accessories (millions of dollars)

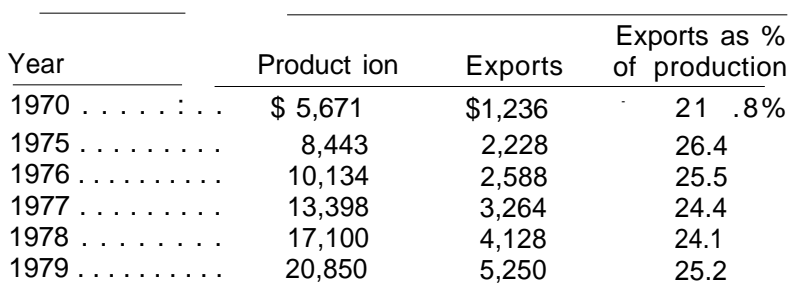

SOURCES 1970-77-Sfaf stlcal Abstract of the United States, 7979 (Washing. ton, D C Department of Commerce, Bureau of the Census, 1979), p 868

1978.79- 1980 U S Idustrial Outlook (Washington, D C Depart. ment of Commerce, Industry and Trade Administration, January 1980), p 252

automobiles, many semiconductors leave the United States as components of computers and other electronic systems. Semiconductors also enter this country via imported consumer electronics products. 
For automobiles (table 5), import penetration was relatively low during the 1960 "s, but during the 1970's imports increased markedly. In 1980, automobile imports took more than 25 percent of the market, Imports of trucks have also increased, as table 6 shows. Most of these are small pickup trucks made by Japanese firms.

In isolation, these tables and charts would indicate that the United States is more competitive in steel than in automobiles, and more competitive in computers than in consumer electronics. They emphasize that import penetration in the range of 15 percent for steel is nothing new, However, the use of highly aggregated figures such as those in the tables does not give a complete picture. Table 5 , for example, does not indicate that almost all imported cars are compacts or subcompacts, sectors in which imports claim roughly 40 percent of the market-import penetration in small cars remained above 30 percent throughout the 1970's. Total import penetration has gone up largely because the small car market has become a greater part of the whole. In fact, imports have captured most o.f the growth in the U.S. automobile market since the 1960's.

\footnotetext{
"'Current Problems of the U.S. Automobile Industry and Policies to Address Them," staff working paper (Washington, D. C.: Congressional Budget Office, Natural Resources and Commerce Division, July 1980), p. 14.
}

Table 5.-U.S. Automobile Production, Total Sales, and Import Sales (thousands)

\begin{tabular}{|c|c|c|c|c|}
\hline Year & U.S. production & $\begin{array}{l}\text { Total new } \\
\text { car sales }\end{array}$ & Import sales & $\begin{array}{l}\text { Imports as } \% \\
\text { of total sales }\end{array}$ \\
\hline 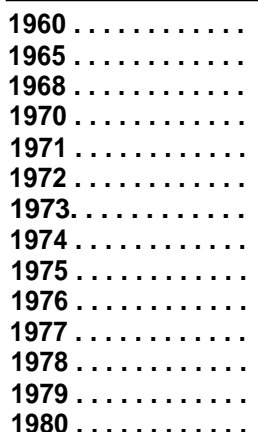 & $\begin{array}{l}6,703 \\
9,335 \\
8,849 \\
6,550 \\
8,558 \\
8,828 \\
9,667 \\
7,310 \\
6,741 \\
8,538 \\
9,294 \\
9,153 \\
8,418 \\
6,373\end{array}$ & \begin{tabular}{r|}
6,576 \\
9,313 \\
9,404 \\
8,388 \\
9,831 \\
10,488 \\
11,351 \\
8,701 \\
8,262 \\
9,751 \\
10,826 \\
10,946 \\
10,335 \\
8,977
\end{tabular} & \begin{tabular}{r|}
499 \\
569 \\
986 \\
1,231 \\
1,466 \\
1,529 \\
1,720 \\
1,369 \\
1,501 \\
1,447 \\
1,968 \\
1,946 \\
2,339 \\
2,398
\end{tabular} & $\begin{array}{l}7.6 \% \\
6.1 \\
10.5 \\
14.7 \\
15.1 \\
14.5 \\
15.2 \\
15.7 \\
18.2 \\
14.8 \\
18.3 \\
17.8 \\
22.6 \\
26.7\end{array}$ \\
\hline
\end{tabular}

SOURCES: 1980.79-Automotive News 1980 Market Data Book Issue. 1980-Ward's Automotive Reports Jan 12, 1981

Table 6.-U.S. Truck Production, Total Sales, and Import Sales(thousands)

\begin{tabular}{|c|c|c|c|c|}
\hline Year & U.S. production & $\begin{array}{c}\text { Total new } \\
\text { truck sales }\end{array}$ & Import sales & $\begin{array}{l}\text { Imports as \% } \\
\text { of total sales }\end{array}$ \\
\hline $\begin{array}{l}1973 \ldots \ldots \ldots \ldots \\
1974 \ldots \ldots \ldots \\
1975 \ldots \ldots \ldots \\
1976 \ldots \ldots \\
1977 \ldots \ldots \\
1978 \ldots \ldots \ldots \\
1979 \ldots \ldots \\
1980 \ldots \ldots \\
\end{array}$ & $\begin{array}{l}3,002 \\
2,694 \\
2,260 \\
2,993 \\
3,487 \\
3,722 \\
3,053 \\
1,639\end{array}$ & $\begin{array}{l}3,176 \\
2,884 \\
2,330 \\
3,280 \\
3,807 \\
4,264 \\
3,540 \\
2,487\end{array}$ & $\begin{array}{l}162 \\
244 \\
144 \\
269 \\
240 \\
374 \\
404 \\
485\end{array}$ & $\begin{array}{l}5.1940 \\
8.5 \\
6.2 \\
8.2 \\
6.3 \\
8.8 \\
11.4 \\
19.5\end{array}$ \\
\hline
\end{tabular}


Nor does table 3 indicate some of the more worrisome trends in semiconductor trade. During 1980, Japanese imports evidently took more than 40 percent of the market for a particular state-of-the-art integrated circuit- the 16K RAM. This is a random access memory circuit used mostly in computers and capable of storing over 16,000 bits of information.

\section{Productivity}

Another measure of an industry's ability to compete internationally is the degree to which its labor productivity-defined as value-added per worker-hour or physical output (units, tonnes, ., .) per hour-has kept pace with other domestic industries. (Capital markets in various countries are now more strongly linked than in the past; although differences in costs of capital exist, labor costs and labor productivity are usually more important for competitiveness than capital costs and capital productivity. ) In general, industries with lower-than-average productivity growth can expect increasing competition from abroad. Footwear and apparel are examples of American industries with seriously lagging labor productivity; neither is competitive internationally.

The productivity comparisons in this section are between domestic industries; they do not juxtapose U.S. and foreign industries. As explained in appendix A, direct international comparisons are not meaningful for competitiveness unless related to aggregate productivity changes in the two countries. For example, if aggregate productivity in Japan were to double compared to the United States, a particular Japanese industry would have to more than double in productivity to improve its relative position. This is because the exchange rate should shift-at least in principle-to account for aggregate productivity differences between the two countries.

The particular measure of productivity chosen also affects comparisons of competitiveness. Two productivity indexes are used below: 1) value-added per production-workerhour: and 2) the standard productivity index of the Bureau of Labor Statistics (BLS), physical output per employee-hour.
No single indicator of productivity is totally satisfactory. Value-added figures are heavily influenced by differences in industrial structure and by the extent of competition within the industry. This is because a firm's ability to determine its own prices can affect valueadded. More monopolistic industries would be expected to exhibit higher value-added, everything else being equal, Moreover, in some industries prices may include costs that are not directly related to manufacturing. Computer prices often contain implicit charges for software which is ostensibly provided free. This inflates the value-added per worker-hour figure, because software programmers are not counted as production workers.

The BLS productivity data, based on physical output per employee-hour, also have limitations, Most important, they are restricted to labor content; none of the other factors affecting productivity are accounted for. While the time spent by all employees is included, not just production workers, the effects of capital investment-for instance, in new process technologies-or of rates of capacity utilization, are hidden. Such factors affect output per employee-hour in some industries more than others. In an industry such as steel, the extent to which plant and equipment operate at full capacity varies from year to year, productivity being higher at close to full capacity. Therefore, long-term trends are more meaningful than year-to-year variations.

Table 7 gives value-added per productionworker-hour for steel, three sectors of electronics, and motor vehicles. In addition, aggregate data for all U.S. manufacturing are included. Much of the apparent increases in 
Table 7.-Value"Added per Production-Worker-Hour (current dollars)

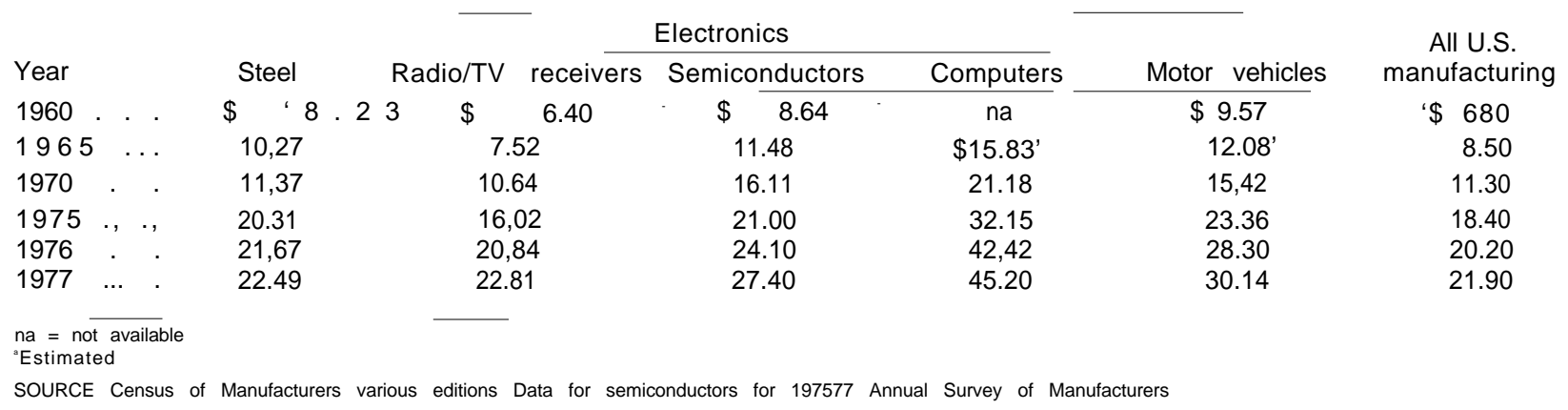

productivity are simply inflation. Figure 3 shows the productivity in each industry as a percentage of the all-manufacturing average, calculated from the data in table 7. The plot gives direct comparisons between each sector and the rest of American industry. thus compensating for the effects of inflation.

For steel, figure 3 shows a slow decline in value-added productivity relative to other industries over the decade of the 1960"s. Absolute productivity remains above the all-manufacturing average, but disregarding fluctuations such as those caused by year-to-year changes in capacity utilization, a gradual downward trend is evident, particularly during the latter half of the 1960's. Relative productivity remained low during the 1970's, except for 1974 when there was a large price rise. Imports quadrupled in tonnage during the 1960's, and tripled as a percentage of American steel consumption. This increased competition, together with Government price controls (ch. 6), helped keep prices down, decreasing value-added productivity compared to the rest of U.S. industry.

Relative value-added productivity for the motor" vehicle industry (figure 3), though falling somewhat in recent years, has remained consistently farther above the all-manufacturing average than for the steel industry. There are two primary reasons. First, automakers have been somewhat freer to raise prices as costs increased. Second, the productivity of the auto industry has also been increasing rapidly on a physical output basis (as shown by the BLS productivity data which follow).
In the three electronics sectors, the value-added per worker-hour data present a mixed picture, The computer industry shows consistently high productivity (figure 3 ), roughly twice the all-manufacturing average. This is especially noteworthy because prices for computing capability have been falling. One reason for the high performance on this measure is the large number of technically trained personnel in the computer industry. These employees are not included in the production worker category, thus increasing the productivity ratio. An additional point is that computer prices must cover large costs not included as production expenses, notably for engineering and software. This overhead is a higher proportion of total costs than for most other manufacturing industries. Finally, one company, IBM, has long been dominant, and the industry pricing structure may be less competitive than would be true in, say, steel.

The semiconductor sector is similar to the computer sector in being R\&D-intensive, which again increases productivity on a production-worker-hour basis because the time spent by engineers and other R\&D personnel is not included. On the other hand, price competition is stronger than in computers, so much so that many of the labor-intensive portions of semiconductor manufacture have been transferred abroad. This is one reason why the productivity figures for semiconductors in table 7 and figure 3 are not particularly high-in general being less than for automobiles, though greater than for steel. However, productivity in the semiconductor industry, as for computers, is notoriously dif - 
Figure 3.- Value-Added Productivity of U.S. Industries as Percent of All'Manufacturing Average

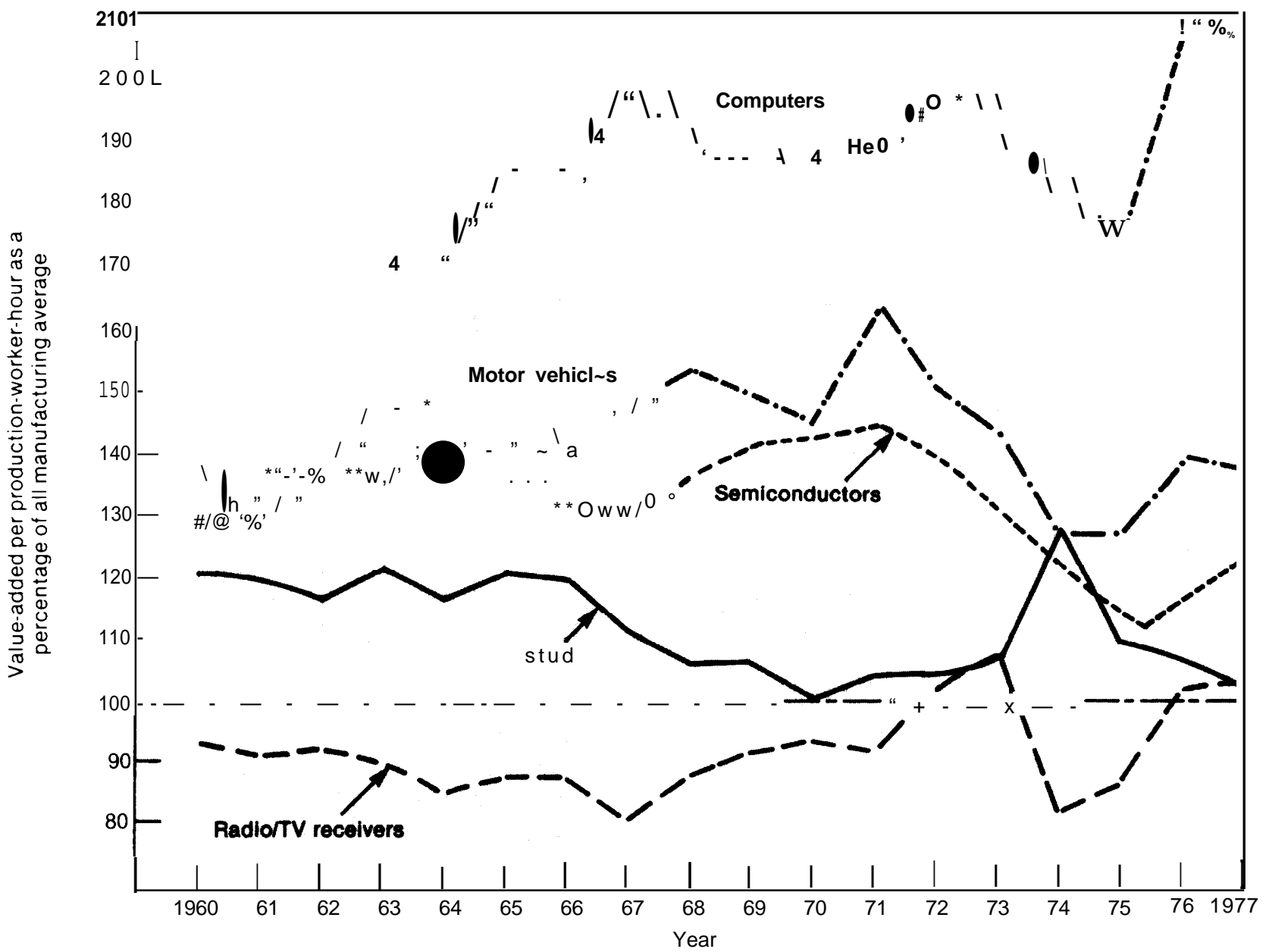

SOURCE Calculated from table 7

ficult to measure in any meaningful way because of the high rate of technical change. Falling prices for a given functional capabili$\mathrm{t} y$ or given level of performance distort value-added figures and other cost/price indicators, In effect, price is not an adequate measure of the real value of a semiconductor device, because a dollar spent on a semiconductor this year buys much more than a few years ago. This is also true for computers and other products whose performance depends on semiconductors - in contrast to industries such as steel or automobiles.

The remaining sector, consumer electronics, is represented in table 7 and figure 3 by radios and TVs. On a value-added basis, this sector has approximately kept pace with other U.S. manufacturing industries. However, the BLS figures discussed below demonstrate that physical productivity has improved markedly for that portion of consumer electronics manufacturing still conducted in this country rather than offshore.

Figure 4 provides an alternative picture of changes in relative productivity-using the BLS index based on total physical output (rather than dollar value) per employee-hour. All employees are counted, not just production workers. Semiconductors and computers are omitted from this table, because physical 


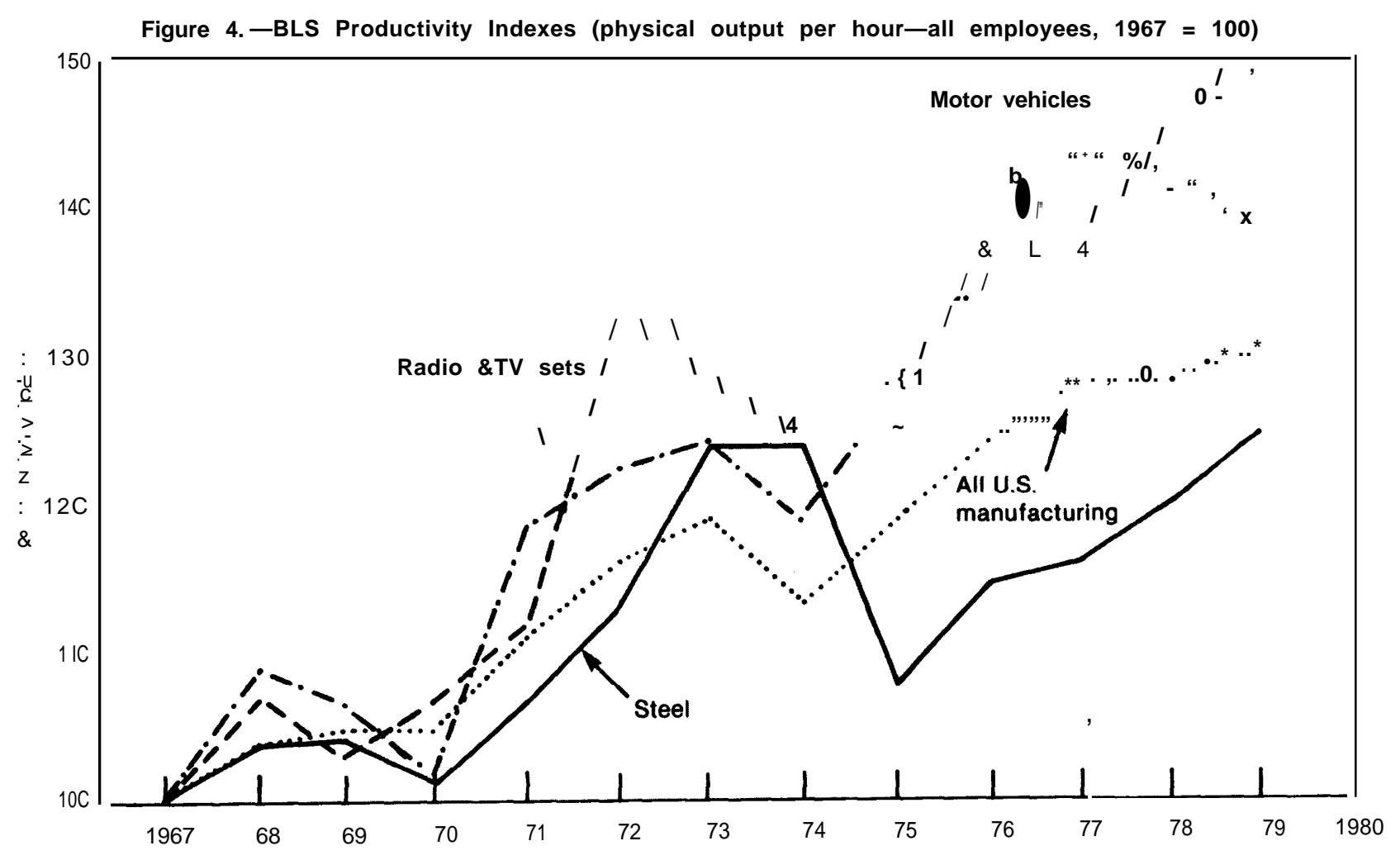

SOURCE F'roducfivlty /ndexes for Se/ected /ndus/r es (Washington, D C Bureau of Labor Statlstlcs)

output has lit tle meaning for industries where a single chip or a single computer can now do what 10 did a few years ago.

In figure 4 the motor vehicle industry again exhibits substantially better than average productivity growth, while steel lags. The years 1973 and 1974 demonstrate how capacity utilization affects productivity in steel. Both were years of relatively high output; physical productivity was up about 10 percent as a result. In contrast, the high value-added productivity for 1974 (figure 3) was caused primarily by price increases averaging 27 percent (prices have no direct effect on the BLS index). Productivity increases in radio and TV have also been well above average. The results on a physical or per-unit basis (figure 4) are much more impressive than on a dollar-value basis (table 7 and figure 3) because intense competition has resulted in falling prices.
With the exception of the steel industry, there is little in the productivity data for these industries to suggest competitive difficulties stemming from an inability to keep pace with other domestic manufacturing sectors.

The next set of data-table 8-compares productivity trends in the United States and Japan, In this table, the situation of a particular sector relative to the rest of the domestic industry is the important comparison; average productivity growth in Japan compared to the United States is less meaningful, nor can industries in the two countries be compared on any simple basis (for one example, the sectors are not defined identically). Aggregate Japanese productivity remains well below that in the United States; the greater rate of advance shown in the table is at least in part attributable to the larger increments available to countries starting at low absolute levels of productivity. Nonethe- 
Table 8.- Productivity Growth for the United States and Japan, 1970-79

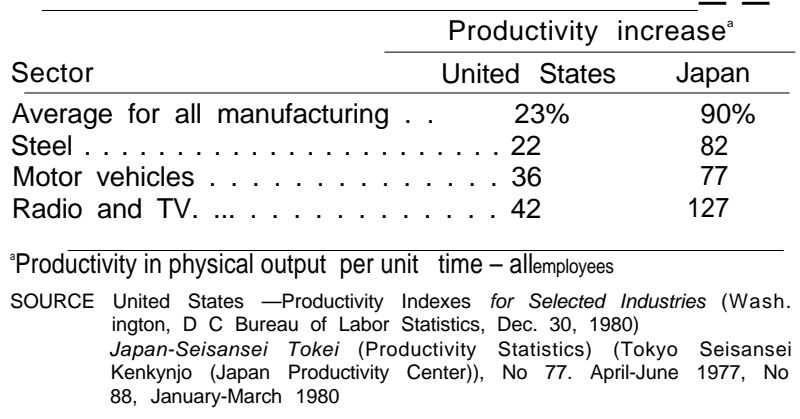

less, in particular industries-e.g., steel or automobiles-labor productivity in Japan may be close to or greater than in the United States; direct comparisons are difficult for a variety of reasons (see ch. 5 on automobiles),

In both countries, productivity in the steel industry rose at a slightly lower rate than for manufacturing as a whole. However, Japan's productivity in motor vehicles has also fallen relative to other Japanese industries, while in the United States automobiles show productivity growth which is considerably greater than the average. The significance of comparisons of one year to another (1979 to 1970) should not be exaggerated. In 1979, U.S. productivity dropped for both steel and motor vehicles compared to the previous year, largely because of recessionary effects-i.e., output. hence capacity utilization, decreased. In contrast, productivity y in Japan was greater for both industries in 1979 than in 1978 . Nonetheless, table 8 would indicate, all else being equal, that automobile manufacturing in the United States should have enhanced competitiveness on a cost basis. All else has evidently not been equal.

Table 8 shows Japan's apparent improvement in consumer electronics to be very high. Even though American productivity in this sector has also increased more rapidly than the average for all manufacturing, the indicated productivity improvements in the Japanese consumer electronics industry have been much greater. These data go a long way towards explaining the strong price competition in consumer electronics over the past decade.

\section{Wage Rate Trends}

When firms or industries grant wage increases faster than their productivity increases, it is sometimes claimed that their international competitiveness must suffer. In fact, this is an overstatement, because inflation by itself does not impair competitive ability if exchange rates are free to adjust. On the other hand, if a particular industry agrees to wage increases exceeding not only its expected productivity improvements but also the average pay raises in other sectors of the economy, it does risk its competitive position. This is because the industry's costs, and presumably its output prices, would rise more rapidly than those elsewhere in the economy. Adjustments in the exchange rate to offset inflation would only partially offset these cost increases. Assuming that wage rates did not similarly outstrip productivity increases in competing industries abroad, the domestic in- dustry could eventually confront more serious price competition both at home and overseas.

This section reviews wage trends in the three industries. Table 9 gives average wage data, excluding benefits, in current dollars for each industry. Better comparisons would be possible if fringe benefits could be included-particularly as they are much higher in some industries than in others. However, data on benefits are not available for all sectors, thus comparisons across sectors could not be made, Comparing the wage rate increases in table 9 with the BLS productivity index (productivity on a physical output basis) from the previous section shows that the average manufacturing wage in current dollars has increased at a rate greater than productivity for the last two decades. From 
Table 9.-Average U.S. Wage Rates for Production Workers in Current Dollars per Hour'

\begin{tabular}{|c|c|c|c|c|c|c|c|}
\hline \multirow{2}{*}{\multicolumn{2}{|c|}{ Year }} & \multirow[b]{2}{*}{ Steel } & \multicolumn{2}{|r|}{ Electronics } & \multirow[b]{2}{*}{ Computers } & \multirow[b]{2}{*}{ Motor vehicles } & \multirow{2}{*}{$\begin{array}{c}\text { All U.S. } \\
\text { manufacturing }\end{array}$} \\
\hline & & & Radio/TV receivers & Semiconductors' & & & \\
\hline 1960 & $\ldots$ & $\$ 3.08$ & $\$ 2,06$ & $\$ 1.86$ & $\$ 2.60$ & $\$ 2.91$ & $\$ 2.26$ \\
\hline 1965 & $\ldots$ & 3.46 & 2.30 & 2.14 & 3.00 & 3.45 & 2.61 \\
\hline 1970 ., & , . . & 4.22 & 3.00 & 3.07 & 3.75 & 4.44 & 3.35 \\
\hline 1975 & F. & 7.11 & 4.29 & 4.35 & 4.99 & 6.82 & 4,83 \\
\hline 1976 & . . & 7.86 & 4.60 & 4.64 & 5.26 & 7.45 & 5.22 \\
\hline 1977 & $\ldots$ & 8.67 & 4,93 & 5.02 & 5.41 & 8.22 & 5.68 \\
\hline 1979 & . . & 10.77 & 6.03 & 5.98 & 6.13 & 9.74 & 6.69 \\
\hline
\end{tabular}

'Does not include benefits which have tended to rise faster than wages

Does not Include benefits which have tended to rISe faster than wages
$\mathrm{b}_{1} 960$ and 1965 , wage rates are for SIC category 365- Radio and Television Receiving Equipment, except Communicatıon Types

'1960 and 1965 wage rates are for SIC categories 3674 and 3679-Semiconductors and Electronic Components N E C

d 1960 and 1965 wage rates are for SIC category 357-Office, Computing, and ACcountingMachines

SOURCES All U.S. manufacturing-employment andEarnings 19097979 (Washington, D C Bureau of Labor Statistics June 1980)

Electronics: 1960.65-Employment and Earnings, 19091975 (Washington, D C Bureau of Labor Stat\{ stics, July 1976), 7970-U S Census of ManufaC turers 1972, 1975.79-Employment and Earnings, 19091979 (Washington, D C Bureau of Labor Statistics June 1980) Steel-AnnualStatisticalReport (Washington, D C American Iron and Steel Institute, June 1979)

Motor vehicles-Ernp/oyrnenf and Earnings 19091979 (Washington, D C Bureau of Labor Stat\{ stics, June 1980)

1970 to 1979 , the average manufacturing wage doubled (table 9); average productivity in manufacturing increased only 23 percent (table 8).

Such behavior is typical of inflationary periods-in fact is one cause of inflation-but it is not necessarily a sign of declining international competitiveness. Assuming that differences in rates of general price inflation among the major industrialized countries are offset by shifts in exchange rates-often though not always true over long time periods-international competitiveness on a price basis need not be affected by inflation in any one country, A lo-percent price increase due to inflation should be balanced by a decline in the exchange rate, If, however, a particular industry grants wage increases which are greater than the inflation rate, and not counterbalanced by productivity increases, there could be a sharp impact on competitiveness. The question is: has this happened in any of these three industries? To examine this possibility, figure 5 plots wages converted to constant 1967 dollars.

Figure 5 shows-as did table 9-that both the steel and the automobile industry have paid higher wages than the average of all U.S. manufacturers, Much of this difference is due to the strong labor unions in these two industries. The work forces in both the steel and automobile sectors also tend to be older and to have achieved more seniority, hence higher wages, than in many other industries,

The trend in wages over time is more important than comparisons of one industry to another. For all U.S. manufacturing, constant dollar wages rose 6.6 percent during the period 1970 to 1979 while the BLS physical output productivity index rose 23 percent. Thus for U.S. manufacturing as a whole, productivity has increased faster than real wages (again recall that fringe benefits are excluded). For radio and TV receivers, real wages went up only 7,4 percent from 1970 to 1979 , while productivity rose 42 percent. On this basis, the radio and TV sector should exhibit improved competitiveness since its productivity has increased much faster than the average in manufacturing, and wages at about the same rate (that its competitiveness has declined instead of improving indicates that other factors have had an overriding influence, as discussed elsewhere). On the other hand, for the steel industry, constant dollar wages rose by 36 percent and productivity by only 22 percent for the 1970-79 period, Thus, the wage component of production costs for steel rose considerably faster than productivity for this period-in marked contrast to U.S. manufacturing in the aggregate. This is one reason for the deterioration in competitiveness of the American steel industry. The relatively slow rise in productivity is associated with an in- 
Figure 5.-Average U.S. Wage Rates for Production Workers in Constant 1967 Dollars per Hour

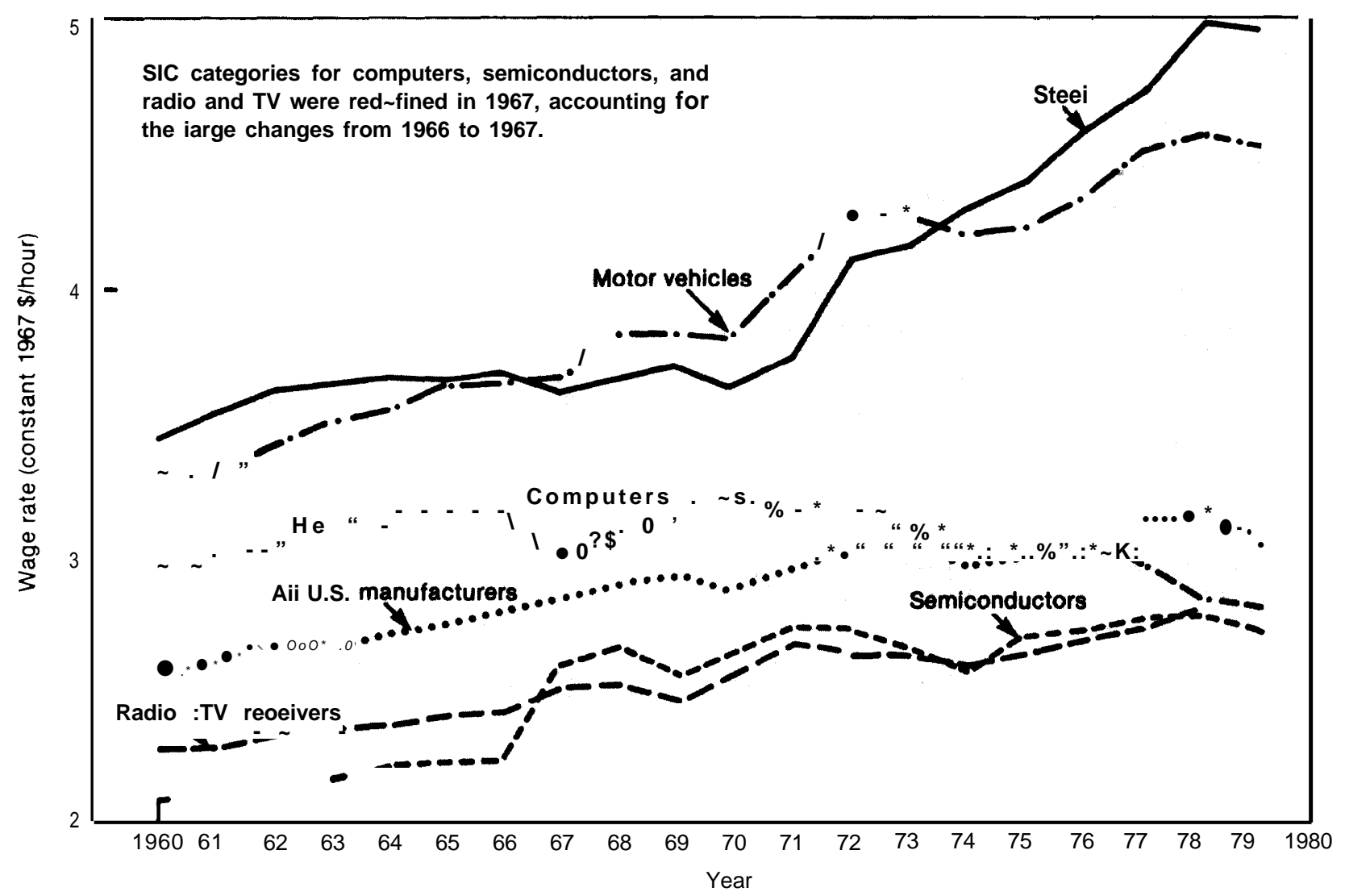

SOURCES All U.S. manufacturing-Employment and Earnings, 1909-1979 (Washington, D C Bureau of Labor Statistics, June 1980) Electronics: 1960.65 -Employment and Earnings, 1909.1975 (Washington, D C Bureau of Labor Statistics, July 1976), 1970-U. S Census of Manufacturers, 1972; 1975 -79-Employment and Earnings, 1909-1979 (Washington, D C Bureau of Labor Statistics, June 1980). Steel-Annual Statistical Report (Washington, D C American Iron and Steel Institute, June 1979) Motor vehicles-Employment and Earnings, 1909.1979 (Washington, D.C. Bureau of Labor Statistics, June 1980)

creasingly obsolescent capital plant, among other factors.

As in steel, auto industry wage levels have been consistently above the all-industry average (figure 5). There the similarity endsmostly because the automobile sector has experienced productivity gains twice those in steel (figure 4). Thus, the effects of higher wages have been at least partially counterbalanced by improvements in output per manhour.

Except for consumer electronics, where real wages grew far slower than productivity, there is little useful data for electronics -again because rapid technological change makes labor productivity figures of little meaning. Those data that are available (e.g., value-added per worker-hour) suggest significant productivity gains in recent years compared to the very modest upward movement in constant-dollar wages (real wages have actually declined in the computer industry).

Finally, the Japanese experience might again be mentioned. Between $1_{9} 73$ and 1979, average real wages in Japan increased about 10 percent. During the same period, labor productivity increased by over 35 percent. This suggests that in many Japanese industries, productivity has been increasing faster than wages - with beneficial effects on competitiveness. 


\section{Other Measures of Competitiveness}

The data reviewed in the preceding sections provide a picture of international competitiveness from a comparative advantage or relative cost standpoint. As discussed in appendix A, there are other possible indicators of competitiveness, often of rather limited significance. Together these also suggest a relative decline of U.S. manufacturing industries compared with major international competitors, Several of these are reviewed below."

One of the measures examined in the "Productivity" section was physical output per employee-hour (the BLS index), International comparisons based on the growth rate of this index show that manufacturing productivity in the United States has grown far less rapidly in the postwar years than in many other industrialized nations-table 10 . Note that although aggregate productivity growth in the United States has slowed in recent years, manufacturing productivity increased at about the same rate during the 1970's as in earlier years. Growth rates for all the countries tended to slow over the past decade, one reason being rapidly rising energy prices, which have affected Western European nations and Japan more than the United States.

Figure 6 demonstrates the long-term effects of slow productivity growth in the United States compared to other industrialized countries. Here each nation's real gross domestic product (GDP) per employee is compared to the level in the United States, in-

M. E. Mogee. Technology and Trade: Some Indicators of the State of U S. Industrial Innovation (Washington, D, C.: Subcommittee on Trade, Committee on Ways and Means, U.S. House of Representatives, Apr. 21, 1980]. dexed as 100 (i.e., GDP per employee as a percentage of the U.S. figure). "These percentages are based on output figures originally expressed in different currencies; when exchange rates shift, and when the shifts are not directly related to differential inflation rates, some distortion is likely. Similarly when monetary systems move from fixed to flexible exchange rates, there can be shortterm distortions. Thus, the trends over time in figure 6 are more meaningful than year-toyear variations.

The data in figure 6 show that output per employee in Japan is still only two-thirds that in the United States; however, the Japanese economy has grown at roughly four times the rate of the U.S. economy since 1950. In contrast, the United Kingdom has grown at almost the same rate as the United States. France and West Germany have doubled their outputs compared to the United States (but recall that it is always easier to catch up). To the extent that a relative decline in GDP is a gross measure of loss in competitiveness, the United States is losing with respect to its major competitors. But in comparison with Japan, all countries have been declining, as also implied by the productivity figures in table 10. At the same time, the United States retains its absolute lead among the countries included in figure 6 .

There has also been considerable concern about the relative state of American technol-

'GDP consists of total goods and services produced within an economy. The primary difference between GDP and GNP is that GNP also includes the net of income of overseas investment overseas brought back to the economy of interest and of foreign earnings that leave that economy,

Table 10.-Average Annual Rates of Productivity Growth in Manufacturing (physical output per hour, all employees)

\begin{tabular}{lccccc}
\hline Time period & $\begin{array}{c}\text { United } \\
\text { States }\end{array}$ & Japan & France & $\begin{array}{c}\text { West } \\
\text { Germany }\end{array}$ & $\begin{array}{c}\text { United } \\
\text { Kingdom }\end{array}$ \\
\hline $1950-70 \ldots \ldots \ldots \ldots$ & $2.4 \%$. & $10.1 \%$ & $5.2 \%$ & $5.8 \%$ & $-2,9 " 10$ \\
$1970-79 \ldots, \ldots \ldots$. & 2.3 & 7.4 & 5.0 & 5.3 & 2.1
\end{tabular}

SOURCE Output per Hour, Hourly Compensation, and Unit Labor Costs In Manufacturing, Eleven Countries 19501979 (Washington, D C Bureau of Labor Statistics, December 1980) 
Figure 6.- Real Gross Domestic Product (GDP) per Employed Person Relative to the United States as 100

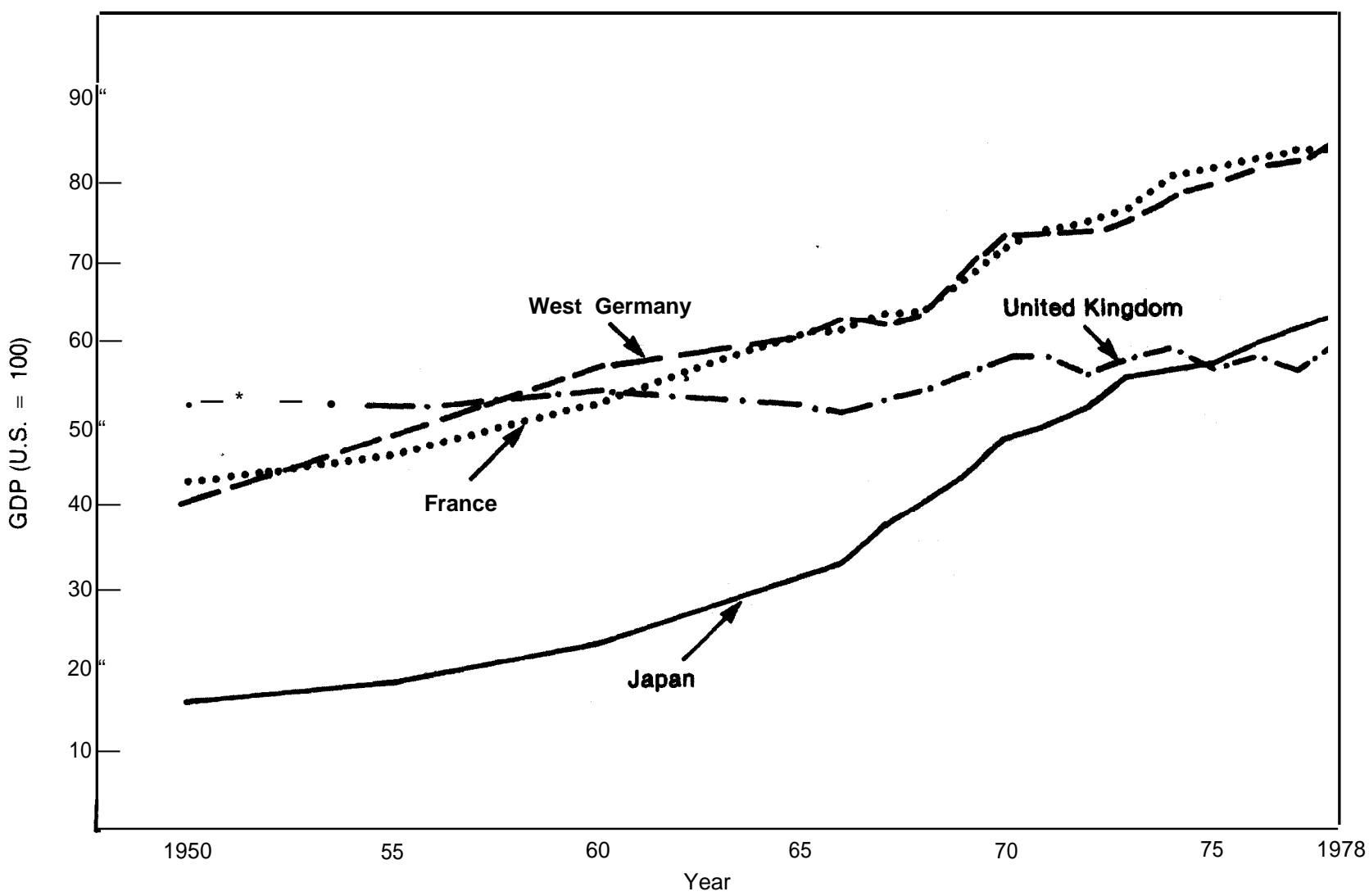

SOURCE: M. E. Mogee, Technology and Trade Some Indicators of the State of U S Industrial Innovation (Washington, D C Subcommittee on Trade, Committee on Ways and Means, U S. House of Representatives, Apr. 21, 1980), p 25 From BLS data

ogy. Leaving aside national defense, this appears to have two distinct thrusts. First, technological advance is one source of product innovations. New and innovative products-resulting in part from $\mathrm{R} \& \mathrm{D}$ - have been a mainstay in U.S. exports of manufactured goods as well as in the expansion of American firms abroad. Now some observers see the Nation's strength in innovation waning. Second, new process technology can be an important means of lowering costs and improving productivity $\mathrm{y}$.

Innovations of the more dramatic type often lead to rapidly expanding sales, large profits, and sometimes to entirely new industries. Early innovators have opportunities for gaining market share and strong competitive positions. Postwar examples include xerogra- phy, the transistor, and Polaroid photography. Process innovations may not attract as much public attention but can be equally important-continuous casting of steel, the float glass process, robots for spray painting automobiles.

It is difficult to compare the state of American technology to that of other nations except on an item-by-item basis. R\&D expenditures can be used, but are a measure of the inputs to activities directed at new products and processes, not the outputs. In absolute expenditures on $R \& D$, the United States leads the Western world by a large margin, as table 11 illustrates. Not only does this country spend more in absolute terms on $\mathrm{R} \& \mathrm{D}$, but the United States spends more as a percent of GDP than its major rivals. The United States 
Table 11.-R\&D Expenditures (all sources) as a Percentage of Gross Domestic Product

\begin{tabular}{|c|c|c|c|c|c|c|c|c|}
\hline & & & & & & & 1967 & 1975 \\
\hline \multicolumn{9}{|l|}{ United States } \\
\hline Total . . & . & & . & . & . & & $2.9 \%$ & $2.3 \%$ \\
\hline Military. & . & & . & . & & $\ldots$ & 1,12 & 0.64 \\
\hline \multicolumn{9}{|l|}{ Japan } \\
\hline $\begin{array}{llll}\mathrm{T} & \mathrm{O} & \mathrm{t} & \mathrm{a}\end{array}$ & & & & . & . & . & 1.3 & 1.7 \\
\hline Military, $\quad \ldots$ & & & $\ldots$ & & . &. & 0.02 & 0.01 \\
\hline \multicolumn{9}{|l|}{ France } \\
\hline Total & & & & & . & . & 2.2 & 1.8 \\
\hline $\mathrm{M} \mathrm{i} \mathrm{I} \mathrm{i} \mathrm{t} \mathrm{ar}$ & $\mathrm{y}$ & & . & , , & & , & 0.55 & 0.35 \\
\hline \multicolumn{9}{|c|}{ West Germany } \\
\hline Total . . & . & . & . & . & . & . & 1.7 & 2.1 \\
\hline Military . . . . & & & & $\ldots$ & & . & 0.21 & 0.14 \\
\hline \multicolumn{9}{|c|}{ United Kingdom } \\
\hline Total . . . . . . & & & & & & . & 2.3 & 2.1 \\
\hline Military. ..., . . . & & & & & & & 0.61 & 0.62 \\
\hline
\end{tabular}

SOURCE: Technical Change and Economic Policy(Paris Organization for Economic Cooperation and Development, 1980) p 30

does spend less as a percentage of GDP than in the past, but total $\mathrm{R} \& \mathrm{D}$ expenditures in constant dollars have not changed much since 1966." Table 11 also shows that U.S. expenditures for military R\&D are greaterboth in absolute terms and as a percent of GDP-than in other countries, Although the proportion of U.S. R\&D effort devoted to defense-related activities has been going down, it is still large, While some military R\&D gives results useful to commercial industries, not all military technologies contribute to competitive strength.

Although R\&D spending can be disaggregate in various ways, the relative contributions to competitive ability of basic research, applied research, and development (the latter receiving by far the largest expenditures)

"Mogee. op. cit.. p. 8 cannot be readily disentangled. However, some observers believe that the United States is now overemphasizing short-term $\mathrm{R} \& \mathrm{D}$ with immediate payoffs at the expense of longer term work aimed at maintaining the science and technology base.

As table 12 shows, in the United States only a small proportion of Governmentfunded R\&D goes towards the advancement of knowledge (i. e.. both basic and applied $\mathrm{R} \& \mathrm{D}$, but not directed at specific products or processes). The table indicates that the two strongest rivals of the United States in hightechnology industries-Japan and West Germany-devote more than half of all government-funded R\&D to the advancement of knowledge, while the U.S. spends less than 5 percent on this category. Of course, Japan in particular spends little on defense.

In most nations the portion of total $R \& D$ funded by industry which goes toward basic research runs between 3 and 10 percent, While industries in both Japan and West Germany spend a greater fraction of their own R\&D funds on basic research than in the United States, the differences are a few percentage points-not nearly as striking as the divergence in government funding shown by table 12 .

\section{To summarize: 8}

1. Total U.S. expenditures on industrial (including military) $\mathrm{R} \& \mathrm{D}$ have been rela-

Technological Change and Economic Policy (Paris: Organization for Economic Cooperation and Development, 1980), p. 36.

"Mogee, op. cit.; also Technological Change and Economic Policy. op. cit.

Table 12.-Percentage Allocation of Government-Funded R\&D by Objectives, 1975

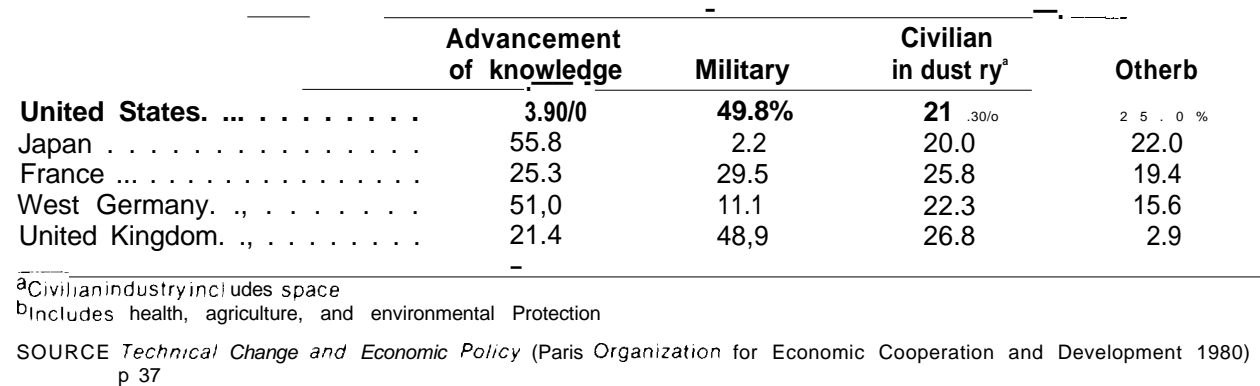


tively stable in constant dollars for about 15 years. Private sector funding has been rising at an average annual rate of nearly 5 percent, while Federal Government expenditures have been falling since the late 1960's with only a slight recovery in the past few years.

2. Total R\&D expenditures have been a declining portion of U.S. GDP for 15 years.

3. Other nations-e.g., West Germany and Japan-have been increasing R\&D expenditures both absolutely and as a percentage of GDP. Japan has recently set a long-term goal of spending 3 percent of its GDP on R\&D. But in absolute terms, R\&D expenditures in the United States remain much greater than in any other Western country.
These trends do not prove that relative declines in R\&D spending have harmed U.S. competitiveness. Other countries have increased their technological capabilities through a variety of means-only one of which is R\&D (technology transfers-e. g., from the United States-are one alternative). Nonetheless the coincidence of relative declines in funding for $R \& D$ and in industrial competitiveness is disturbing.

On the other hand, the United States maintains a large and growing surplus of earnings from licensing fees and royalties for technology. These data are shown in figure 7. Many receipts and expenditures simply represent transactions with foreign subsidiaries of U.S. firms, Moreover, payments are often compen-

Figure 7.-Royalty and License Payments and Receipts of U.S. Firms

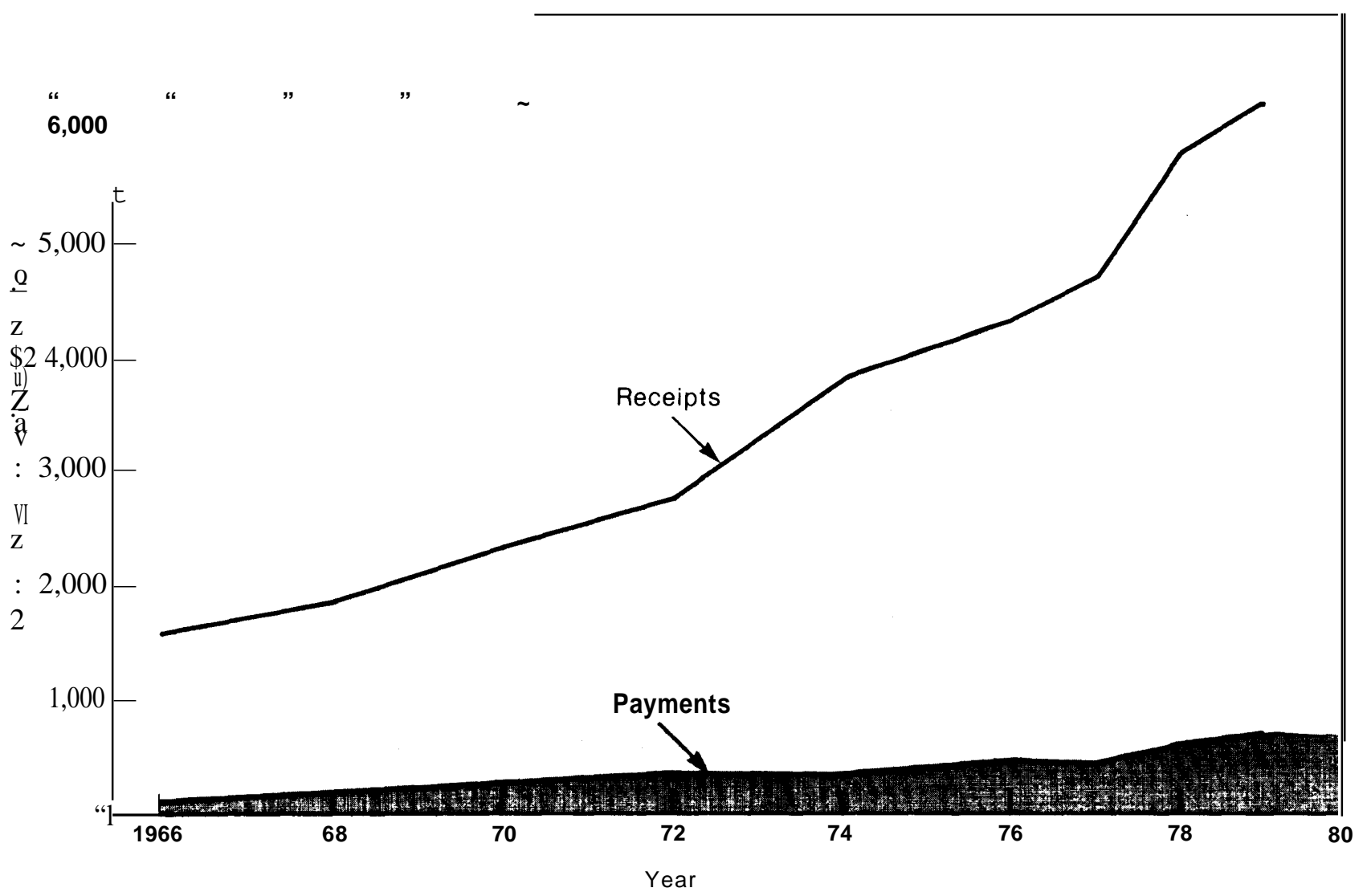


sation for technology developed in earlier periods. RCA, for example, still receives roughly $\$ 50$ million per year from Japanese firms for color TV technology mostly dating from the 1960' s." Still, the balance of transac-

\footnotetext{
'R. A. Joseph. " Automation Helps RCA and zenith keep Color-TV Leadership in face of Imports, wall, street Journal. May 5. 1981. p.56.
}

tions in fees and royalties is one of the few measures specifically related to outputs rather than inputs of $R \& D$ and other activities directed a $t$ innovation. No deterioration in this balance is thus far evident. of course, it is precisely the transfer of U.S. technology to foreign firms [represented by the receipts in figure 7) which some observers blame for slackening U.S. competitiveness.

\section{Summary and Conclusions}

The measures of competitiveness examined in this chapter have been rather general in nature-e.g., productivity across an entire industrial sector. Many other factors are also important for competitive ability-for instance, quality of management or the effects of public policies. Factors of the latter type, some of which are covered in later chapters, often influence measures such as productivity.

Broad economic parameters such as productivity, wage levels, and aggregate R\&D expenditures are certainly important for international competitiveness; more rapid economic growth would help many American industries maintain their competitive positions. Yet the fates of specific firms and industries are only loosely related to aggregate economic growth. In the same way, the overall health of the science and technology enterprise affects the competitiveness of many industries -often in unanticipated ways. It is difficult to link events in any one industry to science and technology in general. Nonetheless, hightechnology industries, notably computers, are large exporters and have also shown rapid productivity advance; by any measure the computer industry appears competitive. The same is true for semiconductors, although here exports and imports are nearly in balance. The competitiveness of both sectors has been helped by wage levels that are low compared to automobiles and steel, However, I he consumer electronics industry- also charac- terized by low wages-is, by the indicators of international trade, the least competitive. Possible explanations for the difficulties experienced by this sector are examined in chapter 5 .

Import penetration is not a new phenomenon in steel and automobiles, although imports have been steadily increasing, particularly in autos. The present competitive problems in the U.S. automobile industry have causes which largely evade the measures examined in this chapter.

The steel industry has been harmed by slow productivity growth and high wage levels; low profits have made it difficult to modernize, although new plant and equipment could lower costs and improve productivity. And, despite the relatively slow rate of productivity growth in steel, the U.S. industry is on average competitive in its absolute labor productivity with Japan. At comparable rates of capacity utilization, the Japanese industry would be superior; but since U.S. steelmaker have in recent years been operating closer to full capacity, their absolute productivity has been comparable to that achieved in Japanese mills, In other sectors, productivity increases compare favorably with the rest of U.S. manufacturing; lagging productivity growth cannot explain the apparent slackening of competitiveness in sectors such as consumer electronics or automobiles. 
CHAPTER 5

\section{Industry-Specific Competitiveness}




\section{Contents}

Overview. ..**...***.****.***********.* $\begin{array}{rr}\text { Page } \\ 69\end{array}$

Steel .*.*..***, .*..***.*...,**....* 70

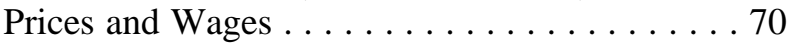

Dumping . . . . . . . . . . . . . . . . . . . 72

Exchange Rate Effects. . . . . . . . . . . . . . 73

Employment . . . . . . . . . . . . . . . . . 74

Demand Patterns . . . . . . . . . . . . . . 75

Electronics . . . . . . . . . . . . . . 76

Consumer Electronics. . . . . . . . . . . . . . . . . . . . . . . .

Semiconductors . . . . . . . . . . . . . . . . 82

Computers . . . . . . . . . . . . . . . . . . . . . 89

Technical Personnel. . . . . . . . . . . . . . . . 90

Comparing the Sectors. ............ 91

Automobiles .. . . . . . ....0.. •....... 92

Imports and the U.S. Industry . . . . . . . . . . . . . . 92

Employment . . . . . . . . . . . . . . . . . . . . . . . . . . . . .

Factors in Competitiveness .............. 95

Small Car Strategies of U.S. Firms . . . . . . . . 99

Summary and Conclusions.

List of Tables

Table No.

13. Potential Influences on Industrial Competitiveness . . . . . . . . . . . . . . . . . . . 69

14. Selected Currency Value Changes, 1971-74 . . . . . . . . . . . . . . . . . . 73

15. Domestic Steel Shipments and Employment, 1969 and 1979.
Table No.

Page

16. import Penetration in Consumer Electronics, $1978 \ldots \ldots \ldots$. . . . . . . 77

17. Areas of Concentration of Japan's VLSI Program . . . . . . . . . . . . . . . . . . 84

18. Comparison of the United States and Japan in Digital Integrated Circuit Technology ................ 85

19. U.S. Automobile Imports by Country of Origin . . . . . . . . . . . . . . . . 992

20. Motor Vehicle Production and Sales Figures ... . . . . . . . . . . . . . 993

21. Distribution by Size of Sales in the U.S. Automobile Market . . . . . . . . . . . . . . . . 94

22. Distribution by Size of U.S. Automobile Production . . . . . . . . . . . . . . . . . . . . . 94

23. Numbers of Dealerships by Manufacturer 99

24. Fuel Economies of Domestic and Imported Automobiles, 1979

\section{List of Figures}

Figure No.

8. indexes for Steel Mill Product Prices, Page Consumer Prices, and Industrial Commodity Prices. . . . . . . . . . . . . . 71

9 Indexes of Input Costs for the American Steel Industry . . . . . . . . . . . . . . 72

10 Employment in the American Steel Industry .................... . 74 


\section{Overview}

Going beyond broad trends in indicators such as productivity, this chapter examines influences on competitiveness that are specific to each industry. Although chapter 4 touched on factors such as $\mathrm{R} \& \mathrm{D}$, these were treated in a general way. At the level of the specific industrial sector-even more, the individual firm-competitiveness springs from a diverse and complex array of influences. Some of these act directly [e.g., quality and reliability of products-themselves depending on other, more subtle factors), some indirectly (e.g., quality of the educational system, political and economic stability). A selection of these influences is listed in table 13. While many are intangible - and few can be quantified-all are important in determining the competitiveness of particular firms and industries. Public policies are woven into many; however, policy effects are left largely

Table 13.- Potential Influences on Industrial Competitiveness

Factor

1. Characteristics of industry and market structure.

2 Characteristics of the labor force.

3. Characteristics of professional personnel

4. Availability of materials and components.

5 Supporting Infrastructure

6. The environment for innovation.

7. Business and economic conditions.

8 Government Interact lons

9 International trade relations

\section{Examples}

The number of firms, their size and production facilities, and degree of concentration and integration influence competition. Market structure includes the size, availability, rate of growth, and degree of saturation of the market,

Both labor costs and availability of skilled workers are important; Government support for the training and education of the work force can be critical, The nature of laborrnanagement relations, type of unions, and mechanisms for worker participation can also influence productivity and competitiveness,

Quality of management and technical personnel are significant determinants of competitiveness. Important characteristics include: the attitudes and value structure of management; aggressiveness in developing, marketing and exporting products: and the degree of interaction and cooperation within the firm among R\&D, marketing, product planning, manufacturing engineering, and quality control personnel.

Assured supplies of the inputs to the manufacturing process (iron ore, petroleum, electronics components) are important for planning and long-term stability. Domestic availability versus dependence on imports can be important.

The infrastructure includes the vendors, subcontractors, other suppliers, and services necessary to support complex technologically based industries. Also Included are basic research organizations and the level of Government support for generic R\&D.

Factors that more directly affect the ability to innovate and the rate of technology diffusion Include: the interactions and synergies among firms within an industry (mobility of personnel. licensing and other Interchanges of technology, openness to inward transfers of technology and management know-how); and the existence of clusters of skills as among the semiconductor firms in Silicon Valley.

Included here are Indicators of overall economic performance such as GNP or GDP, levels of disposable Income, and inflation rates. The nature of capita/ markets (concentration of banking and credit) affect the ability of firms and industries to expand. Also Important are less tangible factors such as consumer confidence, investment expections, and the general climate of political stability and social welfare,

Government regulations that impinge on factory work, supplies of resources, design and sale of products, tax policies, Government procurement policies, and antitrust policies and their interpretations all affect the attitudes and decisions of business. In addition. more intangible factors which are nevertheless important include the tradition of cooperation or conflict within and among Government, business, and labor.

Policies enacted by domestic and foreign governments affecting imports and exports such as taxes on overseas profits, tariffs on imports and reimports after offshore assembly, export credits and subsidies, exchange rates, policies toward technology transfer, and nontariff barriers set the environment for international competition. international agreements and organizations often provide the framework for such policies. 
to chapter 6. In the end, of course, competitiveness rests on the capabilities of individual firms. Even a cursory review of variations over the past few years in sales, profits, and other indicators of success in industries such as steel or automobiles shows how greatly the performance of individual companies can vary.

Each industry and each firm has attributes that make it unique. Industries and firms develop attitudes, even cultures, which shift over time. These are the backdrop for the more concrete and quantifiable indicators of competitiveness discussed in earlier chapters and in the sections below. Thus, lagging competitiveness in steel has different causes than lagging competitiveness in automobiles or consumer electronics.

Just as the causes of shifts in competitiveness differ, so do the consequences-though the most prominent in each case is loss of employment opportunities. Some of these losses are irreversible without large increases in production-increases that could only come through exports. If high volumes of exports are unlikely-as seems the case in industries such as consumer electronics or steel-the alternative is retraining and relocation of workers. In fact, American industries such as steel, consumer electronics, and automobiles are experiencing structural unemployment in its classical sense.

\section{Steel}

\section{Prices and Wages}

Chapter 4 compared the steel industry with the electronics and automobile industries, as well as with U.S. manufacturing in the aggregate. While labor productivity in the steel industry has improved at approximately the national average for manufacturing, hourly wages in real terms have grown much faster than average. In recent years, the industry has agreed to wage increases diverging more sharply from other sectors, even while import penetration has been rising (figure 5). As chapter 4 suggested, increased labor costs should be reflected in price increases for steel greater than price rises elsewhere in the economy. Figure 8 indicates that this has in fact occurred.

The chart compares price behavior in steel to other parts of the economy. Beginning in the 1970's, steel prices rose considerably faster than the general inflation rate as measured either by the consumer price index or the industrial commodity price index. This is in marked contrast to earlier time periods, when steel prices rose parallel to overall price inflation. Moreover, prior to 1970 , real wage increases in the steel industry were well below the industry's productivity gains.
Despite the rapid price increases shown in figure 8 , profits for the industry as a whole have been gradually decreasing; in recent years the steel industry has been substantially less profitable than other U.S. manufacturing sectors.

In addition to wages, many of the other elements of production costs for steel have also been increasing, particularly costs of energy. Figure 9 shows trends for energy and material inputs to ironmaking and steelmaking. While all the indexes show doubling periods of 10 years or less, these rapid price rises do not affect all firms equally. For example, some integrated firms have their own reserves of coal and iron ore; nonintegrated steelmaker are more heavily dependent on prices of scrap and electricity, Nonetheless, figure 9 demonstrates that price increases for steel have been caused by rising energy and materials costs as well as wage rate inflation. Although labor costs, including fringe benefits, tripled between 1967 and 1978, the costs of metallurgical coal went up more than twice as fast.

'Technology and Stee) industry Competitiveness (Washington, DC.: Office of Technology Assessment, U.S. Congress, June 1980], pp. 120-122. Profitability varies considerably from firm to firm. 
Figure 8.--Indexes for Steel Mill Product Prices, Consumer Prices, and Industrial Commodity Prices $(1967=100)$

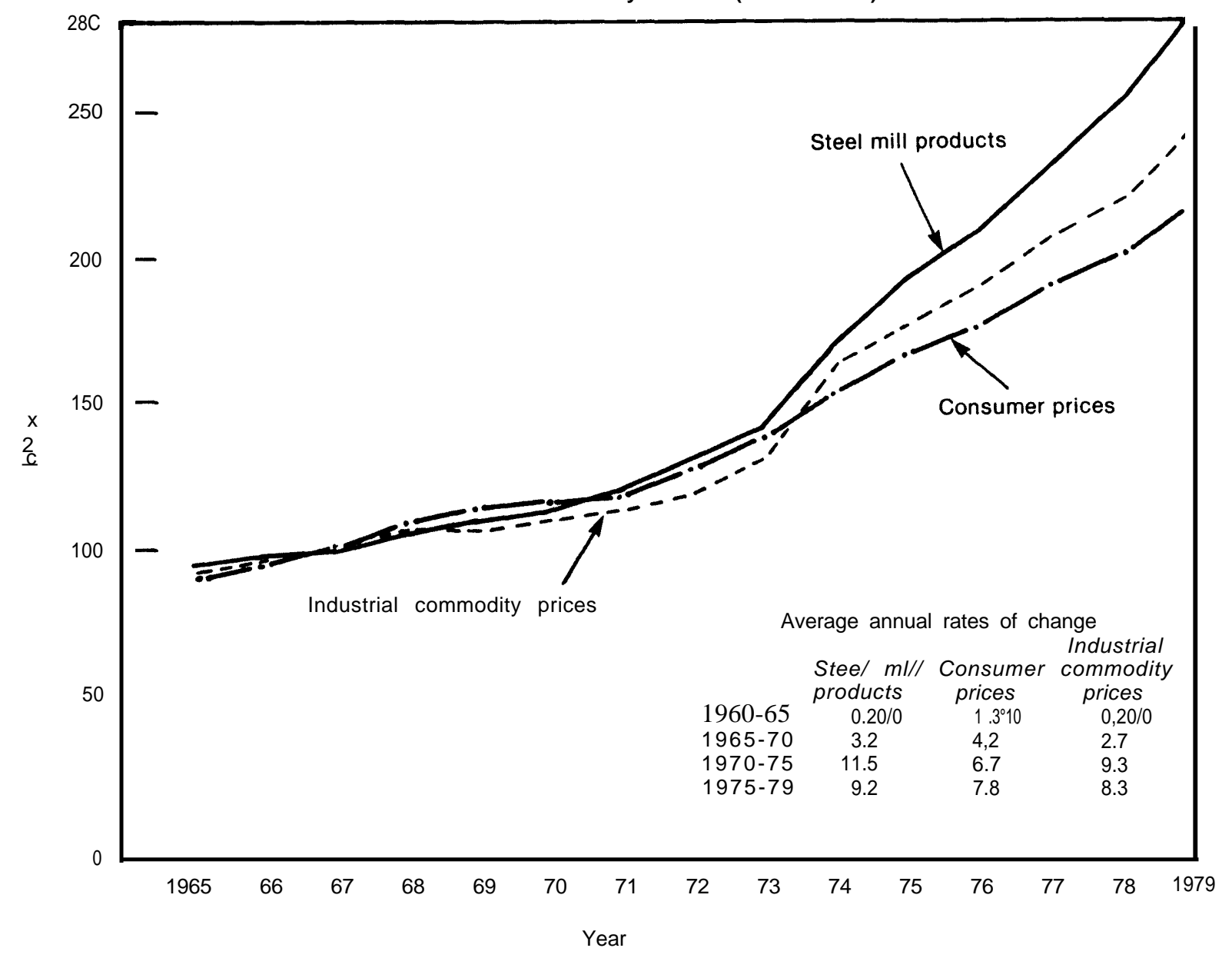

SOURCE Bureau of Labor Stat[stlcs

In other countries, real wages for steelworkers have also risen faster than productivity. Comparisons of wage and productivity increases show that the American steel industry has done well compared to Europe. However, the fraction of steel costs attributable to labor has risen in the United States compared to Japan because Japanese productivity improvements have offset wage increases. -

The United States has not exported much

Report to the President on Prices and Costsin the United States Steel Industry (Washington, 1). C.: Council on Wage and Price Stability, October 1977], p, 45. steel in recent years-in the vicinity of 3 million to 4 million tonnes annually, about half to Canada and Mexico. Imports from these two countries have been at about the same level, indicating that the Canadian and Mexican industries complement this country's, each supplying certain types of products to particular regions or sectors. For example, about onequarter of Mexico's imports from the United States consist of pipe and other oilfield products, In other parts of the world, U.S. exports have not been competitive, Some observers say this is because the industry insists on selling goods abroad at prices covering full costs rather than marginal costs. 
Figure 9.-indexes of Input Costs for the American Steel Industry (1967 = 100)

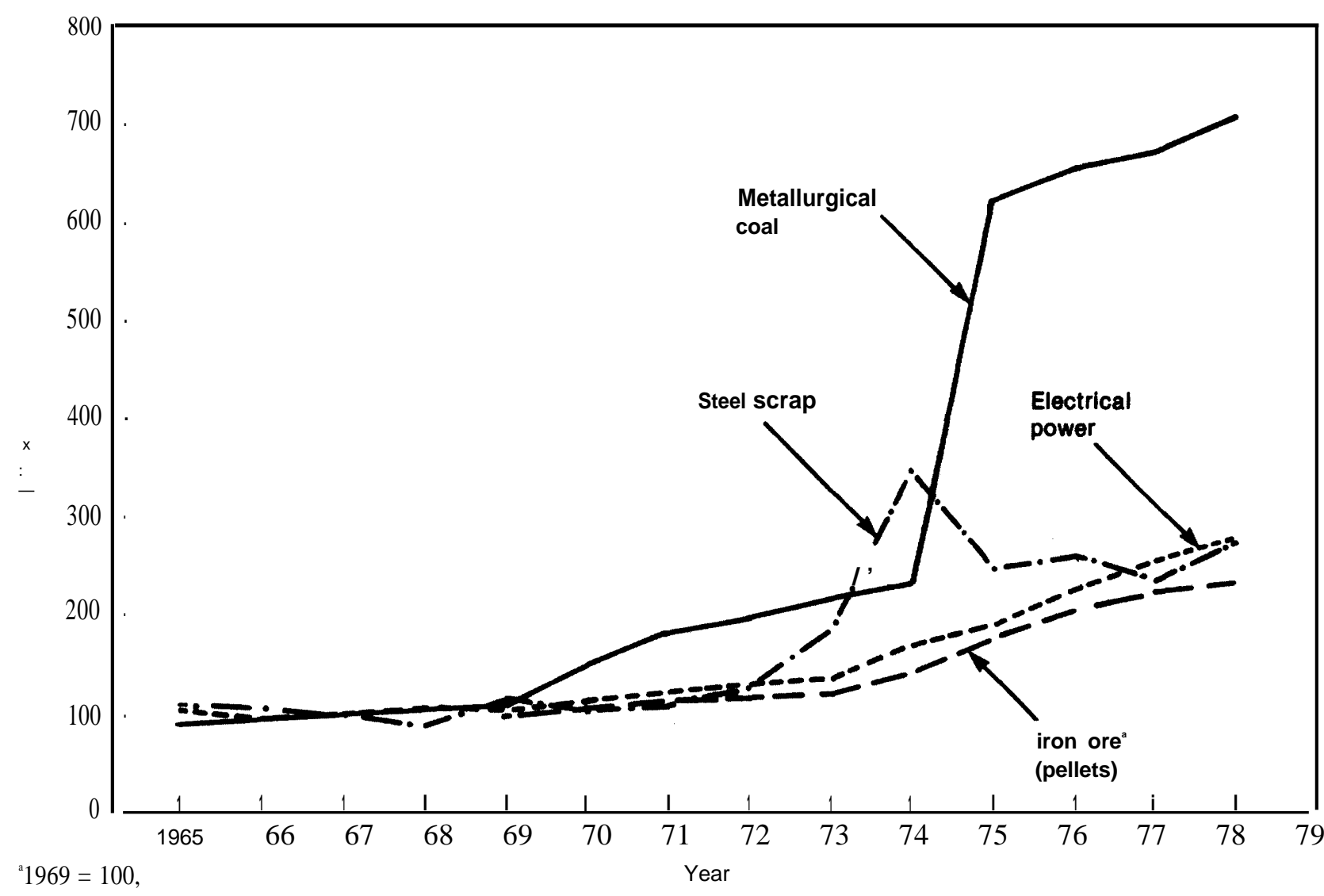

SOURCE Technology and Steel Industry Competitiveness (Washington, D C Office of Technology Assessment, U S Congress, June 1980) p 122, from BLS and AISI data

\section{Dumping}

Dumping occurs when export prices are set below home market prices, or in some cases below costs. Since 1959, the U.S. industry has claimed that foreign steelmaker, particularly European firms, have been dumping steel in the United States,

Incentives for dumping are highest when demand slackens and substantial excess capacity exists. This is because the incremental costs of producing additional output can be quite low, particularly if labor costs in the short run are essentially fixed (see ch. 3). Under such circumstances, the added costs of maintaining relatively high production levels can be small, and sales at any price covering variable costs become attractive. At the same time, firms in this situation prefer to sell the excess output outside their usual markets, so that price cutting will not affect established pricing patterns. Circumstances thus combine to encourage dumping in export markets. Moreover, government-owned steel firms-as in some countries in Europe-can be supported indefinitely from public funds to maintain employment, even though unprofitable.

Dumping and other unfair trade practices are restricted under the General Agreement on Tariffs and Trade. Because low prices are presumed to benefit consumers, dumped goods are allowed to enter the United States unless a domestic industry is injured. If injury 
is found by the International Trade Commission, the Department of Commerce (formerly Treasury) assesses an antidumping duty intended to raise prices to the U.S. market level.

The steel industry, along with other domestic industries, has maintained that processes for establishing both dumping and injury are excessively complex and time consuming, and that the injury test is overly strict. As a consequence, industry leaders assert, the law is unworkable and does not effectively protect them from unfair trade practices by foreign firms. In 1977, largely in response to such criticism, the so-called trigger-price mechanism (TPM) for steel was instituted to supplement existing antidumping laws (see ch. 6). The TPM allows imported steel to enter the United States as long as prices are a certain percentage above the costs of the most efficient producer in the world market-then as now Japan,

Whether U.S. antidumping remedies are inadequate - in general or just for steel-is too involved a question to discuss in depth, but one or two points deserve mention, First, the evidence compiled for OTA'S steel study suggests that European mills, but not Japanese, do have higher average costs than American steelmaker. On the other hand, European firms historically have cut prices at home and abroad when they have excess capacity. American producers, in general, have not decreased prices in such circumstances, preferring to follow full-cost pricing strategies. As long as there is excess world steel capacity, producers in a t least some countries will have incentives to dump. However, if world steel demand grows to meet capacity-as the OTA steel study finds possible $\{-$ then dumping will cease to be a serious threat to the U.S. industry. The real problem would then be the lack of cost (and therefore price) competitiveness with respect to the Japanese and, potentially, with respect to new mills in the developing world.

\footnotetext{
Techology and Steed Industry Competitiveness, op cit. p. 78
}

\section{Exchange Rate Effects}

The deteriorating competitive position of the American steel industry in the late 1960's improved beginning in 1971 when the dollar was allowed to float against other currencies. For some time, the United States had persistent balance-of-payments deficits, in part because the dollar was overvalued with respect to other currencies. When fixed exchange rates were replaced by a floating exchange rate system, the dollar fell against most currencies (table 14), improving the competitive position of the United States in steel and other industries. As the accumulated effects of inflationary imbalances dissipated, the relative prices of many American products became more competitive.

Since 1971, exchange rates have been largely market-determined. Over time, rates have tended to mirror differences in inflation among various countries. Although governments sometimes try to influence exchange rates-because holding them below the market level will make their exports more attractive-such a strategy is difficult to maintain for long in open currency markets.

Short-term fluctuations in exchange rates about the long-term equilibrium level can also influence competitive position. Between the fall of 1978 and the spring of 1980, the average production costs of Japanese steel, converted to dollars, fell from about 8 percent above U.S. costs to 23 percent below U.S. costs as a result of swings in the yen/dollar

Table 14.-Selected Currency Value Changes, 1971-74

\begin{tabular}{|c|c|c|c|}
\hline Currency & $\begin{array}{l}\text { Par value- } \\
\text { August } 1971 \\
\begin{array}{c}\$ \text { currency } \\
\text { unit }\end{array}\end{array}$ & $\begin{array}{l}\text { Rate- } \\
\text { June } 1974 \\
\begin{array}{c}\$ / \text { currency } \\
\text { unit }\end{array}\end{array}$ & $\begin{array}{l}\text { Percent } \\
\text { change }\end{array}$ \\
\hline $\begin{array}{l}\text { British pound } \\
\text { French franc } \\
\text { German mark } \\
\text { Japanese ye }\end{array}$ & $\begin{array}{l}\$ 2.40 \\
0180 \\
0273 \\
0.00278\end{array}$ & $\begin{array}{l}\$ 2.36 \\
0.203 \\
0373 \\
00035\end{array}$ & $\begin{array}{l}-18^{\circ} 0 \\
12.9 \\
364 \\
26,6\end{array}$ \\
\hline
\end{tabular}

SOURCE: $R$ H Mason $R$ B. Miller. and D.R. Weigel The Economics of Interna tional Business \{New York: John Wiley \& Sons. 1975\} p 90 


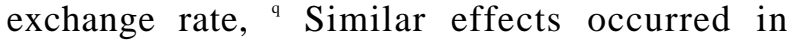
other industries, with obvious consequences for the cost/price competitiveness of Japanese imports in U.S. markets. While the Japanese Government may have influenced such shifts in the past, as Japan's capital market becomes more closely linked to world capital markets-an explicit goal of their government-currency rate pegging will become more difficult.

+p. F. Marcus and K. M. Kirsis, "The Steel Strategist, " Paine Webber Mitchell Hutchins, Inc., June 1980, p. 1. Quoted in U.S.Japan Trade Report (Washington, D. C.: Subcommittee on Trade, Committee on Ways and Means, U.S. House of Representatives, Sept. 5, 1980), p. 10.

\section{Employment}

When competitive advantages shift, employment levels may change. Declining employment in the domestic steel industry has often been blamed on increased competition from abroad.

As figure 10 shows, total employment in the American steel industry has fallen more than 20 percent since peaking in 1965. The rate of decline has been more than twice as rapid for hourly workers as for salaried. Two questions are most important: 1) To what extent have imports been the cause of employ-

Figure 10.-Employment in the American Steel Industry (annual averages in thousands)

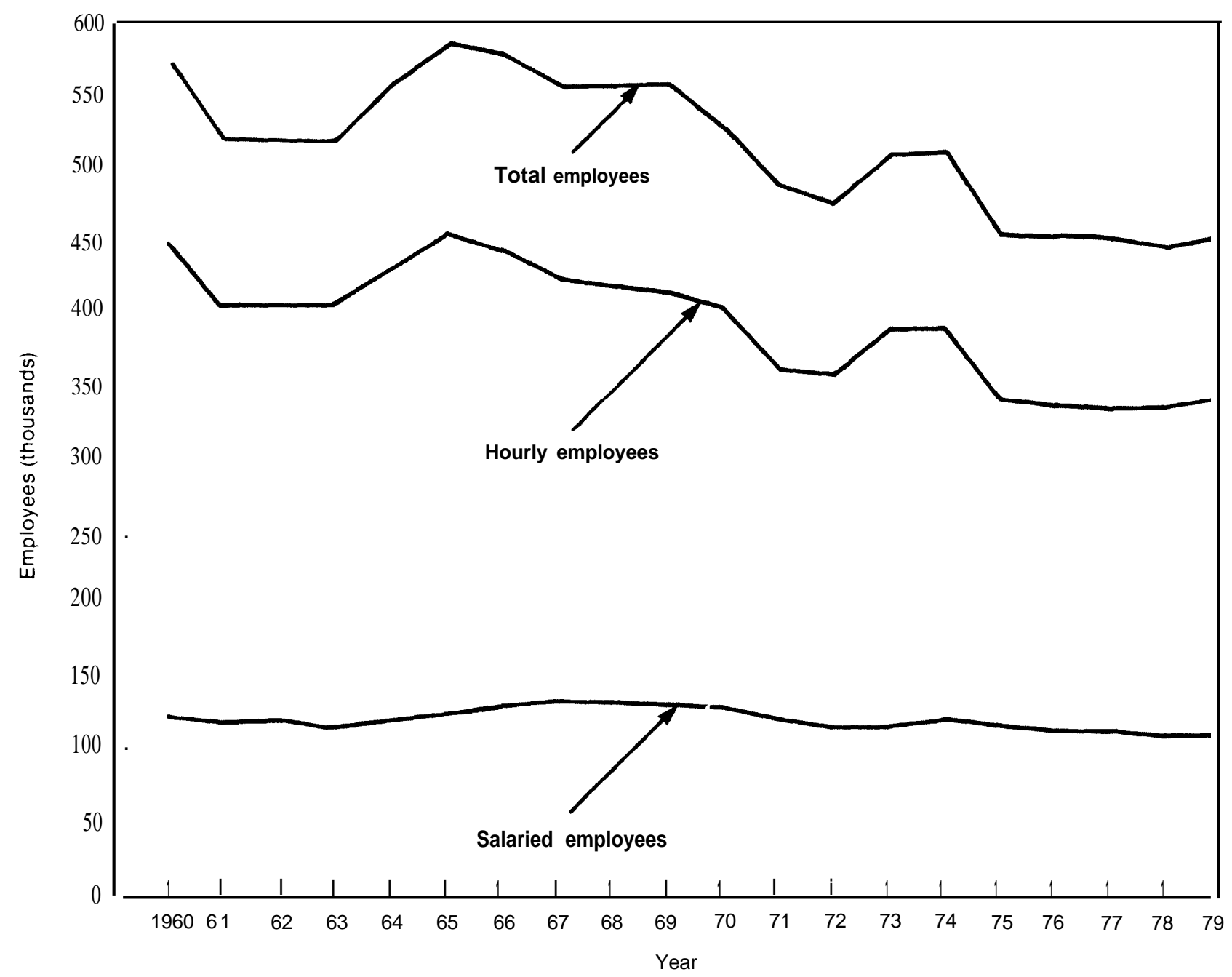


ment decreases? and 2) What would be the employment effects of higher domestic production?

Rising imports always decrease job opportunities. However, this is not the only factor at work. Table 15 gives steel production and employment for a pair of years a decade apart. Shipments were higher in 1979, but total employment fell by more than 100,000 because of increased productivity. Had domestic production replaced some or all of the imports in either year, employment would have been higher. But the basic conclusion remains: the most important cause of declining employment has been rising productivity, not increased imports.

This conclusion has significant policy implications, For the competitiveness of the steel industry to improve, its productivity must continue to increase, thus cutting costs. However, the inevitable result would be further employment losses unless total production could be substantially increased. At current production levels, the goals of improved international competitiveness and stable or rising employment are fundamentally opposed,

The fact that policies intended to maintain employment often work against increased efficiency is illustrated by the European experience. In Europe, despite subsidies or direct government ownership, steelmaker have not in general been able to achieve costs as low as in the United States or Japan. Moreover, the least competitive industries appear to be those where political pressures for maintaining employment have been greatest. For ex-

Table 15.-Domestic Steel Shipments and Employment, 1969 and 1979

\begin{tabular}{|c|c|c|c|c|}
\hline Year & $\begin{array}{c}\text { Domestic } \\
\text { shipments } \\
\text { (thousands } \\
\text { of tonnes) }\end{array}$ & $\begin{array}{l}\text { Total } \\
\text { employment } \\
\text { (thousands) }\end{array}$ & $\begin{array}{l}\text { Tonnes } \\
\text { shipped } \\
\text { per } \\
\text { worker }\end{array}$ & $\begin{array}{c}\text { I report } \\
\text { penetration }\end{array}$ \\
\hline $\begin{array}{l}1969 \\
1979\end{array}$ & $\begin{array}{l}85,165 \\
90,958\end{array}$ & $\begin{array}{l}554 \\
453\end{array}$ & $\begin{array}{l}154 \\
201\end{array}$ & $\begin{array}{l}14.2 \% \\
16.1 \%\end{array}$ \\
\hline
\end{tabular}

ample, the British steel industry, largely owned by the government, lost $\$ 1.3$ billion in its latest fiscal year, and is reported to be planning new layoffs totaling more than 50,000 workers. Enhancing the American steel industry's international competitiveness, while certainly desirable, will not have large positive impacts on employment,

\section{Demand Patterns}

The structure of demand for steel is changing in ways that are important to the competitiveness of the industry (ch, 7). Economic growth is the most important determinant of worldwide steel demand, but steel use does not necessarily rise as rapidly as gross national product, For example, steel consumption in the industrialized world is now significantly less than in 1973, At the same time, in the developing world, increased steel demand has spurred the expansion of capacity. South Korea, although still a minor producer on the world scale, has quadrupled its steel output in the last 5 years. Mexico and Brazil have been adding steel capacity much faster than the industrialized nations. In the future, all three countries could be efficient producers and potential competitors in world markets.

Even under the best of circumstances, therefore, the American steel industry is likely to continue to diminish in importance relative to the rest of the world. It will share this fate with the steel sectors of virtually all industrialized economies,

The developed countries appear to be in a much stronger position in alloy/specialty steels than in carbon steels. In part this is because the demand mix for steel products has also been changing in these countries. Demand for alloy and stainless varieties is rising rapidly. Specialty steel use will continue to increase-production of synthetic fuels, for instance, will depend critically on specialty alloys. Shipments of alloy steels now account for over 10 percent of U.S. tonnage. There

'Y. M. Ibrahim, "British Steel Reports \$1.3 Billion Loss,", New York Times, July 30, 1980, p. D 1. Some of the loss was due to a strike: losses the previous vear were only $\$ 735$ million. 
has also been a shift towards high-quality sheet products as opposed to structural steel in most of the developed world. These changes partly reflect increases in the production of manufactured goods at the expense of construction, partly changes in applications. For example, increased demand for fuel-efficient automobiles is affecting the steel industry. Less steel is being used in each car due to down-sizing and the substitution of lighter materials such as aluminum and plastics. The move to lighter cars is also stimulating demand for high-strength steels, which are higher valued.

Despite the tradeoff between productivity and employment, the decline in size of the U.S. industry relative to the rest of the world, and continuing pressure by other steel-prpducing nations, there are factors operating to the advantage of the U.S. industry,

Changes in demand toward higher strength, higher priced steels give the industry an opportunity to advance through R\&D. High-technology products, particularly alloy/specialty steels, may offer new export opportunities. Nevertheless, while the U.S. industry is probably on a par with other advanced nations in product technologies, it is generally somewhat behind Japan and the best of the European producers in the installation and use of process technologies. ${ }^{G}$

As the OTA steel study also shows, there may be significant opportunities for process innovations in the future-timely adoption of ch. 9 .

'Technology and Steel industry (Competifiveness, op. cit.,

\section{Electronics}

\section{Consumer Electronics}

More than any other segment of these three industries, foreign competition has had major impacts on consumer electronics. As noted in chapter 4 , large percentages of virtually all consumer electronics products sold in the United States are manufactured abroad. Table 16 gives figures for 1978; im-

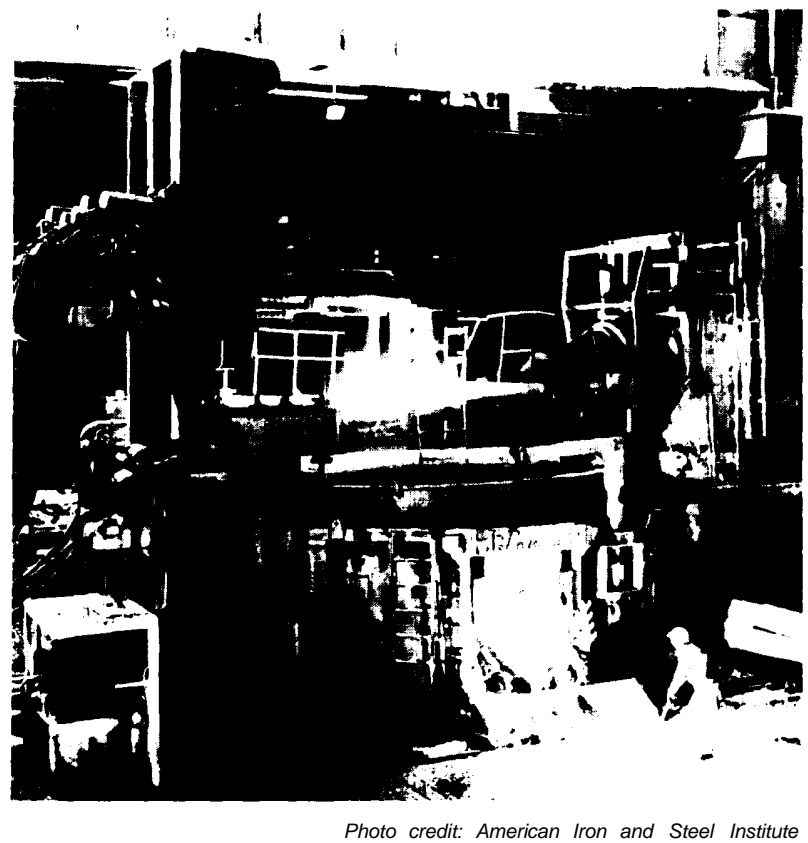

Electric furnace

which might give the United States important technological advantages (some process innovations might, however, benefit other nations more), In any event, modernization and updating of facilities would cost several billion dollars per year-capital that does not seem currently available because of the generally poor profitability of the industry in recent years.' Attracting capital is a challenge that the steel industry shares with electronics, automobiles, and other sectors of U.S. industry-all of which compete for investment funds,

'Ibid., ch. 10,

ports would have taken much more than 18 percent of color television sales for that year if the Orderly Marketing Agreement (OMA) with Japan had not caused Japanese firms to switch to assembly in the United States, Furthermore, table 16 understates the significance of imports because many products assembled in the United States and counted as domestic production include substantial 
Table 16.-Import Penetration in Consumer Electronics, 1978

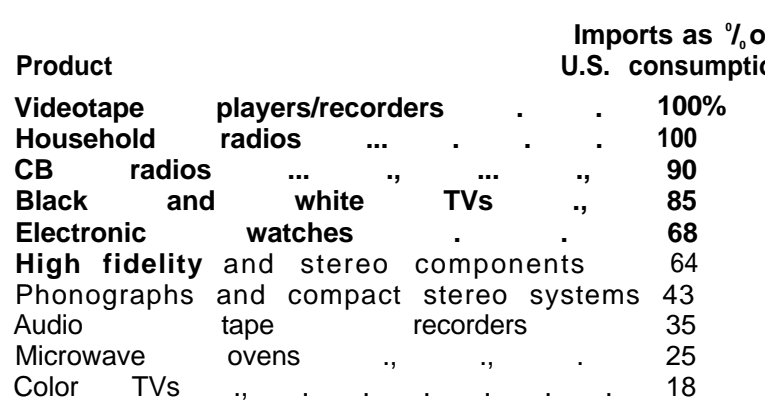

SOURCE The U S Consumer Electronics Industry and Foreign Competition Executive Summary final report under EDA grant No 0626 0700210 Department of Commerce, Economic Development Administration May $1980 \mathrm{p} 2$

foreign value-added. Not only components and subassemblies such as circuit boards, but complete chassis are often imported, though most picture tubes are still made in this country.

Because of rising imports, increased productivity, and the movement by U.S. firms toward overseas production to control costs, employment in consumer electronics has declined dramatically since the mid-1960's. The work force today is barely half the size of 15 years ago, Employment has recently increased slightly, but this has been the result of OMAS insulating the U.S. TV market.

The Move Overseas.-TV receivers-color and monochrome-account for nearly half the total market value of consumer electronics products in the United States; this segment typifies the factors affecting the entire industry.

The first major threat to American manufacturers of TV sets came from Japan, Within Japan, the Ministry of International Trade and Industry (MITI) encouraged and helped to finance the development of transistorized TV designs during the 1960 's. ${ }^{8}$ While much of this work was carried out in the laboratories of Japanese firms, the basic color TV technology was licensed from U.S. consumer electronics manufacturers.

${ }^{\circ}$ E. Sugata and T. Namekawa, "Integrated Circuits for Television Receivers, "IEEE Spectrum, May 1969, p. 64.

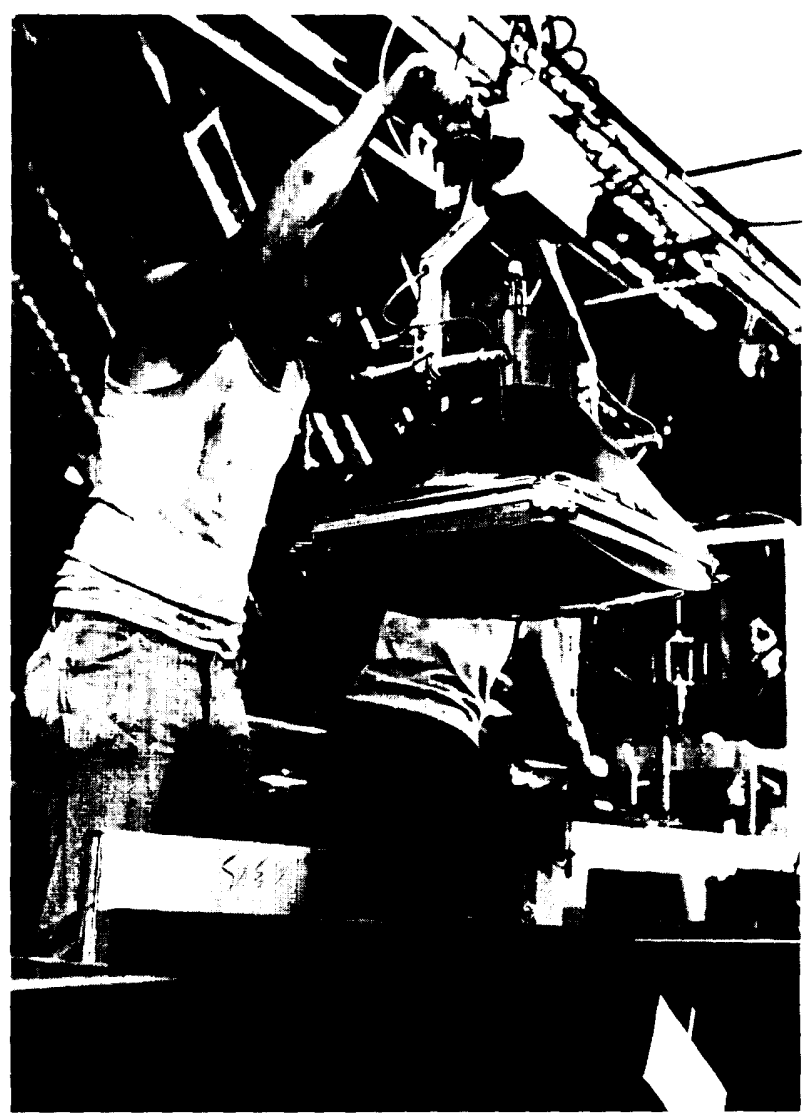

Photocredit RCA

Worker uses an air pressure lift to hoist a 25 -inch picture tube into a console cabinet

Replacing vacuum tubes with semiconductors complemented the overall strategies of Japanese manufacturers. These strategies included the development of large export markets, creating economies of scale. The advantages of transistorized chassis designs (which were developed at the same time in the United States by Motorola) included:

1. Lower manufacturing costs (though at first the transistors themselves were more expensive than the vacuum tubes they replaced), the benefits tending to be magnified at higher production levels because assembly could be automated more readily.

2. A far more reliable product [primarily because of the intrinsic reliability of transistors), reducing the servicing re- 
quired. Japanese firms thus did not need extensive networks of repair facilities in their export markets.

The initial Japanese penetration into the United States focused on particular market niches, notably small-screen sets and private brands (sets sold under the trade names of retailers such as Sears), where low price was critical. Sony, the one exception, chose instead to stress high quality and a prestigious image. Import penetration was accompanied, as for steel, by dumping complaints brought by American firms. The dumping issue is discussed in more detail in chapter 6. While dumping has been proven under U.S. law, it has not been an overriding factor in the success of Japanese TVs in the marketplace.

Prior to the rapid sales gains of imported TV sets, the American market had been dominated by franchised dealers carrying wellknown brand names. However, the Japanese chose to sell through alternative channels such as discount outlets where price was important. Here their reliability advantage came into play, because discount stores rarely offered servicing. The strategy was not without risk, since reliability problems would have reinforced the rather skeptical view of Japanese products then held by many consumers.

As imports found increasing success, American manufacturers responded to the competition's strengths: quality, reliability, and low production costs. American firms typically combined rapid adoption of transistorized chassis designs-more rapid than might otherwise have been planned-with a search for lower cost production methods. Given the spectrum of available production technologies, most U.S. firms chose to lower their costs by moving some of their manufacturing to foreign countries. Low wages were the driving force. While tax havens offered by foreign governments-and U.S. tariff policies that limit duties on reimports after offshore assembly to the value-added overseas -may have encouraged transfers abroad, the basic motivation was to reduce labor costs.

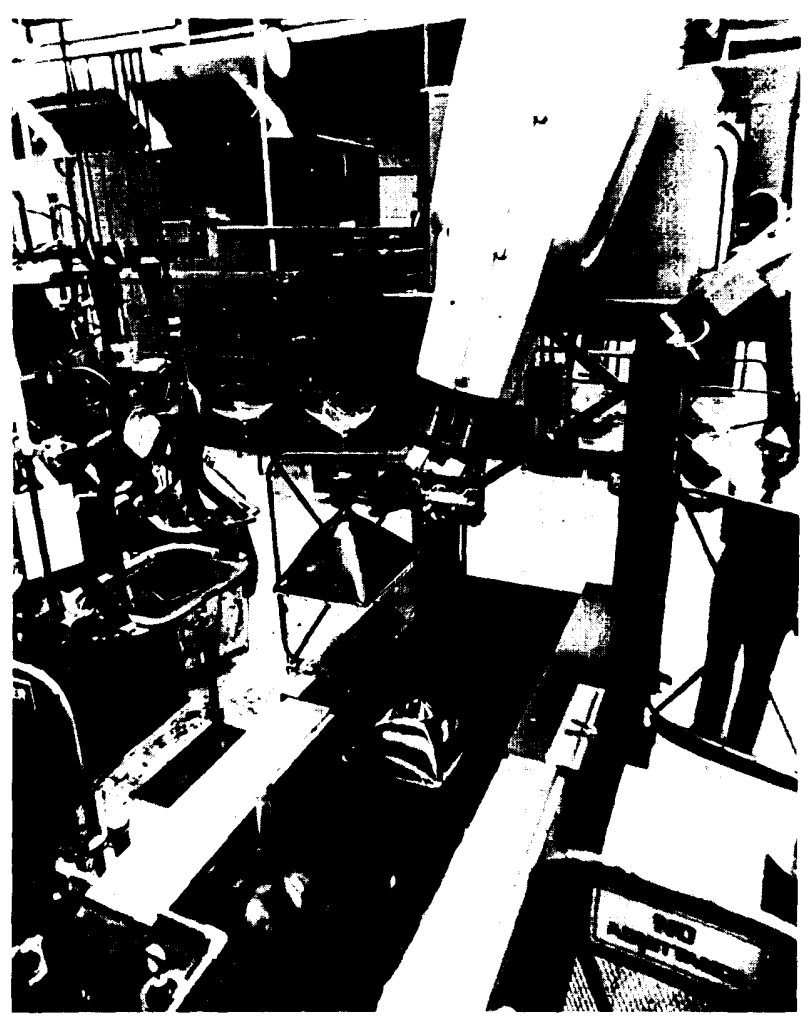

Photo credit RCA

Robot handling TV picture tubes

As if to emphasize that American manufacturers had little choice but to transfer production overseas, the Japanese now find themselves in a similar competitive bind. With wages in Japan rising rapidly, Japanese electronics firms are losing their cost advantages. Faced with increasing competition from rapidly industrializing nations such as Taiwan and South Korea, the Japanese are establishing assembly facilities elsewhere in the Far East. To some extent, moves to other countries were stimulated by OMAs, which at first applied to Japan alone. But even without OMAs, the transfer of production would have become necessary. The United States is not alone in being affected by changing patterns of comparative advantage: Japan has also been a victim-now in consumer electronics, earlier in textiles and shipbuilding, soon perhaps in steel.

Japanese TV manufacturers now have products that rank among the best in features 
and performance, as well as reliability and freedom from service, ${ }^{9}$ Thus there now seems rough technological parity, with Japan equivalent to the United States in product technologies, perhaps superior in process technologies, (Some observers claim that the Japanese are ahead in the use of automation, but little directly comparable data exist,)

Success in the TV market has also given the Japanese an easier entree into markets for other electronics products, as well as carryovers into different industries, Consumers now seem to perceive many Japanese products as good values-well designed and of high quality for the price-whether electronics, automobiles, cameras, or motorcycles.

Research and Development.-R\&D leading to transistorized chassis designs was an important part of Japanese success in TVs. In the United States, consumer electronics firms have not recently seemed vigorous in their R\&D efforts, although firms such as RCA and General Electric have high overall levels of technological capability. In any event, there are signs that consumer electronics R\&D has declined in the face of falling profits, Fewer than 1 percent of the employees in the U.S. radio and TV sector, for example, are engaged in $\mathrm{R} \& \mathrm{D}$. In the electronic components sector, which includes semiconductors, the figure is 3 percent, Significantly more R\&D personnel evidently work on consumer products in Japan. In some respects, the American industry seems caught in a downward spiral - low profits leading to cuts in R\&D, which in

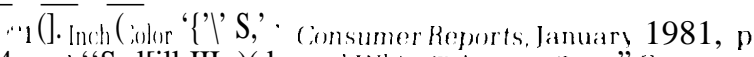
.14, and "Srrl[ill III; )( k-; md-White Televiswon Sets." Consumer Regorts. March 1980 p. 205. Fealures (such as remole I uning]

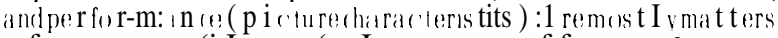

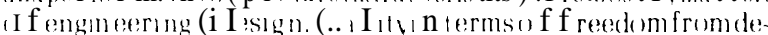
fects, and reliabilits as measured by mean-time-betw een faitureor similat $r$ par $\mathrm{r}$ melers, a realsodependentondesign. However, qua I i t vandrel labi I i t depend as wel 1 on factors such as

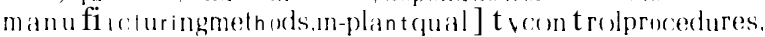
a 110 mall), gem1111 tandorgan izalionof perst ) 11 nel. p: I r tocular 1 , assembl versonnel ' 1 hese are (I fte $\mathrm{n}$ morenearhmanagemen $\mathrm{t}$ thanemgineering func II) ms. Qualitvandrelia [) II] IL, and their sturres, will be (i iscusser $i_{n}$ (let a iln the fortheomng ( )'1 A

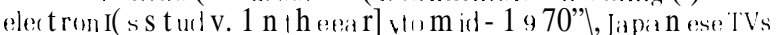
seem to have had t) elter reliabilit $\}$ : while $[1, \mathrm{~S}$. products have since improve ( $i$, Japanese firms have evidentlv been able? to maIntaintheir $\mathrm{r}$ edgen reliabilats turn may lead to fewer product innovations and still poorer performance. The question is: Can the situation be turned around?

The answer may be no. The United States is the world's largest market for video cassette recorder/players, a technology that originated in this country; but these products, even when sold under American brand names, are all made in Japan. The next major new consumer electronics product will be the video disk player. Although the technology remains in flux, Japanese firms are working on all three of the systems being developed. Given their demonstrated ability to rapidly bring new products to market in volume and at low cost, the Japanese may eventually dominate this technology as well. Even if U.S. video disk technologies such as the RCA system emerge as winners in the marketplace, production may move overseas-either to American-owned offshore facilities, or to foreign companies manufacturing under license.

Why are American firms-apparently at the forefront of electronics technologiesdisplaced when products move from $R \& D$ to commercialization, and especially to manufacturing and marketing? One common response centers on production costs, and suggests that the United States simply cannot match Japan in the manufacture of high-quality products at low cost; it is an old answer with some new dimensions. At one time, for many industries, it was claimed that Japan's competitiveness was based on cheap labor, Today this seems less important. Instead, Japan's ability to produce at low cost is often attributed to scale economies and experience (the learning curve phenomenon), and to advantages gained through horizontal and vertical integration-as well as to abundant supplies of investment capital, The export orientation of Japanese firms, and home markets that have been protected-more so in the past than currently-are also factors.

The overall scale of the leading Japanese consumer electronics firms is considerably larger than that of their American counterparts because the Japanese market their 
products worldwide." Manufacturers in Japan thus have potential advantages in economies of scale and experience, regardless of where their production facilities are located, To raise production volumes to match the Japanese, American firms would have to compete worldwide with the Japanese-and the Taiwanese and Koreans. At this late date, that seems unlikely,

The structural characteristics of Japanese firms may also contribute to their performance. Major consumer electronics manufacturers in Japan also make other electrical and electronics products. This integration can in principle yield R\&D synergies, as well as learning economies in component production. Most Japanese TV-makers produce their own semiconductors; at least in theory, semiconductor developments can be closely coupled to the needs of the consumer division. At the same time, consumer goods provide a readymade market for new semiconductor devices, removing much of the risk from their development.

Vertical integration linking consumer products and semiconductors also has negative aspects. The strength of the United States in semiconductors has often been attributed to the dynamic, entrepreneurial character of domestic merchant semiconductor firms. In the United States, large integrated electronics companies such as RCA and GE have not been notably successful in semiconductors, Often, a lack of flexibility is blamed.

Large integrated firms in Japan have developed their own ways of achieving flexibility: use of supplier firms, affiliates, and subcontractors; extensive training programs for employees; and a wage system in which a substantial fraction of annual pay may come as a bonus. Combined with employment policies which give many employees high job security, Japanese firms can move into new areas without creating anxiety in their work force or destabilizing existing activities. Further con-

"The U.S. Consumer Electronics Industry and Foreign Competition, final report under EDA grant No. 06-26-07002-10, Department uf Commerce, Economic Development Administra tion, May 1980. p. 27. tributing factors are management systems that diffuse responsibility widely, so that corporate risk-taking need not imply personal risk-taking; managers do not feel tied to the income statement for the next quarter.

While vertical integration in any country carries both advantages and disadvantages, it does appear that long-term success in the consumer field will require at least some internal capability in semiconductors. ICs are now central to the development of new products. Digital audio, digital TV (the Philips video disk uses digital encoding), electronic toys and games, calculators, home computers-all depend on semiconductor technology; ${ }^{11}$ many of these products are inconceivable without large-scale ICs. (Texas Instruments is an example of a vertically integrated U.S. firm strong in nontraditional consumer products while not making Tvs at all,)

The Future.-Consumer electronics manufacture in the United States has declined markedly; the remaining production is often little more than final assembly. Firms such as RCA, with its video disk, and Zenith, which is entering the home computer market, are certainly not conceding consumer products to foreign competitors: both have also maintained their historical market shares in color TVs. Nonetheless, the traditional home entertainment sector of the industry seems less than dynamic.

When other U.S. firms-mostly semiconductor manufacturers-have attempted to enter consumer markets, they have not always succeeded. The difficulties encountered by new entrants with products such as hand calculators and electronic watches resulted partly from foreign competition, partly from lack of experience in consumer markets, In some cases, products have been designed with little marketing research-perhaps because the companies involved were accustomed to dealing with technically sophisticated purchasers whose needs they under-

\footnotetext{
'M. Kikuchi and Y. Kawana, "VLSI in Consumer Electronics." IEEE Transactions on Electron Devices, vol. ED-26, April 1979. p. 279.
} 


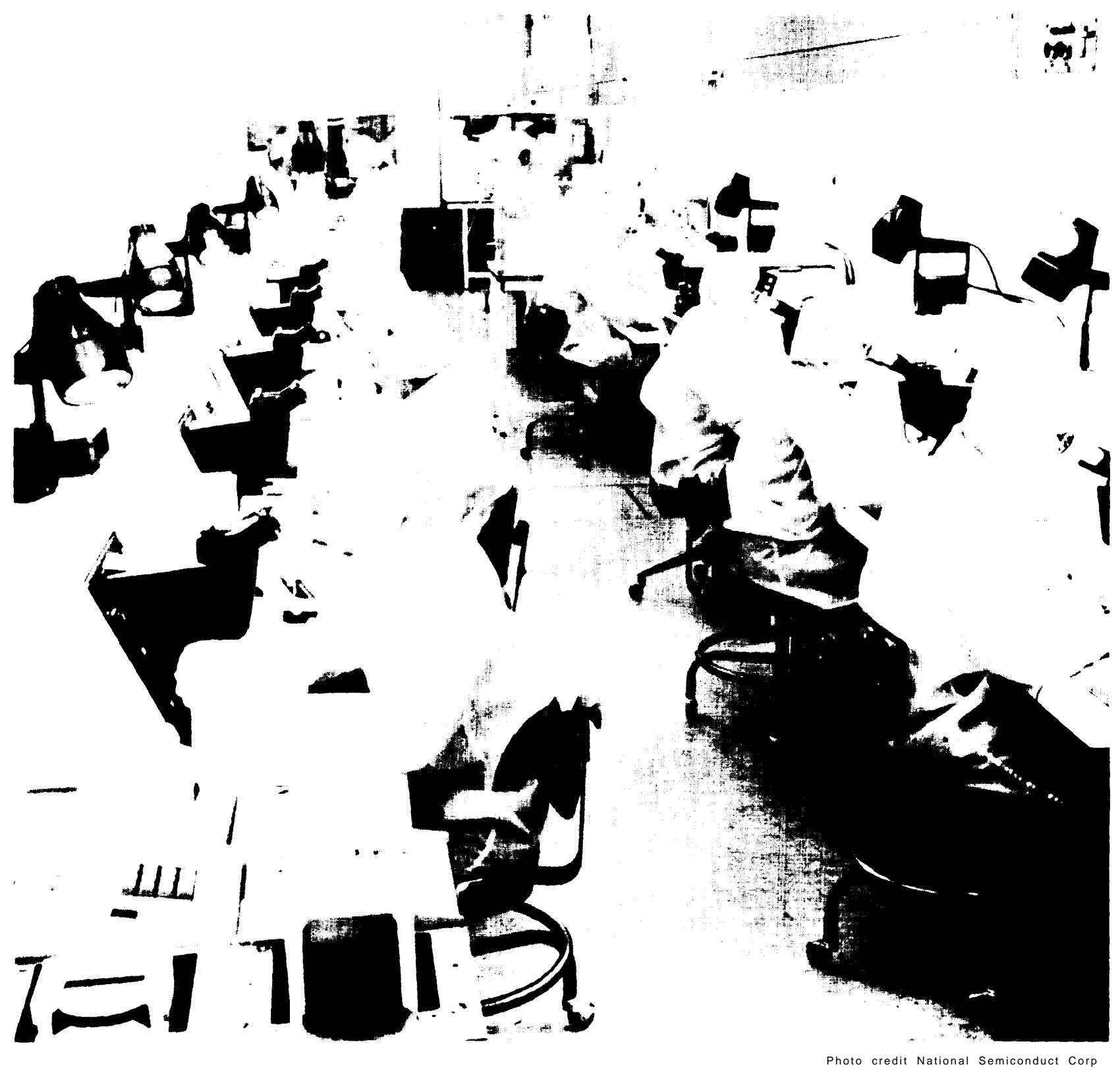

Workers in a clean room testing semiconductor wafers

stood. The Japanese have made such mistakes in the past, but are now more careful in their efforts to anticipate consumer preferences.

Were forward integration by U.S. semiconductor manufacturers to continue-and be successful-the structures of both consumer and component markets would change. In the past, semiconductor firms seldom tried to enter markets, such as radios and TVs, already served by other companies, but developed entirely new products. Such patterns will probably continue because this is where the greatest opportunities lie. New products offer rapid market growth and the chance to establish a strong position ahead of the competition. Costs of production are not so important when a firm can market unique products 
or otherwise attain a technological advantage.

At the same time, today's new product is tomorrow's mature one, and maturity tends to bring intensified competition. The U.S. market remains the largest in the world and will always be an attractive target; so long as Japanese consumer electronics firms are safe from foreign competition in their domestic markets (and in many other parts of the world) they will be a formidable presence here. American semiconductor and computer firms have demonstrated the advantagesperhaps now the necessity-of competing on a world scale, The same may be true in consumer electronics.

\section{Semiconductors}

There are really two semiconductor industries-one consisting of firms selling in the open or merchant market, the other comprised of the semiconductor divisions of integrated companies. The latter may produce exclusively for internal use (captive production), or sell on the outside as well.

Most of the firms in the merchant market began as independent, entrepreneurial concerns. Many have since been acquired by other companies; but the industry is still typified by manufacturers such as Intel (which remains independent), and Fairchild (now owned by Schlumberger, a French concern). Headquarters for most of the merchant firms are in "Silicon Valley," near San Francisco.

The largest of the captive producers are IBM and Western Electric; each is strong in a variety of product and process technologies. Most computer firms design and produce some of their own semiconductors, often lowvolume custom ICs; many other companies are also integrating into semiconductors to be able to supply at least some of their own needs and to have in-house R\&D capability. Some vertically integrated electronics firms -e.g., Texas Instruments and Motorolaalso sell large numbers of semiconductors in the merchant market. Other systems-oriented firms which make and sometimes sell ICs include Lockheed, Rockwell, and Westinghouse.

The number and diversity of firms which design and produce semiconductors attest to the importance of this technology, A strong case could be made in favor of semiconductors and their applications as the technologies most vital to a modern industrial economy.

Although captive semiconductor operations are a substantial source of technological strength for the United States, there is little data available for captives that bears directly on competitiveness. Thus, as in chapter 4, much of the attention below focuses on merchant firms. Nonetheless, captives account for 40 percent of domestic IC production. ${ }^{12}$

Despite recent large increases in semiconductor imports from Japan and the Far East, particularly ICs for computer memory such as the $16 \mathrm{~K}$ RAM, the indicators examined in chapter 4 revealed no evidence of competitive decline by the United States. The 16K RAM is a high-technology device, demanding state-ofthe-art processing capability, but at the same time is a standardized, commodity-like product, As mentioned in chapter 4, Japanese firms evidently have claimed more than 40 percent of the U.S. market for these circuits. The Japanese achieved this penetration by offering high-quality, competitively priced parts at a time when U.S. manufacturers could not meet the demand, The most important reasons for capacity shortfalls by U.S. firms were a reluctance to add new capacity in the wake of the 1974-75 recession, and market demand that was considerably greater than projected. ${ }^{13}$

While semiconductors continue to epitomize U.S. competitiveness, there is concern

\footnotetext{
"Competitive Factors Influencing World Trade in Integrated Circuits, publication No. 1013 (Washington, D. C.: U.S. Inlernational Trade Commission, November 1979), pp. 82, 84. The percentage has been relatively stable over the past few years.

“ "'Effect of RAM Imports Into U.S. Disputed; Shortages Mav Trigger Increases in Prices,"' Electronics, Nov. 8, 1979, p. 40.
} 


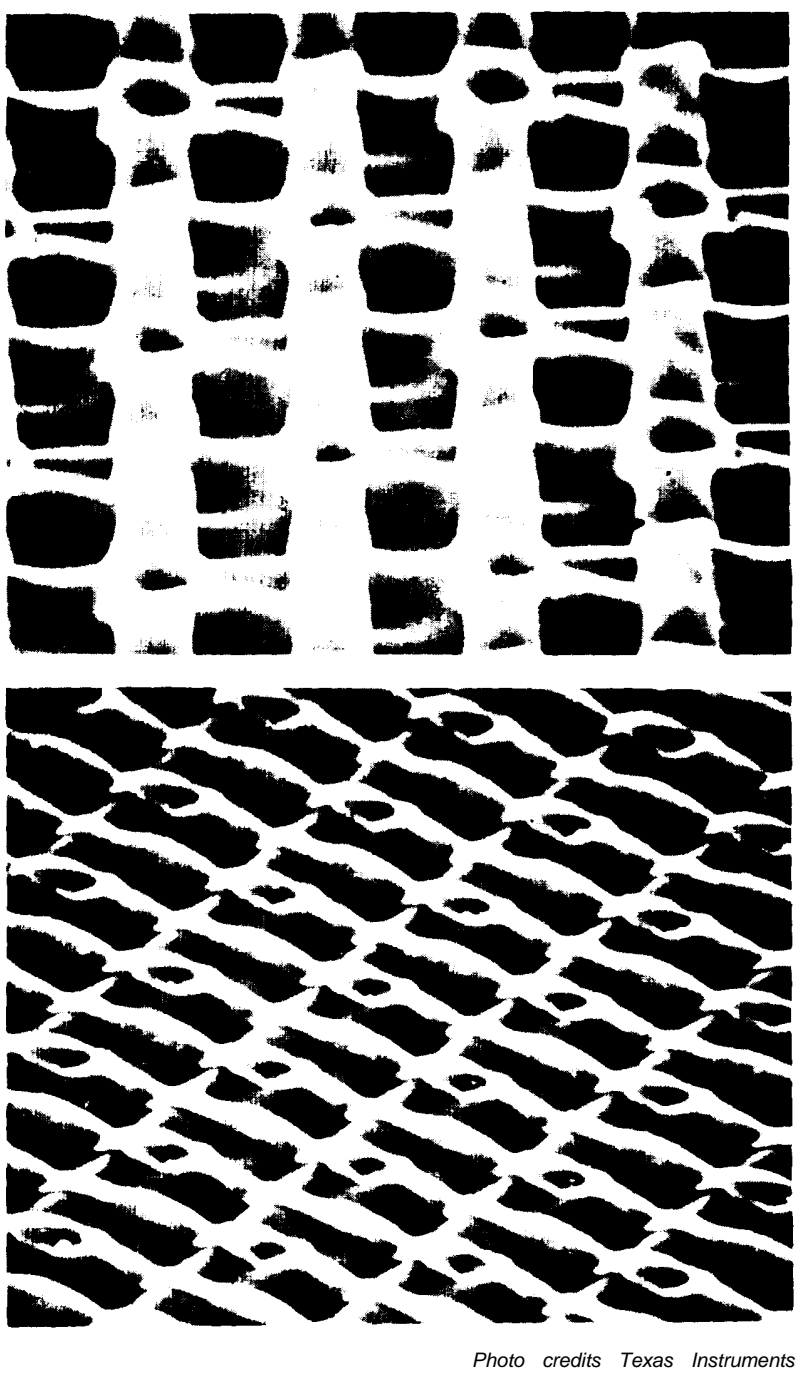

Scanning electron micrographs of memory cells for a $64 \mathrm{~K}$ random access memory (RAM)

for the future of even this sector." It is not based on any perception of imminent distress in the domestic industry, but rather on the extraordinary efforts by companies and governments elsewhere to match or exceed the United States. Production of ICs in Japan has recently grown even faster than in the United States. Through May 1980, Japanese IC production was up 50 percent over 1979: investments by Japanese semiconductor firms dur-

I. Gresser, High Ter hnology and Japonese Industrial Policy

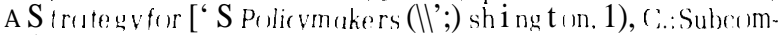
$\mathrm{ml}$ t teeon Trade, Commit teeon Wavsand Means, U.S.House of Representatives. Oct. 1, 1980 ). ing the 1980 fiscal year were scheduled to increase their production capacity by a further 60 percent.

Foreign Competitive Efforts.-As a result of the importance of semiconductors, both commercially and for national defense, governments in virtually all industrialized nations have been concerned lest he technology become a U.S. monopoly.

Such worries have not bee 1 entirely unfounded. World semiconductor sales grew 23 percent last year-ICs even faster-and are expected to increase another 15 percent in 1981, 't) When technology-intensive products experience market growth at rates this high, it is quite possible for some firms-and some nations-to fall behind and never catch up (until the technology stabilizes). Many of the earlier entrants in the U.S. semiconductor market experienced this fate-including a number of large and capable firms-and either accepted a secondary position in the industry or withdrew from the marketplace.

In 1978, nearly one-half of European semiconductor needs - and well over half in ICswere supplied by exports from the United States or by European subsidiaries of American firms. Many European governments have been concerned lest they fail to maintain viable indigenous semiconductor industries; a number have established government support programs, as has Japan. ${ }^{17}$ These programs have sometimes included protective trade barriers, as well as government-funded or subsidized R\&D. For example, in Japan, MITI has sponsored a 4-year cooperative R\&D program aimed at very large-scale integrated circuits (VLSI), one of a number of governmentsupported efforts to enhance the technological capability of the Japanese electronics industry.

"Ilmming Semiconductor Industres, Their Future Examined." Japan Report. Joint Publications Research Service. JPRS L.9314. Sept.26, 1980, p. 41.

"1981 Worla hi/I rketForecast," Electronics Jan. 13, 198 1, pp. 121-144, The percenlages are for the United States.Japan, a nd Wes tern Furope. w hichaccoun $t$ for most sales.

Microelectronics Into the 80's (Luton. Fngland: Mackintosh Public at ions L.td., September 1'179 . 
Japan's VLSI cooperative program involved five leading electronics companies; the government-sponsored portion of the effort ended in the spring of 1980 after expenditures reported at about $\$ 250$ million-shared between industry and government. Some of the MITI funding is supposedly to be repaid in the event of commercial success; other government funding came in the form of loans. A follow-on project aimed at the commercialization of the VLSI technology developed has now begun. ${ }^{18}$ Scheduled to take 3 years, no direct government funding is involved, although incentives such as tax writeoffs are being continued.

Government support programs in other countries tend to follow similar patterns. Some emphasize applications of ICs rather than R\&D on the devices themselves or on processes for making them. Because the Japanese program appears to have been the most successful, and because the Japanese are widely perceived as the only real threat to U.S. supremacy in semiconductors, U.S. and Japanese IC technology are compared in the next section, with particular attention to the outcomes of the VLSI program. (This subject will be treated in more depth in the forthcoming OTA electronics study. )

U.S. and Japanese Semiconductor Technology. - Both discrete semiconductors and ICs were invented and commercialized in the United States. Virtually all major innovations in semiconductors have originated in this country. ${ }^{19}$ American firms have also dominated worldwide sales, still holding more than 60 percent of the world market-a classic example of a technology gap creating the conditions for an internationally competitive industry, Note that this world leadership by the U.S. semiconductor industry occurred while domestic companies competed fiercely among themselves-a competition that has

${ }^{14 \cdot " S e v e n ~ P r i v a t e ~ F i r m s ~ T u r n ~ A t t e n t i o n ~ t o ~ M a k i n g ~ V L S I ~ C i r-~}$ cuits," Japan Economic Journal. Aug. 12, 1980, p. 7.

"A Report on the U. S. Semiconductor Industry (Washington, D.C.: Department of Commerce, Industry and Trade Administration, September 1 979).p. 100. embraced price cutting as well as rivalry in device designs and process technologies.

Although the United States had at one time a technological lead in semiconductors over the rest of the world amounting to several years-a lead that the United States still largely possesses over Europe-the Japanese have managed to close the gap. They are now in many cases at or near technological parity with the United States, and their market power is rapidly increasing. One important force in Japan's ability to catch up was the captive market for semiconductors provided by her strong consumer electronics industry. However, the discrete devices and linear ICs used in consumer products are not as critical to competitive success in semiconductors as the digital ICs that go into computers and other advanced systems. Japan's VLSI cooperative program was intended to strengthen her capability in digital ICs, with the goal of creating a technological base in VLSI adequate to support a globally competitive computer industry.

The VLSI cooperative program concentrated on process technologies, as shown by table 17, rather than device technologies. One reason for the Japanese to emphasize processing may have been to get better cooperation among the participating firms. Although process technology is critical to competitive success in ICs, there is less proprietary knowledge than for product designs.

While it is difficult to locate sufficient information for sound judgments on the technological results of the VLSI program, there

\section{Table 17.-Areas of Concentration of} Japan's VLSI Program

\author{
Process technologies \\ Electron-beam and X-ray lithography \\ Super-clean facilities \\ Large-diameter perfect crystals \\ Improved evaluation techniques for crystals \\ Oxide growth and removal techniques \\ Device technologies \\ Logic design \\ Simulation \\ Circuit layout \\ SOURCE: VLSI Technology Research Association
}


seems to be a consensus in the American technical community that the Japanese have made substantial progress. Although they probably did not reach the goals originally set, the work of the VLSI laboratories in lithography and lithographic equipment is particularly well known.

Nor is it clear to what extent the VLSI program itself was responsible for advancing Japanese capabilities, as compared to the progress that would have been made anyway. The five firms involved are leaders in the Japanese industry, with active R\&D programs and excellent capability. Most likely, the cooperative program did not have extraordinary impact-at least in terms of direct technological payoffs, For one thing, the funding level-somewhat more than $\$ 50$ million a year-was simply not that high (only half of what some individual companies in the United States, such as Texas Instruments, spend annually on R\&D),

In judging the results of the VLSI program, one might also question the extent to which the participating firms would have contributed their best people and best ideas. Japanese firms normally compete strongly with one another, There is no reason to believe that they would willingly share knowledge that might give competitive advantages. Because of the goal-oriented nature of government-industry relations in Japan, the psychological influence of the VLSI program was perhaps as important as the technical outcomes. That is, by providing a highly visible unifying locus for Japan's semiconductor R\&D efforts, the program may have helped stimulate the technological progress of the entire industry, The anxiety aroused within the United States by the VLSI program would have strengthened this effect.

What, then, is the current state of Japanese IC technology relative to the United States? While not an inclusive listing (e.g., it refers primarily to digital MOS technologies), table 18 gives comparisons on several dimensions, based largely on discussions with American engineers. Comparisons, as in this table, always come down to matters of judg- ment, and there are bound to be disagreements; for example, some sources claim that Japan is ahead in silicon materials-i.e,, the ability to understand and control the properties of the crystals from which ICs are made. The breadth of the categories also obscures important distinctions-for example, U.S. firms clearly lead in some types of memory circuits. These caveats do not alter the primary message - that Japan has made considerable progress toward closing the technology gap in ICs.

The United States is ahead of Japan in 2 of the 10 categories included in table 18 , behind in only 1-deep ultraviolet lithography, a technology American firms have largely chosen not to pursue. (The quality question is discussed more fully below.) The majority of the categories in the table deal with processing. Much of the equipment used to make semiconductors is designed and built by independent firms - mostly American-selling on a worldwide basis, Therefore the Japanese have access to essentially the same process technology as U.S. semiconductor manufacturers. However there is a good deal of knowledge and experience needed to use the equipment to best advantage; the table refers in large measure to this sort of capability.

The judgments in the categories for design of memory circuits (e. g., RAMs) and microprocessors are generalizations concerning

\section{Table 18.-Comparison of the United States and Japan in Digital Integrated Circuit Technology}

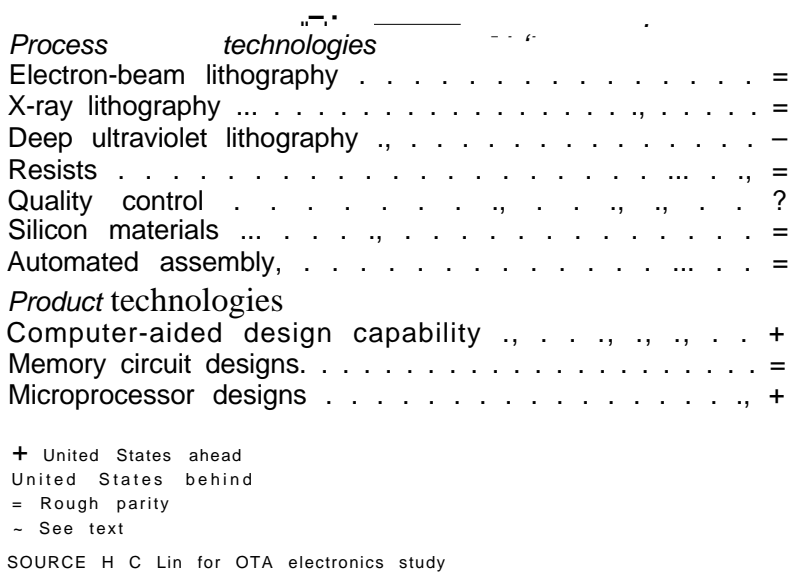


relative capability to design and develop new circuits, not to manufacture them. Designing and building memory circuits is demanding; nonetheless, these ICs are relatively standardized, commodity-like devices-the sort of product in which the Japanese have often proved their strength. At the same time, new standard memory circuit designs have always come from U.S. firms. While Japanese manufacturers have proved they can keep up

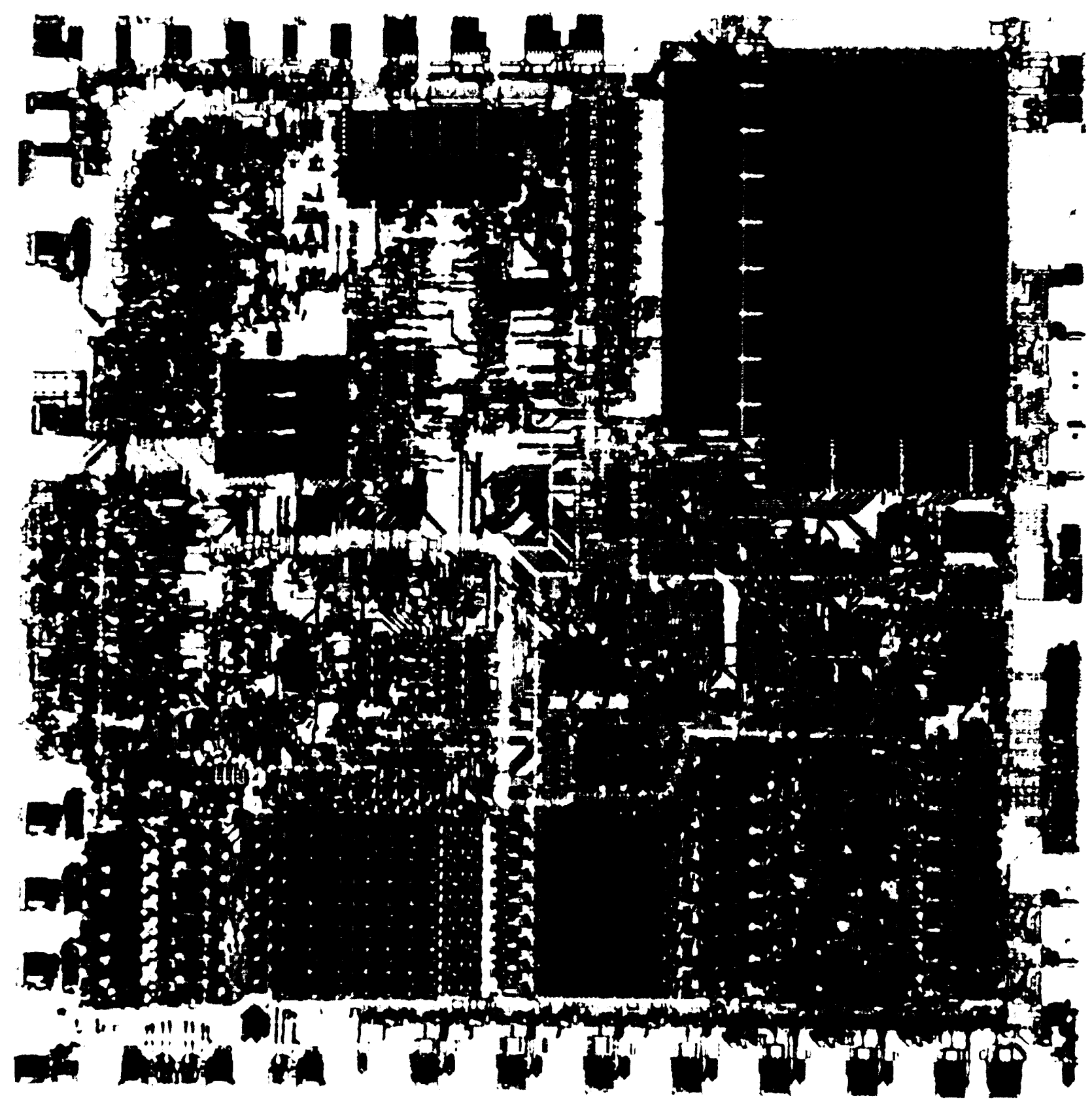


in this technology, they have yet to design a circuit that has become accepted as a standard,

Microprocessors are more difficult to design than memory. The evolution of memory circuits is relatively predictable, at least at present. Microprocessors make greater demands on ingenious design, capacity to innovate, and marketing ability, One of the keys to designing and marketing a successful microprocessor is anticipating the needs of the user; programing ease and flexibility of application - which in turn depend on factors such as instruction sets, architecture, and speed-are important attributes. The United States has always been strong in these areas; thus, it is no surprise that it leads Japan in microprocessors, While it would be wrong to assume that the Japanese cannot innovate in microprocessors or digital logic, there is little evidence that they have yet done so.

One other technology in table 18 might be singled out-computer-aided design (CAD). Designing ICs becomes much more complex, time consuming, and expensive as levels of integration go up. CAD can improve design productivity. This technology-which uses computer software developed especially for circuit design applications-is also one in which the United States is now ahead. CAD will be extremely important for future competitiveness; the present lead is reassuring but needs to be maintained,

The question of IC quality and reliability will be treated at length in the OTA electronics study, but also deserves mention here. Quality refers to the percentage of ICs which meet specifications and function properly on delivery. Reliability refers to frequency of failure in service or average life before failure. Ample evidence exists that, in the past, Japanese ICs sold in the merchant market had higher quality. '(' However, the reliability of U.S. as compared to Japanese ICs is a more clouded issue. American firms claim that

The most dramatic da ta has been presented by, 11) executwe of an Amerie, 111 firm. Hewlett-Packard. See R. Comnolly. "Japanese Make? Quality-control Pitch," Fler tromes, Apr. 10.

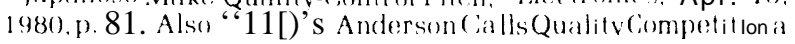
'f lorse Rar (I. 'Flectromurs.Mayl 9. 1981. p. 128, their reliability has always been as good as the Japanese; however, the Hewlett-Packard data-as well as some but not all of the data developed for the OTA electronics studyindicate that Japanese firms may also have had better reliability (for RAMs). Unfortunately, no information is available concerning the quality and reliability achieved by largescale captive producers in the United States-one reason for the question mark in table 18. Firms making semiconductors for their own use have high incentives to maximize quality and reliability because the costs of downstream failures escalate rapidly.

While almost everyone concedes that Japanese quality was at one time better, the U.S. industry claims now to be matching Japanese levels of quality, This assertion cannot be verified; but it does seem that the Japanese remained slightly ahead into early 1981. The reasons for the (past) differences are several, but in the end come down to the strength of management's commitment to quality as a goal of production. Whether improvements in quality add significantly to net manufacturing costs is an important question but one that cannot be answered without a great deal of proprietary data.

The most important facet of the quality issue for competitiveness in semiconductors is the parallel with Japanese penetration of U.S. TV markets. There too, Japanese firms entered the United States with higher quality (and higher reliability) products that helped them gain market share. Although the U.S. TV manufacturers eventually caught up, the Japanese had already established themselves —and remain strong competitors. It appears that the same pattern is being followed in ICs-at least for memory products. (Japanese success in automobiles is also linked to quality and perceptions of quality as selling points. )

Although quality does not appear to have been a particular goal of the Japanese VLSI program, several of the technologies listed in table 17 are important for making ICs to high standards of quality and reliability, And, regardless of final judgments on the success 
of the VLSI program, table 18 indicates that Japan is at or near technological parity with the United States in many important aspects of semiconductor technology. It seems unlikely that Japan will outstrip the United States in R\&D-intensive devices such as microprocessors. However, in the more straightforward memory circuits - and in productivity and quality control - the Japanese have already demonstrated their technological competitiveness. Where success depends heavily on the ability to mass produce semiconductors to high standards, Japan will be strong.

In addition to the privately funded followons to the VLSI program mentioned aboveaimed at applications-MITI is sponsoring a new Japanese cooperative effort in computer software. Like VLSI technology, software is critical for competitiveness in computer systems. Japan has been weak in software; this effort is further evidence of her intent to become a strong global competitor in computers. Japanese firms already have adequate capability in hardware, as discussed below.

The U.S. Government also funds semiconductor R\&D. The Defense Department has recently begun a major effort in VLSI, the Very High Speed Integrated Circuit (VHSIC) program. VHSIC is to be funded at about $\$ 210$ million over 6 years; thus, it is comparable in spending level to Japan's VLSI effort, The basic difference is that VHSIC emphasizes applications to military systems. The Japanese program - as with government support for semiconductor technology in other nations-is directed at commercial technologies, Some of the VHSIC R\&D will yield spinoffs in the commercial portion of the U.S. industry; however, it is too early to judge their potential significance.

Vertical Integration. - As discussed previously, considerable forward integration has been taking place in the U.S. semiconductor industry. While firms such as Texas Instruments and Motorola have always been integrated, other merchant manufacturers are also moving into end-product markets. At the same time, other companies have been integrating backwards into semiconductors, usu- ally to be able to supply some fraction of their own needs. And, in several recent cases, formerly independent semiconductor firms have been purchased, sometimes by foreign concerns. The purchased companies-e. g., Mostek, Fairchild, Intersil-are expected to remain in the merchant market. But the loss of their independence, in the view of some, may threaten the spirit of aggressive entrepreneurship and innovation that has characterized the merchant semiconductor sector in the United States. Although many observers welcome vertical integration as a positive competitive response to changing market conditions-bringing with it infusions of capital and management experience-to others it represents a potential loss of the characteristics that have made the U.S. industry so successful,

There is little question that integration will continue; it is in the strategic interests of the managements of firms that are now in the merchant market, as well as those making end products. More basic questions deal with the capabilities of semiconductor firms to finance further expansion, including forward integration and entry into new markets.

Capital Supplies. - The semiconductor industry has been growing so rapidly that some firms have been hard pressed to generate sufficient cash flow to keep up with internal needs. At the same time, according to many industry spokesmen, external capital has not been available or has been too expensive.

In many respects, the capital needs of the semiconductor sector follow the classical pattern of an industry expanding so fast that it outstrips its capacity for internal funding. Cash flow shortfalls are compounded by VLSI process technologies that are increasingly capital intensive. The capital needs of the U.S. semiconductor industry for the decade of the 1980's have been estimated at $\$ 25$ billion to $\$ 35$ billion, compared to $\$ 4$ billion to $\$ 5$ billion for the 1970 's, ${ }^{21}$ This level of funding

"J.F. Bucy, "Semiconductor Industry Challenges in the Decade Ahead," IEEE Solid-State Circuits Conference, San Francisco, Calif.,Feb. 13-15, 1980. 
may not be available from the capital market on terms the companies find acceptable, Industry leaders contrast this situation with that of their Japanese competitors. Not only does the Japanese Government provide direct R\&D assistance for commercial technologies, but capital is said to be less costly than for American electronics firms, ${ }^{22}$

The same basic argument-that capital costs in Japan are low compared to the United States, in part because of policies followed by the Japanese Government - is made by other American industries. At its root, the argument rests on the structure and organization of the Japanese financial system, its impact on capital formation and, not least, the capital structure of Japanese firms. ${ }^{23}$ These are complex topics, which are deferred to the forthcoming OTA electronics study. Here it is simply suggested that while external sources of capital-primarily debt-do seem available on more favorable terms, the advantages of Japanese firms in terms of internally generated capital may be overstated-except as a function of their relative size (large firms have more flexibility in allocating capital internally). For example, the cash flow available to Japanese electronics companiesbasically the sum of net profits and depreciation-appears generally comparable to American firms. The low profits characteristic of Japanese industry are in many cases counterbalanced by rapid depreciation, That the government channels funds-primarily in the form of bank loans- to support some sectors of Japanese industry is another matter, While this is certainly an important aspect of Japanese industrial policy (see app, D), capital allocation by the Government is a mechanism which U.S. industries would presumably oppose. Likewise, the high debt/equity ratios still characteristic of Japanese firms-though use of debt has been gradually decreasing-

. "[;,S, and Japanese Semiconductor Industries: A Financial Comparison." prepa reel for the Semiconductor Industry Assoriation by Chase Financial Policy. June 9, 1980.

'Or] the first of these, see Y. Suzuki, Monev and Banking in Con temporary lapon (New I Iaven, Conn.: Yale University Press, 1980). For the latter Japmese Corpora te Finance: J977-j 980 (London: In ternational Business In forma tion Inc.. The Financial Times Lid , 1977). would be unacceptable to both managements and lenders in the United States.

\section{Computers}

The international computer industry is similar to the semiconductor industry in several respects. Both have depended for many years on technologies developed primarily in the United States. In both industries, U.S.-based multinationals operate manufacturing facilities in many parts of the world, although there is far less reimporting of computers after foreign assembly than for semiconductors or consumer electronics, Computers, like semiconductors, have been targeted by foreign governments as sectors in which independent strength (i.e., independent of the United States) is a matter of national interest. Although the world computer industry has historically relied on technology licensed from the United States, foreign governments have been uncomfortable with this relationship, Thus, for computers as for semiconductors and steel, there has been considerable government intervention in other parts of the world.

Efforts by foreign countries to strengthen their computer industries have had mixed results, In Europe, despite financial assistance and government-fostered mergers, American manufacturers retain about two-thirds of all sales, U.S. computer technology is more advanced, with European manufacturers often emulating older American developments. Even in Japan, which has restricted both imports and direct foreign investment, U.S. computer firms still account for 45 percent of the market..$^{24}$ If there is an industry in which the United States is internationally competitive par excellence, it would have to be computers.

Any significant changes in these longstanding patterns of competition are again likely to emanate from Japan. The Japanese strategy in computers parallels that used in consumer electronics and semiconductors (as

24"Computers: Can the U.S. Recapture Its Japanese Market," Business Week. Aug. 25.1980.p. 72, 
well as automobiles). Japanese firms have started by building a basic technological capability, largely through licensing arrangements with U.S. firms, They have then proceeded to establish a viable presence in particular market niches, from which more complete market coverage can be attempted. In computers, countervailing strategies by American firms have made this more difficult.

To illustrate, Japanese firms (Mitsubishi, Fujitsu, Hitachi, Toshiba) began by licensing computer technology from the United States, as well as from Europe, In 1960, IBM apparently exchanged its patent rights for permission to begin manufacturing computers in Japan. ${ }^{25}$ IBM now accounts for some 30 percent of Japanese computer sales, a low figure compared to its share in other industrialized nations-where IBM typically has half the market-but impressive for Japan. Thus, the Japanese did not succeed, as they had in consumer electronics, in using entry barriers to protect their fledgling computer industry from foreign competition.

Still, the Japanese have managed great strides since 1970, when they began giving greater attention to computers. Japanese hardware now seems to be largely competitive with American, although until recently their main strength had been in small- and medium-sized systems. ${ }^{26}$ While, in contrast to the consumer and semiconductor sectors, Japanese computer firms have yet to establish any real presence in the U.S. market, they clearly intend to try,

Although Japanese firms have achieved parity or near parity in hardware, they lag significantly behind the United States in software. Because software is a major source of competitive strength in the computer industry, American companies retain an important advantage. Software, and software support, along with customer service in a more gener-

"Y. Kimizuka, Densunki Gyokai (The Computer Industry) (Tokyo: Kvoikusha, 1977), pp. 98-99.

${ }^{2}$ A. Durniak and C. Cohen, "U.S. Beachhead for Japanese Computers Is Only the Start, "Electronics, Mar. 27, 1980, p. 113 . al way, have always been among the strong points of the U.S. industry, especially IBM. ${ }^{27}$

As one might expect, the Japanese were quick to recognize their weakness in software. It is too early to judge the success of the MITI-orchestrated software R\&D effort. The plan, which began during 1980, centers around the cooperative Computer Basic Technology Research Association, which has a 5year budget of about $\$ 235$ million and involves the leading Japanese computer manufacturers. Among the thrusts of the program are networking and data base management, as well as operating systems and Japanese language information processing capability." Based on their past success with other technologies, it seems probable that Japanese computer firms will, one way or another, succeed in largely rectifying their software deficit. Software technology is widespread internationally; just as Japan's automakers have begun to hire American and European stylists, so its computer manufacturers could hire software specialists from other countries if they have difficulty developing indigenous capabilities.

\section{Technical Personnel}

Before leaving electronics, one other potential constraint on the competitiveness of U.S. firms should be mentioned-the supply of technical manpower, particularly electrical engineers, computer scientists, and technicians. This has perhaps been of most concern to semiconductor firms, but also applies to

Many observers have attributed IBM's market positinn to nonhardware factors. See.e.g. B. T. Ratchford and G. T. Ford "A Study of Prices and Market Shares in the Computer Mainframe Industry," Journal of Business, vol. 49, April 1976, p. 194.

\}" Electronic Computer Industry," Japan Report No.115. Joint Publications Research Service, JPRS 77203, Jan. 19, 1981, p. 58. Software costs, particularly for applications programing, are escalating rapidly compared to hardware costs (in all parts of the world) because the productivity of programmers has not been increasing, Generation of software is becoming a significant entrepreneurial activity in the United Slates, with many new en t rants striving to establish themselves in the marketplace. Major innovations in software might tend to unsettle the industry: on the other hand, new programing languages such as Pascal, and now Ada, are forces for standardization and stability. 
computers, indeed to all high-technology sectors of the industry.

At present, recent college graduates in electrical engineering and computer science are in short supply, The problem is one of absolute numbers; but there are also shortages of graduates with particular skills-e.g., the ability to deal with both hardware and software. Demand by employers for new graduates in electronics and computer specialties is expected to rise by as much as 35 percent in $1981 .^{29}$

Part of the reason for the current shortages can be laid to the relatively poor job market for engineering graduates during the early to mid-1970's. The widely publicized slump discouraged many students from enrolling in technical fields. While enrollments have now picked up, the cutbacks in engineering school faculties and facilities that accompanied earlier enrollment declines have not been reversed, in part because engineering enrollments have proven cyclical in the past. Shortages of faculty and teaching equipment presently exist in many fields of engineering - a situation which, if allowed to persist, could have serious long-term consequences for competitiveness in virtually all U.S. industries, as well as for national security.

Japan is now graduating significantly larger numbers of electrical engineers than the United States-one-third more for 1977-the reverse of the situation at the beginning of the decade, and a foreboding sign. ${ }^{30}$ However, the United States has large numbers of midcareer engineers, some of whom are underutilized. There appears to be ample scope and incentive for retraining efforts which would help meet the needs of U.S. industry while also improving career prospects for such people. Many of these engineers missed the IC revolution, and, more importantly, the software revolution. They could benefit greatly

P. Hamilton, "19810utlook Seen as Bountiful," Electronics. Jan. 27, 1981, p.174.

"The Elect rical Engineering Gap: The United States Versus Japan," The Rosen Electronics Letter, Feb. 21, 1980, p. 7, from retraining that emphasized a mix of advanced hardware/software skills.

\section{Comparing the Sectors}

Several of the more important similarities and differences among the three sectors of electronics that have been examined are listed below:

1. The United States no longer has an overwhelming technological leadin any of these sectors, but semiconductor and computer markets are still rapidly growing and volatile; technological change is much faster than in consumer electronics. Major innovations in consumer electronics might or might not upset the current competitive situation in that sector. But the pace of technical change in semiconductors and computers virtually guarantees future shifts in the competitive positions of some firms-e.g., those making products such as microcomputers,

2.In the sectors experiencing rapid growth and technical change-semiconductors and computers - U. S. firms remain highly competitive, Important reasons are their long-standing strength in innovation and their skill at adapting to changing conditions. In contrast, American consumer electronics firms are having difficulty competing on a cost basis in mature products with Japanese and other Far Eastern producers-a similar problem to that afflicting the U.S. steel and automobile industries,

3. Again because of the rapid market growth in semiconductors and computers, employment is rising despite productivity increases. In the mature segments of consumer electronics markets, such as TVs, employment has declinedthough it may now have stabilized. New generations of consumer electronics products could change this, but not if foreign firms take the initiative and become the successful innovators.

4. American semiconductor and computer firms are competing aggressively on a 
worldwide basis with all comers. Furthermore, major U.S. firms, particularly in computers, have achieved a significant presence in the domestic Japanese market. This may be a necessary ingreclient for maintaining global competitiveness. As long as American firms can ac- tively compete inside Japan-which from time to time may demand the support of the U.S. Government-they should be able to remain competitive, though perhaps not dominating world markets as in the 1960's.

\section{Automobiles}

The motor vehicle (automobile and truck) industry in the United States entered a deep recession in sales and employment in 1980, when domestic automakers lost more than $\$ 4$ billion. Production of passenger cars has been falling since 1977, much more steeply in 1980, Sales of domestic cars were lower in 1980 than in any year since 1961. Several hundred thousand autoworkers found themselves laid off. For trucks, the decline was even steeper, with production off by 46 percent. Even for subcompacts, domestic capacity utilization fell; the U.S. industry could have produced as many as 1 million more subcompact and compact cars during $1980 .{ }^{31}$ But as sales of American-made cars dropped, imports from Japan continued to rise (table 19).

While sales of Japanese cars increased steadily through the 1970's, imports from Europe remained more-or-less stable (in the case of West Germany, they have decreased considerably - in part because Volkswagen now assembles cars in the United States). As

"'The Automobile Crisis and Public Policy: An Interview With Philip Caldwell,", Harvard Business Review, January/February 1981, p. 73. table 19 shows, Japan's proportion of imports to the United States doubled from 40 percent in 1973 to 80 percent in 1980 .

The past year was exceptional because in previous depressed markets, sales of both domestic and imported automobiles dropped. For 1980, total passenger car sales fell 13 percent-but import sales went up by 3 percent, while domestic sales were down by 21 percent (table 5 in ch. 4). Sales of Japanese imports increased by 8 percent. Even domestic subcompacts experienced 5 percent lower sales (U.S. full-size cars were down 37 percent). ${ }^{32}$ Such a rise in sales of Japanese cars in the face of recession is striking-and to some observers prima facie evidence of the American industry's loss in competitiveness, The next section considers this question in more detail.

\section{Imports and the U.S. Industry}

Large declines in output are not unusual in the motor vehicle industry, which has a long history of such behavior-associated with

${ }^{2}$ Ward's Automotive Reports, Jan. 12, 1981.

Table 19.-U.S. Automobile Imports by Country of Origin (thousands)

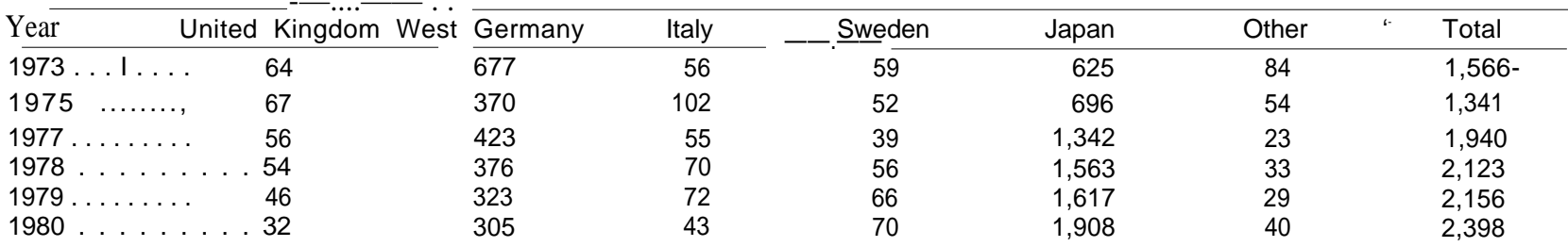

NOTE West German figures exclude production by Volkswagen of America Totals may not sum due to rounding Since 1977, most of the Other"' Imports have been from France 1980 figures are for sales

SOURCES 1973.79-Department of Commerce, Bureau of the Census 1980-Ward's Automotive Reports, Jan 12, 1981 
the business cycle. Furthermore, production tends to fluctuate more than sales, as dealer inventories periodically increase and decrease.

Table 20 and the discussion following treat automobiles and trucks together. The table shows domestic production, plus sales of both domestics and imports, for 1978 through 1980. The peak sales year for passenger cars and trucks together was 1978 , slightly above 1973 (1973 was the peak for passenger cars alone). From 1978 to 1979 , total sales dropped by 1.4 million (9 percent). Sales of American-made cars and trucks fell by 1.76 million (14 percent), production by somewhat less because of inventory buildups. Thus much of the decrease in production and sales of domestic vehicles was the result of slackening demand; regardless of imports, sales and production in 1979 would have dropped.

Much the same was true last year, though the decline in domestic production and sales was steeper. For 1980, total sales, including imports, fell a further 17 percent. However, sales of American-made cars and trucks fell by 23 percent (table 20), Again, a slackening in total demand is responsible for much of the drop in domestic production and sales.

If import penetration had remained at the 1979 level of 19.8 percent, domestic car and truck sales during 1980 would still have reached only 9.2 million-assuming domestics substituted for all the extra imports, This compares to the actual level of 8.6 million, If imports displaced a maximum of 600,000 American cars and trucks, then they can account for only one-quarter of the decline in domestic production and sales.

The 23-percent sales decline for American cars and trucks in 1980 is large compared to the decline from 1978 to 1979 but comparable to that associated with the 1974 recession. Likewise, sales fell by 21 percent from 1969 to 1970. Thus, the drop in sales of domestic vehicles during 1980 is not by itself unprecedented, A major difference is that import sales continued to increase in 1980, while in the earlier recession of 1974-75 they decreased along with sales of American cars. As table 5 showed, import sales fell 20 percent between 1973 and 1974,

A primary reason for increases in sales of imports-even in the face of recession and overall slackening of demand-is the shift in the market to small, fuel-efficient cars triggered by rising gasoline prices, as well as shortages and gas lines during 1979. This is a change with important implications for the current and future competitiveness of American firms. Tables 21 and 22 give distributions by size of sales of all passenger cars in the United States-domestics and importsand of production by U.S. firms. The data show that domestic production (table 22) has been heavily skewed toward large vehicles compared to market demand (table 21). In 1980,45 percent of sales were subcompacts, but these accounted for less than 30 percent of U.S. production. Small cars have always predominated among imports, When this segment of the market became more important (table 21), foreign producers-particularly the Japanese, who have done a better job overall than the Europeans in building strong dealer networks and meeting the desires of American consumers-found themselves with, in effect, a windfall.

The shift of the U.S. automobile market towards small cars has not been clear-cut and unambiguous, There was a movement towards small, high-mileage vehicles as a

\section{Table 20.-Motor Vehicle Production and Sales Figures (thousands of cars and trucks)}

\begin{tabular}{|c|c|c|c|c|c|c|}
\hline Year & & U.S. production & Domestics & Imports & '-Tot al & Import penetration \\
\hline $\begin{array}{l}1978 \\
1979 \\
1980\end{array}$ & $\begin{array}{l}\cdots \\
\ldots, \\
\ldots,\end{array}$ & $\begin{array}{r}\mathbf{1 2 , 8 7 5} \\
11,471 \\
8,012\end{array}$ & $\begin{array}{c}\mathbf{1 2 , 8 9 0} \\
11,132 \\
8,581\end{array}$ & $\begin{array}{l}2,320 \\
2,743 \\
2,883\end{array}$ & $\begin{array}{l}\mathbf{1 5 , 2 1 0} \\
13,875 \\
11,464\end{array}$ & $\begin{array}{l}\mathbf{1 5 . 3} \% \\
19.8 \\
25.1\end{array}$ \\
\hline
\end{tabular}

SOURCE Tables 5 and 6 in ch. 4 
Table 21 .-Distribution by Size of Sales in the U.S. Passenger Car Market (domestics plus imports, percent of total sales)

\begin{tabular}{|c|c|c|c|c|c|}
\hline Year & Subcompact' & Compact & Intermediate & Full size & Luxury \\
\hline 1967. & $9.3 \%$ & $15.7 \%$ & $23.6 \%$ & $47.9 \%$ & $3.10 / 0$ \\
\hline $1970 \ldots \ldots \ldots$ & 17.1 & 19.8 & 23.5 & 36.8 & 2.9 \\
\hline $1973 \ldots \ldots \ldots$ & 26.6 & 16.8 & 23.4 & 29.8 & 3.9 \\
\hline $1974 \ldots \ldots \ldots$ & 26.5 & 22.7 & 24.4 & 22.7 & 3.7 \\
\hline $1975 \ldots \ldots \ldots$ & 30.6 & 22.9 & 23.9 & 17.9 & 4.7 \\
\hline $1976 \ldots \ldots \ldots$ & 24.7 & 24.1 & 27.8 & 18.8 & 4.7 \\
\hline $1977 \quad \ldots \ldots \ldots$ & 27.1 & 21.2 & 26.4 & 20.4 & 5.0 \\
\hline $1978 \quad \ldots \ldots \ldots$ & 26.4 & 22.9 & 26.6 & 18.4 & 5.6 \\
\hline $1979 \ldots \ldots \ldots$ & 34.7 & 20.9 & 23.8 & 15.1 & 5.5 \\
\hline $1980 \ldots ., \ldots$ & 45.3 & 18.6 & 20.5 & 12.0 & 3.6 \\
\hline
\end{tabular}

ancludes all Imports

SOURCES Through 1979-Automotive News 1980 Market Data Book issue, p 16 1980- Ward's Automotive Reports, Jan 12, 1981

Table 22.-Distribution by Size of U.S. Passenger Car Production (percent of total production)

\begin{tabular}{lccccc}
\hline Year & Subcom pact & "C o m p c t & I ritermed i ate & Full size & Luxury \\
\hline $1973 \ldots \ldots \ldots \ldots$ & $10.20 /$. & $18.8 \%$ & $28.0 \%$ & $37.8 \%$ & 5.170 \\
$1974 \ldots \ldots \ldots$ & 15.4 & 27.5 & 28.4 & 23.6 & 5.1 \\
$1975 \ldots \ldots \ldots$ & 12.7 & 30.6 & 27.2 & 23.0 & 6.6 \\
$1976 \ldots \ldots \ldots$ & 7.6 & 33.6 & 30.8 & 22.2 & 5.9 \\
$1977 . \ldots \ldots \ldots$ & 7.7 & 26.9 & 32.0 & 26.5 & 7.0 \\
$1978 \ldots \ldots \ldots$ & 16.4 & 24.4 & 25.1 & 2.5 & 6.5 \\
$1979 \ldots \ldots \ldots$ & 23.8 & 23.4 & 24.0 & 20.4 & 6.5 \\
$1980 \ldots \ldots \ldots$ & 28.3 & 29.6 & 13.3 & 4,7
\end{tabular}

SOURCES 1973-79-Pet/ton for Relief Under Section 201 of the Trade Act of 1974 From Import Competition From Imported Passenger Cars, Light Trucks, Vans, and Utility vehicles submitted by, the International Union, United Automobile, Aerospace. and Agriculturaltmplement Workers of America (UAW), before the US International Trade Commission, June 12, 1980

1980- Ward's Automotive Reports, Jan 12, 1981

result of the "energy crisis" of the mid1970's-when subcompact sales reached 32 percent-then a reversal, as the market for large cars picked up again. This is evident in the domestic production figures for subcompacts and full-size cars in table 22, as well as in the sales figures.

U.S. automakers have made lower profits on small cars than on large because costsboth fixed and variable-have not been as strong a function of size as prices. This situation is changing as new small cars begin to sell at higher prices than the larger models they replace. Despite a reluctance to lose some of the profitability that came with big cars, the failure of American manufacturers to move more rapidly and consistently into small cars was not so much poor judgment as a reflection of contradictory market signals. These signals resulted in part from two concurrent Governmental policies-corporate average fuel economy standards, and continued price controls on oil (as well as low taxes on gasoline) which in turn held down gasoline prices (ch. 6). These juxtaposed policies confused the market and heightened uncertainty among the automakers. The result in 1980 was a mismatch between domestic production and market demand-which is now strongly oriented toward small cars, the Japanese mainstay.

Some American firms have also had difficulty marketing their small cars-particularly those of older design. Ford and Chrysler had considerable unsold dealer inventory in subcompacts during $1980 . .^{33}$ High inventories of small American cars existed despite lower prices for some U.S. models-a price difference which was even greater when discounts

"Auto Situation: 1980) (Washington. D.C.: Subcommit tee on Trade, Committee on Ways and Means, U.S. House of Representatives, June 6. 1980], pp. 25-26. 
for American cars, and surcharges for Japanese imports (occasionally as much as $\$ 1,000$ ) are included. ${ }^{34}$ But while sales of domestic subcompacts actually dropped in 1980, there have been few signs of slackening demand for Japanese cars. American manufacturers are counting on newly designed 1981-model and later small cars to reverse these trends.

\section{Employment}

Production cutbacks such as those that occurred in the U.S. industry in 1980 are always accompanied by layoffs-the unemployed autoworker is not a new phenomenon. From the peak production work force in 1973 to the 1974 trough, employment in the auto industry declined by one-third. This is not to minimize the very real problems created by unemployment in this industry, accentuated by the concentration of automobile manufacture in the industrial Midwest. Furthermore, it is quite possible that the current round of unemployment is more than a short-term problem, But from a policy standpoint, this point is important: Restricting imports of automobiles (from Japan) might ameliorate current employment decline, although the extent of this is by no means obvious (it depends on the number of consumers who would purchase American cars if imports were not available). Restricting imports will not alter in any fundamental way the highly cyclical nature of the industry, nor will it necessarily blunt the difficult, longer term competitive problems faced by U.S. automakers and parts suppliers.

Long-run employment expectations for automobiles are similar to those for the steel industry; the same basic conflict exists between productivity and job opportunities. Were domestic motor vehicle production to recover completely, maintaining or improving U.S. competitiveness would still imply raising productivity — which reduces employment opportunities. Based even on optimistic assump-

"Current Problems of the [1. S, Automobile Industry and Policies to Address Them, staff working paper-, Congressiona 1 Budget of ffice, Natural Resources and Commerce Division, July 1980, pp. 16-17. tions for future sales, some analysts believe auto industry employment could drop permanently by 100,000 or more workers over the next 10 years - to which job losses in supplier firms would add. Slower than expected market growth, along with cyclical down-turns, could raise the figure substantially, Note that this potential employment loss is comparable to total employment in the U.S. consumer electronics industry.

\section{Factors in Competitiveness}

Consumer purchases of Japanese cars are results of product mix, perceived value in terms of design features and equipment, styling, perceptions of differences in quality, and other factors-as well as fuel economy. The competitive situation in automobiles appears to be similar in a number of respects to that in consumer electronics, especially TVs, In both cases, the Japanese entered the United States in particular market niches-small screens, small cars, They established a reputation for well-designed, high-quality products at reasonable prices. In this, they have succeeded in ways that European automakers have seldom managed (Volkswagen is the principal exception), The Japanese have also established strong dealer networks - an important source of their ability to steadily increase sales in the United States.

Much of the product appeal of Japanese consumer goods in general-whether TVs, automobiles, motorcycles-does seem to be nonprice. The Japanese are aggressive marketers-at home, in the United States, and in other parts of the world. They now hire stylists from Europe and the United States, and have rapidly moved from producing cars that were perceived as overornamented and underfunctional to being among the leaders in design.

At the same time, there is nothing new or unusual about Japanese automobileswhether in appearance and packaging, or engineering. Many of the more successful imports are quite conventional, with front engines and rear-wheel drive, While Japanese firms are now building more front-wheel 
drive models, they lagged the Europeans markedly in this trend. However it has not hurt them in the American market. Toyota did not have a front-wheel drive car in the United States until 1980. Datsun entered a few years earlier, but with a car-the F-10-which was widely considered a poor design and which did not sell. The F-10 was quickly replaced by the 310-a model perceived as considerably superior. This is a typical example of Japanese response to consumer preferences. Products that meet with poor response are dropped, generally to be replaced by better ones. The Japanese did not quit the American market when their first offerings proved un- appealing to American consumers; they persisted, and steadily improved their sales. This is the real significance of table 19 .

Except for fuel economy, the success of Japanese imports does not then rest on their technology. In fact, relative technological capability-as opposed to engineering design - does not at present play a major role in the worldwide automobile market. Both product and process technologies are well diffused, with developments such as three-way catalytic converters or robots for automated spotwelding available to all manufacturers. In this respect, the automobile industry is more

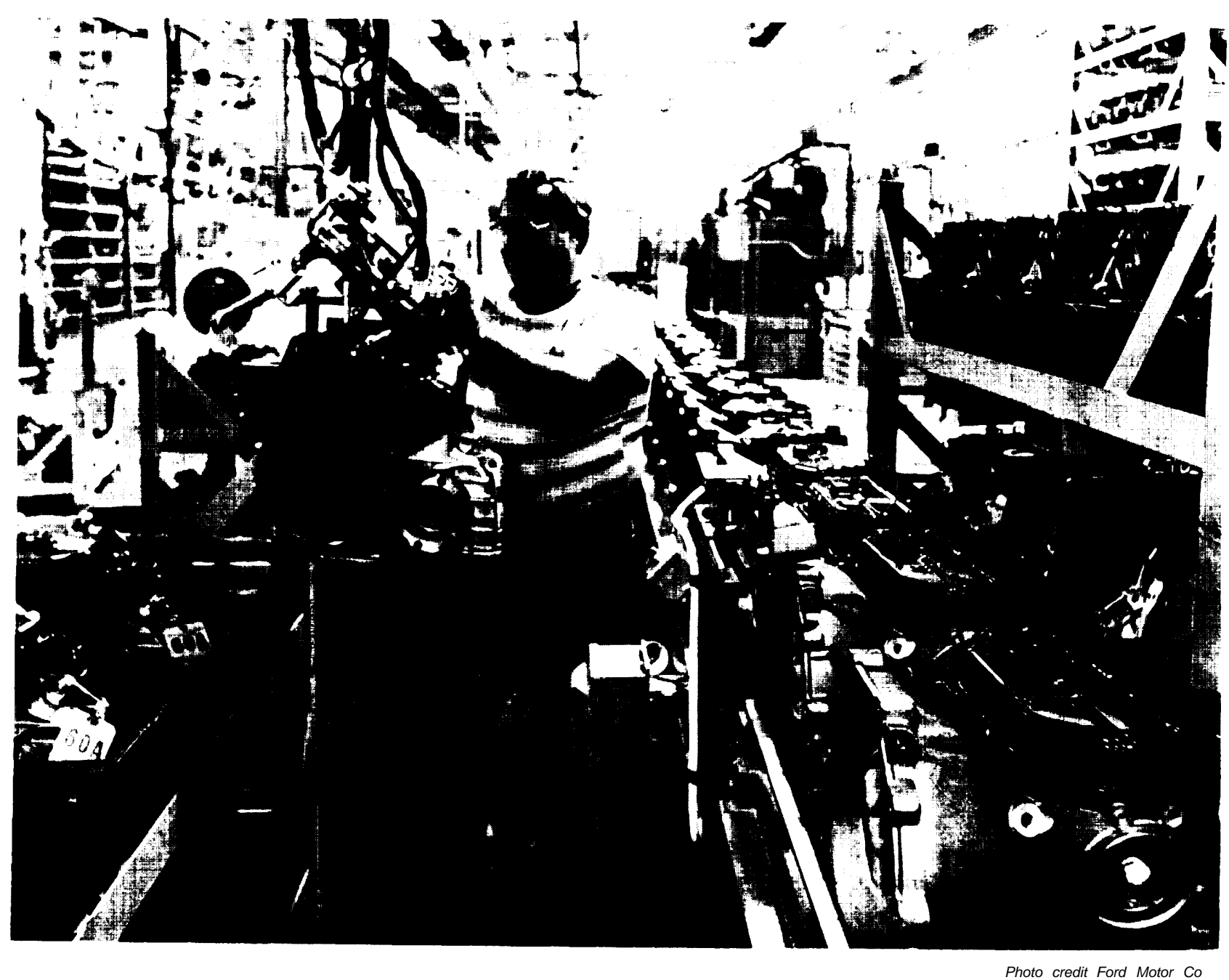

Automatic transaxle assembly 
like steel than it is electronics. In steel, the technology is also a universal one, although there are always pockets of special knowledge. In contrast, for semiconductors and computers, the United States has maintained a technological lead in some areas. This gives U.S. electronics firms competitive advantages that do not exist in automobiles.

Japanese automakers do appear to have significantly lower costs of production than their American counterparts. A cost advantage gives flexibility in developing competitive strategies; for example, quality can be upgraded through better paint and trim, or more standard equipment included for the same price. Most important, lower production costs mean greater margins for cutting prices when sales are slow, as well as higher potential profits for reinvestment or attracting outside capital.

The actual magnitude of the Japanese advantage is uncertain. For subcompact cars, the manufacturing cost differential appears to be of the order of $\$ 1,000$. While shipping may add $\$ 500$ or more, many Japanese imports would still have lower delivered costs than cars made here.

Lower manufacturing costs in Japan stem in part from lower wage rates- especially among suppliers and subcontractors, but also in the Japanese automobile firms themselves -in part from labor productivity that may be somewhat higher than in the United States, and perhaps also from economies of scale. Wage rate differences are probably most important. Other cost elements also vary between the two countries-for example, the Japanese can take advantage of their cheaper steel, Moreover, costs depend critically on production volume-cost curves for automobile manufacture are notoriously steep. The huge losses sustained by U.S. automakers in 1980 stem in large part from low production levels.

For such reasons, estimates of cost differentials are complex and should be approached with caution. Even "comparable" subcompact cars are not the same; costs can be cut by careful engineering design, as well as a good working relationship between product engineering and manufacturing functions. Costs also depend on the extent of vertical integration within a company, which varies considerably between and within the two countries, Japanese automakers subcontract much of their manufacturing; just as for American Motors and Chrysler, they are generally not highly integrated. In Japan, even assembly may be subcontracted. ${ }^{35}$ Japanese automakers rely on extensive networks of affiliated firms and suppliers; they also use contract labor within their own plants. The relationships between the manufacturers and their suppliers are certainly different from those in the United States; in some cases the ties may be close enough that the operations should be considered functionally integrated. But arms-length relationships such as are common in the United States also exist in Japan. Both wage levels and labor productivity are likely to vary among the parent firm, its subsidiaries and affiliates, and other subcontractors and suppliers. Within a given firm in either country, there will be differences from plant to plant and car line to car line.

In the absence of better information, several past estimates of manufacturing cost differentials have assumed that labor content (essentially productivity) for U.S. and Japanese cars was roughly the same, and that most of the Japanese cost advantage came from lower wage rates. On this basis, manufacturing costs in Japan would be $\$ 500$ to $\$ 1,000$ lower than in the United States, ${ }^{36}$

"Japan's Big Automakers Farm Out Work," Japon Report. Joint Publications Research Service I, 9290. Sept. 8, 1980 . p. 34

"R. A. Leone. W. J. Aberna thy, S. P. Bradley, and J. A. Hunker, "Rc ul;i fion and Terehologioal Innovation in the Autemobile Industry, " report to O'TA under cont race No. 9333800.0, May 1980. pp. 52-53; A. Katz. "Statementuf the? Department uf Commerce," World A u to Trade Cu rren t Trents and Structural Problems, hea rings (Washingtom, 1). C.:Suboummittee on Trade. Commi t t eeon Ways and Means, U.S. House of Representatives, Mar. 7. 18,1980). p. 232. one American firm has estima ted labor produrtivity on the Japanese industry to be? 10 percenthigher than in the Lnited States- "Response of Ford Motor Company," World Auto Trude, op. cit., p. 96. The Federal Trade Commission u as unable to verifva productivity 
More recently, some observers have claimed that Japanese subcompact cars embody substantially lower labor content, hence a production cost advantage of $\$ 1,200$ to $\$ 2,000$. ${ }^{37}$ Such estimates are based on reports that Japanese automakers achieve markedly superior labor productivity and manufacturing efficiency through a variety of production engineering and quality control techniques. This seems contrary to the implications of the patterns of productivity growth in motor vehicles shown in table 8 (ch. 4)-36 percent for the United States for the period 1970-79, 77 percent for Japan. Mindful that productivity figures of this sort are not directly comparable, it still appears that the more rapid increase in Japan would, on the average, bring the absolute labor productivity for automobile manufacture in that country closer to, but not necessarily ahead of, that in the United States. Nonetheless, the very high rates of capacity utilization in Japanese auto plants over the past 2 years-coupled with low capacity utilization in the United Statescould result in substantially greater cost advantages for Japanese automakers than would exist if the two industries were operating at comparable levels.

Although there is currently no real consensus on whether labor productivity in the Japanese automobile industry is significantly different than in the United States, some of the concerns now emerging are remarkably similar to those expressed earlier for industries such as steel and consumer electronics. There too, the apparent competitive advantage of Japanese firms was at first attributed

frontimued from page 97 )

adva $\mathrm{n}$ tage for the Ja pa nese -M. P. Lynch.e t a 1., "Comments of the Slaff of the Federal Trade Commission Before the International Trade Commission, Certain Motor Vehicles and Certain Chassis and Bodies Therefor.," Oct.6, 1980, p. 9 and app. A. pp. $11 \mathrm{ff}$.

The Department of Transportation estimate is $\$ 1.500$ to \$2,000-The U.S. Au tomobile Industry. 1980: Report to the President From the Secretary of Trunsportution, publication No. D(YI'-(3-10-8 1-2 (Washington, D.C.: DOT, January 1981), pp. 40-44: Professor W. J. Abernathy of the Harvard Business School now estimates $\$ 1,200$ to $\$ 1,800-N$. Call, "It's Later Than We Think" (interview with Abernathy), Forbes, Feb. 2, 1981 , p. 65 . Both estimates are based on the same unpublished report of a consul ting firm. to cheap labor (and often to unfair trade practices). Later, factors such as productivity, the Japanese work ethic, and the management systems of Japanese firms came to the fore. These are complex and poorly understood topics-several of which will be explored in more depth in the OTA electronics study. But questions of manufacturing efficiency and labor productivity-and their sources-deserve further mention.

Japanese manufacturing industries have in a number of instances demonstrated productivity levels equal and sometimes superior to U.S. industries. Japanese firms have also shown that they can make products of high quality. Relatively high productivity and relatively high quality characterize Japanese manufacturers in industries as diverse as cameras, steel, electronics, and motor vehicles. While some observers stress cultural factors among the attributes contributing to the high performance of Japanese corporations in such industries, it is easy to overemphasize their importance. Many aspects of labor relations in Japan-the multitier labor market, the so-called lifetime employment system, seniority-based pay scales-are based on rational organizational principles.)" Patterns of education and training for employees of large corporations-whether factory workers, technical professionals, or managers-have their sources in the historical development of the Japanese economy, particularly the rapid industrialization which began in the late 19th century. ${ }^{39}$

Corporate management in Japan differs in various ways from that in the United States, but here too cultural factors are only one among the many forces that have shaped the modern Japanese manufacturing organization. To say that Japanese firms achieve high productivity because their employees work hard and long, or that they maintain high

"H. Shimada, The Japunese Employment System (Tokyo: The Japan Institute of Labor, 1980); R. E. Cole, Work, Mobility, and Participation: A Comparative Study of American and Japanese industry (Berkeley, Calif.: University of California Press, 1979).

"S. B. Levine and H. Kawada, Human Resources in Japanese Industrial Development (Princeton, N. J.: Princeton University Press, 1980). 
quality because factory personnel are painstaking and diligent, does little to illuminate sources of competitiveness. After all, most of the techniques of quality control practiced in Japanese factories, along with manufacturing engineering methods of all types, are based on principles developed in the West, imported to Japan, and adapted to Japanese organizations, These methods continue to be taught in American schools of engineering and management, Like product technologies in the steel and automobile industries, they are part of a common body of knowledge available to firms all over the industrialized world.

To leave manufacturing costs and return to the ingredients of successful automobile marketing in the United States, one of the critical factors is certainly the dealership system. When imports-both European and Japanese -lacked large, aggressive, and loyal dealer networks, they were not perceived as serious threats, For many years sales of imports suffered because dealers were few and scattered, spare parts unavailable, service poor, and resale value low. The primary exception was Volkswagen, which established a strong group of dealers during the 1960's. The major Japanese importers have now done the same, as table 23 shows. In many respects, the establishment of a viable network of dealers has been at the center of the strategy of Japanese importers. No doubt they learned from the example of Volkswagen, and the failures of other European firms to establish themselves in the U.S. market. As the table indicates, over the last 5 years the numbers of dealers for U.S. cars have declined slightly, but all the Japanese makes have increased their representation (many dealers sell both imports and domestics). While there are still far fewer dealers for imports, those handling Japanese cars may be healthier. Dealers for Honda, Datsun, and Toyota sell more cars on the average than American car dealers. '(' Their current profit margins should also be high because popular import models have often been in short supply and selling for premium prices,

"Automotive News 1980 Market Data Book Issue, pp. 19, 48.
Table 23. - Numbers of Dealerships by Manufacturer

\begin{tabular}{|c|c|c|c|}
\hline \multirow[b]{2}{*}{ Firm } & \multicolumn{2}{|c|}{ Dealerships } & \multirow{2}{*}{$\begin{array}{c}\text { Percentage } \\
\text { change 1975-80 }\end{array}$} \\
\hline & 1975 & 1980 & \\
\hline $\begin{array}{l}\text { General Motors } \\
\text { Ford, } \\
\text { Chrysler } \\
\text { American Motors } \\
\text { Datsun. } \\
\text { Toyota. } \\
\text { Volks wage n } \\
\text { M a z d a } \\
\text { Honda } \\
\text { S u b a r u } \\
\text { Fiat . . . . . . }\end{array}$ & $\begin{array}{r}.11,860- \\
6,773 \\
5,193 \\
\text { rs } 1,862 \\
. \quad 940 \\
. \quad 947 \\
1,201 \\
\text { a } \quad 375 \\
. \quad 409 \\
. \quad 568 \\
. \quad 691\end{array}$ & $\begin{array}{r}11,425 \\
6.514 \\
4,419 \\
1,701 \\
1,069 \\
1,062 \\
1.015 \\
759 \\
740 \\
738 \\
640\end{array}$ & $\begin{array}{c}-3.7 \% \\
-24 \\
-15.0 \\
-86 \\
+13.7 \\
+12.1 \\
-72 \\
+102.4 \\
+80.9 \\
+461 \\
-7.2\end{array}$ \\
\hline
\end{tabular}

SOURCES: 1975- Ward's 1976 Automotive Yearbook (38th ed. Detroit. Mich. 1976) pp 34119

1980-Automotive News 1980 Market Data Book issue pp. 4854 For both years the number of dealers is that on January 1st

\section{Small Car Strategies of U.S. Firms}

In planning their corporate strategies, domestic automakers did not anticipate that consumer preferences would shift so rapidly toward small cars with good fuel economy, Nor did importers; Japanese firms had large inventories in the United States prior to the doubling of gasoline prices during 1979 and 1980, Before this, big cars had been selling well.

While American automakers have been introducing new-generation subcompactsGM's Chevette in 1976, Chrysler's Omni/Horizon in 1978-their product lines in small cars remain thin. Even with the introductions of the Chrysler K-car and Ford's Escort/Lynx for the 1981 model year, the Japanese manufacturers still offer many more small cars and a broader selection of subcompacts.

Historically, manufacturers outside the United States have stressed small, inexpensive, and economical vehicles. In both Europe and Japan, high gasoline prices and a variety of public policies-e.g., steep taxes on weight, engine displacement, or horsepower-have encouraged small size and good fuel economy. Increasingly, U.S. automakers-who have, after all, been quite successful in many foreign countries-are being forced away from their traditional product strategies in their home market, These strategies emphasized comfort and ride, size, du- 


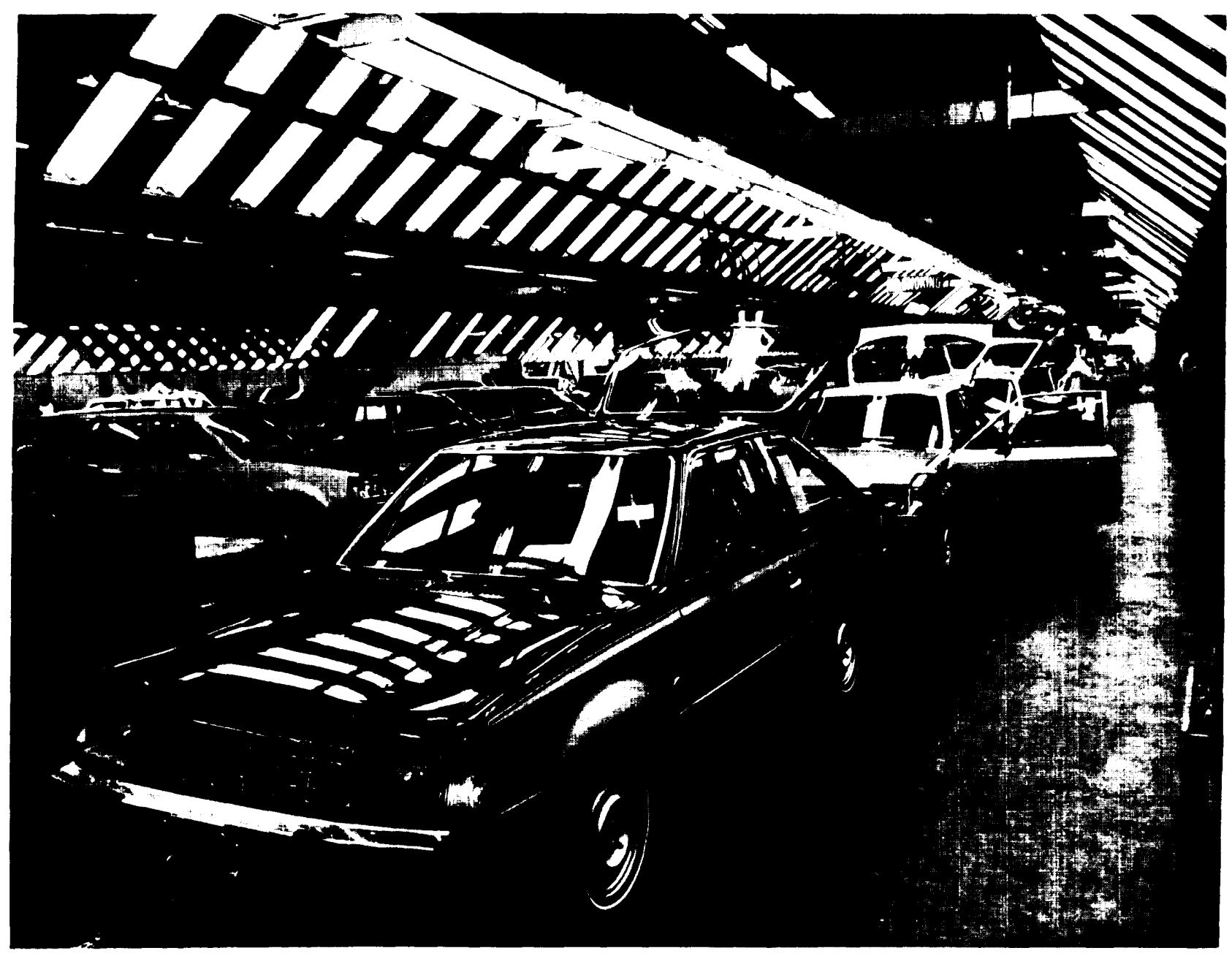

Photo credit Ford Motor Co

Final assembly area for Ford Escort/Lynx

rability, and at times performance. Optional equipment, whether functional or cosmetic, has also been important. Now American manufacturers have to compete in terms of fuel economy and space utilization here as well as overseas, The changes, helped along by Government fuel economy standards [ch. 6), have been sharp. By 1979 the production-weighted average fuel economy of a new domestic car had reached 19.2 miles per gallon, compared to 12.9 miles per gallon in 1974."

"*Innovation and Fuel Economy Among Domestic and Imported Cars, " World Auto Trade: Current Trends and Structural Problems, op. cit., p. 24.
Initial efforts to improve fuel economy focused on weight reduction. The average domestic car weighed $4,35 \mathrm{o} \mathrm{lb}$ in $1975,3,7 \mathrm{oo} \mathrm{lb}$ in 1979. These reductions were accomplished by "downsizing" and shifting to lighter materials-replacing iron and plain carbon steel with plastics, aluminum, and high-strength steel. More front-wheel drive cars are now appearing. These save weight primarily by allowing overall vehicle size to be decreased for given interior dimensions.

During the 1970's, American firms also began more actively marketing captive imports-small cars produced by wholly or par- 
tially owned foreign firms. As American manufacturers are currently unable to count vehicles in their corporate average fuel economy figures unless the value-added in the United States is greater than 75 percent (scheduled to be reduced to 50 percent for the first 150,000 cars by the Automotive Fuel Efficiency Act of 1980), the incentives to sell captives have not been great.

A side-by-side comparison of U.S. and imported cars by weight class, table 24 , reveals that American automakers are competitive in fuel economy. However, the table also shows how slim American product lines are (or were in 1979) in the lower weight classes and smaller sizes. While the domestic manufacturers had no models in the lowest weight class - 2,000 lb-there were 10 imports. As it happens, two-thirds of import sales in 1979 were in the 2,500-lb weight class and below, against only 7 percent of domestic sales. In contrast, almost 80 percent of domestic sales were in the 3,500- to 4,500-lb classes. The average fuel economy of domestic cars does exceed that for imports in each category where comparisons are possible except the 2,50()-lb weight class, where the difference is small.

It appears that a significant part of the current difficulties of American firms stems from the thinness of their product lines in the small car classes which are becoming more and more popular (e.g., table 24, also tables 21 and 221. Even for the 1981 model year, the top 20 cars in EPA mileage rating are foreign in manufacture and/or design (the Volks-

Table 24.- Fuel Economies of Domestic and Imported Automobiles, 1979

$\begin{array}{lccccc}\begin{array}{l}\text { Weight } \\ \text { class }\end{array} & \begin{array}{c}\text { Number of } \\ \text { models }\end{array} & \begin{array}{c}\text { Average } \\ \mathrm{mpg}\end{array} & \begin{array}{c}\text { Number of } \\ \text { models }\end{array} & \begin{array}{c}\text { Iverage } \\ \mathrm{mpg}\end{array} \\ 2,000 & \mathrm{lb} & 0 & - & 10 & 32: 6 \\ 2,500 & \mathrm{lb} & 11 & 281 & 34 & 28.3 \\ 3,000 \mathrm{lb} & & 47 & 224 & & 21.4 \\ 3,500 & \text { Ib } & 65 & 197 & 20 & 18,5 \\ 4,000 & \text { Ib } & 56 & 17.4 & 9 & 15.1\end{array}$

SOURCE: World Auto Trade Current Trends and Structural Problems hearings (Washington D C Subcommittee on Trade Committee on Ways and Means U S House of Representatives Mar 7 and 18 1980) p 25 Averages are not sales weighted wagen Rabbit diesel is made here but was developed in Germany). Furthermore, many consumers, faced with a choice among two or three variations on a domestic subcompact, or half-a-dozen Toyota models, might well find a particular Toyota that was more appealing to them, The product strategies of the Japanese firms-emphasizing variety, as well as quality and fuel economy-thus seem to be working well (many buyers now rate imports distinctly superior in quality"),

To keep up with the changing market-and with Government regulations for fuel economy, emissions control, and safety -U.S. automakers continue to face large capital expenditures. These have been estimated at $\$ 70$ billion for the period 1979-85 ${ }^{43}$-more than half to be spent in the United States. It seems likely that even GM will need to borrow-perhaps $\$ 5$ billion to $\$ 10$ billion-to accomplish the redesign and retooling required. Ford has already borrowed, and has also announced cutbacks on planned expenditures because of disappointing cash flow. Chrysler's precarious financial situation is well known. Foreign firms do not have to invest at comparable levels because they already produce mostly small cars.

Assuming investment funds were available, would U.S. firms be able to compete effectively with imports in the compact and subcompact classes? Past experience indicates that this may not be as easy as some have assumed. To begin with, the import market share is now 25 percent nationally-and considerably higher for subcompacts. Import sales have been at 50 percent in California, a bellwether automobile market. "History suggests that market share losses are not easily reversed in the short run. Furthermore, the Japanese have clearly established their credibility with the American consumer, They have reputations for building high-quality

\footnotetext{
"R. Irvin, "Japan: Quality Cars." Autoweek, July 21, 1980. p. 10.

"The L. S, Automobile Industry 1980: Report to the President From the Secretary of Transportation. op. cit..pp. 65-66.

"P. E. Hollie, "Foreign Car Surge in California," New'York Times, Mar. 26, 1980, p. 111,
} 


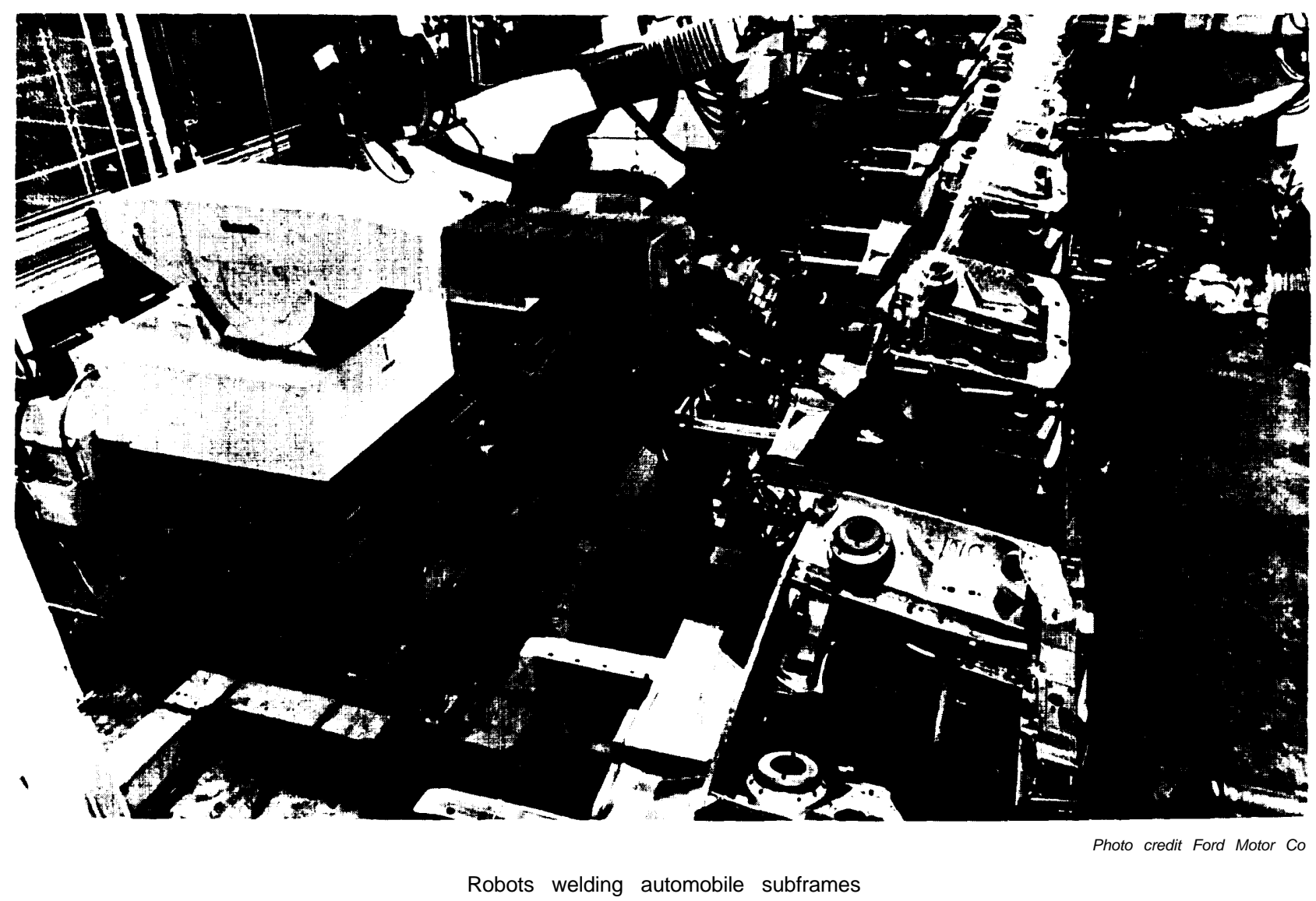

cars at reasonable prices-cars that do not require frequent repairs and that have good resale value. Their dealer organizations are strong. Lower manufacturing costs give them freedom to cut prices to maintain sales. American automakers have proved that they can compete in Europe and elsewhere with small cars; the extent to which overseas experience can be transferred back to the United States will be an important element in their long-run competitive prospects.

\section{Summary and Conclusions}

The competitive positions of firms in each of these industries result from complex sets of factors-some quantifiable, others intangible. Each sector is increasingly challenged by competitive pressures on a worldwide basis - a common theme for U.S. industry.

A distinguishing feature of the steel industry is its wage pattern. That pattern shows a tendency, accelerating in recent years, for wages to increase faster than the national average in manufacturing. Wages in foreign steel industries have also been going up. But while the American steel industry has achieved productivity gains similar to those of European steelmaker, productivity increases have been greater in Japan. Most U.S. firms have been unable to effectively compete for export sales with the lower priced (but sometimes higher cost) products 
offered by foreign steelmaker. They have also been in a poor position to combat imports and dumping at home,

Although steelmaking costs in Europe are generally higher than for American firms, the marginal cost export pricing strategies followed by many European steelmaker lead to import sales in the United States at dumping prices. In contrast to the Europeans, Japan's steelmaker have a production cost advantage-stemming from factors such as more modern plant and equipment, lower wages, exchange rate effects, and a well-developed raw material supply network, The hard fact is that the Japanese have become very efficient and aggressive competitors.

Employment in the American steel industry has declined by more than 20 percent since 1965. However, the major cause of falling employment has not been rising imports, but rising productivity. Moreover, to increase the competitiveness of the steel industry its productivity will need to be further increasedfor example, by modernizing its plant and equipment, Employment will thus continue to decrease unless production expands. Because of slow domestic market growth, the only way to expand production sufficiently would be through exports - which is unlikely, given excess world steel capacity (there may be promise in exports of alloy/specialty steels). At current production levels, then, goals of improved international competitiveness and stable or rising employment in this industry are fundamentally opposed.

This tradeoff between employment and productivity is a subset of a larger group of domestic and international economic problems. Economic growth is the single most important determinant of demand for steel; in a climate of domestic and international economic slowdown, it is especially difficult for the U.S. industry to increase its share of a sluggish world market. With excess capacity the current norm in industrialized nations, and increased capacity the trend in newly industrializing countries such as South Korea and Mexico, the American steel industry is likely to continue to diminish in importance relative to the rest of the world.

Among the positive signs is the scope in the United States for modernization, and for process $\mathrm{R} \& \mathrm{D}$ aimed at lower costs and higher productivity (which would however decrease employment opportunities). Changing demand patterns-toward higher strength, more expensive steels - also provide opportunity for the domestic steelmaker. Increasing the technological content of the industry's offerings is one way for it to compete against international rivals who can sell standard products more cheaply.

Imports and foreign production have had greater impacts on consumer electronics than on any other sector OTA has examined. Over the last 15 years the size of the work force has been cut in half and the overall position of U.S. companies in the domestic market has declined markedly, The success of Japanese TV manufacturers in penetrating particular market niches, and then expanding through emphasis on low-priced, highquality products has been remarkable. Were it not for OMAs set up to regulate the flow of imports, the position of American color TV manufacturers would have eroded even further.

A renewed commitment to $R \& D$ in hightechnology consumer products could be one path to enhanced competitiveness for U.S. manufacturers, New products that rely on semiconductor devices may provide opportunities for the stronger U.S. firms in the oldline home entertainment sector, as well as for new entrants from other parts of the electronics industry. While there are potential disadvantages as well as advantages to vertical integration, forward integration by semiconductor firms may be increasingly attractive as the value-added in consumer electronics becomes more heavily concentrated in integrated circuits.

It is probably not an exaggeration to say that the semiconductor industry-and particularly, the applications of semiconductor 
technology-are now the ingredients most vital for the future of an advanced industrial economy. From the U.S. perspective, the semiconductor industry is also notable in that, while American firms are currently extremely competitive worldwide, there is concern about the future because foreign firms and governments have set out to systematically advance their technological capabilities, as well as their market positions,

In semiconductors, more than steel and autos, technology is a primary focus of concern. American companies were responsible for the initial development of most types of semiconductor devices, but recently the technology gap between the United States and Japan has narrowed. Japanese firms are now at or near parity with the United States in many areas, helped by R\&D support from the Japanese Government. Although Japanese companies are unlikely to overtake their U.S. rivals in ICs such as microprocessors that depend on clever design, the Japanese have already demonstrated their capabilities in more straightforward circuits.

While Japan's cooperative VLSI program has been important, the major impact of this government-sponsored effort was perhaps less a matter of technology than psychology, By providing a unifying focus for $R \& D$, such cooperative projects contribute to the technical capability of Japanese firms both directly and indirectly.

A deserved reputation for high quality has also contributed to the competitiveness of the Japanese electronics industry. This is an area where U.S. firms have renewed their efforts; but the Japanese will undoubtedly also continue to progress.

U.S. semiconductor firms face rapidly escalating capital requirements for $\mathrm{R} \& \mathrm{D}$ and to meet the growing demand for their products. Vertical integration will continue in the United States; it is in the strategic interests of the managements of firms now in the merchant market, as well as those that make end products. Mergers and backward or forward integration can give complementary product lines, captive markets, synergistic environments for $\mathrm{R} \& \mathrm{D}$ and product development, and sometimes capital,

In computers, American firms have always been extremely competitive. Here, as for semiconductors, the real question is whether U.S. firms will be able to maintain their positions. Past efforts by foreign firms to compete directly with IBM and other U.S. computer manufacturers have seldom had much success. Even in Japan, where measures were taken to promote domestic firms and discourage imports, U.S. producers still account for 45 percent of the market.

The advantages of U.S. computer manufacturers have come from extensive service and support capabilities and broad product lines, as well as their technology, American firms have dominated hardware as well as software developments, and have also become skilled at marketing on a world scale, These determinants of competitive success are unlikely to change, even amidst the market shifts associated with the increasing relative importance of minicomputers and microcomputers, and the blurring of boundaries between the computer and the communications industries. Software will continue to grow in significance-an area in which the Japanese industry has been weak, but one which it has targeted for development.

For automobiles, as for steel, import penetration is nothing new. While the recent downturn in sales of domestic cars has precedents, given the cyclical behavior characteristic of the industry, the important fact is that more than 25 percent of the U.S. market is now taken by imports (and import penetration is even higher in the most popular subcompact class). The Japanese have led this wave of imports; since 1973 the Japanese share of all imported cars sold in the United States has gone from 40 to 80 percent.

While some have argued that imports are the primary cause of the apparently declining competitiveness of U.S. automobile firms, it is difficult to make this case. Although Japan's automakers have real advantages in lower 
manufacturing costs, some Japanese carslike some Japanese TV sets-have the proven ability to command premium prices in the American market. Among the reasons for lower production costs in Japan are the extensive use of affiliated and subsidiary firms and subcontractors - which may depress average wages.

A considerable portion of the difficulty experienced in 1980 by U.S. automakers was the result of economic recession and nonprice factors, including the sudden shift in consumer demand to small cars-caused by recent jumps in gasoline prices. Still, much of the sales decline since 1978 can be attributed to a shrinking market, with perhaps onequarter representing domestic production displaced by imports. A major part of the problem has been a mismatch between product design and market demand. The product lines of the American firms are thin in small cars, particularly subcompacts-which are taking a much larger share of the market than as recently as 1978. Imports offer wider selections of subcompact models. Moreover, consumers regard them as high quality, well designed, and good values. U.S. companies remained in a reactive position in this portion of the market through 1980, While new 1981 U.S. models may reverse some of the losses of the last 2 years, Japanese imports are now well established in the United States; American firms can expect difficulty in regaining market share.

The costs of the current decline fall heavily on unemployed American automobile workers. The magnitude cf employment losses, and the regional concentration of the problem, suggest a need for public policy measures to more effectively deal with such dislocations (ch. 8). Because of the tradeoff between productivity and employment, jobs in the domestic automobile industry will not regain their former levels even in good sales years.

Despite the differences among these industries, there are common themes. All three, like their counterparts abroad, are now more exposed to the rigors of international com- petition. The U.S. market in these sectors is also a much smaller fraction of the total world market than in the 1950's. American firms which do not export or manufacture overseas are bound to shrink in relative importance.

Profits have declined-in some years disappeared-in steel, consumer electronics, and automobiles. This cuts into the cash flow available for modernizing and rebuilding competitiveness. Statements focusing on the need for capital to foster competitiveness have come from leaders of all three industries, and from other sectors of the American economy. If universally true, they would be a severe indictment of domestic capital markets-usually thought to be the best developed in the world. However, each industry has different reasons to advance for the causes of its capital shortfall. In semiconductors, it is primarily rapid growth and the rising capital-intensity of VLSI. In steel, expenditures are needed to meet environmental and workplace standards, as well as to replace outmoded plant and equipment. The automobile industry must spend large amounts on redesign and retooling to produce small, high-mileage cars, In each instance there does in fact appear to be a good possibility that the market will not supply all the funds that industry desires. This is typically because expected returns are lower than for alternative investments.

The problems that have been described typify the dilemmas which other U.S. manufacturing industries face, or will face in the not-too-distant future. Perhaps the most important conclusion, illustrated by all three industries, is that the technological advantages possessed by American firms in the earlier postwar period have now been significantly eroded, Even in electronics, where American companies have been world competitors par excellence, the U.S. technological lead is in many cases now marginal.

A second and related theme is the cost of declining competitiveness. The benefits of international trade and competition are signifi- 
cant-e.g., in bringing new products to consumers, often at lower prices. Increased competitiveness and productivity can raise living standards and slow inflation, But there are also serious losses. Declining employment opportunities in steel and automobiles stem mostly from productivity growth, Nonetheless, imports always cost U.S. jobs, The loss in employment opportunities has its most serious impacts on particular regions and groups. The inescapable fact is that the structural changes underway in the United States and the world economy entail long-term employment declines in traditionally important sectors of the economy, 
CHAPTER 6

\section{Government Policy Effects on the Three Industries}




\section{Contents}

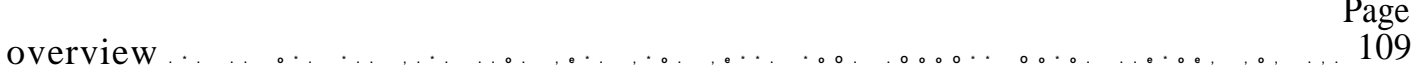

Steel ${ }^{*}{ }^{*}{ }^{*} 9^{* *}{ }^{*} .{ }^{* * *} .{ }^{* *} . .^{* * * * *}{ }^{* *} .{ }^{* *} .0 \mathrm{e}^{* *} \mathrm{e}^{* * * * * *} .^{* * * * * * * * * *} .^{* *} .^{*},{ }^{* *} 110$

Wages and Prices ., .................................. 110

Trade Policy. . . . . . . . . . . . . . . . . . . . . . . . . . . .................111

The Solomon Plan . . . . . . . . . . . . . . . . . . . .........................112

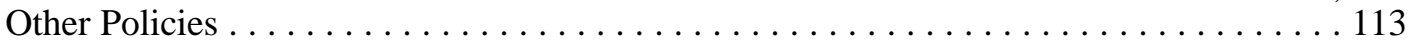

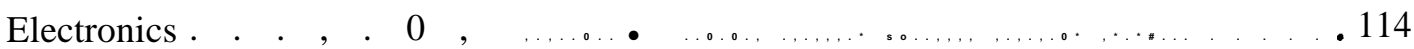

Consumer Electronics . . . . . . . . . . . . . . . . . . . . . . . .......................114

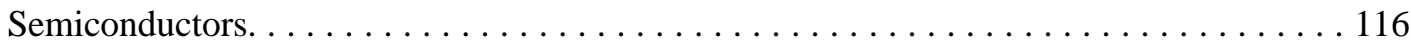

Computers . . . . . . . . . . . . . . . . . . . . ...... \$ .............117

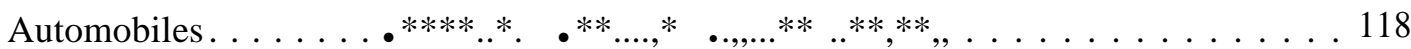

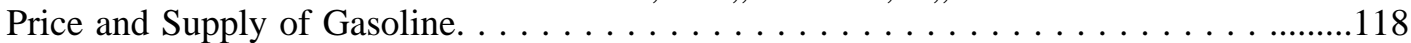

Roads and Highways. . . . . . . . . . . . . . . . . . . . . . . . . . . . . .......120

Regulation . . . . . . . . . . . . . . . . . . . . . . . . . ..................120

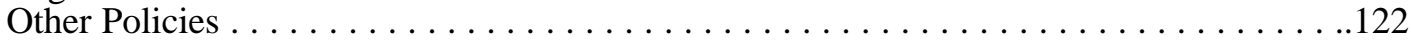

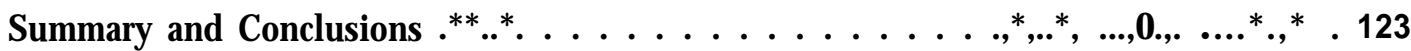




\section{Government Policy Effects on the Three Industries}

\section{Overview}

This chapter outlines some of the more important ways that policies pursued by the U.S. Government have affected the steel, electronics, and automobile industries; chapter 7 will then consider their future prospects based on a variety of factors, including public policies.

Despite the many policies that influence the international competitiveness of American industries-directly, as do U.S. foreign economic policies, or indirectly, as do tax policies-competitiveness itself has rarely been a primary or even a secondary concern of the Government. And, because most policies are pursued for other reasons, judgments or evaluations of the ways in which such policies affect competitiveness are seldom straight forward.

Most of the examples given below are measures with sector-specific impacts. Industry is not only affected by sectoral and macroeconomic policies, but also by other Government actions having largely aggregate objectives-e.g., labor law or support for education. While policies of these types often have significant effects on competitivenessand a number of policy categories with aggregate goals and outcomes are reviewed in chapter 8-the present chapter focuses on measures with sector-specific outcomes.

Trade policies, for example, particularly those dealing with imports, have been consistent influences on both the steel and the consumer electronics industries since the late 1960"s. Economic and tax policies are impor$\tan \mathrm{t}$ for all industries, but have been particularly so for steelmaking because of its high capital needs.
In consumer electronics, a notable aspect of trade policy has been the lack of final resolution of antidumping proceedings, despite a lapse of more than 10 years since the first complaints were filed. In contrast, the semiconductor and computer sectors have not been strongly affected by trade policiesnor in recent years by public policies of any type. At earlier stages in the evolution of both technologies, however, U.S. defense and space programs provided important support -especially Government purchases, but also R\&D funding.

Regulatory policy has been the core of Government involvement in the activities of automobile manufacturers. Regulations dealing with safety, emissions, and fuel economy have constrained automobile design-for imports (except for mileage standards) as well as domestically produced vehicles. But regulations have seldom put the U.S. industry at any disadvantage-many regulations are more burdensome for imports than for domestic producers. Other public policies affecting transportation in general-particularly the construction of roads and highways-have had deep and long-lasting effects on the automobile industry, as have U.S. energy policies. Macroeconomic demand management-as manifested, for example, in interest rateshave also been potent forces on this industry.

Industrial competitiveness ultimately depends on the aggregated performance of many individual firms. But public policies in the United States seldom address economic efficiency and competitiveness directly; intervention in private industry has been considered neither desirable, nor even a wholly 
legitimate activity for Government. Nevertheless, the Government plays an important role in determining the conditions and environment for the conduct of business-whether purely domestic or involving international trade; public policies often shape corporate strategies and decisions in oblique and in- direct ways, acting in parallel with many other factors (see table 13 in ch. 5). Therefore the discussion below is largely descriptive; only in a few cases do the impacts of Government policies on competitiveness seem clear and unambiguous.

\section{Steel}

Beyond aggregate policies dealing with matters such as environmental protection, two main streams of Government policy have affected the steel industry in the United States. These have been, first, Government involvement in determining prices and wage levels, and, second, U.S. trade policy, primarily as it has affected imports of steel.

\section{Wages and Prices}

Because of the size of the steel industry and the widespread use of its products elsewhere in the economy, steel prices have a highly visible ripple-effect, attracting Government pressure to hold down prices in attempts to moderate inflation. Strikes in the steel industry can likewise disrupt other portions of the economy, leading to efforts by the Government to avoid or minimize their occurrence and length. President Truman's attempt to nationalize the industry during the 1952 steel strike is but the best-known example of this involvement, Thus, the Government has played a role in the determination of both prices and wages in the steel industry, presumably contributing to the pattern of high wages discussed in chapter 4.

Government attempts to influence steel prices have become more common as inflation has worsened. 'Since the 1960's, "jawboning" has from time to time been aimed at moderating steel price increases. Wage-price controls at several points during the 1970's

\footnotetext{
The industrvis position on such mat ters as outlined in Steel at the Crossrouds The American Sted Indus t ry ill the $1980 \mathrm{~s}$ (Washington, 1). ( ..: American Ironand Steel Institute. Januars 1980). esperially pp. 79-80.
}

applied to steel prices as for other commodities.

Coincident with Government attempts to moderate steel price increases have come the relatively low profit levels characterizing the industry since the 1960's-profits substantially below the average for all U.S. manufacturing. Although there were many other factors at work-not the least being import competition-efforts by the Government to hold down steel prices have depressed profits to some extent. According to a recent analysis by the General Accounting Office, informal jawboning had little real effect, but mandatory price controls-in place from 1971 to 1974 - did decrease the profits of steel firms,

The steel industry contends that Government attempts to dampen price increases have cut revenues significantly, decreasing the capital available for modernizing plant and equipment - both by reducing internally generated cash flow and by making steel less attractive to investors - and contributing to the industry's slackening competitiveness. Of course, if additional capital had been available, it would not all have been invested in steelmaking; some fraction would have gone toward diversification. But it is also true that public policies to stimulate investment in new process technologies aimed at cutting costs and improving productivity have been lacking in the United States-certainly compared to countries such as Japan.

New Strutegy Required for Aiding Distressed Steel Industry (Washington. D. c,: General Accounting Office, Jan. 8, 1981), pp. 6-12 to 6-14.

'Ibid., p. 2-16. The industrvspends roughly $\$ 500$ million annuallyondiversification. 


\section{Trade Policy}

U.S. trade policies have affected all three of the industries under consideration, steel more than any except consumer electronics. The broad context of postwar American trade policy is an important backdrop to effects on sectors such as steel.

After World War II, the United States used its power, then at a peak, to construct the foundations for an open international economic system. This country's trade policy complemented its defense policy by strengthening the economies of America's allies. During those years, and into the 1960's, U.S. industry was preeminent in the world. The American steel industry, for example, produced more than one-quarter of the world's output until 1967,

As U.S. firms became international and multinational (though not in the steel industry), they generally supported free trade. While the commitment to open trade was not unlimited, in general the United States could afford to use access to the American market and assistance to foreign producers to strengthen its allies, But as U.S. firms faced more intense foreign competition, domestic industries started to seek protection. In the steel industry, this began in the late 1960'sthe first major development being Voluntary Restraint Agreements [VRAS) negotiated by the U.S. Government with a number of other steel-producing nations and becoming effective in 1969.

Major issues in postwar U.S. trade policy have thus been: 1) the terms of access to the American market; $z$ ) the effect of foreign government policies on patterns of international trade; and 3) access for U.S. firms to foreign markets. These issues have shifted in importance as the flow of policy control moved away from Congress toward the executive branch in the early postwar years, then more recently returned in part to Congress.

In keeping with the broad direction of U.S. trade policy, the Government has consciously attempted to avoid the use of antidumping laws against foreign steel producers, espe- cially European firms. ${ }^{4}$ Thus to some extent, protection for U.S. steelmaker may have been sacrificed to other interests, particularly the desire to maintain good relations with our allies in Europe. Another factor has been fear of retaliation against U.S. exports or overseas investments. The desire to avoid dumping proceedings was an important motivation for the VRAS on imports of steel, and later the trigger-price mechanism (TPM).

The recent history of trade policy in steel thus begins in 1969 with the VRAs. These consisted of voluntary quotas on imports negotiated by the Department of State with most of the major steel-exporting nations, the quotas growing by 5 percent each year. The rationale was a slump in the U.S. industry, supposedly temporary; the VRAs, it was claimed, would give domestic firms an opportunity to adjust and restore their competitiveness.

To some extent these quotas-along with existing tariffs at about 6 percent-did succeed in insulating the U.S. industry; domestic steel production was as much as 10 percent above the levels that would have been expected without VRAs, and profits also increased.' However, during the 6-year period when VRAs were in effect (between 1969 and 1974) capital expenditures remained significantly below the level of 1968,(' although steelmaker added to their debt in several years. To some extent, a vicious cycle-poor profits, low expectations for the future, plus high costs of meeting environmental regulations and high costs of investment in new production technologies-led the managements of many steel firms to strategies emphasizing protection and divestment.

At the same time, the United States continued to have the most profitable major steel

ID. Driscoll. "Steel and the European Community: The Protection Issue," Congressional Research Service issue brief No. IB 80061 . Aug. 6. 1980

J. Jondrow, F. Devine. L. Jacobson, A. Katz. and I). O'Neill. Removing Restrictions on Imports of Steel (Arlington, Va.: Pub) lic: Research Institute. Center for Naval Analyses. May 1975). p. 3-56.

"The U.S. Steel Industry and Its Internationul Rivals (Washington. I).C.: Staff Report. Federal Trade Commission. November 1977 ). p. 74 . 
industry in the world, But relative to other U.S. industries its profitability was poor. It was no surprise to find capital flowing elsewhere.

Thus, VRAs had little apparent effect in providing "breathing space" for the industry to revitalize. Instead, the pressures of foreign competition compounded the other problems faced by the industry and led to renewed calls for restrictions on imports, particularly those "dumped" on the American market. By late 1977, the industry was in a slump that caused the closing of 14 major mills at a loss of over 20,000 jobs. The TPM followed in 1978.

First, however, the administration called on Anthony Solomon, then Undersecretary of the Treasury, to formulate a "comprehensive program" for the steel industry-in large measure to forestall antidumping suits against European steelmaker.

\section{The Solomon Plan}

The Solomon plan had four general objectives: ${ }^{7}$

1. stimulate efficiency;

2. ease the burden of adjustment for both industry and labor;

3. provide incentives for modernization through tax, investment, and financial assistance; and

4. expedite relief from unfair import competition while maintaining the overall U.S. posture favoring open trade.

Only a portion of the plan was implemented. Most significant was the TPM, which set reference prices for 32 categories of steel products, covering 90 percent of imports. These prices, established by the Department of Treasury, were to be based on the cost of production in the most efficient steelmaking nation, Japan, plus transportation costs, 8percent profit, and 10-percent overhead. Imports sold below this price would trigger an expedited dumping investigation.

A. M. Solomon, "Report to the President: A Comprehensive Program for the Steel Industry\},"' December 1977.
The TPM evidently suffered from lax enforcement as well as problems in establishing the reference cost levels, ${ }^{8}$ the latter associated particularly with exchange rate fluctuations and variations in capacity utilization. Trigger pricing was a political compromise that provided some import relief, while allowing our European allies to export to the United States at prices below their costs of production, (Strict enforcement of antidumping laws would have been an effective embargo on much European steel). One effect of the TPM was, therefore, to allow European exporters to raise prices and cover a larger fraction of their costs, helping them more than American firms.' The TPM may also have raised the prices Japanese firms could charge. While increasing revenues for American steelmaker, it increased costs for American firms that buy steel for use in their own products.

Although the complete Solomon plan was not implemented, several other recommendations-including the establishment of a loan guarantee program-were carried out, The Economic Development Agency (EDA), part of the Department of Commerce, was authorized to extend over $\$ 550$ million in loan guarantees to steel companies. As for other EDA loans and loan guarantees, maintaining employment was the primary objective. The loan program was small in terms of the capital needs of the industry as a whole, which by all estimates reach several billion dollars per year; it helped weaker firms and was not oriented toward new technology."]

The EDA loan guarantee program has had some success in meeting its limited objectives of supporting ailing firms and saving jobs. But trade policy measures such as the TPM and the earlier VRA'S have shown little evidence of creating an environment conducive to the revitalization of the industry. Steelmaker have been able to protect some profits, but in-

\footnotetext{
"Administration of the Steel Trigger Price Mechanism (Washington, D.C.: U.S. General Acounting Office. July 23, 1980).

"Technology and Steel Industry Competitiveness (Washington. D.C.: Office of Technology Assessment, L.S. Congress. June 1980). p. 150.

"Ibid.. pp. 105-106.
} 
centives for using these profits to diversify out of steelmaking remain strong.

Another recommendation of the Solomon plan to be adopted was a shortening of depreciation schedules for steelmaking equipment from 18 to 15 years. While this gave a small increase in cash flow available for reinvestment, capital cost recovery periods in the United States remain longer than for many of our international rivals. ${ }^{12}$ The Steel Tripartite Advisory Committee recommended in the Solomon report also remains in existence. Drawing its membership from industry, labor, and Government, the tripartite committee helped to formulate the Carter administration's steel policy and has served as a model for similar committees in other industries-e, g., that formed during 1980 to consider the problems of U.S. automobile manufacturers,

Despite the comprehensive program urged in the Solomon report, the competitive position of the domestic steel industry is no better today than when the report was issued, As discussed in chapters 4 and 5 , the competitive slide of the integrated portion of the industry stems in large part from high wage levels combined with slow' productivity growth. Government policies have thus far done little to attack the underlying problems of capital investment for modernizationwhich could reduce energy consumption as well as cutting costs and improving productivity. One reason is that in the United States, actively strengthening an industry such as steel has not been widely perceived as a legitimate goal of public policy.

\section{Other Policies}

Among the many Government policies with broad objectives but sector-specific impacts on the steel industry, the most visible have been environmental standards and workplace health and safety regulations. During the 1970's, meeting Occupational Safety and Health Administration (OSHA) and Environmental Protection Agency (EPA) regulations

\footnotetext{
"Ibid.,p. 323.

Ibic\}. ! p. 59
}

required capital expenditures by the U.S. steel industry averaging about $\$ 365$ mill jon a year, 17 percent of annual capital investment. "This is less than industry spending for nonsteel diversification. ${ }^{14}$ (Diversification can give useful stability to firms in cyclical industries such as steel. )

In other countries, public pressures have also led to increased capital expenditures for safety, health, and environmental controls. From 1971 to 1977, Japanese steel industry capital costs for environment al compliance were 65-percent higher than $\mathrm{L}^{\mathrm{T}}$. S, levels, ' Expenditures by European producers have been similar in magnitude to those in the United States, but governments in both Europe and Japan have often subsidized some of the costs. Even in the United States, nearly half of capital expenditures for pollution cent rol have been financed through industrial development bonds-in effect, Govern ment-subsidized loans. "Because European steelmaker have not in any case been cost competitive with U. S, producers- in cent rast to the $\mathrm{J}$ apanese-it seems unlikelv that the American steel industry has been seriously harmed in any relative sense by differences among the industrialized countries in environmental or workplace regulations,

Energy policies in the United States directly affect the competitiveness of the steel industry and will be increasingly significant in the future. Costs of coal and electricity are important-coal primarily for integrated steelmaker, electricity for minimills as well as integrated producers using electric furnaces.

The effects on the competitiveness of the steel industry of measures such as those dealing with energy or the environment have often been viewed by policy makers as incidental. Though the cumulative effect of many such policies, each of which has only a mar-

\footnotetext{
Ibid..p. 3.)1.

"!'('Lt' Strategy Kequiredfor Aiding Distressed Steelndus triop.cit, pp 2-16 to 2-18,

'1'('( \}11101( gy and SteelIndustry Competitiveness, op. cit"

Ibid.. p. 346.
} p. 68 . 
ginal impact (positive or negative), can be major, evaluation of net impacts is seldom attempted. A possible task for industrial policy would be to attempt a more encompassing perspective towards the dilemmas faced by industries like steel. This could be a useful step in deciding what, if any, role the Government should play in efforts to maintain and enhance the competitiveness of such industries.

\section{Electronics}

The diversity of products and technologies in the electronics industry carries over to policy matters. Different types of policies have been important to different parts of the industry. Electronics firms have not always agreed on which Government policies would be desirable. For example, in the protracted controversy over dumping of color TVs and other alleged unfair trade practices, firms such as RCA that have extensive international activities and receive licensing revenue from Japanese producers took a "free trade" position. Companies with primarily domestic operations pressed strongly for Government policies to protect the industry.

In the computer industry, there is likewise no community of interest between IBM and many of the smaller firms, particularly those making plug-compatible equipment of various types, Several of these firms have brought suit against IBM alleging unfair competition. This part of the electronics industry has also been unsettled by the ongoing attempts of the Federal Government to resolve the complex policy issues that are arising as computers and information technologies overlap the regulated communications industries. In the semiconductor sector, merchant and captive manufacturers do not always share common concerns.

\section{Consumer Electronics}

As for the steel industry, Government actions concerning trade have been important to the U.S. consumer electronics sector, While most of the attention has focused on imports, concern has also been expressed over policies dealing with foreign investment and offshore assembly, the latter currently favored by U.S. tariff laws. " Organized labor, in particular, has often criticized such tariff policies - which have helped keep down costs for U.S. semiconductor firms as well as TV manufacturers, but are claimed to "export" jobs. "Still, treatment of imported consumer electronics products, particularly color TVs, has been the core of U.S. policies affecting this industry.

Dumping complaints-claims that imported TV receivers were being sold at less than "fair value"-began in 1968, when the Electronics Industries Association (EIA) alleged massive dumping of Japanese TVs. 'Y The EIA claimed that Japanese firms were able to cut prices in the United States by maintaining artificially high price levels at

SW-S. 806. 30 and 807.00 of the (1. S. tariff schedules provide for duty-free treatment of some materials and components sent a broadfor fu r-i he $r$ p rocess $i n g$ or a ssem bly and thenreimported.The duly-free value of imports entered under these provisions gives an indicatiomof 111 eex I en $t_{0} f_{1}$ f fshore assembly. For TV receivers, th e d u 1 v-free por $t \mathrm{i}$ on of i m ports increasedfrom 9 percent in 1975 to 17 percen $t$ in 1977. (See Im port Trendsm '1 SUSItems 806.30 and 807.00)(Washinglon, 1). (';: Internat ional Trade (oommission publication 1029. January 1980).p.38. ) Iuty-free conten 1 of semiconductor imports ruse? from 30 10 60 percent between 1975 and 1978

"Whether foreign investment decreases domestic job) opportunities depends un the assumed course of events in the absence of the overseas invest men 1 -which can never be known. Assuming that the industry would decline precipitously if it did not move some opera lions overseas genera 1 I y leads to a prediction that foreign investment saves domestic jobs. See, for example. The Impact of International Trade and Investmen $\mathrm{t}$ on Employment(Washington D. (a.: Department of Labor, 1978).

${ }^{14} \mathrm{~A}$ countervailing duly case was also filed by Zenith in 1974 , wh ich claimed that rebates of the Japanese commodity ta $x$ un exported 'IVs const i 1 u ted a subsidy. This event ually went to the [J. S. Supreme Court, where it was decided against Zenith in 1978. An antitrustcase filed by Zenith andanother plaintiffalleging a conspiracy bv Japanese firms to dest rov the $\mathrm{U}$. S, consumer electronics industrv-was recently dismissed but will almost certainly be appea 1 ed. 
home, helped by import barriers. Japanese firms, while acknowledging higher domestic prices, contended that the difference was due to higher taxes and marketing costs. (Spurred by news reports of the dumping charges, Japanese consumers in fact organized an 8month boycott of color TV sales, eventually forcing prices in Japan down somewhat.)

In the United States, it was not until 1971 that the Treasury Department and the International Trade Commission issued positive findings of dumping and injury on the EIA complaints. During 1973 the amounts of the antidumping duties were determined (for the period 1970-71 only), But by the end of 1980 only a fraction of the duties assessed had been collected. Furthermore, no duties for the period 1973-75 had been collected, and assessments past 1975 had not been completed. The post-1975 duties alone could total more than $\$ 100$ million. ${ }^{20}$

This 12-year history demonstrates the inadequacies of antidumping procedures in a case where both dumping and injury have been consistently demonstrated. An industry legally entitled to protection has not received it. Nonetheless, the failure of public policy in this case-partly a reluctance by Government agencies commit ted to free trade to pursue the complaints - may not have had a critical effect on the course of the domestic industry. As discussed in chapter 5, Japanese consumer electronics manufacturers had many other advantages over American firms: lower costs, a measure of government R\&D support, and an aggressive determination to penetrate markets on a worldwide basis, At least some of these companies would probably have succeeded in the United States without dumping. A telling point is that Sony, one of the most successful of the Japanese firms, has never been implicated in dumping and has been able to command premium prices in U.S. markets.

The most disturbing aspect of this history from a public policy standpoint is the un-

\footnotetext{
Impert Reporter. Bureau of National Affairs. Apr. 30.1980 p. A-2.
}

certainty that has persisted over the past 12 years. The conflicts within the Government and between Government and industry-the lack of final resolution in the antidumping proceedings - created a climate in which U.S. consumer electronics firms had to plan for the future without knowing what the trade policy environment would be. This uncertainty extended to importers as well. But an important goal for industrial policy should be to reduce uncertainty, not create it.

During this period of unresolved dumping proceedings, the U.S. Government also negotiated import quotas on color TVs, first with Japan, later with Taiwan and South Korea. An upshot of "escape clause" proceedings brought before the International Trade Commission in 1976, unfair trade practices were not at issue.

The Orderly Marketing Agreements (OMAS) for color TVs were ostensibly intended to give the U.S. consumer electronics industry a chance to rebuild its competitiveness-in this analogous to VRAS for steel. In reality, a more important aim of the color TV restrictions was probably to encourage foreign manufacturers to set up U.S. assembly operations as an aid to maintaining domestic employment. This objective was in fact accomplished (ch. 5). Many of the indications of rebuilding or of sustained competitiveness that are evident-e.g., RCA's video disk developments-would probably have taken place in any event.

The OMAS with Taiwan and South Korea were recently extended through mid-1982. Under the new agreements, each country will be permitted to increase its color TV exports to the United States-from 526,000 for the year ending June 30,1980 , to 1 million in 1982. At the same time the OMA with Japan was allowed to expire because U.S. imports of Japanese TVs have dropped markedly. As happened with Japanese producers, the extended OMAS with Taiwan and Korea will probably encourage firms from these countries to establish manufacturing operations in the United States. If these OMAS had been 
allowed to end, imports from Taiwan and Korea would most likely have jumped.

\section{Semiconductors}

There are comparatively few current Government policies with marked sector-specific effects on the semiconductor industry. While public comments by industry executives have sometimes included allegations of unfair trade practices by the Japanese-e.g., in connection with rapid import penetration in 16K RAMs - no formal complaints have been filed. The industry has also claimed that subsidies and supports by the Japanese Government-as exemplified by the VLSI cooperative $R \& D$ program described in chapter 5constitute unfair competition. ${ }^{21}$ The agreement on government procurement reached by the United States and Japan at the end of 1980-affecting primarily the purchasing practices of Nippon Telegraph \& Telephone Public Corp. - may help to ease some of the friction between the two countries over trade in semiconductors.

In the past, the Government activities with the greatest impact on the U.S. semiconductor industry were R\&D support and procurement associated with military and space systems. Except for the new Very High-Speed Integrated Circuit (VHSIC) program of the Department of Defense, the major impacts of such programs have already been felt. Much the same has been true for the computer sector, where Government-sponsored R\&D and purchases of equipment were important to the early development of the industry, but have since faded in significance.

Both the transistor, invented at Bell Laboratories in 1948, and the integrated circuit (IC), developed by Texas Instruments and Fairchild Semiconductor in the late 1950's and early 1960's, sprang from company-

"For a sampling of the industrv's concerns see:M. Hodgson (ed.). An American Kesponse to the Foreign Industrial Challenge in High Technology Industries, proceedings of the Semiconductor Industry Associat ion Government Policy Conference. Monterey. Calif., June 18-19, 1980 (Palo Alto, Calif.: Worden Fraser Publisher, 1980), funded R\&D programs. ${ }^{22}$ Nonetheless, Government support was crucial to engineering development-first for transistors, later for ICs. Market incentives provided by the military, primarily through procurement, were more important than direct R\&D funding. ${ }^{23}$ Purchases for the U.S. space program likewise aided the early growth of the industry.

More recently, military and space markets have declined in size and importance relative

${ }^{22}$ N. Asher and L. D, Strom, "The Role of the Department "f Defense in the Development of Integrated Circuits," Institute for Defense Analyses paper P-1 271, May 1977.

${ }^{2 \cdot} \mathrm{J}$. R. Tilton, International Diffusion of Technology: The Case of Semiconductors (Washington, D. C.: The Brookings Institution, 1971), pp. 90-91.

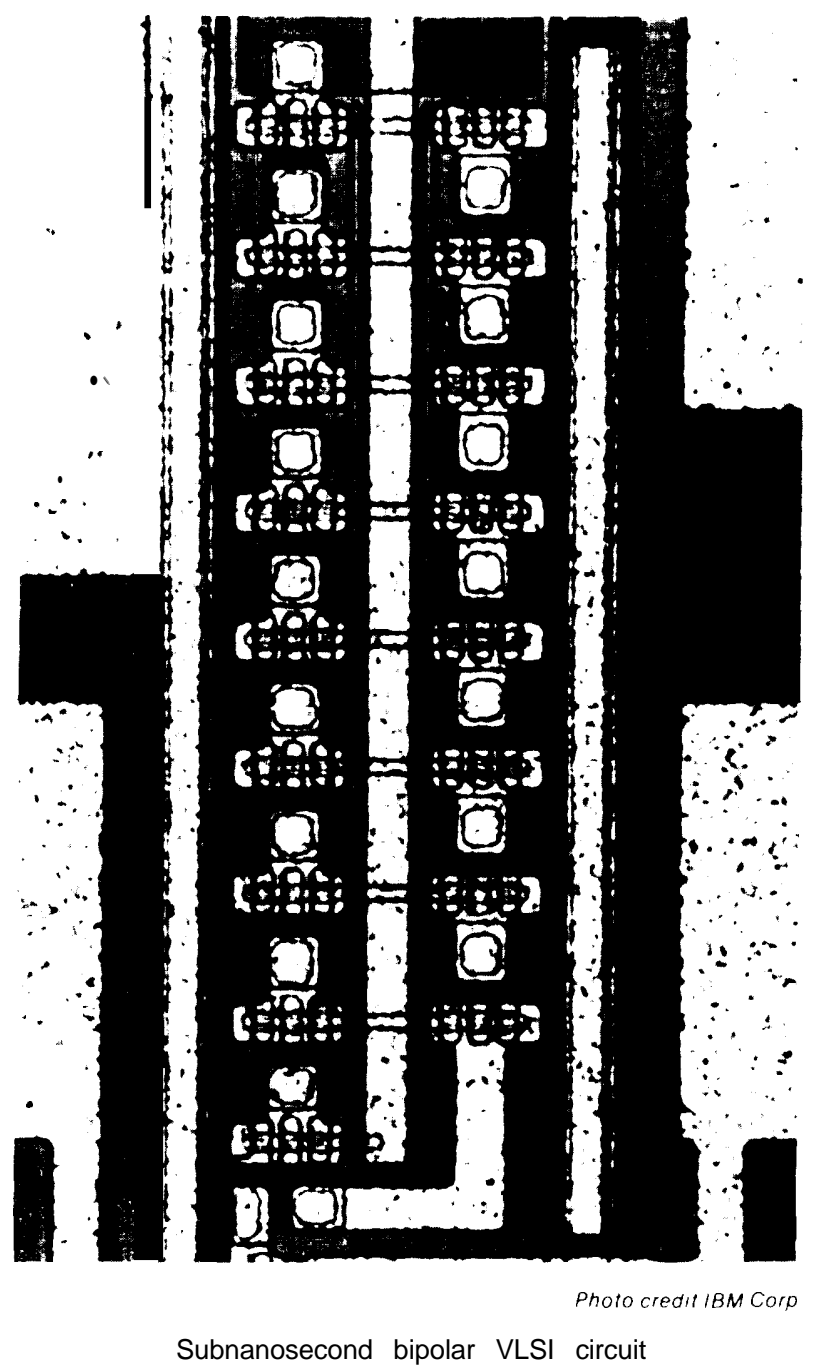


to commercial sales-this being one of the reasons for the VHSIC program. Although directed at specialized military applicationsprimarily signal processing-and more rapid use of VLSI in fielded equipment, VHSIC spending will stimulate the commercial semiconductor industry in a real though limited way, mostly by accelerating the pace of $R \& D$ in areas such as lithography and computeraided circuit design.

Another important support for the semiconductor industry - this one indirect-has been education and training of engineers and scientists, primarily through Governmentsponsored R\&D within universities. Less of this funding is now available than in the 1960 's, a cause for concern to many in the industry because of the current shortage of technical professionals.

From a Government policy viewpoint, a noteworthy aspect of the development of the semiconductor industry is the impetus for the integrated circuit provided by an Air Force program aimed at "'molecular electronics' during the late 1950's. Molecular electronics never came to fruition, but the effort stimulated the invent ion and development of the IC. ${ }^{24}$ If the Air Force program had been directive rather than stimulative-i. e., if Government policy had tried to force the technology down the path of molecular electronics-IC development might have been delayed. Instead, military needs stimulated private expenditures leading to the new technology; it did not come from the Air Force's own laboratories or from Government-funded R\&D.

\section{Computers}

The early history of this sector is also marked by a strong Government presence, through both R\&D support and purchases.'; Since the 1950's, Government influence has been more tangential. Trade policies have had little effect on the development of the computer industry beyond U.S. support for

\footnotetext{
Asher and Strom, op. cit., p. 14.

J. T. Soma, The Compruter Industry /Lexington. Mass.: Lexington Books. 1976), ch. 1.
}

open international trade; American computer firms have generally had price advantages as well as technical superiority. Under such circumstances, trade barriers have been unimportant except in the case of Japan and to a lesser extent the United Kingdom,

$\sim$ An area where policy may become increasingly significant is computer software. Software is presently almost impossible to protect: programs typically cannot be patented, and copyrights can be easily circumvented. More workable protection for proprietary programs could help safeguard the U.S. lead in software.

Within the United States, perhaps the most important Government action in recent years has been the antitrust suit brought against IBM in 1969-and still in trial, Some observers have suggested that a Government victory might harm the international competitiveness of the U.S. computer industry, given IBM's worldwide dominance of markets for larger size computers. In this, as in the antitrust suit which seeks (among other things) to divest Bell Laboratories from AT\&T, these observers have seen a policy that could run counter to the interests of U.S. competitiveness: antitrust enforcement has only recently begun to consider worldwide-as opposed to purely domestic-market conditions. Others contend that antitrust measures aimed at decreasing industrial concentration will enhance U.S. competitiveness-that the tradiitional reliance of the United States on bala need competition is a key to effectiveness worldwide as well as in domestic markets.

Governments in the United States and elsewhere have been slow in coming to grips with the many issues raised by the blurring of boundaries between the computer and communications industries. With computers talking to one another over telephone lines, widespread networking and distributed processing, and electronic mail, teletext, and videotext on the horizon, it is increasingly difficult to distinguish data processing from data communications. Because communications, unlike data processing, has been a regulated industry, government policies are having to 
be reconsidered in light of the overlap between these sectors created by technological change.

This brief review of public policies with major effects on consumer electronics, semiconductors, and computers-ranging from trade policies and their administration to communications regulations-illustrates the variety and diversity of impacts on this industry. Most of these policies have been developed on a case-by-case basis, and-as was typical for the steel industry-with aims other than competitiveness and economic efficiency. The favorable impacts of Government procurement on the semiconductor industry, for example, were not a central concern of policymakers, even though the Department of Defense recognized the importance of a healthy electronics industry to U.S. military strength.

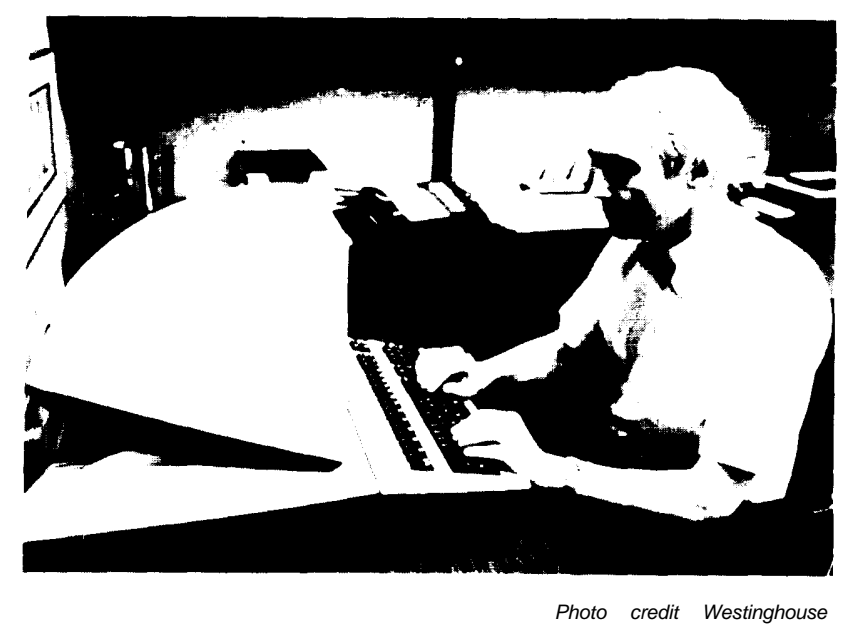

Terminal for an electronic mail system

\section{Automobiles}

Current sector-specific policies toward the automobile industry can be traced back to the 1950's, when smog in the Los Angeles basin was attributed in part to automobiles. Government regulations to reduce emissions and enhance auto safety multiplied during the 1960's and 1970's; fuel economy regulations were instituted in 1975, The automobile industry now finds its products heavily regulated; at the same time, its manufacturing processes are monitored by EPA and OSHA, and its sales affected by many policies that indirectly influence demand for automobiles-energy policies, interest rates, credit controls.

Today, automakers see themselves as facing two major sets of policy-related problems: 1) absorbing the costs of regulation; and 2) dealing with Government policies that are perceived as sometimes ambiguous and conflicting, and that are not always stable over time (the industry itself contributes to delays and confusion in automobile regulations, as in the case of passive restraints). But two past
Government policies have also had deep, long-term though indirect impacts on the automobile industry. Both encouraged the production of big cars designed with little attention to fuel economy. The first is the series of decisions that kept the price of gasoline low in the United States-the second, public policies supporting a system of roads and highways unmatched in the rest of the world. Both were supported for many years by a broad political consensus.

\section{Price and Supply of Gasoline}

The United States has traditionally had low gasoline taxes and low import charges on foreign oil. For many years these policies helped to keep fuel prices low. Even after decontrol, gasoline in the United States still costs far less than in most other parts of the world-and the market incentives for consumers to buy small, fuel-efficient automobiles are correspondingly lower. (By 1975, the domestic automakers had nonetheless taken 
positions in support of gasoline price decontrol, )

Thus until recently, the cost and availability of fuel was a minor consideration for most automobile purchasers in the United States. When this changed suddenly in 1979-80, the consequences for domestic automakers were severe. Moreover, if gasoline prices in this country were to rise to levels comparable to those in Europe and Japan, consumers would presumably find the larger domestic cars still less desirable. While public policies in the United States as they affect gasoline prices continue to favor domestic automakers, Government decisions have contributed to the erratic nature of gasoline price rises, as well as to shortages and gasoline lines, and thus to the currently depressed market for American cars. These decisions have come in a highly politicized environment-one where consensus has been elusive and the terms of the debate have often been outstripped by events.

In the simplest view, policy makers in the United States have been caught between two conflicting objectives, The first is a need to allow fuel prices to increase, encouraging conservation and reducing U.S. dependence on foreign oil. The second is a desire to keep fuel prices low as a brake on inflation and to minimize the burdens on low-income segments of the population. As one result, rather than a gradual, predictable rise in gasoline prices-which would have allowed both automakers and consumers to plan ahead-gasoline prices (and supplies) have moved suddenly and unpredictably, The difficulties that would in any case have been caused by external disruptions - such as the 1973 Arab oil embargo and the monopoly control exercised by the OPEC cartel-have thus been more acute,

For example, gasoline prices quickly rose by more than 20 percent in real terms following the 1973 October War and the Arab oil embargo. Subsequently, the small car share of the U.S. market increased sharplygoing from 38 percent in 1972 to 49 percent in
1974 and 53 percent in $1975 .{ }^{2,)}$ Import sales did not rise appreciably; most of the increase in 1974 was taken by domestic small cars (see table 5 in ch. 4).

Yet gasoline prices soon stabilized-and even went down in real terms during the period 1974-78. One reason was the Energy Policy and Conservation Act (EPCA), which became law at the end of 1975. The Act did two things. It established mandatory fuel economy standards for auto fleets. At the same time, EPCA kept oil prices under strict controls. During this same period, OPEC followed a policy of moderation in oil pricing and fuel taxes remained low.

Many consumers refused to accept the reality of the "energy crisis." The market share of small cars fell slightly-from 53 percent in 1975 to 48 percent for 1976 and 1977. More significantly, capacity utilization for domestic subcompacts dropped to less than 54 percent in 1976 and 1977, while plants for intermediate and full-sized cars operated at or near full capacity."

The years 1974 to 1977 thus presented American manufacturers with a difficult set of decisions. On the one hand, they could sell all the large cars they could build-and at healthy profit margins. But the Corporate Average Fuel Economy (CAFE) standards built into EPCA required that they move toward better fuel consumption, EPCA did not require that cars be small in size, but downsizing was clearly in order to increase mileage, In fact, the law favored downsizing and other means of gaining relatively small improvements in the mileage of big cars over building new high-mileage subcompacts. But it was also obvious that each manufacturer would eventually need a substantial fraction

Auto Situation: 1980 (Washington, D).C.: Subcommittee on Trade, Committee on Ways and Means. U.S. House of Representatives. June 6,1980 ). p. 13. Small cars are defined as subcompacts and compacts.

"Certain Motor Vehicles and Certain Chassis and Bodies Therefor," prehearing report to the Commission and Parties. International Trade Commission. Washington, D.C.. Sept. 10 , 1980. p. A-40 
of subcompacts in order to meet fleet averages for later years,

Nonetheless, in the mid-1970's small cars were not selling well and American manufacturers were reluctant to believe that their customers would want them in large numbers. Moreover, profits on small cars were low. Thus domestic automakers tended to hedge their bets. In 1976-the same year it introduced its new subcompact ChevetteGeneral Motors announced that it would downsize its entire fleet by 1985 . Ford decided to import the subcompact Fiesta rather than building it in the United States-which meant that it could not be counted in the CAFE figures-and as a result did not have a competitive domestic subcompact until the 1981 model year. Chrysler introduced its subcompact Omni/Horizon in 1978 but relied on outside suppliers for engines, which limited attainable production levels.

In general, then, American firms were not well-prepared for the end of consumer ambivalence toward small cars-triggered by events at the end of 1978 and the beginning of 1979. Large OPEC oil price increases, the Iranian revolution, and the beginning of decontrol of domestic oil prices caused major shifts in the U.S. automobile market. Gas lines reappeared during the summer of 1979. Prices at the pump more than doubled over a 2-year period. As in 1974-75, consumers turned to small cars-their market share rose from under 50 percent to nearly 65 percent in 1980. Japanese auto firms had extra production capacity available to meet the new demand, U.S. manufacturers, in contrast, might have had even fewer small cars on the market in the absence of the CAFE standards in EPCA.

\section{Roads and Highways}

A second major indirect influence on the U.S. automobile industry-one now less important than in years past-was the extensive development of roads and highways which culminated in the Interstate Highway System. And, in contrast to many other coun- tries, public policies in the United States put railroads and other public transportation at a relative disadvantage compared to automobiles and trucks.

Federal aid for highway construction dates from 1917; State highway systems were universal by 1924. Secondary highways and city streets, in particular, have been heavily financed from general tax revenues. The development of both inter- and intra-city roads and highways - together with the long distances between population centers in the United States, and our energy policies-contributed to the development of the characteristic American automobile: comfortable and durable but also large. The legacy of the big American car-which evolved in isolation from other world markets-has left the industry for the moment in a rather weak position. It is easy to lose sight of this history in the current discussion of fuel economy/emissions/safety regulations. The Government has for years been making policies that affected the industry. In the past these policies were welcomed by all-and often actively supported by the automakers. This is no longer the case.

\section{Regulation}

The three primary categories of product regulations that affect the automobile industry cover emissions, fuel economy, and safety. "EPA administers the emissions and fuel economy standards - which have been largely set by Congress-while the National Highway Traffic Safety Administration (NHTSA) has responsibility for automobile safety. In addition to regulation of automobiles as products, manufacturing operations come under the purview of EPA and OSHA.

Regulation of automobile emissions began during the early 1960's in California. The first Federal standards took effect in 1968, Originally, only hydrocarbons and carbon monoxide were controlled. Rather minor en-

-'The Automobile Calendar:Recentand Pending Federal Ac. tivities Affecting Motor Vehicles (Washington, D. C,: United States Regulatory Council. January 1981). 
gine modifications-PCV valves, retarded ignition timing, and slightly leaner air-fuel ratios-were sufficient to meet the early standards.

Regulations for later years called for further reductions in hydrocarbons and carbon monoxide, with restrictions on nitrogen oxides taking effect in 1973. Scheduled reductions in all three pollutants were steep and essentially arbitrary in magnitude. At the time, the automakers claimed that standards scheduled for the mid-1970's would be costly to meet and perhaps technologically impossible. Today, controversy over the costs and benefits of emissions standards continues. Opponents of standards have claimed that increased purchase prices of automobiles and decreased fuel economy outweigh the benefits of the stringent control levels that the Clean Air Act and its amendments require,

Beyond costs and technical feasibility, the timing of emissions standards has been at issue. Timing is closely tied to technical feasibility. The manufacturers have claimed that standards could not be met on schedule, and perhaps could not be met at all. Widespread driveability problems with cars produced during the mid-1970's gave evidence of the technical problems.

Another consequence of emissions standards which rapidly became apparent was the fuel economy penalty associated with engine modifications for pollution control. Retarded spark timing, exhaust gas recirculation, and thermal reactors all decreased engine efficiency. Catalytic converters allowed some ground to be regained, but the lead-free gasoline needed to prevent catalyst poisoning meant compression ratios had to be lowered, canceling some of the possible gains. While the magnitude of the tradeoffs between emissions control and fuel economy may have been overstated during debates on these regulations, the incompatibilities between the two goals illustrate the complexities of such issues.

The staging of fuel economy regulations was also controversial. While no longer an issue for automobiles-because the demands of the marketplace have recently outstripped CAFE regulations-manufacturers have continued to oppose the mileage standards scheduled for light trucks. As the question of possible fuel economy standards for the post-1985 period comes into focus, there may again be debate over passenger car mileage standards and their timing.

Fuel economy regulations and now the market have forced U.S. automakers to make large capital investments in new vehicle designs that foreign manufacturers-with their existing high-mileage fleets-have generally been able to avoid. But the very fact that the market is now demanding small, economical cars demonstrates that the premise behind the fuel economy standards was sound.

Safety standards have thus far been relatively easy to meet from a technical standpoint-unlike emissions regulations. Nonetheless, they have remained a source of considerable conflict between Government and the automakers. Of particular concern at present are passive restraint requirements. U.S. automakers have argued that these give an advantage to the Japanese since small cars do not have to be equipped with passive restraint systems until 1984, while large cars must have the systems by 1982 (delays in these regulations have recently been proposed as part of the Reagan administration's automobile industry aid package).

OSHA standards apply to automakers as to other manufacturing industries, Examples of production operations affected include exposure to paint fumes and to lead associated with soldering body joints. At the same time, workplace standards also exist in other countries; there is little evidence that OSHA has placed U.S. automobile manufacturers at a marked disadvantage,

The total regulatory environment for automobiles in the United States now constrains vehicle designs in many ways. Regulation grew rapidly during the 1970's, with little attention to tradeoffs and side-effects. At present, there are signs that automobile standard- 
setting is maturing, as both Government and industry accommodate themselves to political pressures and technological realities.

Over the past decade, regulations have clearly had major impacts on the U.S. automobile industry, but-except for fuel economy standards (and manufacturing regulations) - they have affected foreign manufacturers wishing to sell in this country at least as much. In most cases, American firms have been at a relative advantage.

The question of the differential impacts of regulatory standards is nonetheless more complex than it first appears. Product regulations might seem to treat imports and domestic autos alike; the Government establishes some standard which all manufacturers must meet, In reality, product regulations can create barriers to the entry of imports or, alternatively, encourage purchases of foreign cars, Particular regulations may also burden (or favor) some domestic manufacturers more than others, giving those less burdened a competitive advantage. For example, decisions on particulate and nitrogen oxide standards for diesel engines will affect the competitive position of General Motors and Volkswagen of America compared to other domestic automobile firms because only these two have so far made substantial commitments to diesels.

More generally, regulatory compliance requires $R \& D$ and testing programs that are not a function of the number of cars to be produced. Large-volume manufacturers such as General Motors, Ford, Nissan, and Toyota can comply with regulations at significantly lower costs per vehicle than small-scale manufacturers. Thus, regulations often give competitive advantage to big companies. Moreover, European producers, whose home countries have much looser emissions regulations, must spend significant amounts per vehicle to bring them into compliance with U.S. standards, Japan, in contrast, has mandated emissions levels comparable to those in the United States; Japanese cars have not needed significant redesigns to meet American standards.
Some regulations, especially the CAFE rule which applies to all manufacturers selling in the United States, have also had significant secondary effects. The CAFE standard defines any vehicle with more than 75 percent domestic value-added as American-made, anything with less as an import. American manufacturers cannot bring in cars they build overseas and count them against their CAFE figures; likewise, Volkswagen is keeping its American-built Rabbit at less than 75percent domestic value-added so it can offset its less fuel-efficient imported models. The value-added rule was intended to protect American jobs, but cuts both ways.

While regulations of many types now restrict the freedom of action of automobile manufacturers, their objectives-as in the case of safety standards-lie by-and-large outside the industry itself; just as emissions regulations are intended to help control air pollution and its possible harmful effects, so fuel economy standards were aimed at conserving petroleum and reducing U.S. dependence on oil imports.

\section{Other Policies}

Tariffs and local content rules are the most significant barriers to trade in automobiles. Foreign governments often use local content requirements to protect domestic employment. ${ }^{29}$

Government agencies also influence the activities of the U.S. automobile industry in other ways, for instance through economic adjustment policies. Thus-in addition to EPA, NHTSA, and OSHA - the Departments of Labor, Justice, and Commerce, the Office of the U.S. Trade Representative, and the International Trade Commission, among others, all can affect the competitive position of the industry. Even the Small Business Administration (SBA) is involved in the industry's current problems, because many dealerships qualify as small businesses. During 1980,

\footnotetext{
"Auto Situation:1980, op. cit. pp. 93-103.
} 
SBA guaranteed more than $\$ 100$ million in loans to nearly 500 auto dealers. 30

The fragmentation which results from this plurality of interests and agencies is typical of public policies affecting industry in the

D•(E“"I)etrtJit”s New Sales Pitch, " Business Week, Sept 22 , 1980, p. 78 .
United States, but has advantages as well as disadvantages. The absence of coordination and centralized control in U.S. industrial policy can lead to flexible and adaptive response. Regulatory policies affecting the automobile industry may not always have been well-coordinated, but they have benefited consumers and the public at large in many ways,

\section{Summary and Conclusions}

In these three industries, Government policies with major sector-specific impacts have sometimes exhibited a lack of coherence and continuity. In steel, a variety of trade measures have provided some insulation from import competition, but seldom actively promoted adjustment to changing conditions in the world industry, Coupled with these policies have been environmental and other regulatory measures that have demanded significant capital spending-though not at levels that seriously affected competitiveness.

In consumer electronics, a long-running string of dumping complaints has never been satisfactorily resolved. OMAS intended to protect the domestic industry and maintain employment have saved some jobs but not promoted restructuring or other adjustment except by encouraging foreign investment. Other portions of the electronics industry have not recently been strongly influenced by Government policies, but neither have domestic programs to countervails supports and subsidies in foreign countries been seriously cons idered.
The automobile industry has suffered, along with many other portions of the U.S. economy, from irresolution and lack of consensus on energy policies, There have also been conflicts among some regulatory policies, and, again, little recognition of the structural changes the industry has faced.

In general, public policies toward these industries have not supported or promoted continued competitiveness and adjustment to changing economic conditions: such concerns have seldom been among the goals of policy in the United States. There has been no real agreement on the appropriate role of Government in either distressed industries or growth industries, except where national security is directly affected. As industries in other countries increasingly challenge the United States in both domestic and export markets, public policies which bear on productive efficiency and competitiveness are likely to need reexamination. 
CHAPTER 7

Prospective Competitive Futures 


\section{Contents}

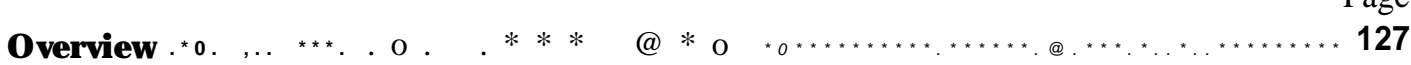

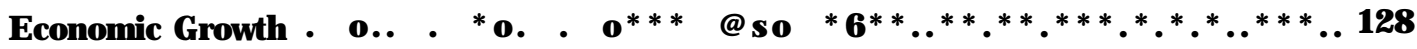

Steel.**. .*Oo. *.*.**..* .*..*..*...*****.***..***..****.**..****.*.*.*.*129

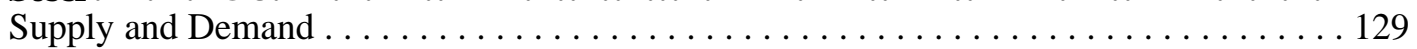

Future Competitiveness. . . . . . . . . . . . . . . . . . . . . . . . . . . . . 129

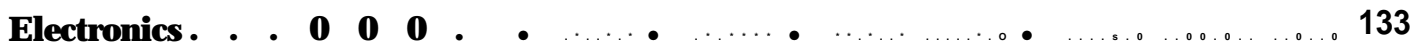

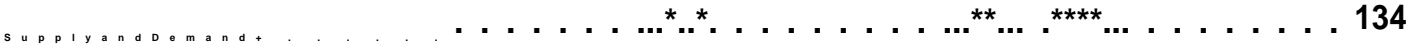

Technology . . . . . . . . . . . . . . . . . . ....................135

Future Competitiveness. . . . . . . . . . . . . . . . . . . . ....................137

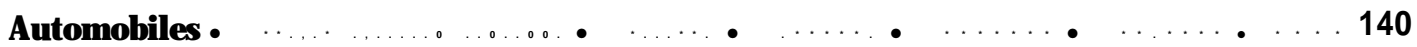

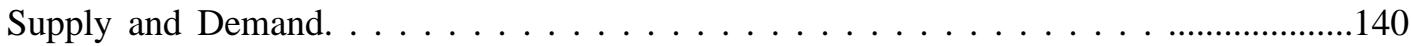

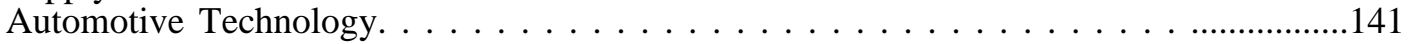

Future Competitiveness. . . . . . . . . . . . . . . . . . . . . . . . .............143

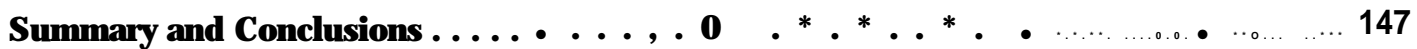

\section{List of Tables}

Table No. Page

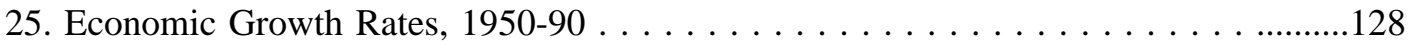

26. World Raw Steel Capacity and Demand Estimates . . . . . . . . . . . . . . . 129

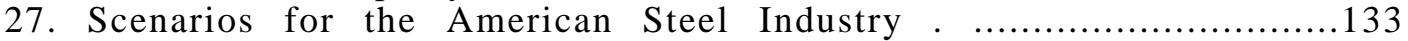

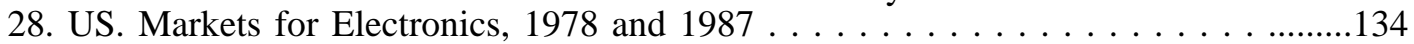

29. Estimated World Semiconductor Production by Geographic Location of Firm

Headquarters . . . . . . . . . . . . . . . . . . . . . . . . .........135

30.Projected Sales of passenger Cars in Major World Markets. . .................140

\section{List of Figures}

Figure No. $\quad$ Page

11. Projected Increase in Density of RandomAccess Memory Circuits . ............136

12. Projected Decrease in Cost per Bit for RandomAccess Memory Circuits. . ........136 


\section{Prospective Competitive Futures}

\section{Overview}

At several points, earlier chapters touched on the futures of the steel, electronics, and automobile industries. Here, probable trends in each sector are examined more directlya rather speculative exercise. Although attempts are made to look ahead to the end of the century, uncertainty quickly mounts past the next few years.

A major source of uncertainty is the timing of technological developments, This is particularly true in electronics, where the technology is evolving rapidly. Even in steel, new process technologies could bring significant departures from present methods-such as direct reduction of iron ore, in limited use already, or plasma arc steelmaking. Although potential technological changes in the automotive industry may not seem as radical as in other sectors, newly refined powerplants, increasing use of electronics, and downsizing and repackaging represent substantial shifts in automobile design.

The future prospects of these sectors depend heavily on rates of economic growth for both the United States and the world. In an unstable international political and economic environment, long-term growth remains largely unpredictable, though reasonable bounds can be drawn. For instance, it is unlikely that the industrial nations will soon regain the growth rates of the 1950's and 1960's. At the same time, by the end of the 1980 's, rates of economic growth in the industrialized world seem likely to surpass the depressed rates of the 1970's. The developing countries are not expected to do much better in the current decade than in the 1970's, although their growth rates should continue to exceed those of the industrialized nations.

The competitiveness of the American steel industry during the rest of the century will depend heavily on the ability of firms to generate and attract capital for modernization, on continuing shifts of production to new and efficient nonintegrated mills, and on the strength of competition from imports. Some of this import competition will arise from burgeoning steel capacity in the developing world. Domestic steel demand will rise only slowly. U.S. capacity will likewise remain relatively stable-perhaps increasing slowly, perhaps contracting slightly.

In electronics, as technology continues its rapid advance, sectors such as semiconductors and computers will remain sources of U.S. strength. Market growth will be fueled by a multitude of new applications. Competition on a world basis will intensify, but the United States should remain the leader in both technology and production-though its world market share will probably continue to decrease somewhat-provided that the industry's needs for capital, manpower, and open markets are met. It is also likely that more labor-intensive operations will continue to move abroad, where wage rates are lower.

Automobile sales will, as for steel, experience only slow growth in the developed countries because markets are close to saturation. Growth in demand will be considerably higher in the Third World, particularly in wealthier, rapidly industrializing countries. But while independent steelmaking firms are common in developing countries, automobile manufacture will be dominated by a few large corporations operating on a translational basis with widespread production facilities. Two of these firms are likely to be American-owned, Foreign competition in the ,lucrative U.S. market will remain intense. No doubt imports will have continuing success, but their penetration in the United States may recede somewhat from 1980 levels, 


\section{Economic Growth}

A key determinant of the future prospects of the American steel, electronics, and automobile industries will be economic growthboth in the United States and in the rest of the world. A healthy domestic and international economy is vital to these, as to other industries, because it makes adjustment to changing circumstances-e. g., adoption of new technologies-easier.

Assuming a moderately expanding labor force, relatively slow increases in Government expenditures, and a gradual decline in inflation and unemployment rates between 1980 and 1990, the U.S. gross domestic product (GDP) should grow at roughly the same rate as for the past 30 years: about 3,3 percent per year in real terms (table 25). In the 1970 's the average was somewhat less.

Table 25 indicates that in other industrialized countries, rates of growth are also expected to accelerate. The period from 1950 to 1970 was one in which GDPs in Europe (with the exception of the United Kingdom) and Japan grew at rates considerably above that of the United States. All experienced major declines in rates of growth during the 1970's.
The continued high growth rates expected for Japan are noteworthy, although these are much lower than for the 1950's and 1960's.

Slow growth in the industrial countries will have its effects on developing nations. The Third World is heavily dependent on industrial countries as markets for exports, Given favorable international economic conditions, developing countries should be able to sustain economic growth rates roughly equal to the 5to 6-percent level of the 1970's (see table 25). As might be expected, oil-exporting developing countries have excellent prospects for the coming decade,

The following sections, dealing with the steel, electronics, and automobile industries individually, assume moderate economic growth. If expansion in the U.S. and world economies is substantially below the forecasts, impacts on the steel and motor vehicle industries are likely to be severe; these industries are particularly vulnerable to economic downturns. The outlook would be less clear for electronics, which at times in the past has seemed almost recession-proof, and at other times has shared in aggregate downturns.

Table 25.-Economic Growth Rates, 1950-90 (gross domestic product (GDP))

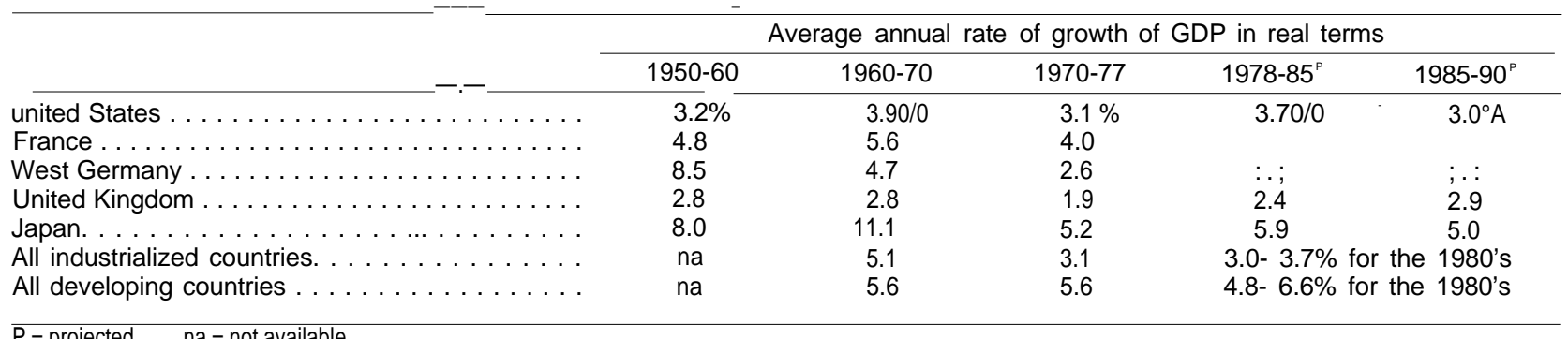

na $=$ not available

SOURCES Historical - Individual countries Statistical Abstract of the United States, 1979

All industrialized countries World Development Report, 1979 and 7980 (Washington, D C The World Bank, 1979, 1980)

Projections-Energy Policies and Programs of IEA Countries, 1979 Review (Pans Organization for Economic Cooperation and Development, 1980), pp 54, 121, 151, 212, and 223, World Development Report, 1979, p 18, and World Development Report, 1980, pp 6, 11, and 99 


\section{Steel}

The competitiveness of the American steel industry over the next 20 years will be shaped by:

1. the adoption of new process technologies, both those already proven and those still in the developmental stages (new steel technologies are discussed in detail in the OTA steel study);

2. continued restructuring of the domestic industry, with nonintegrated firms taking a larger share of the market:

3. structural change in the world steel industry, including the emergence of developing countries as major steel producers and the possibility that overcapacity may persist;

4. continued reliance by U.S. steelmaker on domestic market demand as the primary spur to growth; and

5. public policies, particularly those that affect the ability of the U.S. industry to generate and attract capital for modernizing and improving productive efficiency.

In addition, developments such as increasing prices for raw materials and energy, and domestic inflation will be important. Few large integrated mills are likely to be built in any of the industrialized nations. Market growth in the United States will be slow, and demand met by modernizing existing mills to increase yield and productivity, by roundout additions to capacity, and by constructing relatively small nonintegrated mills.

\section{Supply and Demand}

Table 26 summarizes forecasts for the world steel industry. Most estimates indicate relatively slow growth in total steel capacity until at least 1985. Projected growth rates for capacity in the $1980-85$ period range from zero to about 1.3 percent. Higher growth in capacity is expected for $1985-2000$ as the excess of capacity over demand diminishes.
Table 26.-World Raw Steel Capacity and Demand Estimates (millions of tonnes)

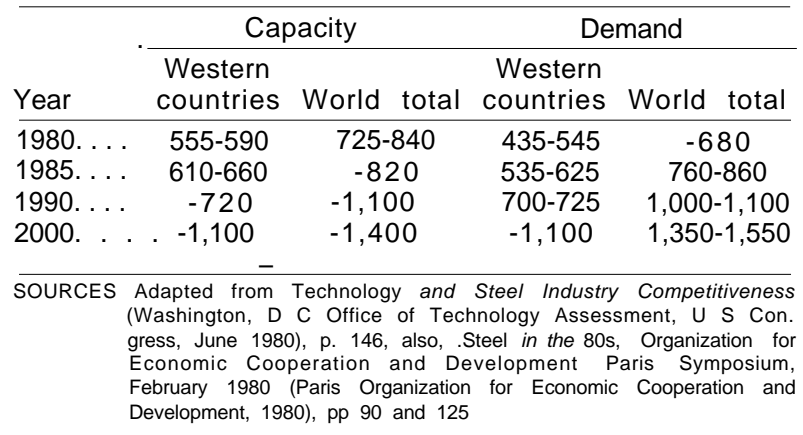

The United States is expected to continue to be a net importer of steel. According to estimates by the Bureau of Labor Statistics, imports will grow slightly faster than exports and the trade deficit in steel may approach $\$ 4$ billion (in 1972 dollars) by 1990 .

\section{Future Competitiveness}

A fundamental competitive problem for the American steel industry is that on average it is no longer the world's most efficient producer (and has not been since the 1960's). A basic question then is: What are the prospects, with and without new public policies, for the industry to become competitive in production costs? This is difficult to answer. First, while the Japanese may now be the world's low-cost producers, other nations could become prime market opponents of both the United States and Japan in the future. In fact, the Japanese have already sensed their longer term vulnerability and begun to reduce the relative importance of the steel sector to their economy. Japanese industrial policy is now based on the assumption that the country is becoming relatively disadvantaged in steel.

\footnotetext{
${ }^{6-1}$ Employment Projections for the 1980's, BLS bulletin 2030 (Washington,D.C.: Department of Labor, Bureau of Labor Statistics, 1979), pp. 79 and 82.
} 
A second factor complicating estimates of the future competitiveness of the U.S. industry concerns the effects of capital investment. As discussed elsewhere, up to a quarter of U.S. steelmaking capacity is obsolescent. Modernizing this plant' and equipment would increase yields and productivity, decrease energy use, hence cut production costs. All of these are desirable, but new investment cannot guarantee a meaningful increase in U.S. competitiveness in steel. A variety of other factors-both inside and outside the United States-are also important. Although the circumstances certainly differ, the Government of the United Kingdom has invested heavily in steel with no appreciable impact on the ability of the British industry to compete.

Competitiveness also depends, for example, on the characteristics of existing and prospective processing technologies. If steelmaking remains relatively labor-intensive, nations with low wage rates may be able to maintain advantages. If new processing technologies depend on natural gas or petroleum, then countries with abundant supplies of these fuels would benefit. Continued use of coal-based processes would work to the advantage of the United States.

The American steel industry clearly must modernize its plant and equipment by installing technologies that improve yields and productivity and lower costs, just to maintain its competitive position. Among the technologies for which U.S. firms lag in installation and use compared to countries such as Japan are continuous casting and computerized process control. ${ }^{2}$ Other important new technologiessome available now, others prospective-include: refinements to the basic oxygen process involving energy savings, control of alloy content, desulfurization, and degassing; direct quenching of rolled products; and a variety of other thermomechanical processing methods, often continuous. Further off are technologies such as large-scale installations

'Technology and Steel Industry Competitiveness (Washington, D. C.: Office of Technology Assessment, U.S. Congress, June 1980), ch. 9 . for direct reduction of iron ore, plasma steelmaking, and continuous steelmaking. At least some of these are likely to be practical realities by the end of the century.

There is another difficult technological question relating to the future of the steel industry. Efficient scales of operation could move downward with the advent of new processing technologies. For example, the OTA steel-study suggests that direct reduction (DR) processes, apparently already economic in some parts of the world, may soon be more cost efficient in the United States as well. The technical data on DR processes, thus far confined to smaller plants, indicate that scale economies may be less significant than for present steelmaking methods. Moreover, DR appears to be both capital- and labor-saving, although more intensive in its use of energy. Such factors could have substantial impacts on the industry. For example, the potential cost advantages of large facilities based on blast furnaces might diminish, creating a tendency for dispersion of the industry to regional production centers, Internationally, the DR process would give advantages to countries with ample supplies of natural gas, such as Mexico.

What, then, is the outlook for the American steel industry? Production increases at somewhat more than 1 percent per year could be achieved by improvements in yield and productivity stemming from modernization and replacement of capacity. Little or no new capacity would be needed under such circumstances, In addition to modernization-which may be limited by the ability of the industry to generate and attract capital-a number of other factors will help maintain U.S. competitiveness:

1. Major competitors such as Japan can no longer expect large productivity improvements from building new greenfield plants using the latest technology. Because Japan, like the United States, will be adding little if any new capacity, future productivity gains will result from incremental improvements to existing mills. The U.S. industry should be able to 


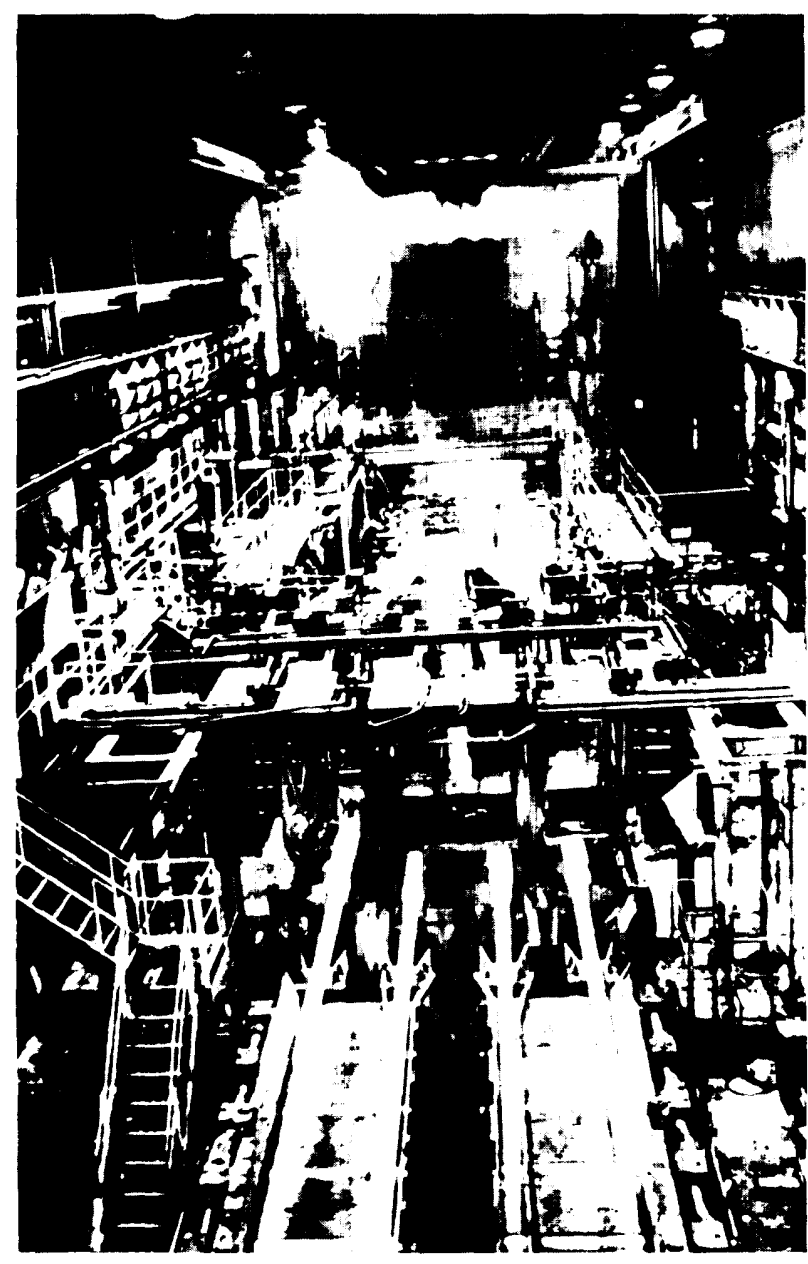

Photo credit American iron and Steel/ Institute

Continuous casting and rolling of steel

retain parity in absolute labor productivity, provided it can continue to operate at higher levels of capacity utilization than Japan.

2. Long-term price trends for raw materials used in making iron and steel-especially energy-should favor the United States, Rising transportation costs will harm the price competitiveness of imports in U.S. markets.

3. In the United States, obsolete mills with high production costs are being closeda rationalization that was probably inevitable. This will help maintain high labor productivity.
4. New and efficient nonintegrated mills are being built in larger numbers.

An important counterweight to optimism is the possibility of continued excess capacity on a worldwide basis. Substantial overcapacity would almost inevitably lead to attempts by foreign producers to dump steel in the United States.

The American industry has been combating dumping for more than 20 years. As a cause of lowered domestic prices and profits, its seriousness remains a matter of debate. \{ A recent survey by the General Accounting Office found that-along with price-quality, plus the availability of some kinds of mill products, were major factors leading to purchases of imported steel. ${ }^{4}$ The large integrated firms, however, claim that dumping is the single most serious problem facing American steelmaker. If excess world capacitiy exists, dumping will almost certainly continue to be a concern-one that may be aggravated where governments own or control steel industries and face strong pressures to maintain employment.

Recently it appears that industry and Government in the United States have moved closer to accommodation on the control of dumping. The latest development-part of the Carter administration's steel revitalization program-takes the form of a reconstituted trigger-price mechanism (TPM). TPM, like other antidumping remedies, is likely to remain a source of conflict, particularly when imports expand and the industry believes the trigger price is too low. However, trigger pricing is more manageable than existing antidumping laws for dealin with widespread and persistent complaints.

Other Government policy initiatives might also help to improve the outlook for the industry. These could take the form of aggregate policies designed to stimulate business in

'R. W. Crandall. "Steel Imports: I)umping or Competition" Reguktion, Jul August 1980. p. 17

"New S trategy Required for AidingDistressed S teplindustry (Washington. I).C..: General Arcounting ()ffict. Jan. 8. 1081), pp. $3-3$ to $3-7$. 
general, or sector-specific programs targeting the steel industry.

Aggregate stimuli are generally intended to encourage new investment by increasing rates of return on invested capital. Most such policies fit into two broad categories: 1) measures that reduce corporate taxes and so increase cash flow; and 2) measures that encourage savings, reducing interest rates and lowering the cost of capital.

Investment incentive schemes would stimulate some investment across the entire steel sector, but most such proposals would have differential effects on various subdivisions of the industry. The large integrated firms have been steadily increasing their long-term debt, and in many cases now appear near the limits of their fundraising abilities in established capital markets. Decreases in effective corporate tax rates-for example, by accelerated depreciation schedules, such as the much-discussed 10-5-3 proposal-would increase the internally generated cash flow available to such companies (for nonsteel diversification as well as steelmaking), While the steel industry presently must depreciate its capital equipment over longer time periods than most other U.S. industries, many proposed tax modifications would increase the ability of industries throughout the economy to attract external capital, Under such conditions, the relative attractiveness of investment in steel might not increase,

In general, accelerated depreciation favors larger firms with larger absolute profits. As a result, such measures might benefit the major integrated steelmaker more than nonintegrated and specialty producers. To the extent that investors judge the latter to have better prospects for high profitability, however, tax changes could help them attract outside investment.

Aggregate (rather than sector-specific) programs fostering the development of new technology would probably not have large effects on the steel industry, Steelmaker have not in the past made heavy investments in R\&D (less than 1 percent of sales, well below many other U.S. industries), ${ }^{5}$ presumably believing the returns insufficient. Aggregate $R \& D$ incentives would be likely to have their greatest impacts on supplier firms. Developments by such firms in process equipment or controls would be available to both domestic and foreign steelmaker, and therefore would probably have only marginal net effects on competitiveness. Sector-specific incentives or programs for steel $R \& D$ would be more likely to enhance the long-run competitiveness of the U.S. industry.

For reasons such as those outlined above, the OTA steel study concluded that without targeted Government support the industry might be unable to modernize and build its competitiveness. Examples of the forms such assistance might take can be found in the steel revitalization program announced by President Carter on September 30, 1980. In addition to the modified TPM, it included proposals for liberalized depreciation allowances, tax credits for investment, relaxed environmental standards, increased adjustment assistance, and initiatives to encourage R\&D.

Most observers agree that at the core of the industry's difficulties are its very large capital needs for modernization-table 27. The capital base for the industry is now as much as 25 percent obsolescent; just to replace the outdated capacity would cost more than $\$ 30$ billion,' The renewal or high-investment scenarios in the table would require substantial Government assistance, much greater than the Carter steel plan provided for. ${ }^{7}$ The potential effects of such assistance on competitiveness can only be judged in the context of structural changes occurring elsewhere in the world steel industry.

Although the American steel industry is primarily domestic-with few exports or foreign investments-its future is inextricably tied to the changing competitive environment worldwide, At present, Japan is the most effi-

\footnotetext{
'Technology and Steel Industry Competitiveness, op. cit., p. 275.

"New Strategy Required for Aiding Distressed Steel Industry. op. cit.. p. 2-9.

Ibid., p. 7-12,
} 


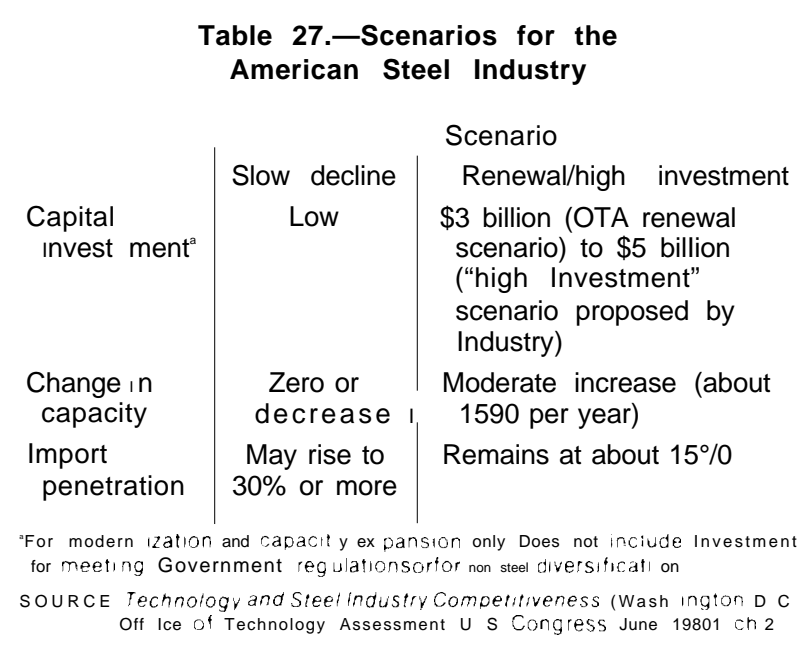

cient steel-producing nation; European firms enter the U.S. market when they have excess capacity. However, developing countries are becoming significant factors, now accounting for about 30 percent of U.S. imports. Despite mill construction costs in industrializing countries that may be 20 - to 30 -percent higher than in the United States,\}' Third World steel capacity is expected to reach 100 million to 105 million tonnes by 1985 , This would increase their share of free world production to 15 percent, versus 10 percent in 1978. Most of the new capacity will be used to meet internal needs, but some Third World steel may find export markets in the United States and other industrialized nations, including Japan. Countries such as Korea have already taken over some Japanese export markets. In virtually all industrializing countries, steel production plays a central role in development strategies. Symptomatic of the growing importance of the steel industries of "Technology and Steel Industry Competitiveness, op. cit. p.
326

\section{Electronics}

Predictions about the future of the electronics industry are risky because the technology is evolving so rapidly. Even where developments seem to be following stable and the developing world is a recent estimate by the International Iron and Steel Institute that, for 1980, steel production in the industrialized countries fell by 8 percent, while rising 4 percent in developing countries."

An increasing number of technology transfers and financing consortia are being arranged between developed countries such as Japan and those which are now industrializing such as Brazil. "Over the next 20 years, the latest technology and methods could become concentrated in those countries installing new facilities. It is quite possible that Third World steel industries will develop along pat terns similar to those found in advanced countries such as the United States: a small number of firms in nat ions with in tegrated steel capacity may produce most of the raw steel output of the region or group of countries they serve (just as a rela tively small number of integrated companies supply most of the U. S. market). In addition, a much larger number of nonintegra ted companies might use electric furnaces and/or finishing equipment to produce or finish the simpler kinds of steel products. (Over 50 developing countries have some type of steel industry, but only 19 have integrated steelmaking capacity. )

Such factors need careful analysis before new public policies are designed. Increased investment in the Un i ted States could lower the average age of plants and raise productivity without substantially enhancing competitiveness-but be necessary just to maintain the present position of the American industry.

\footnotetext{
"L1'\{]rlcl ('rude Steel OutputDrups," ASM New' Februat ro 1981. p. 1. 302
}

predictable paths, surprises can occur. It is not only impossible to project trends in electronics technologies very far-particularly for semiconductor devices and their applica- 
tions-it is also difficult to forecast applications in other industries,

Automobiles, for example, are becoming an important market for integrated circuits (ICS). Other applications that are providing (or will provide) large markets include: office equipment such as word processors, electronic funds transfer systems, electronic mail as well as telephone and other communications systems, and the continually expanding market for digital logic and memory in computer systems. Generalities about such applications are easy, But the timing of growth in markets, their eventual dimensions, and the sorts of technologies that will prove dominant are more problematical.

\section{Supply and Demand}

No long-term projections of worldwide demand for electronics products are available. Short-run sales forecasts generally predict growth at better than 10 percent per year for most segments of the industry.

Longer range estimates for the United States alone have been made. Table 28 is a forecast, by broad categories, of sales in the United States of electronics end products for 1987. This table indicates that total sales will more than double over a 10-year period. Such predictions are typical of the continued rapid expansion expected in this industry. The fast-

"P. Evison, Electronics: The Market to 1982 (London: The Financial Times Ltd., Business Publishing Division, 1978], p. 5.

Table 28.-U.S. Markets for Electronics, 1978 and 1987 (billions of current dollars)

\begin{tabular}{|c|c|c|}
\hline & \multicolumn{2}{|c|}{ Sales } \\
\hline & 1978 & 1987 \\
\hline Business/office . & $\$ 5(6 \%)$ & $\$ 15(8 \%)$ \\
\hline Communications & $13(17 \% 0)$ & $32(17 \%)$ \\
\hline Consumer. . & $8(10 \%)$ & $14(7 \%)$ \\
\hline Computers . & $23\left(30^{\circ} / 0\right)$ & $63(33 \%)$ \\
\hline Government/military & $16(21 \%)$ & $34(13 \%)$ \\
\hline Industrial. $\ldots \ldots \ldots \ldots \ldots$ & $6(8 \%)$ & $14(7 \%)$ \\
\hline instruments $\quad \ldots$ & $6(8 \%)$ & $16(8 \%)$ \\
\hline Total . . . . . . . . . & $\$ 77$ & $\$ 191$ \\
\hline
\end{tabular}

SOURCE: H H Jones, "Forecast of VHSIC/VLSI Market s," VHSIC A New Era in Electronics, San Francisco, Calif , American Institute of Aeronautics and Astronautics, May 15.16, 1980 est growing segment is expected to be computers-the slowest, sales to Government and the military. The table also projects that U.S. consumer electronics markets will expand at lower than average rates, While table 28 includes only end products, components such as ICs and other semiconductor devices will grow at least as rapidly as the average for end products.

Of the three sectors of particular interest - consumer electronics, semiconductors, and computers-consumer electronics sales will also grow the slowest on a world basis-at least in the developed countries. Markets for more mature consumer products-e.g., TVs and home audio equipment-will increase at relatively moderate rates. ${ }^{12}$ Sales of newer consumer products-video-cassette recorders/players (VCRS), digital clocks and watches, microwave ovens, video gamesare expected to grow more rapidly. Markets for many of these products are far from saturated. If prices fall, and particularly if some rationalization of VCR technology occurs, consumer demand should be strong.

Semiconductors will show stronger growth than consumer electronics. Table 29 gives near-term estimates of world semiconductor production. In this table, overseas production by U, S.-owned firms is attributed to the United States, On this basis, growth in IC production for American-based companies (both merchant and captive) is expected to average over 20 percent for the next few years. Slower rates of growth, near 10 percent per year, are projected for Europe. In Japan, 20-percent growth rates are also anticipated,

Sales of computers and related data processing equipment are also expected to increase at high rates, The most rapid growth will be in minicomputers, desktop or personal machines, and small business computers, Office automation and data communications will expand at comparable rates.

Exports of computers and peripheral equipment have been projected to increase at

\footnotetext{
Ibid., p. 33
} 
Table 29.-Estimated World Semiconductor Production by Geographic Location of Firm Headquarters (millions of current dollars)

\begin{tabular}{|c|c|c|c|c|}
\hline \multirow[b]{2}{*}{ Headquarters location } & \multicolumn{4}{|c|}{ Production } \\
\hline & 1978 & 1980 & 1981 & 1982 \\
\hline \multicolumn{5}{|l|}{$\begin{array}{l}\text { United States } \\
\text { Ics }\end{array}$} \\
\hline 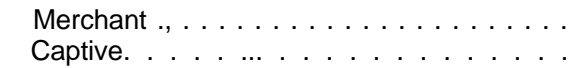 & $\begin{array}{r}\$ 3,238 \\
1,344\end{array}$ & $\begin{array}{r}\$ 5,640 \\
2,580\end{array}$ & $\begin{array}{r}\$ 7,330 \\
3,400\end{array}$ & $\begin{array}{r}\$ 8,790 \\
4,080\end{array}$ \\
\hline 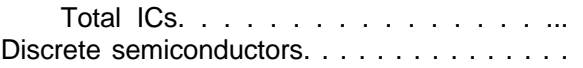 & $\begin{array}{r}\$ 4,582 \\
1,540\end{array}$ & $\begin{array}{r}\$ 8,220 \\
2,200\end{array}$ & $\begin{array}{r}\$ 10,730 \\
2,530\end{array}$ & $\begin{array}{r}\$ 12,870 \\
2,910\end{array}$ \\
\hline $\begin{array}{l}\text { Total semiconductors } . . . \\
\text { Western Europe }\end{array}$ & $\$ 6,122$ & $\$ 10$ & $4 \$ 3,860^{-}$ & $\$ \overline{15,780}$ \\
\hline $\begin{array}{l}\text { Total ICs. } \ldots . \ldots \ldots \ldots \ldots \ldots \\
\text { Discrete semiconductors, }\end{array}$ & $\begin{array}{r}\$ 453 \\
960\end{array}$ & $\begin{array}{r}\$ 680 \\
1,080\end{array}$ & $\begin{array}{r}750 \\
1,150 \\
\end{array}$ & $\begin{array}{r}830 \\
1,220 \\
\end{array}$ \\
\hline $\begin{array}{l}\text { Total semiconductors } \ldots \ldots \ldots \ldots \\
\text { Japan }\end{array}$ & $\$ 1,413$ & $\$ 1,760$ & $\$ 1,900$ & $\$ 2,050$ \\
\hline 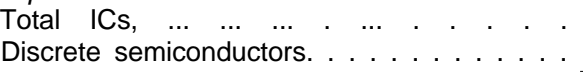 & $\begin{array}{r}\$ 1,195 \\
1,295 \\
\end{array}$ & $\begin{array}{r}\$ 1,850 \\
1,570 \\
\end{array}$ & $\begin{array}{r}2,220 \\
1,730 \\
\end{array}$ & $\$ 2,660$ \\
\hline Total semiconductors . . . . . . . . . . & $\$ 2,490$ & $\$ 3,420$ & $\$ 3,950$ & $\$ 4,560-$ \\
\hline $\begin{array}{l}\text { Rest of world } \\
\text { Total ICs, . . . . . . . . . . . . . . . . . . . . . } \\
\text { Discrete semiconductors. . . . . . . . . . . . . }\end{array}$ & $\begin{array}{r}\$ 82 \\
985 \\
\end{array}$ & $\begin{array}{r}\$ 730 \\
1,050 \\
\end{array}$ & $\$ \begin{array}{r}940 \\
1,090 \\
\end{array}$ & $\begin{array}{r}\$ 1,130 \\
1,130 \\
\end{array}$ \\
\hline Total semiconductors $\ldots . . . \quad . .$. & $\$ 1,467$ & $\$ 1,780$ & $\$ 2,030$ & $\$ 2,260$ \\
\hline $\begin{array}{l}\text { Total integrated circuits. } . . \\
\text { Total discrete semiconductors }\end{array}$ & $\begin{array}{r}\$ 6,712 \\
4,780 \\
\end{array}$ & $\begin{array}{c}\$ 11,480 \\
5,900 \\
\end{array}$ & $\begin{array}{r}\$ 14,640 \\
.6,500 \\
\end{array}$ & $\begin{array}{r}\$ 17,490 \\
7,160 \\
\end{array}$ \\
\hline Total semiconductors . . . . . . . . & $\$ 11,492$ & $\$ 17,380$ & $\$ 21,140$ & $\$ 24,650$ \\
\hline
\end{tabular}

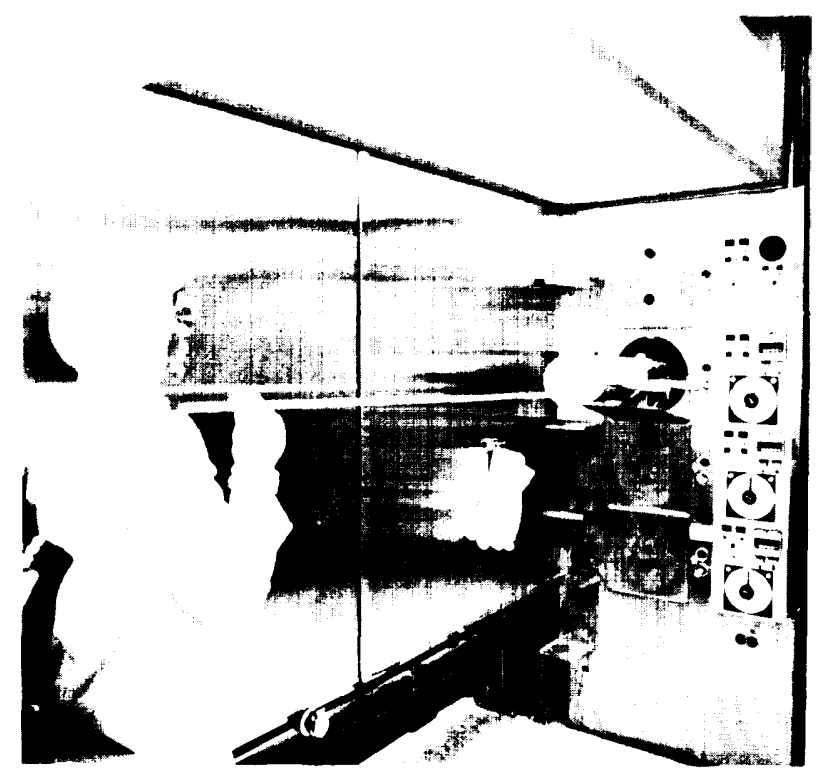

Fhoto credit Natronat Semiconductor Com

Semiconductor wafers being loaded into diffusion furnace an annual rate of 6.3 percent, far outstripping the 2.7-percent growth rate for imports. ${ }^{13}$ By 1990, the dollar value of computer exports should be more than 12 times the value of imports.

The rapid growth and technological change expected throughout much of the electronics industry should make it easier for the United States to maintain its competitiveness, These are the conditions under which American firms typically thrive,

\section{Technology}

The consumer electronics sector might be considerably altered by the successful commercialization of new product technologies such as flat screen TVs, particularly if the innovators are firms outside the mainstream

'Employment Projections for the 1980's, BLS bulletin 2030 (Washington. D.C.: Department of Labor, Bureauof Labor Statistics, 1979$)$, pp. 79 and 82. 
home entertainment sector. Microcomputers for home use may also become important consumer products, perhaps evolving along with VCRs, video toys and games, and TV receivers into integrated home entertainment and information systems. The timing of such developments is unpredictable.

Progress in major categories of semiconductor devices-such as ICS for computer memory or microprocessors-seems at present to be following predictable patterns. For memory circuits, as density increases (fig. 11), costs per bit go down (fig. 12). Figure 11 indicates that the rate of density increase in dynamic random access memories (RAMs) is slowing; the 64K RAM is still in infancy and may not outsell $16 \mathrm{~K}$ devices until 1983, pro-

\section{Figure 11.-Projected Increase in Density of Random Access Memory Circuits}

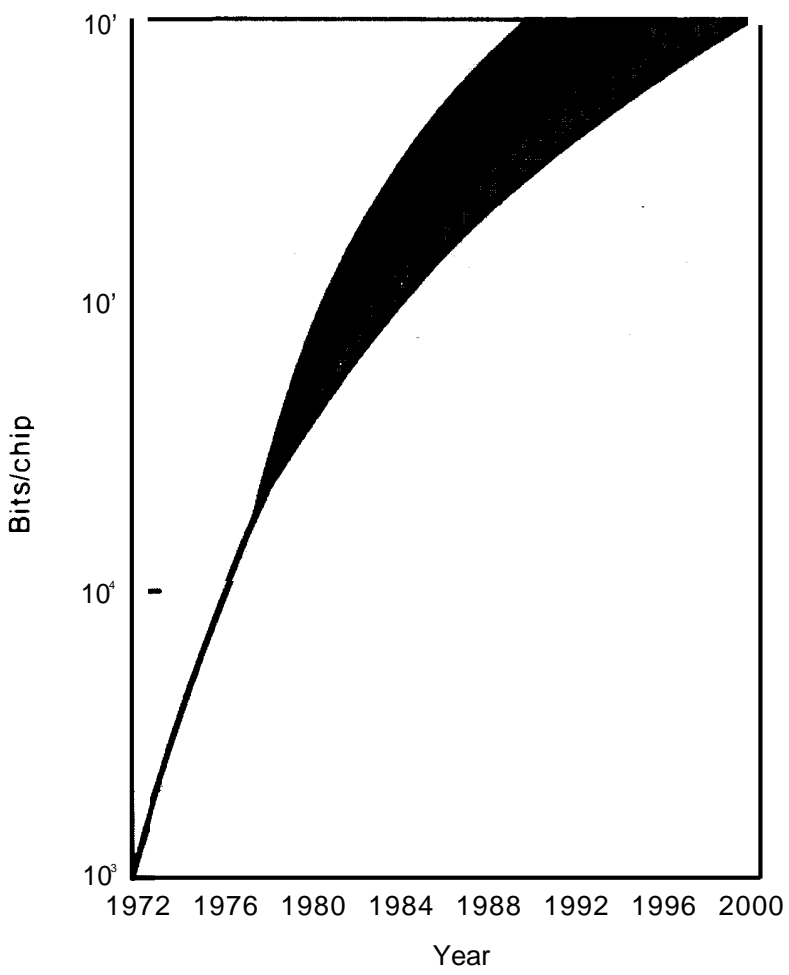

SOURCE K D Wise, $\mathrm{K}$ Chen, and R E YokelyMicrocomputers: A Technology Forecast to the Year 2000 (New York John F Wiley \& Sons, 1980), p 57 duction of $64 \mathrm{~K}$ RAMs having proven more difficult than anticipated. '4

Microprocessors are likewise continuing their evolution - from 4 bit to 8 bit to 16 bit. The market has yet to decide which of the various 16-bit microprocessor designs will be the biggest sellers, but 32-bit processors are already on the horizon. Needless to say, there is also continuing evolution and innovation in other types of semiconductor devices, for example, gate arrays for logic, displays, and solid-state transducers. Among the most important are ICs for interfacing digital circuitry with the analog world-essential for

"J. G. Posa, "Dynamic RAM's: What to Expect Next," Electronics, May 22, 1980, p. 119.

Figure 12. - Projected Decrease in Cost per Bit for Random Access Memory Circuits

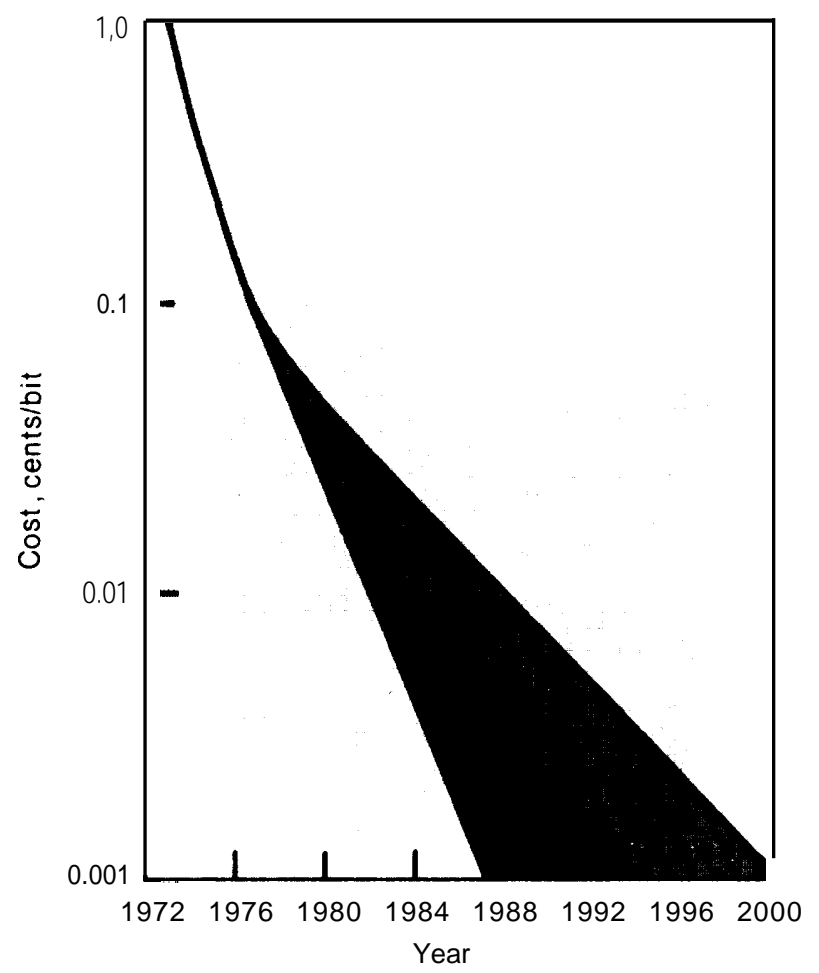

SOURCE K D Wise, K Chen, and R E Yokely, Microcomputers A Technology Forecast to the Year 2000 (New York John F Wiley \& Sons. 1980). p 57 
many applications of semiconductor electronics.

In several respects, computer technology evolves in parallel with that of semiconductors. This has been true since the late 1950's, when discrete transistors were adopted for second-generation mainframe machines; logic and memory for computers are now firmly based in IC technology. Innovations such as Josephson junctions for processing, and optical storage, may find a place in the future; but in 1981 computer hardware continues to depend on silicon logic and memory for most such functions, Much of the other hardware in computer systems uses quite different technologies-e. g., disk and tape drives for mass storage, cathode ray tube display terminals, card readers, printers. But even the electromechanical input/output devices depend in various ways on semiconductors.

Computer hardware is diversifying in technology and range of capabilities as minicomputers and microcomputers grow in importance. Furthermore, microprocessors are being used in many new dedicated applications to make other machinery and equipment "smart "- whether automobile engines, telephones, or toys. The bottleneck in many cases-whether computers for computing or for dedicated applications-is software. While hardware costs have been falling, programing costs have not; productivity in software is about the same now as 10 years ago. Furthermore, good programmers are in short supply (ch. 5), Thus, the proportion of user cost accounted for by software has gone up rapidly. In some cases, software represents 90 percent of the cost to the user. While the United States leads the world in software as in hardware, the software bottleneck is a potential constraint on the future growth of computer sales and on applications of microprocessors and computers.

\section{Future Competitiveness}

Chapter 5 examined the present competitive positions of the U.S. consumer electronics, semiconductor. and computer industries.
While the consumer electronics sector did not appear particularly healthy, both the semiconductor and computer sectors continue to be vigorous, and very strong internationally.

If past trends continue, the prospects for the U.S. consumer electronics industry seem mixed at best. American firms face continued strong competition from foreign producers on cost as well as noncost dimensions, particularly in products such as TV receivers. Imports already constitute 85 percent or more of U.S. consumption of black and white TVs, VCRs, household radios, and $\mathrm{CB}$ radios (see table 16 in ch. 5). Although import penetration in color TVs is much lower, this is due to restrictions imposed by Orderly Marketing Agreements.

There are two basic questions for future competitiveness:

1. To what extent is labor intensity likely to fall as a result of new technologies. allowing U.S. firms to repatriate offshore operations?

2. Will American firms be able to compete in new generations of consumer electronics products?

The first question depends on both product and process technologies, Automated manufacturing requires product technologies appropriate to the available process techniques. For example, vacuum tubes were too fragile for automatic insertion using methods available for transistors and ICs. In any case, although labor content for many products will continue to fall, competition in the consumer electronics sector is so intense that low wages in overseas locations will probably continue to attract much of the value-a(i(ied. Japanese firms are also moving to other far Eastern countries with lower wage levels.

The second question deals with the ability of U.S. firms to compete in emerging consumer electronics products. Just as most U.S. TV manufacturers lagged the Japanese in adopting sol id-state designs, American firms did not aggressively develop new ho)me entertainment products during the 1 970's (except for 
electronic toys and games). No American company makes consumer VCRs. In video disk players, RCA is making a strong bid, but faces intense competition from disk systems developed in Europe and Japan.

Outside the traditional home entertainment (radios, TVs) portion of the industry, U.S. firms have been much more aggressive in developing new products-e,g., home computers, electronic toys and games. The Japanese have not yet mounted a challenge to U.S. microcomputer producers. As the markets for these products grow, Japanese companies will probably begin to compete in hardware, but may have more trouble developing attractive software packages.

U.S. firms do not retain the technological advantages of 10 years ago in semiconductors or computers. Even so, their positions remain strong. In both industries, the United States is a leader in innovation and new product development-simply not as far ahead as in the past. There will be vigorous future competition in both sectors, particularly from Japanese companies.

As in any industry which is rapidly growing, ample opportunities will exist for both gains and losses in market share-depending on factors such as success at R\&D and prod-

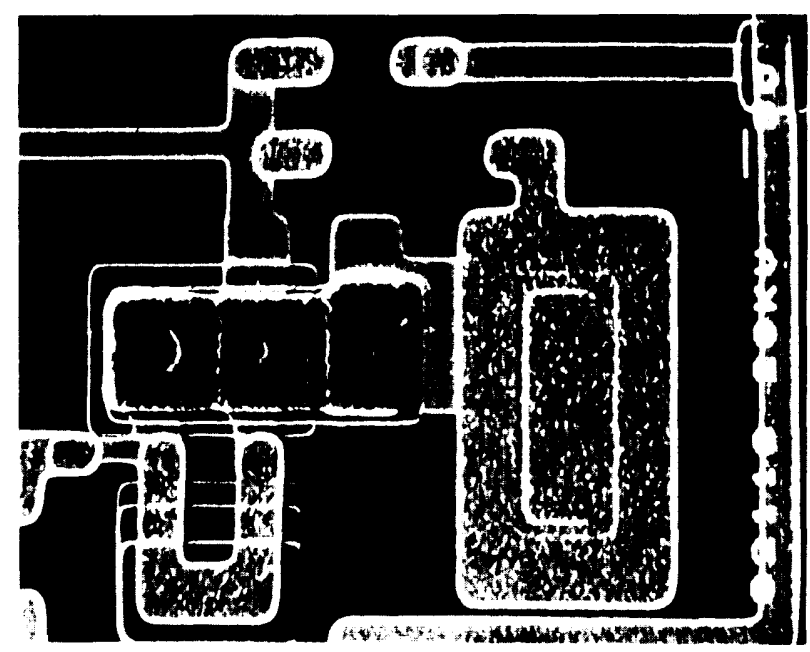

Photo credit IBM Corp.

Experimental Josephson junction logic gate-a candidate for future computers that could operate many times faster than those of today uct development, as well as marketing. Further shakeouts in semiconductors and computers may occur, and more American firms could be absorbed through mergers or takeovers. In some cases, foreign manufacturers may establish strong positions, as they have in consumer electronics. On an overall basis, however, the United States should remain the strongest force in the world market for semiconductors and computers. At the same time, the relative strength of the United States will probably decline,

To maintain competitiveness in the future, U.S. firms must have: 1) sufficient capital to keep pace with rapidly expanding markets; 2) an adequate supply of technicians, engineers, and scientists to staff their operations; and 3) access on fair terms to foreign markets. Not all manufacturers will fare equally well in meeting these needs. Profits in the semiconductor industry have sometimes failed to keep pace with capital needs for expansion, According to several estimates, the U.S. semiconductor industry may have to invest more than $\$ 30$ billion during the 1980's to maintain its current market position (ch. 5). Not only is the industry growing, it is becoming more capital intensive; an IC fabrication facility cost about \$2 million in the late 1960's-now the cost is $\$ 50$ million or more,

Virtually all U.S. electronics firms could benefit from public policies encouraging increased $\mathrm{R} \& \mathrm{D}$, and investment in new production facilities. Among the suggestions have been tax credits for $R \& D$, encouragement of industry-funded R\&D in universities, and cooperative (Government/industry/university) technology centers, Most costs associated with R\&D - in this or any industry - can now be deducted in the year incurred: but $R \& D$ typically amounts to only a small fraction (e.g., 10 to 20 percent) of the expenses associated with commercializing new products or processes. Thus, tax policies in the United States are not a particularly strong stimulus for innovation, " In foreign countries, incen-

${ }^{15} \mathrm{C}$. A. Barrun, "Microelectronics: A Survey," The Economist, Mar. 1, 1980, p. 4.

"'T. Gallagher, "Tax Policy and Industrial Innovating, "Congressional Research Service, Jan. 11, 1980. 
tives are often more extensive. The Japanese Government, for instance, gives a tax credit of 20 percent for increases in R\&D spending, as well as a variety of sector-specific tax breaks-for example, to firms developing computer software. Given the importance of $\mathrm{R} \& \mathrm{D}$ in electronics, there is ample scope in the United States for new policies to stimulate developments in both product and process technologies, and in particular to encourage the commercialization of $\mathrm{R} \& \mathrm{D}$.

Accelerated depreciation of manufacturing equipment would not affect semiconductor producers to as great an extent as firms in many other industries. Equipment used by semiconductor manufacturers can already be depreciated rapidly because the advancing technology makes equipment obsolete in short order. Changes in depreciation schedules might be more beneficial to consumer electronics firms.

A more generalized policy for encouraging capital investment, designed to stimulate the venture capital markets which are important for many high-technology industries, would be to allow capital gains tax rollovers; if funds were reinvested within a specified period of time, capital gains taxes would be deferred. There are many other possible avenues for encouraging new capital investment broadly across American industry. The effects of such policies vary widely among sectors-and among firms within a sector, The costs and benefits of such policies can in fact only be evaluated on a sector-by-sector basis.

Public policy could also help to increase both numbers and quality of technical personnel-a crucial part of the human resource for the U.S. electronics industry. Examples include R\&D support to colleges, universities, and technical schools that train engineers and technicians, funding for purchases of laboratory equipment for use in research or instruction, and student loan programs.

Kijoheno Kuisetsu (An Explication of the Law for the Promot ion of Speci fic: Machinerv and Information Industries] ('Tokvo: Tsusho SangvoSho(MITI), 1980), p.78ff.
Not only might the Government act to enhance the attractiveness of investment and to ensure adequate supplies of trained manpower, but it can also promote free trade and investment. U.S. firms sometimes assert that they are denied access to foreign markets, particularly in Japan. The Japanese market for electronics products is now more open than in years past, and impediments to U.S. firms with operations in Japan less serious," but improvements can still be made. Particularly important for the future is the ability of U.S. firms to compete on even terms within Japan through direct investment as well as exports,

The Multilateral Trade Agreements (MTAs), ratified by the United States in 1979, are a further step toward a more open system of international trade. Japan and the European Community made important tariff concessions for computers and electronics components, However, the tariff decreases by themselves are not expected to have major impacts on U.S. exports, First, the tariff reductions are now scheduled to be staged over an 8-year period, and so would not be in full force until the late 1980's (the staging is still being negotiated). More important, nontariff barriers to trade have been the true impediments to U.S. exports of electronics products.

The MTAs include language covering nontariff barriers such as licensing, product standards, customs valuation, and government procurement. As the dispute between the United States and Japan over the procurement practices of the Nippon Telegraph and Telephone Public Corp. indicates, the effectiveness of the accords will depend on how they are interpreted and enforced. Yet the combined impact of tariff reductions and new agreements on nontariff barriers could result in a significant increase in U.S. access to foreign markets, If American firms are allowed to compete on an equal footing with their foreign competitors in all markets, their

${ }^{14} \mathrm{~J}$. Gresser. High Technology and Jupanese Industrial Policy: A Strategy for $[1, \mathrm{~S}$, Policymakers (Washington, I), C.: Subcommi t tee on Trade, Commit tee on Ways and Means, 1]. S. House of Representatives, Oct. 1, 1980), p. 57. 
proven ability to innovate and to develop new products should enable them to maintain a strong presence in semiconductors, computers, and other high-technology branches of electronics. On the other hand, a movement towards protectionism by the United Statesin any industry-could impede the further opening of international markets and harm competitive American firms.

\section{Automobiles}

World automobile production is dominated by large firms with headquarters in the United States, Western Europe, and Japan. Though production takes place in many other countries-sometimes under the constraints of local content rules-it is usually carried out by foreign subsidiaries of the major U.S. or European firms; Japanese automakers have thus far preferred (and mostly been able) to produce at home and export.

While assembly will probably remain dispersed, automobiles produced by a given firm in different countries are becoming more similar. The "world car" will share many design features wherever built. This will make international production-for example, engines in one country, transaxles in another-easier, Government regulations-in the United States and other countries-will continue to be strong influences on automobile design and engineering.

Like steel and other mature industries, automobile markets in the United States are growing only slowly. Sales will expand more rapidly in most other parts of the world, particularly in developing countries. In the two decades prior to 1980 , the number of autos in the U.S. fleet doubled; the number in Western Europe quadrupled. Over the next two decades, it is the automobile fleets in Eastern Europe and the Third World that will triple or quadruple. As in the steel industry, there is substantial overcapacity at present in the world automobile industry, Market growth, even with optimistic assumptions for industrializing countries, is not likely to be rapid enough to keep all of the world's auto plants busy.

\section{Supply and Demand}

Projections for long-term expansion in the U.S. market for automobiles (and light trucks) generally fall in the range of 0.4 to 2 percent per year. ' $g$ Growth at the low end of this range, table 30, would give sales of a little over 12 million passenger cars in the year 2000 .

Table 30 also includes forecasts for other parts of the world. The growth rate expected

${ }^{14}$ U.S. Industriul Outlook 1980 (Washington, D. C.: Department of Commerce, 1980), p. 281, estimates 1.5 to 2 percent, Another recent forecast (U.S. Automobile Industry Trends for the 1980's, A Delphi Forecast (Chicago,: Arthur Anderson \& Co., 1979)) predicts domestic sales by U.S. automakers to be $11 \mathrm{mil}$ lion to 12 million cars in 1985, rising to 12.5 million to 13 million by 1990 (about 2-percent average annual growth), A later panel (Worldwide Competitiveness of the U.S. Automotive industry and Its Parts Suppliers, Arthur Anderson \& Co., February 1981 ) predicted less than 1 percent annual growth. In addition, the 1979 Delphi panel predicts that Japanese firms will produce 225,000 to 300,000 cars in the United States by 1985 and 500,000 to 600,000 by 1990 . Thus Japanese production in the United States might account for close to 3 percent of the 1985 market, 5 percent by 1990 . The panel expects Japanese imports to add another 15 percent-about 1.5 million units-to the 1990 figure.

Table 30.-Projected Sales of Passenger Cars in Major World Markets

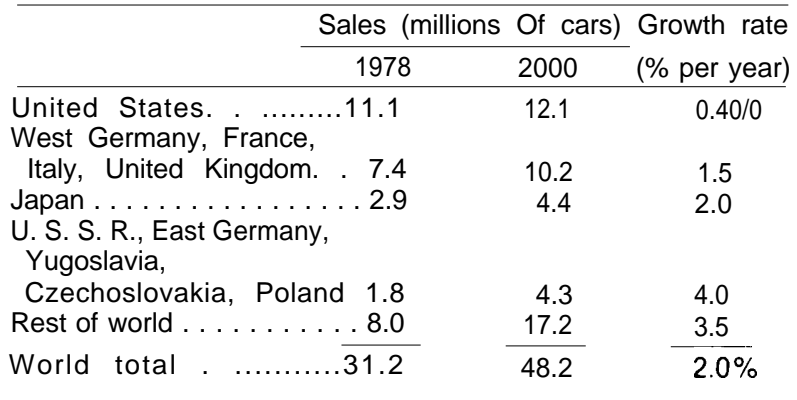

SOURCE The Changing World Automotive Industry Through 2000 (Cambridge, Mass Arthur D Litle, Inc , January 1980) 
in the United States is the smallest by far-a factor of 5 below that for the world as a whole. The consensus on this point seems clear: market growth in the United States will be slower than growth in GDP (table 25), as well as slower than sales growth in other countries. ${ }^{20}$

Along with a market that is more nearly saturated than many others, rising energy costs will constrain motor vehicle sales. Although the United States is highly dependent on cars and trucks for transportation, the fleet is already very large and many vehicles are not heavily utilized. Rising fuel costs may encourage replacement of older, less-efficient automobiles, and developments in specialized vehicles such as very small commuter cars might also help sales. But with multiple-vehicle ownership already common, these effects are not likely to be dramatic. Thus market expansion will remain slow.

The net U.S. trade balance in motor vehicles and parts will almost certainly remain negative. Although imports of passenger cars exceeded 25 percent of the U.S. market during 1980, most observers think their share will decrease somewhat. Estimates for the 1990 period generally show imports in the 15to 20-percent range. Given the presently unsettled state of the market, there is ample room for uncertainty; import market shares greater than 20 percent are not impossible.

Table 30 projected sales in the major countries of Western Europe increasing from 7.4 million in 1978 to 10.2 million in 2000 , an annual growth rate of about 1.5 percent. Sluggish growth in Europe would be of concern to Ford and General Motors, which have large European operations. (Ford, with a manufacturing capacity of 1.8 million units, and General Motors, with 1.6 million, have about 25 percent of total European capacity. )

Annual rates of market growth projected for Japan are about the same as for Western

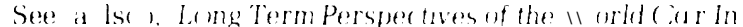

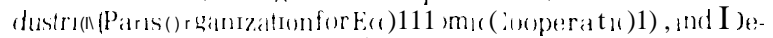
velopment, Februarv1978): h Bhaska r, The Futule of World Mutur Induatru(Neu York Nokuls Pub)lishing. 1980j.
Europe-1 to 2 percent (table 30). Much faster growth is expected for the countries of Eastern Europe and the Third World. Table 30 shows 4-percent annual growth in Eastern Europe: by 2000, sales in Eastern Europe may equal those in Japan.

Forecasts for the developing world vary widely-from 3.5 percent annual grow th - to 9 percent, " There will be much variation from country to country, with demand depending on income levels, fuel costs, and other factors. The more rapidly industrial izing countries, particularly those where automobile manufacturing facilities are located, will likely fall at the high end of the growth range, By 2000, the Third World may account for 30 percent of world auto sales, becoming the largest of the markets listed in table 30 . Firms that can capitalize on these rapidly expanding markets will emerge at the end of the century in strong competitive positions.

\section{Automotive Technology}

The fundamentals of automotive technology are relatively stable, although engineering designs have been changing-particularly for cars made in the United States. An automobile is a rather complex system: regulations and consumer demands for greater gas mileage have forced changes in the way the individual elements of the system are designed, and also the way they are integrated. Big gains in fuel economy-while preserving interior space, reliability and durability, and flexibility in use-come from modifying the system at many points. Powerplants are refined, as are transmissions; aerodynamic drag and rolling resistance are reduced; weight decreased. Front-wheel drive is now commonly chosen to give more interior space for a vehicle of given size and weight-particularly important for small cars-though at the expense of somewhat greater mechanical complexity and thus higher manufacturing costs.

"The Changing World Automotive Industry Through 2000 (Cambridge. Mass.: Arthur L). Little, Inc., January 1980)

"Long Term Perspectives of the World Car Industries. op. cit. 
Technological change through the end of the century is likely to continue to follow these patterns. Powerplants and package sizes will become smaller. Eight-cylinder engines will be replaced by sixes and fours. Three-cylinder engines will also appear. The detail design of spark-ignition engines will be continually modified and improved to more nearly optimize fuel economy and emissions. Diesels will be more widely used, but alternative heat engines are not likely to see widespread application.

Engine weights for given power output will continue to be reduced by means of thinner walled castings, as well as increased use of aluminum for components, including cylinder heads and some engine blocks. Plastics and ceramics may become practical for limited use in internal engine applications, Efficiency will be improved by reducing engine friction and heat rejection to the cooling system. Compression ratios may increase somewhat as combustion chamber designs are tailored to available fuels and electronic control systems are used to prevent detonation. Integrated engine control systems will be even more important for regulating parameters such as fuel-air ratio and spark timing to maximize fuel economy consistent with permitted emissions levels. Improved transmission designs-perhaps eventually continuously variable transmissions-will further integrate engine and transmission control. Relatively large increments in driving cycle fuel economy could result from such systems,

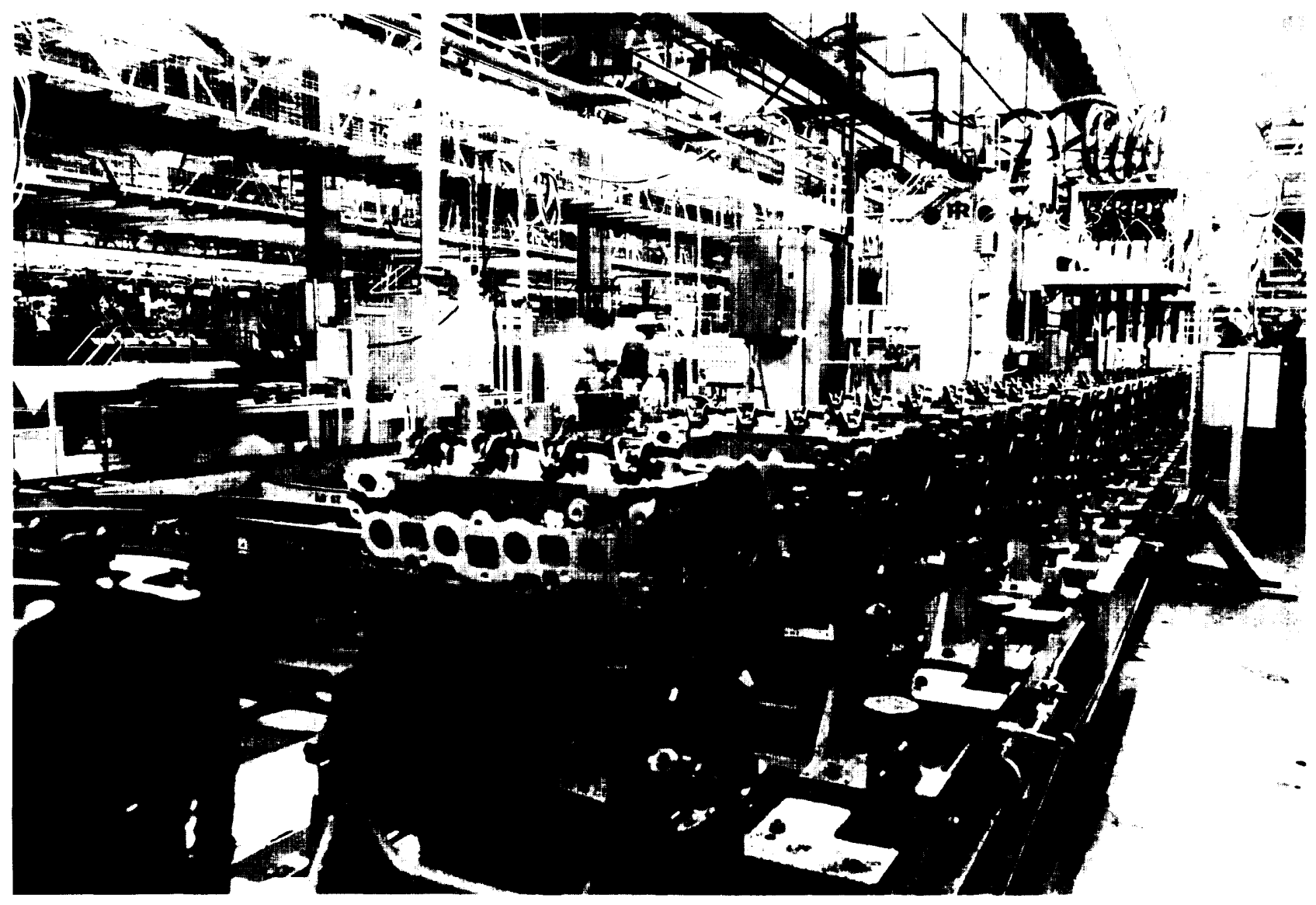

Four-cylinder engines for 1981-model U.S. small cars 
which would permit engines to operate in the speed and load ranges where efficiency is highest,

Turbocharging, though costly, will be used more widely, particularly on diesel enginesbut continuing applications of diesels to passenger cars may be limited by emissions regulations. The outlook for alternative fuels is uncertain, and in the United States depends to a considerable degree on energy policies; technologies can probably be developed to accommodate whatever fuels-including synthetics-are available.

Prospects for electric vehicles, like alternative heat engines, seem to keep receding into the future. While a slowly growing presence in the marketplace is possible, significant penetration of electric passenger cars by the end of the century appears unlikely.

Just as in powertrains, technological change elsewhere in the vehicle system will be gradual though cumulatively significant. Downsizing and weight reduction will continue; more high-strength steel, aluminum, and perhaps magnesium will help cut weight. Plastics and composites will appear in primary structural applications-perhaps wheels, for example.

Further changes in package designs are more problematical, The fleets of most U.S. automakers will be largely front-wheel drive by the late 1980 's. The market for specialpurpose commuter cars has yet to be tested in the United States, If very small two-passenger cars should prove popular, Japanese manufacturers-with their experience in halfliter ' microcars' - may initially have an edge.

Developments in manufacturing technology will also be gradual but cumulatively have major impacts, particularly when associated with new materials. Innovative manufacturing techniques may speed the use of structural composites. For metals, near-net-shape processing will continue to be a goal, as will

"J. Yamaguchi, "Three Semi-Automatics for Light Cars, ' Automotive Engineering, vol. 88, September 1980, p. 119. more rapid machining, Pressure for low production costs, along with somewhat longer time periods between model changes, will maintain the incentives for large-scale dedicated manufacturing facilities. FIexible automation-e.g., use of robots-will also increase, particularly for arduous and potentially health-threatening tasks such as painting and welding, and for work demanding precision or high quality.

U.S. manufacturers will participate in developments in motor vehicle technology on a more-or-less equal footing with automakers in other parts of the world, As in the past, unique technology is not likely to play a major role in the competitiveness of automobile firms,

\section{Future Competitiveness}

Much of the recent public debate over the problems of the U.S. automobile industry has centered on the slump in sales by domestic manufacturers during 1980, and the concurrent rise in imports from Japan, Both the United Auto Workers and the Ford Motor Co, asked for import quotas and/or tariff increases, blaming Japanese imports for the bulk of the difficulties of the domestic industry.

Trade protection-whether tariffs or quotas or both-would aid the domestic industry to the extent that imports are a cause of its current problems. As pointed out in chapter 5 , there are a variety of other factors at work-recession, high interest rates, rising gasoline prices, and shifting consumer tastes, But if trade restrictions were imposed, they would nonetheless tend to increase sales of domestically produced vehicles, raise profits, and also raise employment in both the auto firms and their suppliers.

The rationales for limiting imports of automobiles (and light trucks) are similar to those used earlier to justify quotas and other measures intended to insulate the steel and consumer electronics industries (ch. 6). Restrictions on imports for a limited period of time could, in principle, allow domestic firms 
to increase their revenues, hence their ability to generate investment capital. Investmentin new products as well as in plant and equipment-could help the industry to revitalize itself and restore its competitive position. The U.S. automobile industry does have large capital needs, as discussed below and in chapter 5. A key question for policymakers considering trade restrictions such as quotas or tariffs is: To what extent will limiting imports of cars and trucks increase the cash flow available to American automakers for reinvestment? The corollary, of comparable importance, is: What would be the costs and benefits to the economy as a whole of such measures?

Increases in capital available for new investment would depend essentially on increases in sales of domestic vehicles resulting from trade protection, and on the price increases that might result because of lessened competition from imports in the marketplace, These two factors are of course interrelated; higher prices would be expected to reduce sales. Presumably, the increase in sales volume of domestic cars resulting from import restrictions would be less than the reduction in imports because some consumers would defer purchases if denied imports. However, import restrictions could also help the industry attract external capital by decreasing the risks perceived by lenders, Reductions in unemployment among autoworkers would be a direct benefit to the economy because payments for unemployment insurance and trade adjustment assistance would decrease. Many other less direct benefits could follow-e.g., revival of local economies in regions heavily dependent on the automobile manufacturers and their suppliers.

The costs to the public at large of import restrictions-primarily through higher prices - could also be large, perhaps several billion dollars." Thus, it is not clear that import restrictions could substantially benefit the domestic industry without imposing high costs on consumers. Even if import relief

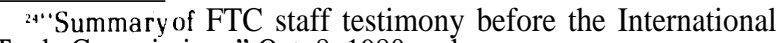
Trade Commission, " Oct. 8, 1980, p. lo. measures helped solve the near-term difficulties of the U.S. auto industry-e.g., profitability and employment - they might still have little effect on long-term problems of restructuring, particularly the need for investment capital to finance redesign and retooling, simply because these capital needs are large compared to the probable results of import restrictions.

Expenditures both here and overseas by U.S. firms for conversion to newly designed small cars-including costs of engineering design and development, as well as new plant and equipment-are estimated at about $\$ 7 \mathrm{o}$ billion (in 1980 dollars) during the 1979-85 period (ch. 5), more than double the rates of capital spending during the 1970's. Most spending estimates have been based on changeovers to product lines that will meet the Corporate Average Fuel Economy mileage standards scheduled for these years. If market demand for small, high-mileage cars continues to outrun these standards, or if the Government calls for large additional improvements in mileage for the post-1985 period, then further rounds of redesign and retooling could be required. This would place an additional and heavy burden on the U.S. industry, Not only would automakers face new outlays, but facilities that are now being designed and built for downsized cars might become obsolete well before the investments had been paid back. Under such circumstances, the financial resources of even the strongest American manufacturers might continue to be stretched in comparison to their overseas competitors, who can undertake more gradual changes in their own car lines-which in many cases already include models considerably smaller and more economical than any exported to the United States (e.g., the Japanese microcars mentioned above).

Should aid for U.S. automakers directed at such long-term concerns be judged necessary -whether as a supplement or a substitute for trade restrictions-this could, as for the steel industry, take the form of either aggregate or sector-specific policies, Relaxation 

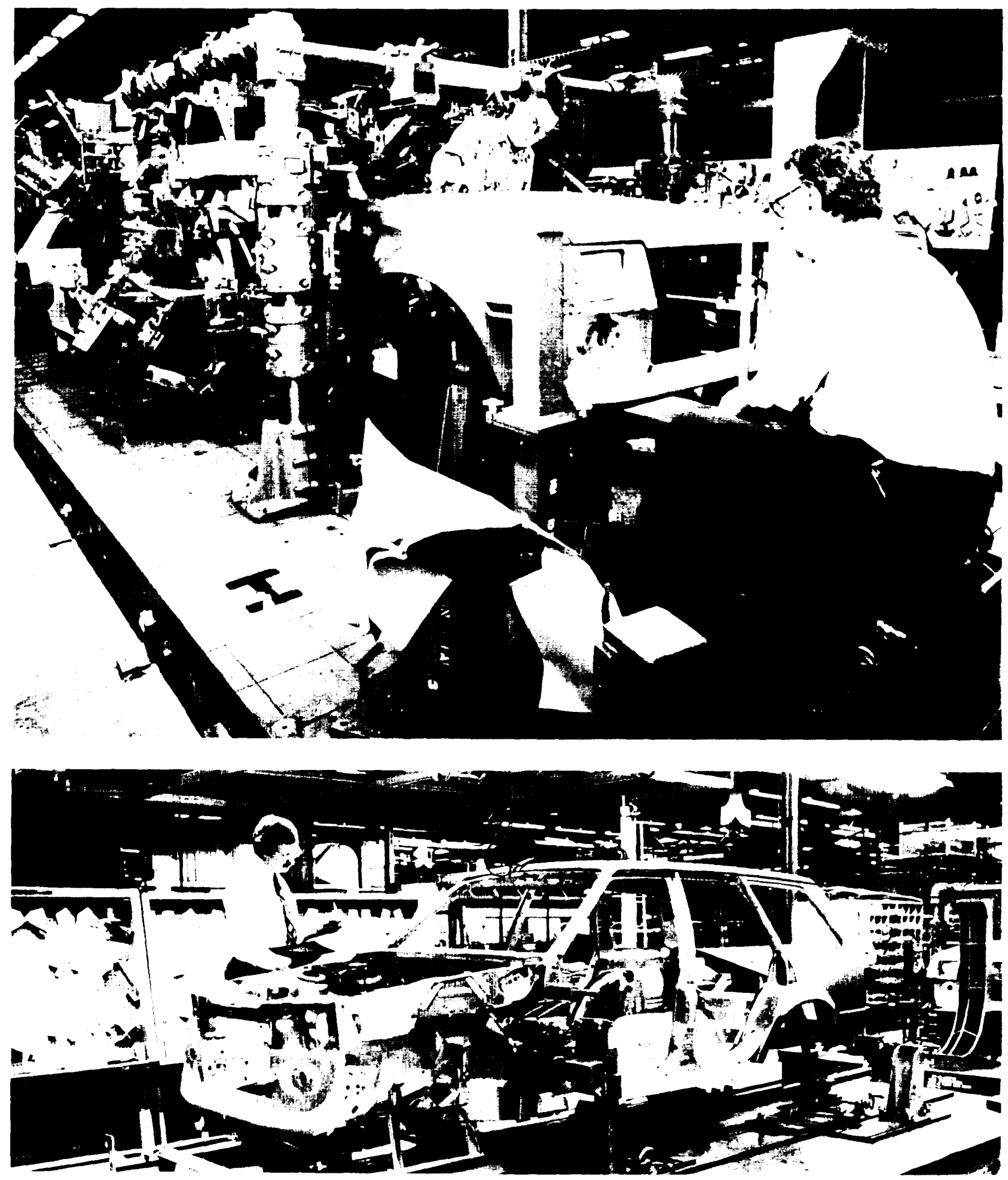

Photo credit Ford Motor Co

Quailty inspection using body gages supplementing regular assembly line inspection 
of regulatory standards provides an example of the latter. The more commonly proposed types of aggregate policies have been those mentioned earlier in the context of other industries-measures designed to increase capital investment across all sectors, such as accelerated depreciation allowances or lower tax rates.

That aggregate policy changes would help the U.S. automobile industry raise substantial amounts of capital is not immediately obvious. Automakers already depreciate special tooling over a 3-year period. Tooling expenditures accounted for nearly 40 percent of the industry's total spending on plant, land, and equipment in $1979 .{ }^{25}$ The scope for significant cash flow benefits from measures such as IO-5-3 depreciation may thus be limited. Of greater importance, most types of tax incentives are directly beneficial only when a company is profitable and has paid taxes at some point during the preceding 3 years. Generalized tax changes would do little to help firms losing money unless refundable taxesin the form of payments for years when losses occurred-were adopted. Expectations of improved profitability in the future, however, could help attract outside investment,

If policies intended to apply in the aggregate appear insufficient to meet the needs of the automobile industry, sector-specific programs could be enacted. Examples include: tax credits; still faster writeoffs for plant and equipment, e.g., a l-year depreciation period for special tooling; loan guarantees; and relaxed environmental and safety standards requiring lower levels of investment by domestic manufacturers (but also by manufacturers of imports).

The last two forms of aid have already been implemented to some extent. Chrysler currently depends on Federal loan guarantees, and the Reagan administration has recently proposed a package of relaxed regulatory standards which, it is claimed, would

${ }^{25}$ "Current Problems of the U.S. Automobile Industry' and Policies to Address Them," staff working paper (Washington, D. C.: Congressional Budget office, National Resources and Commerce Division, July 1980), p. 53. save domestic firms up to $\$ 1.4$ billion in future expenditures.

Greater certainty over future regulations -including fuel economy standards-could also help by creating a more stable climate for investment. Even more important, this would allow automakers to plan investments -in both new vehicle designs and new production facilities-with greater assurance that they would not be outmoded by changing regulations.

Regardless of its immediate problems, the U.S. automobile industry appears to have the capacity to remain internationally competitive. The two largest domestic manufacturers are strong worldwide and have been for many years (this is a major difference between the steel and automobile industries). Their chief international rivals-particularly in Europe-also have their ups and downs. Many American small cars are competitive in price with imports (although the profitability of small car production in the United States remains uncertain). U.S. firms are placing renewed emphasis on reliable, high-quality products, As the domestic industry begins to produce a broader range of small, highmileage cars, and as the economy emerges from recession, the larger American automakers should again become healthy and competitive.

At the same time, many observers expect a shakeout in the world auto industry, with less than 10 firms-perhaps only 6 or 7 -dominating global markets by the end of the century, (This is not to say that small manufacturers of high-priced specialty cars could not continue to prosper. ) If this scenario comes to pass, two of the firms would probably be General Motors and Ford. The others might be the larger European firms such as PeugotCitroen, Fiat, Volkswagen, Renault, plus Nissan (Datsun), and Toyota. General Motors appears to have ample resources to adapt as needed. Ford will have more difficulty, but is not alone. Some of the European firms-most notably BL Ltd. (formerly British Leyland). but also Fiat and Peugot-are in rather pre- 
carious financial straits, and may need continuing assistance from their governments.

As part of this worldwide restructuring, automobile firms are becoming more closely tied through joint design and/or production ventures. The increasing similarity of cars produced in various parts of the world is part of this trend. The larger American manufacturers are all linked to foreign automakersnot only their overseas subsidiaries, but also through partial interests in Japanese firms (General Motors-Isuzu, Ford-Toyo Kogyo, Chrysler-Mitsubishi). Other ties involving U.S. producers may develop; in the AMCRenault case, the state-owned French partner is now dominant, Worldwide, more than 70 joint ventures currently link automobile manufacturers.

Motor vehicle production in rapidly industrializing countries such as Spain, Mexico, Brazil, and Korea-both to serve local needs and for export-will make the industry increasingly a translational one. ${ }^{26}$ Parts manufacture and assembly for the Ford Escort, for example, is spread over seven countries. Such changes will also affect supplier firms-where there will probably be a good deal of consolidation in the years ahead. To some extent, manufacturing facilities are being located in developing countries because of local content requirements; many countries look to automobile production, along with steelmaking, as a foundation for industrialization. But low labor costs are also important-just as for TVs or semiconductors. The ability to adapt to this changing world structure of production and sales is one of the keys to prosperity-perhaps survival-for the major automobile manufacturers of the United States, Europe, and Japan,

${ }^{*} \mathrm{~S}$. Iall. "The International Automotive Industrvand the Ieeveloping World." WorkdDeselepment vol. 8. 1980, p.789.

\section{Summary and Conclusions}

The electronics and automobile industries are evolving toward more fully international operations; the world steel industry is also becoming more dispersed. Yet the patterns in each sector differ: as shown in earlier chapters, they are unique in their specifics.

Competition will remain intense in world steel markets as long as overcapacity exists, Raw steel capacity is being added by Third World countries, aided by joint ventures and technology transfers from steel firms in industrialized nations. While none of the American companies have extensive international opera tions, they will nevertheless be affected by these trends, along with steelmaker elsewhere. The impacts will be particularly significant if Third World steelmaker have excess capacity and export to the industrialized count ries.

Structural change in the U.S. steel industry is likely to continue, with nonintegra ted firms taking a more prominent place, and alloy/spe- cialty steels continuing to be a strength. The competitiveness of large, integrated firms will depend to a considerable extent on their ability to generate or attract capital for moderniza tion. New technologies for mak ing iron and steel will also play a $\mathrm{n}$ important role in shifts in competitiveness over the rest of the century,

The electronics industry is already thoroughly international in sectors such as semiconductors and computers, in most parts of the world dominated by American firms. Consumer electronics is also an international industry, but here most of the leading worldscale manufacturers are Japanese, While semiconductors, computers, andotherhightechnology branches of electronics will continue their rapid growth, demand in consumer electronics will spring from new products and from the industrializing countries, where markets are far from saturat ion. If the U.S. electronics industry cangenerate cap i ta 1 , 
find qualified personnel, and maintain open access to foreign markets, it will continue to be highly competitive in sectors such as semiconductors and computers. Recovery of the U.S. consumer electronics sector would remain problematical, and appears to depend on successful commercialization of new products.

In the automobile industry, the era of the "world car" is beginning. International design efforts are a reality, with Americanmade cars increasingly resembling those developed in Europe and Japan. These changes are evolutionary; automobile technology is not likely to change radically through the 1990's, but continual refinements to existing design concepts will have dramatic cumulative impacts.

Growth in U.S. automobile sales will be slow-as in most of the industrialized world.
The fastest expansion, hence the greatest opportunities for multinational automakers, will be in Eastern Europe and the Third World. The most successful of the world's automakers will be those that can maintain their competitiveness in the developed world while also establishing strong positions in emerging markets.

Given current trends, there may be a further concentration of the world automobile industry, with perhaps as few as six or seven large firms commanding most of the market by the end of the century. Such a restructuring would be difficult and painful. American firms will continue to be among the world leaders, but will not be able to rest unchallenged in their home market. Not only are imports likely to provide continued competition, but Japanese firms will probably begin assembling cars, as well as light trucks, in the United States, 


\section{CHAPTER 8 Policies Toward Industry in the United States}




\section{Contents}

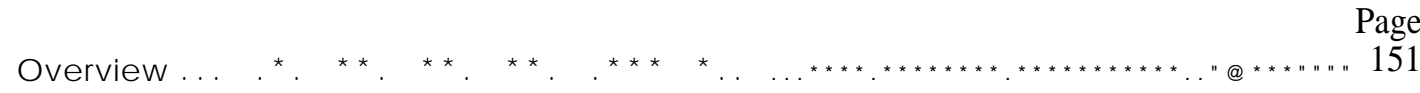

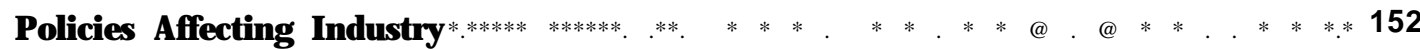

Macroeconomic Policies . . . . . . . . . . . . . . . . . . . . . ... ........ . .." 153

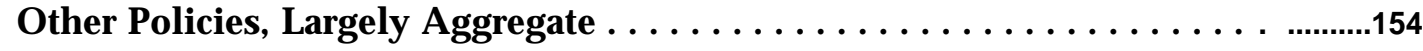

Industrial Policy for the United States .****** .******.. ..*..***. .***9..*. ..** 157

Industrial Policy Reconsidered. . . . . . . . . . . . . . . . . . 0, ................157

The Political Context. . . . . . . . . . . . . . . . . . . . . . . ....................158

Prerequisites for IndustrialPolicy . . . . . . . . . . . . . . . . . . . . . . ........159

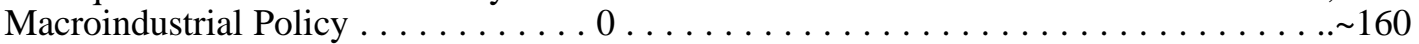

Moving Toward Industrial Policy . . . . . . . . . . . . . . . . . . . 0........162

Summary and Conlusions . . . . .....0.. .0..0,00 ******O* •*,..*.. • ○..***** 165 


\section{Policies Toward Industry in the United States}

\section{Overview}

Chapter 6 reviewed public policies having sector-specific effects on the U.S. steel, electronics, and automobile industries, Chapter 7 outlined likely competitive futures for each of the three industries, A major point of chapter 7 was the increasing intensity of competition on a world scale in all three industries.

The slackening competitiveness described in earlier chapters, to which Government policies have sometimes contributed, suggests that new policy approaches be considered. In the past, the U, S. economy has functioned reasonably well without a consciously developed industrial policy. Attempting major changes in the formulation and implementation of policies toward industry will be a difficult but perhaps necessary undertaking.

This chapter sets U.S. competitiveness, and the public policies which affect it, into the context of industrial policy. "Industrial policy," as used here, refers to the broad array of Government policies that directly or indirectly affect industry. Included are elements of trade policy, domestic economic policy, regulation, adjustment, and science and technology policies, The use of the term industrial policy does not necessarily imply planning, or sectoral intervention in the affairs of particular industries, although such approaches have been favored in some countries (see app. D).

A distinction between policies having sectoral and aggregate objectives-between those directed at a single industry and those directed at a number of sectors or at the entire economy-has been adopted at several points in this report, and particularly in the remainder of this chapter. Not only has sectoral targeting been an important component in a number of foreign industrial policies, but similar approaches have sometimes been advocated for the United States. Just as there are many types of policies that have aggregate objectives and cut across sectors, so there are different sorts of sectoral policies. For example, some sectors may be selected for promotion as future growth industries; alternatively, sectoral measures may be directed at distressed industries-intended to help rebuild them or to manage decline. Support may be given to industries judged important to national security, or for regional development. While industrial policy can be approached from other perspectives, the sectoral/aggregate distinction highlights issues involving both equity and economic efficiency. These are central to decisions facing policymakers in the United States.

Some degree of government intervention is inevitable in a complex industrial society. A distinguishing characteristic of U.S. industrial policy is the ad hoc use of the wide array of policy tools available (and their varying success). The result has been industrial policy which is largely de facto in nature, rather than consciously developed. Many public policies have, in one way or another, affected industry; but they have not been unified by a coherent set of objectives outlining the desired impacts on particular industrial sectors or on the economy as a whole.

Is this necessarily the case? If a consensus existed on the need for a more coherent industrial policy, could it in fact be formulated and implemented, or are there features of our political and economic system that present overriding obstacles? Would an industrial policy aimed at promoting competitiveness and related social objectives be effective? These questions-dealing with political and 
economic feasibility-are at the heart of decisions facing Congress. If no effort is made to develop a more coherent industrial policy, decisions affecting industry will continue on a case-by-case basis. With exceptions such as some macroeconomic policies, most individual policy tools are likely to be limited in range and impact. The key to an effective industrial policy lies in their cumulative results; a continuation of past practices will not lead to significant improvement.

OTA'S study of competitiveness suggests that Congress consider establishing a more explicit basis for industrial policy. While an ad hoc approach worked in the past, this report suggests that it may not suffice in a world of intensified competition-one where the United States no longer enjoys the technological advantages and relative economic strength that it possessed in the 1950's and 1960's. Industrial policy cannot by itself cure inflation, lagging productivity growth, or trade imbalances. It could help set these problems into perspective and provide more effective measures for attacking them.

Industrial policies in other countries sometimes include measures such as centralized economic planning that run counter to the U.S. tradition of flexible and pluralistic decisionmaking. OTA outlines below a "macroindustrial policy" option for the United States that would provide a framework for the development of a more coherent industrial policy in keeping with American traditions, Such a policy would include a conscious effort to build a national consensus on objectives, based on a strengthened capability for sectoral analyses of problems facing the U.S. economy. It would rely on market forces and aggregate policy measures wherever possible-sensitive to the imperfections and failures of the market system, but aiming to improve its workings rather than supplanting it. Macroindustrial policy would continue to utilize sector- or firm-specific policies, but only when other policy tools proved inadequate.

Such an approach would change the process by which the U.S. Government influences international competitiveness. None of the existing repertory of policy tools would be abandoned outright. Nor would radically new measures be introduced. But the process of deciding what to do in given circumstances would change to take a larger view of the needs of the U.S. economy. The effect would be to alter the political process by which Congress now legislates in areas such as taxes, regulation, and trade, OTA is thus suggesting a broader and longer term perspective on industrial policy than common in many recent discussions of this topic. The framework discussed below is one in which the major legislative issues affecting competitiveness might be approached by a Congress that was modifying past political processes. Among the reasons for doing so is the growing public perception that competitiveness has a constituency far wider than those with jobs or profits immediately at stake.

\section{Policies Affecting Industry}

A number of policy tools with largely aggregate objectives influence industry in the United States. The purpose of this section is to review several types of aggregate measures that could be incorporated in industrial policy. While chapter 6 discussed policies in the context of the steel, electronics, and auto- mobile industries, here the view is broader. Measures that affect many sectors, such as macroeconomic policies and R\&D stimuli, are emphasized. Macroeconomic and tax policies, trade policy, and science and technology policy are all nominally discrete categoriessome but not all aspects of which affect in- 
dustry. A better developed industrial policy would seek to coordinate and integrate, but not replace, such policy categories.

Some aggregate policy measures-regulations or taxation-have direct effects on industry. Others operate indirectly: education and many $R \& D$ policies affect all industries. Even explicitly sector-specific policies often have secondary and sometimes unexpected effects. For example, regulations affecting passenger cars contributed to increased sales of light trucks and vans-which were less tightly regulated-during the 1970's.

Where policies toward industry in the United States have been ad hoc, nations such as France have sometimes relied on elaborate economic plans and targeting of industries for promotion. In some countries, government guidance of industry is strengthened by incentives, pressure, or coercion. Industrial policies in such countries often feature direct subsidies to specific sectors, In contrast, sector-specific policies in the United States have more often been regulatory than promotional. Here, sectoral policies have been developed for agriculture, utilities (and nuclear power generation), communications, and transportation (railroads, trucking, airlines) but rarely for manufacturing industries, except those heavily involved in national defense. Subsidies have typically been indirect and seldom highly visible. Policy makers in the United States have traditionally claimeddespite the examples of Lockheed or Chrysler-to prefer aggregate policies, to believe that decisions at the microlevel of specific industries and individual firms are best determined by the market.

\section{Macroeconomic Policies}

Macroeconomic policy is not subsumed by industrial policy but overlaps and interacts with it. Fiscal and monetary policies are used to dampen swings in the business cycle affecting aggregate output, employment, and prices. Their aims and consequences extend far beyond any given industrial sector.
The interdependence of individual industrial sectors and the aggregate economy is critical to industrial policy, Economic growth in the aggregate eases adjustment within and among sectors. To a considerable extent, the problems of individual sectors are caused by, or aggravated by, problems at the macro level-witness the effects of high interest rates and recession on the automobile industry.

Strongly influenced in the United States by Keynesian thinking, both monetary policy (control of the money supply, as by interest rates), and fiscal policy (taxation and Government expenditures) have been used in attempts to counter short-term swings in the economy. Tax policies and Government spending are linked by the need to raise sufficient revenues to offset expenditures (though the Federal budget has been running substantial deficits, State and local revenues generally exceed expenditures). In addition, tax policies have been used as brakes on expansion near cyclical peaks (by raising taxes) or to stimulate demand when the economy is in recession (by cutting taxes). The tax system can also be used as a conscious and direct tool of industrial policy - e,g., through changes in corporate tax rates, investment credits, depreciation allowances, and capital gains taxes.

Taxes of all types are important to industrial policy because they affect investment decisions.' Some observers take the position that present U.S. tax policies are biased against capital investment in industry and stifle the economy by slouing rates of growth of productivity and output, The argument is that private returns to capital are distorted by tax policies that undervalue investment in industry compared to alternatives such as real estate. A proposed solutions is to lower taxes-both corporate taxes and personal taxes on income from investments in indus-

M. J, Boskin and J. BSherven. "1ss11('s m the 1, / xathonollit?-

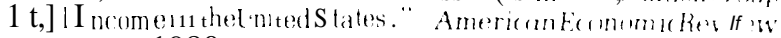
Vol. 70. Mar 1980. p.164. 
try-to increase rates of return. Reduced depreciation periods, lower capital gains taxes, and elimination of "double taxation" of dividends (taxing dividend income as well as corporate profits) are among the modifications most commonly suggested,

The distributional impacts of policies to encourage savings and investment make them the focus of political controversy, When capital gains taxes were reduced in 1978, the telling arguments were those based on capital availability for industry. Supporters held that cutting the capital gains tax would encourage investment in small, innovative, high-technology firms-for which venture capital had virtually disappeared as a result of the 1974-75 recession. There has in fact been a dramatic resurgence in the availability of venture capital for new corporate startups since 1978.

Macroeconomic policies of all types can have significant differential effects on various sectors of the economy-sometimes intentional, sometimes inadvertent. High interest rates-introduced to achieve aggregate objectives in 1966, in 1970, and most recently in 1979-had greater impacts on housing, construction, and automobile sales than on many other portions of the economy, The investment tax credit-designed to stimulate aggregate economic growth '-benefits capital goods industries because it encourages investment over consumption, Industrial policy could provide a vehicle for addressing differential impacts of such types in more systematic fashion, and for coupling macroeconomic policies more closely to problems of industrial development.

Macroeconomic policies-though more closely coordinated than several other categories of policy measures that affect industry-do not spring from a single source, Several groups in the executive branch are involved-including the Treasury Department, the Council of Economic Advisors. the Office

\footnotetext{
'Venture capital availability y will be treated at some lengt $h$ in the forthcoming OTA electronics study.

'J. G. Gravelle and D. W. Kiefer, "The Investment Tax Credit: An Analytical Overview, "Congressional Research Service. 1979.
}

of Management and Budget, and those in the Executive Office of the President concerned with economic policy, The Federal Reserve Board, an independent body, has the central role in monetary policy. In Congress, the House Ways and Means Committee and the Senate Finance Committee are focal points for tax measures, but are not alone in their responsibility y for macroeconomic policymaking. The Joint Economic Committee and the Joint Committee on Taxation, for example, have oversight authority in such areas.

\section{Other Policies, Largely Aggregate}

Beyond macroeconomic policies, many other measures - some aggregate, some sector- or firm-specific-affect the viability of individual firms, the competitiveness of industries, the standard of living.

Regulatory policies may have aggregate or sector-specific objectives. Some are implemented on an aggregate basis but have differential effects-environmental regulations have sharply contrasting impacts on the steel and electronics industries. Other regulations are enacted on a sectoral basis-i e., automobile safety standards.

In recent years, the energy industriesparticularly the petroleum sector-have been affected by complicated sets of price controls, taxes, and direct regulations, The extension of Federal loan guarantees to Chrysler is a current example of a firm-specific policy measure. While the United States has always professed to favor the aggregate approach, political pressures, national security considerations, and other objectives have given us many examples of sector- and firmspecific policies,

Trade policies provide other cases of industry-specific effects, Tariff levels, quotas, and other methods for controlling imports are instituted essentially on an industry-specific or product-specific basis-e.g., the triggerprice mechanism for steel and orderly marketing agreements for color television receivers (ch. 6). Export financing programs likewise have clear sector-specific effects- 
recently on the aircraft and construction industries.

In the United States, the multiplicity of competing agencies and institutions involved with trade issues - as many as a dozenfragments policymaking. Nations with tightly coordinated central bureaucracies may be better able to implement consistent trade policies. Since Federal policy has seldom actively promoted the international competitiveness of U.S. industry, the fragmented process has not in the past been a major concern. An important question now is whether international trade policy can be more effectively coordinated and, if so, how can it be coupled with the domestic side of industrial policy.

Market promotion policies comprise another category of aggregate measures found in the United States and in other Western nations. Such policies are designed to facilitate or improve the workings of the market system. They aim to enhance the performance of the economy as a whole, generally by working on individual markets. Examples include:

- labor market policies, such as employment services, job relocation and retraining subsidies, and other incentives to increase the mobility of labor;

- capital market policies, including loan guarantees;

o science and technology policies, such as R\&D incentives;

- regional development programs;

- antitrust measures.

Such policies are usually intended to counteract what economists term market imperfections-the failure of markets to allocate resources in ways that society judges desirable, "For example, local and regional development programs-e g., investment capital subsidies, tax holidays, job training-may help to overcome barriers to the mobility of capital and labor. Antitrust policies are in-

Market failure as a rationalefor policy is discussed in detail in app. B. The convent ionalterms-market failure and market i mperfection-are un fortuna tebecause perfect $m$ a rke Is a re abst ractions that do not in rea $\mathrm{I}$ it vex is $\mathrm{t}$, tended to combat actual or potential market distortions resulting from monopoly power or anticompetitive practices. Market promotion policies often have sectoral effects, but that is seldom their primary purpose.

Economic adjustment policies are an important subset of market promotion policies. Dealing with the consequences of structural change or shifts in competitiveness, adjustment policies include a variety of measures intended to help both firms and workers cope with changing economic conditions. In the United States, loan guarantee programs have been used to aid industries and firms, as in the Chrysler case. Job retraining and other programs on the Federal level to assist unemployed workers have been more systematic in intent but not notably successful.

Loans and loan guarantee programs have expanded rapidly in the United States over the past few years, often on a case-by-case basis to assist ailing industries or to attract new investment. Such subsidies typically have been used, not as conscious efforts to ease processes of structural change, but to provide piecemeal, short-run assistance. Sometimes the aid is defined by the affected parties, who may be more interested in impeding change than in easing adjustment.

In addition to ad hoc loans and loan guarantees, the Economic Development Administration (EDA) within the Department of Commerce, and the Department of Housing and Urban Development's Urban Development Administration Group, among others, have administered programs that might be termed adjustment assistance. Directed at promoting industrial or economic growth in "depressed" regions, they have been intended to create and maintain jobs. EDA, for example, granted more than 200 loans and loan guarantees in 1979 , totaling over $\$ 600$ million, which are said to have produced 25,000 jobs and saved 15,000 more, ${ }^{\mathrm{s}}$ Trade adjustment

Economic Developmen t Administration 1979 Annual Report [Washington, 1). C,: Department of Commerce, May 9, 1980). More generally, see N. A. Noto, "Industrial Policy Implicit in Federal Business CreditPrograms, "Congressional Research Service Report No. 8 1-12E, Dec. 31, 1980, 
assistance (TAA) approaches the employment problem from the other side-by giving benefits directly to workers who have lost their jobs because of imports. Expanded under the Trade Act of 1974, TAA expenditures for 1980 were about $\$ 1.5$ billion.

Although such programs have been ostensibly directed at development and assistance, they have not been guided by any long-term perspective. In fact, TAA administrators are prohibited by law from attempting to anticipate and plan for dislocations in the economy; they are instead forced into a reactive approach, TAA programs have provided income maintenance, but not the retraining or relocation of workers necessary for effective adjustment,' Too often, economic adjustment assistance in the United States is allocated on a political and geographic basis, too seldom to industrial sectors with good prospects for growth and competitiveness. Such programs are quite different from the subsidies provided abroad to sectors that are expected to be mainstays of future economic growth and competitiveness. Nor has aid to U.S. industry been used effectively to manage contraction in declining or distressed sectors.

Another element in the industrial policies of many countries is the promotion of innovation," In the United States such policies date at least from the creation of the Patent Office.

Some policies for promoting innovation support the technology and science base underlying industry. Others attempt to increase possible rewards to innovators (patents, liberal capital gains taxes), or to reduce their risks (forgivable loans, technical assistance programs, Government procurement). Many current suggestions for improving the climate

${ }^{6}$ R. A. Hobbie, "Trade Adjustment Assistance for Workers," Congressional Research Service Issue Brief No.IB80082, Nov. 19, 1980, p. 1

G. R. Neuman, '*Adjustment Assistance for Trade-Displaced Workers, "The New International Economic Order; A U.S. Response. D. B. H. Denoon, ed. (New York, N. Y.: New York University Press, 1 979], p. 109.

' $\{$ Policies for the Stimulation of Industrial Innovation, Vols.I andII (Paris: Organization for Economic Cooperation and Development, 1978 ). for innovation in the United States focus on altering tax policies to increase incentives for risktaking by private industry. ${ }^{g}$ As with trade and economic adjustment, there is no real locus for policies dealing with technology and innovation. Agencies involved range from the Office of Science and Technology Policy, the Departments of Defense, Energy, and Commerce, to the National Science Foundation and the National Aeronautics and Space Administration.

Government policies in the United States could be modified in ways that would improve the climate for innovation-by removing some of the obstacles and risks, increasing the potential rewards. While such an effort might be an important part of industrial policy, it is also an area where the arguments for reliance on market forces are strong. Innovation is a risky and uncertain activity, sometimes resulting from $R \& D$ efforts aimed at entirely different outcomes. Because chance and uncertainty characterize the process, there may be less of a role for planning or direct action by Government, more for enhancing the environment for innovation through indirect measures.

The United States has had many other policies-both aggregate and industry-specificwhich influence the behavior of industry. Among those which have not been discussed here, but which nonetheless have substantial indirect effects, are defense policies and education. As pointed out in chapter 4, much of the $R \& D$ performed in the United States is aimed at national security objectives. This strengthens U.S. capabilities in many fields of technology, and sometimes leads to developments that prove commercially significant, Public education is, over the long run, especially critical because it affects the human resource-the skills and abilities of the people employed in U.S. industry-production workers, engineers, and managers.

"See,e.g., Stimulating Technological Progress, A Statement hy the Research and Policy Committee of the Committee for Economic Development. January 1980; and The Impact of Tax and Financial Regulatory Policies on Industrial Innovation (Washington, D. C.: National Academy of Sciences, 1980). 
Government policies in this country have seldom been directly concerned with competitiveness and economic efficiency. Such matters may now deserve more attention. Political and economic realities will determine which policies can be most effective under various circumstances. The interplay between economics and politics is in fact at the heart of the decisions facing the United States.

\section{Industrial Policy for the United States}

OTA'S study of the steel, electronics, and automobile industries shows that even the most vital sectors, such as semiconductors, now face challenges in adapting to new international realities. Among the changing circumstances are: narrowed technological advantages; the rise of aggressive foreign competition-in overseas markets as well as in the United States; and efforts by foreign governments to promote their own industries. Congress may want to consider new strategies designed to maintain and enhance U.S. competitiveness and to deal with regional and employment dislocations.

The basic choice is not between Government policy and no policy-intervention or nonintervention. An industrial society cannot function without some government involvement in the affairs of industry. The crucial questions concern the form and effect of public policies: What sort of industrial policy is most compatible with the U.S. political and economic system, most appropriate in the present context?

\section{Industrial Policy Reconsidered}

Different people use the term industrial policy in different ways. For some, industrial policy means sectoral policies-such as Japan's VLSI program-which feature direct government promotion of targeted industries. But industrial policies seldom rely on sectoral measures alone.

The analysis on which industrial policy is based must nonetheless be carried out on a sector-by-sector basis-as illustrated by the earlier chapters of this report-whether policy measures are aimed at promoting com- petitiveness or at other objectives that depend on economic efficiency.

The policy instruments chosen can be sector-specific, aggregate, or a mixture; some countries emphasize one type more than the other, A sectoral emphasis typically entails promotion, subsidy, or protection of selected industries. An aggregate emphasis focuses on incentives for innovation, labor and manpower policies, adjustment assistance, and the traditional spectrum of monetary, fiscal, and tax policies.

Sectoral policies are often intended to help countries develop and maintain segments of their economies that are judged important to the national interest, such as defense industries or those that export. In some countries, sectoral measures are used in attempts to speed structural adjustment-e.g., by moving resources from industries in decline to those with seemingly better long-term prospects. Japan has developed plans to promote a transition from heavy industries, particularly those that are energy-intensive, to knowledge-intensive, high-technology sectors -an effort to anticipate and adjust to shifts in comparative advantage.

Sectoral policies are sometimes said to involve picking "winners" and "losers." In principle, winners get government support, while public policies also help to cushion and manage decline, In practice, pressures for a protectionist industrial policy come from distressed industries trying to reverse their losses. Picking winners is a difficult task for governments, picking losers still more so. The unhappy result in either case can be interference with normal market processes at the expense of overall economic performance. 
In contrast, aggregate policies such as market promotion measures aim to enhance market mechanisms but not to replace market decisions. It is not an easy task to predict which industries will rise or decline, nor are growth and contraction absolute and irreversible, Aggregate policies do not depend on such predictions. They are also more consistent with the principle that government intervention should not overtly discriminate among sectors and/or firms. Those who favor an aggregate approach to industrial policy say that sectoral policies tend to distort market signals, leading-particularly in the long term-to misallocation of resources. In addition, market promotion policies, once in place, may respond more flexibly to changes in labor, capital, and product markets than sectoral policies (see app. B on the economics of industrial policy).

A fundamental task for industrial policymakers, regardless of whether they choose a sectoral or an aggregate emphasis, is to set priorities, select policy tools, and evaluate progress within a consistent framework. In the United States, consistency and continuity in approach would distinguish a consciously developed industrial policy from the ad hoc approach taken in years past. Industrial policy also requires agreement on objectives, and mechanisms for coordinating policies consistent with political and institutional realities.

\section{The Political Context}

In many respects, the de facto industrial policy of the United States is a consequence of a political system that fragments power and presents obstacles to the formulation and implementation of coherent policies of many types, A diffused and decentralized policymaking apparatus provides many channels for interested parties to press their case; it can give redundancy and flexibility to accommodate uncertainties and complexities. Such a system may encourage competition of ideas, ultimately producing a decision that is more widely accepted than one made by a small group. But under such conditions, it is easier to say that the country might need a better developed industrial policy than to propose realistic steps for achieving it,

In a pluralistic and decentralized political system, industrial policy might not always produce the desired results. Competitiveness springs from a rich and complex ecology (table 13, ch. 5), in which public policies are but one element among many. Tampering with the ingredients that have brought success in the past always carries dangers, One potential danger is that firms or sectors losing out in the marketplace might dominate the policy process. Distressed sectors or firms, and their employees, may be the first to seek protection or assistance from the Government, while the indirect costs and benefits of such measures may be so broadly distributed that other groups do not even recognize that their interests are at stake, The more successful firms and industries generally prefer to remain autonomous. Another possible danger is that a more tightly coordinated industrial policy could stultify competition and innovation, ultimately jeopardizing long-term economic efficiency. The essence of the problem is to find ways of formulating industrial policy that are more effective than the current ad hoc methods, while preserving flexibility.

Because the decline of firms or industries may not be permanent, and reversal could appear feasible through industrial policy measures, difficult and painful decisions may need to be made in a highly politicized atmosphere, In the last analysis, fears that sectors in temporary or long-term decline may dominate do not constitute a persuasive case against industrial policy. The possibility of capture by distressed sectors will always exist-and may be more likely in the absence of industrial policy. A coherent framework for industrial policy could guide evaluation of the claims of competing firms and industries, making it easier to avoid measures that favor special interests at the expense of long-term competitiveness and other social goals. 


\section{Prerequisites for Industrial Policy}

If consensus grows on the need for a more coherent industrial policy, the Government's institutional capabilities would need to be developed. Two prerequisites for industrial policy are: 1) mechanisms for reaching agreement on objectives that are acceptable to Government and various interest groups; and 2) improved analytical capability on the part of Government agencies concerned with economic efficiency and competitiveness.

Industrial policy requires cooperation and consensus-among Government, labor, business, consumer and other interest groups, and the public at large-sufficient at least for agreement on basic goals. The traditionally adversarial relationships among such groups in the United States form an obstacle to industrial policy-in contrast to countries such as Japan where cooperation is often viewed as a key to industrial policymaking. While the extent of cooperation abroad is sometimes exaggerated, the differences between the United States and Japan are nevertheless striking. The question for U.S. policy makers is: What sort of agreement on the ends of policy can, as a practical matter, be fashioned within the context of the American political and economic system?

Advisory groups such as the Steel Tripartite Committee already have a role in policymaking, primarily at the level of particular industries or sectors. Calls for increased cooperation among Government, business, and labor are now common, but neither agreement on broad industrial policy objectives nor substantial cooperation in implementation has yet been attained-in part because of the deeply rooted distinctions between public and private sectors in the United States.

From the beginning, business and industry in this country were free to pursue entrepreneurial ambitions-in contrast to nations like France where a strong state bureaucracy played a central role in industrialization. Such patterns of extensive government involvement in framing industrial strategies differ markedly from the American case, where the lack of a feudal past, plus our vast resources, permitted a rapid and independent flowering of industry.

Following the Depression and World War II, industrial policy and economic planning became the norm in many Western nations, but not the United States. Discussion of an expanded role for Government still arouses distrust and condemnation in this country, where the adversarial tradition has been viewed as healthy. Suspicion of Governmentbusiness accommodation is a historical tradition. Even the Department of Commerce has lacked ties to its nominal constituency-business and industry-comparable in strength to those characterizing agencies such as the Departments of Labor or Agriculture. New policy initiatives must take these historical patterns into account; to change them Would be a long-term undertaking.

Labor, consumer, and environmental interests must also be included in formulating industrial policy. Such groups are justifiably concerned that the costs of policy and the burdens of adjustment be equitably distributed. Experience abroad with industrial policy suggests that the participation of labor and public interest groups is essential for a well-rounded perspective. There are many ways in which labor, for example, can contribute to industrial policy and competitiveness-not only by safeguarding the rights of workers, but also by helping to develop an atmosphere in which the contributions of individual employees to improvements in productivity and product quality are maximized.

Participation by such groups is not enough. To develop more effective policies, the Government would need to strengthen its analytical capacity for evaluating competitiveness, as well as for choosing policy tools. Especially if the Government decides to selectively intervene to promote competitiveness, it must have an independent capability for analyzing alternatives.

"See, for example, R. E. Cole. "Will QC Circles Work in the? U.S.?" Quality Progress. July 1980. p. 30. Cole stresses that methods such as quality circles cannot be treated as quick fixes or panaceas. 
Many parts of the Government-including the Departments of Commerce, Labor, and Treasury; the International Trade Commission; the Council of Economic Advisers; and the Federal Trade Commission-already study and regulate industry and the economy as a whole. Numerous other agencies have at least a limited capability. Improving the ability of public agencies to analyze industrial competitiveness is nevertheless critical for a better developed industrial policy, Specifically, Government agencies could cultivate a greater appreciation of the ways in which industry functions at a practical level-the level of technology, the shop floor, the R\&D laboratory, the marketplace. Effective industrial policy demands efforts to anticipate future trends based on a concrete and realistic understanding of the sectors in questionempiricism rather than abstraction, theorizing, and empty statistics.

In addition to judging the competitiveness of particular sectors, evaluating the cost effectiveness of policy alternatives is vital. As the economic arguments for industrial policy initiatives outlined in appendix B suggest, there is no prima facie case for intervention in a market economy-even a highly imperfect one. The basic tests are: 1) Do the benefits exceed the costs? and: 2) Are the benefits and the costs distributed with an acceptable degree of equity? Determining the answers is inevitably complex and difficult. Witness the protracted controversies over costs and benefits of various motor vehicle regulations: passive restraints, 5 mile-per-hour bumpers, braking distances for tractor-trailer trucks.

These two prerequisites-improved mechanisms for developing consensus among interested parties, and a strengthened capability for analyzing competitiveness-are essential to the long-term success of industrial policy.

\section{Macroindustrial Policy}

OTA'S analysis of the steel, electronics, and automobile industries-all three of critically importance to the U.S. economy - suggests that Congress consider the option of a more coherent industrial policy The problem is to develop a replacement for the present patchwork of policies that is compatible with the American political and economic system. "Macroindustrial policy" is an approach which seems feasible in light of this country's traditions, as well as the structural features of our policymaking system. While there are potential dangers to pursuing a more integrated industrial policy, the advantages appear more compelling. Foreign experience shows that there are many approaches, a variety of policy tools available. OTA'S examination of the past history and future prospects of the industries covered in this report reinforces the logic of a macroindustrial policy approach. It is discussed below essentially as an organizing perspective, not a blueprint.

Fundamental to macroindustrial policy is an emphasis on the links and commonalities among industrial sectors, and a preference for economic adjustment through market mechanisms where possible. To improve the environment for industrial growth and competitiveness, a macroindustrial approach would stress aggregate policy measures to stimulate savings and capital formation, modernization of the capital stock of U.S. industry, investment in new and innovative technologies, and competition by U.S. firms on a world scale. Upgrading the capabilities of the labor force could be another central feature - providing workers with satisfying jobs and ensuring an adequate supply of employees at all levels, including management, with skills suited to a high-technology economy,

Macroindustrial policy would seek to integrate the goals of industrial development with other social objectives. The need for integration is illustrated by the dilemma created by productivity improvements in slowly growing industries such as steel. As earlier chapters show, continued productivity increases are required to maintain competitiveness, but as productivity rises employment opportunities in a particular industry can decrease. If the economy grows rapidly enough, jobs may keep pace. But when economic advance slows-as it did during the 
1970's-productivity growth can lead to unemployment in some industries. Tradeoffs of these sorts are examples of problems of industrial change that several European nations have addressed more systematically than has the United States. The macroindustrial approach would value employment opportunities across the economy as a whole above maintaining employment in particular sectors.

An important task of industrial policy is to determine when different types of policy measures are appropriate and practical. The macroindustrial perspective would be based on sector-by-sector analysis of industry, but would choose aggregate over sectoral measures where possible. By stressing long-term and structural issues aimed at creating a stable climate for industrial growth and development - capital formation, technological advance, education and training of workers, the promotion of structural adjustmentsuch an approach might avoid capture by narrow special interests and enlist the support of a broad array of groups.

Macroindustrial policy could incorporate elements such as the following:

$\check{Z}$ Measures for supporting technology and science, particularly generic technologies of commercial importance-e.g., computer-aided design and manufacturing, tribology (friction, lubrication, and wear), materials processing, production engineering - and R\&D directed at commercial products and processes.

- Measures for increasing the potential rewards to innovation, and otherwise indirectly stimulating $R \& D$ and the development of new products and processes.

- Policies to encourage and facilitate domestic technology transfer, particularly the diffusion of technologies to smaller businesses.

- Policies to increase rates of capital formation in the economy as a whole, along with measures encouraging investment in more efficient production facilities (such as continuous casters for steel) and new technologies. Both tax and reg- ulatory policies could be directed at such objectives.

- Support for education and training of the labor force, including retraining of employees displaced by technological change, Improvement appears possible in the preparation of both production workers, semiskilled and skilled-welders, toolmakers, electronics technicians-and at professional levels. In particular, the engineering work force could be substantially upgraded in both numbers and quality by supportive public policies.

- Economic policies designed to ease adjustment to changing circumstancese.g., by smoothing flows of capital and labor from distressed firms or industries, or those with limited future growth prospects, to sectors that offer rapid growth and future competitive strength.

- A more coherent set of trade policies that would support exporting by competitive U.S. firms and industries, improve protection against "unfair' import competition in the domestic market-as defined by the domestic laws and international obligations of the United States and its trading partners-and press for equitable treatment of American firms that seek to invest and sell overseas. Such policies would not be inconsistent with the traditional U.S. posture favoring open world trade, but would be intended to ensure that U.S. industry is not placed at a disadvantage compared to foreign rivals.

- Economic and industrial projections on a more detailed analytical basis than is now common, with particular attention to technology and to the efforts of foreign countries.

While macroindustrial policy would prefer measures such as those listed above, other varieties might also be necessary-for example, to ensure national security. If traditional macroeconomic policies (monetary, tax) proved inadequate to address a particular problem, then other types of aggregate pol- 
icies-those cutting across a number of sectors-could be used: for example, market promotion policies (e.g., innovation, competition). If these too proved insufficient, then sector-specific or firm-specific policies could be employed. But the central feature of the macroindustrial framework is its preference for aggregate policies.

\section{Moving Toward Industrial Policy}

If Congress decides to work toward a more coherent and explicit industrial policy, several avenues are open-e.g., building on past initiatives concerned with exporting or with innovation. Over the past several years, many congressional committees and subcommittees have held hearings on international trade, industrial innovation, export policy, capital formation, and related topics that fit within the approach OTA has suggested for macroindustrial policy. There has also been considerable interest in trade reorganization. Such activities could provide a foundation for the further development of industrial policy.

Questions of productivity, industrial competitiveness, and economic efficiency have also moved toward the forefront of attention in the executive branch and the public at large. Despite widespread interest, there are still differing interpretations of what industrial policy for the United States means and differing opinions on whether an integrated industrial policy would be desirable.

Within Congress, a considerable number of committees and subcommittees have responsibilities relating to industrial policy, but there is no one committee in either House with industrial policy as a primary responsibility. In the Senate, the Finance; Commerce, Science, and Transportation; Appropriations; and Budget Committees all have interests in certain subsets of industrial policy concerns, but so does the Banking, Housing, and Urban Affairs Committee-which found itself with responsibility for the Chrysler loan guarantees-as well as the Foreign Relations; Environment and Public Works; and Labor and Human Resources Committees. In the House, the Ways and Means; Banking, Finance, and
Urban Affairs; Appropriations; Energy and Commerce; and Small Business Committees all make policies affecting industry, as do the Education and Labor; Foreign Affairs; and Science and Technology Committees. The Joint Economic Committee has oversight jurisdiction but not legislative authority. It might therefore be appropriate for Congress to consider activities aimed at clarifying the meaning and implications of industrial policy; at examining institutional capabilities for analyzing the problems of industry and reaching consensus on objectives; and at fitting ongoing legislative activities into an evolving industrial policy framework or perspective. Concrete actions Congress might consider in the near term are outlined below.

One example of response to continuing interest in problems related to competitiveness and industrial policy has been the formation of congressional caucuses organized to deal with policy issues such as exporting and innovation-as well as those focused on particular industries (e. g., the Steel Caucus). Congress might wish to reshape such activities to explicitly encompass industrial policy. A more decisive step would be to create a formal task force on industrial policy-or alternatively, an ad hoc committee-to bring together members and staff from various committees. Formulation, coordination, and evaluation of industrial policy measures might benefit from such mechanisms for facilitating interactions among the various committees of the House and Senate that are responsible for legislation directly affecting industry. Other useful activities could include seminars on industrial policy topics such as those organized during 1980 by the Congressional Reseach Service and the Congressional Clearinghouse on the Future.

Recognition of industrial policy in the executive branch has been reflected in limited form in proposals for "economic revitalization," as well as efforts such as the Domestic Policy Review on Industrial Innovation carried out by the Carter administration. More specifically focused on the international trade competitiveness of U.S. industry were a pair of executive branch studies mandated by 
Congress in the Trade Agreements Act of 1979. These studies-on export policy ${ }^{11}$ and on U.S. competitiveness ${ }^{12}$-were coordinated by the Trade Policy Committee. Congress could choose to request such reviews on a continuing basis, as it did for the 5 year outlooks on science and technology required by the National Science and Technology Policy, organization, and Priorities Act of 1976.

Other opportunities within the executive branch might be found in a revitalized $\mathrm{Na}$ tional Productivity Council. The Council, established by executive order in 1978, was intended to provide a focal point for executive branch activities related to productivity, superseding the National Center for Productivity and Quality of Working Life, whose authorization had been allowed to expire. To date, the Productivity Council has had little visibility, but it could be strengthened.

Congress might also reinforce efforts to develop cooperation and consensus on the objectives of industrial policy beyond the Government itself. The recent trend toward advisory committees and commissions such as the Steel Tripartite Advisory Committee reflects a desire by both Government and the private sector to stimulate meaningful dialog. Congress could seek to broaden such committees to include stronger representation by labor and particularly by public interest groups, and also to ensure that such committees reflect the breadth and diversity of industry-e.g., that they include representation from firms that have performed both poorly and well. Moreover, Congress could encourage such committees and commissions to move beyond narrow sectoral interests toward the broader concerns of industrial policy as a whole.

A further step would be to create a council or other group to directly address the groundwork for industrial policy. Such a council could be located within the executive branch

\footnotetext{
Report of the President on Export Promotion Functions and Potential Export Disincentives (Washington. D.C.: Department of Commerce. September 1980).

"Study of U.S. Competitiveness." Economic and Trade Policy Analysis Subcommittee of the Trade Policy Staff Committee. July 1980.
}

and might have a small staff and an advisory board of experienced and respected individuals from outside the Government (i. e., from business, labor, universities, and public interest organizations).

Such efforts would be essentially preparatory, The recent executive branch reviews of exporting and trade competitiveness remind us that discussions of industrial policy in the United States remain unfocused and preliminary. Knowledge and expertise relevant to analyses of industrial policy and competitiveness are now widely diffused within the Government. The review of competitivenessconducted mostly by the Department of Labor-devotes little attention to technology, while from the OTA perspective technology is an essential element in such an examination. Yet within the Government, technological expertise is concentrated in agencies and laboratories with operational responsibilities such as the Department of Defense, the National Aeronautics and Space Administration, and the Department of Energy, Such agencies are not oriented toward industrial policy.

OTA has emphasized the desirability of improving the analytical capability of the Federal Government as a step towards a more coherent industrial policy precisely because the capability which Government can now bring to bear is spread so thinly through the agencies. Another way Congress could begin to lay groundwork for industrial policy is thus by improving the institutional infrastructure for such analyses.

For instance, an analytical group intended as a locus for industrial policy might be formed by drawing together skills and expertise from existing agencies and attaching it to an executive branch program-perhaps to an upgraded and expanded Bureau of Industrial Economics in the Department of Commerce (although much more than economics is needed-e. g., expertise in technology, as well as in the analysis of social impacts). Alternatively, a group with ongoing policy responsibilities could be added to an independent agency such as the International Trade 
Commission. Another option is for Congress to strengthen its own capability.

Among the functions of such a groupwhether located in the executive or legislative branch-might be economic and industrial projections. Its other responsibilities could include: analysis of technological developments in the United States and abroad; evaluations of the impacts of Government regulations on competitiveness; and acting as a central point for digesting and disseminating information on trends in markets, international trade, and technology in forms useful to business and industry. Because similar work is sometimes carried out in other Government agencies-with widely varying effectiveness - as a first step, it might be appropriate simply to conduct a review of existing analytical capabilities relevant to competitiveness, economic efficiency, productivity, and industrial policy. Such a review would not be another study of competitiveness itself, but an inventory of capabilities for analyzing competitiveness.

In all probability, movement toward a more coherent industrial policy in the United States will prove slow and incremental. Therefore, Congress is likely to face important decisions on policies affecting industry before any clear framework or perspective for industrial policy emerges. As as result, it seems appropriate for OTA to suggest, based on the preceding chapters, those elements of a macroindustrial approach that appear to have the highest priority-both for improving the performance of the American economy in the near term, and from the longer term perspective of maintaining and enhancing U.S. competitiveness over the 20-year period of substantial industrial change outlined in chapter 7 .

In the near term, the climate seems favorable for tax policies intended to encourage capital investment that could improve the productive efficiency of U.S. industry. OTA'S study of the steel, electronics, and automobile industries indicates that such measures could have positive effects if tax policies are designed with these objectives in mind. Be- cause U.S. industries compete for investment funds among themselves and also with nonindustrial sectors of the economy, undifferentiated tax cuts might not lead to increased investments in modernization of equipment, upgrading of worker skills, or technology development. Tax policies that are specifically designed to encourage productive investment in industry, and to stimulate R\&D and the development and diffusion of new commercial technologies, are more likely to have directly beneficial impacts on competitiveness and productivity,

Congress could also give a high priority to more effective measures for stimulating industrial innovation. A continuing effort in Congress and the executive branch on several fronts dealing with innovation-e.g, cooperative $\mathrm{R} \& \mathrm{D}$, patent policy, development of better mechanisms for the diffusion of technology, evaluation of Government regulations - could be a significant contribution to the development of industrial policy.

On a longer term basis, OTA'S study indicates that the United States-along with many other industrialized countries-could profitably develop more workable and effective mechanisms for economic adjustment. Adjustment policies-e.g., for increasing the versatility and mobility of labor, for managing the decline of sectors that have lost competitiveness, for retraining people with obsolescent skills-have not functioned well here or abroad. Such problems are likely to intensify in the years ahead-they will certainly not disappear. The disappointing results of programs such as Trade Adjustment Assistance indicate that economic adjustment may be a policy area that Congress and the executive branch need to reevaluate,

Education and training of the work force is essential for both innovation and for effective economic adjustment. Government policies and corporate decisions are made by individuals whose attitudes, values, and skills are shaped in part by their education. Industry depends on skilled workers, capable engineers, and competent managers to build and maintain competitive firms and industries. 
Investment in the human resource could be the most vital single element in a macro- industrial policy oriented toward the longterm needs of the U.S. economy.

\section{Summary and Conclusions}

This chapter began with a brief review of policies having largely aggregate objectives. The dominant tradition in the United States has been reliance on fiscal, monetary, and tax policy to promote overall economic welfare and to moderate extremes in the business cycle, While the competitiveness of U.S. industry is directly related to aggregate economic health, there has seldom been any attempt to couple macroeconomic policies to policies dealing with individual industries, nor has competitiveness been a common goal of public policies,

Other types of aggregate measures have also had shortcomings. Economic adjustment policies in the United States have been reactive rather than prospective and supportive. Trade adjustment assistance functions primarily as unemployment compensation, and does not confront the real problems of adjustment-mobility, education and training. Science and technology policies have sometimes overemphasized science at the expense of technology - a more directly determining factor for international competitiveness. U.S. trade policy has yet to fully reflect that the country no longer enjoys technological advantages so large that it can refrain from insisting on fully reciprocal treatment in terms of both tariff and nontariff barriers.

While the United States was able to operate quite successfully without a consciously developed industrial policy in the past, circumstances have changed, U.S. firms are more exposed to foreign competition both here and overseas. Other countries have rapidly developed their economies and their technological abilities. American firms are no longer the undisputed world leaders in many markets that they once dominated. It is not clear that the United States-faced with declining industries, slow economic growth, friction with our allies over trade, constraints on supplies of energy and other resources, persistent inflation, and structural unemployment-should continue as in the past.

A compelling argument in favor of the industrial policy alternative is that, in its absence, political pressures may lead to haphazard, counterproductive policies intended to aid particular industries or firms. Such action tends to interfere with economic growth and adjustment. A market economy inevitably produces winners and losers. The winners generally have few grievances to press through political channels. The losers are likely to attempt to use the political process to reverse their losses. Industrial policy could provide a consistent framework for evaluating the claims of interested parties, and for judging the costs and benefits of policy alternatives,

OTA suggests "macroindustrial policy" as an approach to the task of developing an integrated perspective on policies toward industry. By emphasizing aggregate and market promotion measures, macroindustrial policy would aim at flexible response to changing conditions, not a rigid "strategy," Macroindustrial policy would minimize aid to specific industries, rather attempt to ease the transformation to a high-technology, resource-efficient society, It would place high priorities on retraining and educating workers with the skills needed for new jobs and on encouraging labor mobility; on technological innovation, in manufacturing processes as well as products and services; on incentives to improve capital formation, energy efficiency, and productivity; on open trade and competition in domestic markets coupled with support for American industries seeking to export. The intent of such a policy would be to retain and supplement the dynamism, competition, and adaptability that have traditionally characterized the U.S. economy, 
Appendixes 


\section{Defining International Competitiveness}

One of the immediate problems in analyzing international competitiveness is that no consensus exists on its definition. The term "competitiveness" is not used consistently in public discussions; in fact, contradictory meanings are sometimes implied within the same article or report. This appendix attempts to bring order to the subject by explicitly setting forth several of these definitions.

Some definitions of competitiveness are rooted in economics and stress production costs and market prices. In other cases, the definitional origins are technology based, and terms such as "technology gap" are used. For example, if one nation's superior technology enables it to manufacture products that are beyond the capabilities of other nations, the economists' view of cost competitiveness is irrelevant. The United States possesses such an advantage in some products discussed in this report -e.g,, particular types of computers or integrated circuits. On the other hand, there are clear relationships between other types of technological developments and costbased competitiveness measures. Superior manufacturing or process technology-as opposed to product technology-is one way to achieve low Costs,

International competitiveness is fundamentally related to the global structure of comparative advantage. Countries tend to export goods in which, for one reason or another, they are advantaged, and to import other items. The sources of a particular nation's relative advantages tend to vary widely, but may include such factors as fertile agricultural land, abundant labor or capital supplies, large and affluent markets yielding possible scale economies, and unique technological capabilities. Clearly, with so many possible sources of advantage, any simple definition of competitiveness is likely to be incomplete, Still, for analysis to proceed, definitions are required.

The discussion below begins with perhaps the simplest of definitions, that having to do with relative costs. A country (or industry within a country) is internationally competitive if it can produce an item at lower cost than can others. Clear1y. other matters are also important in competitiveness; but even ignoring them, some useful conclusions can be drawn. The discussion continues by developing alternative definitions and by con- sidering how they relate to the comparative cost definition, if at all. For example, some observers claim that for a country to remain internationally competitive, it must be technologically superior in the development and production of manufactured products that can be exported. These products presumably would be either technically superior or cheaper than similar i terns made elsewhere. Such a definition is, therefore, closely related to those based on comparative costs.

The following sections treat these subjects in greater detail, with particular attention to the steel, electronics, and automobile industries.

\section{Economic Framework-Comparative Advantage as a Descriptive Device}

The discipline of economics provides a welldefined, if sometimes oversimplified, view of international competitiveness, one that flows directly from the notion of comparative advantage. In a comparative advantage framework, competitiveness is a matter of relative prices or, ultimately, costs of production and distribution. Simply stated, if one firm's selling price in a particular location is higher than another's, then the first firm is not competitive, all else equal, To be sure, all else may not be equal, However, the benefit of the comparative advantage framework is that it begins with a definition of competitiveness that most observers can accept as reasonable. In addition, using comparative advantage brings to the fore aspects of competitiveness that might otherwise be ignored in formulating public policies.

In a comparative advantage context, international pricing patterns should be closely related to production, distribution, and selling costs. These, in turn, are determined by considerations such as the prices of raw materials, purchased components, and other factors of production (labor, capital equipment, etc.), together with manufacturing technologies. Note that the available manufacturing technologies may give firms in some parts of the world cost advantages over producers elsewhere. For example, if all these technologies are labor-intensive, then nations with relatively inexpensive labor would normally be expected to be low-cost producers, assuming that the workers possess the necessary skills for 
dealing with the technology. Low labor costs have been one of the factors leading to the strong competitive positions of Asian nations such as Japan and Taiwan in consumer electronics, where assembly processes have in the past been quite labor intensive (although the use of automation is now increasing),

In the broadest possible sense, therefore, nations tend to export items that best utilize their available resources, and import other products. Moreover, with flexible exchange rates, exports and imports are likely to be nearly equal in monetary terms. 'Therefore, in a real but limited sense, exports are required to finance imports. These simple statements lead to several conclusions that remove much of the confusion from popular discussion of trade issues:

1. It is not possible to "lose competitiveness" across the board. If a nation trades internationally, at least some of its industries must be competitive.

2. If a nation's overall productivity growth, however productivity be defined and measured, is lower than in other countries, this need not result in a loss of competitiveness for all industries if the exchange rate is free to adjust. instead, there will be a relative decline in real per capita income. To be sure, the effects may not fall uniformly on all industries. Industries for which productivity growth is lower than the national average will likely find themselves growing "less competitive' in the comparative advantage sense, For example, one of the problems of the U.S. steel industry-as discussed in chapter 4-has been wages that have risen more rapidly than output per man-hour. Although average productivity in man-hours per tonne of steel has increased at a respectable rate, and is still among the highest in the world, the labor cost content has increased more rapidly than in other countries, resulting in declining cost competitiveness for the American steel industry.

3 Capital investment in a particular industry aimed, for example, a $\mathrm{t}$ improving labor productivity may not make the industry (or firm) internationally competitive. This is true even in cases where the productivity gain exceeds that of foreign competitors, It is possible that the nation's overall productivity growth will exceed that of the industry (firm) in question,

Even an the Linited States, $w$ hir h might he considered a special case for a varietwof reasons, the surplusonguods and serveces in 1979 was onl vabuet 2 pereent of I hevalue of expor Is
If that happens, the international competitive position of the industry (firm) may deteriorate, despite its best efforts at improving productivity.

4. When industries lose international competitiveness because of relatively rising prices, this may be a signal that resources should be internally reallocated within the country, unless prospective technological changes promise to yield productivity improvements which are greater than expected for the economy as a whole. Note the emphasis on the word internal; the productivity improvements may or may not be greater than those abroad.

5. If average productivity over all industries increases "much faster in one country than in others, then it is likely that some formerly competitive industries in that country will become noncompetitive. This will be true even if their productivity improves faster than that of their overseas rivals.

The conclusions above can be extended in a number of ways. For example, competitiveness on an industrywide basis has been emphasized. In some industries, however, certain firms may be fully competitive in a relative price sense, while others face difficulties. The American steel industry presents a case in point, the efficiencies of different firms varying considerably. And too, individual firms may be competitive in some product lines, but not in others, For example, firms such as RCA and Xerox have dropped out of the computer sector while remaining highly competitive in other products (in this case, the principal competitors were domestic, not foreign).

The essential point is that-whether speaking of entire industries, of individual firms, or of product lines within firms - a loss of competitiveness often provides at least prima facie evidence that the industry (firm) has not kept pace with other domestic firms, not to mention industries abroad. Furthermore, it is by no means obvious that investment in new equipment or new technology will solve problems of competitiveness. This depends on the nature of the investment or technology, its impact on relative productivity, and the responses by both domestic and foreign rivals. In short, evolving patterns of comparative advantage in the world may leave no simple remedies for shifts in competitiveness.

The discussion above has left aside a number of other factors that can affect competitiveness, many of which are discussed elsewhere in this report. From an economic perspective, these addi- 
tional factors may introduce market distortions that give erroneous price signals in the global marketplace. For example, governrnents can provide otherwise noncompetitive industries with direct or indirect subsidies (direct payments. preferential allocation of credit, tax benefits). Another example of market (Distortions lies in the contraclictory effects of past U.S. Government policy in the areas of automobile fuel economy and prices for gasoline. By legislating corporate average fuel economy standards while con trolling oil prices a $\mathrm{t}$ relatively low levels, the Government created a conflicting set of market signals [ch. 6), confusing consumers and perturbing corporate decisions. Dumping-selling exports at prices less than charged in domestic markets (or, under some circumstances, at less than cost) -also distorts prices, Such practices have been frequently alleged in steel and in consumer electronics during recent y'ears.

When distortions of these types exist, governments can attempt to offset them and improve the opera $\mathrm{t}$ ion of the market - e.g., by assessing antidumping duties intended to restore "normal" prices. In some cases, however, the market may be providing price indicators that are accurate from the standpoint of resource allocations," but have political\}' unacceptable consequences. The political difficulty in decontrolling energy prices was, of course, responsible for the contraditory Government policies noted above

Conflicts between economic and political concerns that can be difficult to resolve may arise when noncompetitive industries appear essential to national security. This is one of the motives behind the support which various governments have, on occasion, provided to all three of the industries considered in this study: the importance of both the steel and automobile sectors to U.S. security have recently been vigorously argued. In still other cases, a reallocation of resourcesaway from noncompetitive industries and toward competitive ones-might cause massive employment dislocations. While in the long term, reallocation and restructuring might be desirable from an economic standpoint, in the short term the dislocations often appear politically and socially intolerable. The result may be public policy measures such as trade barriers that protect declining industries a $\mathrm{t}$ the expense of economic efficiency. As discussed elsewhere, it is desirable that policy decisions reflect the real costs of such alternatives.

Policy problems arising from technological change can also be difficult to resolve. New prod- uc $t$ and process technologies can affect different nations in markedly different ways. For example. the magnitude of the productivity increase that results from a particular manufacturing method - perhaps software-prograrnmable industrial robots-will not be the same for a 11 countries. This will be true even when the technology is widely available and all nations have the capacity to implement i I. Productivity increases will depend on factors such as the extent to which the new methods are applicable to the mix of products made $\mathrm{i} n$ each country, and the wage rates for the labor displaced. Furthermore, from a public policy standpoint, new technologies may have consequences that are difficult to predict. Thus a policy directed at improving the technology of a particular U.S. industry-e.g. a Governmentsponsored R\&D program-might result in new products or processes that are better suited to the economic environments of other countries.

\section{Technology Gaps}

A frequently cited source (of U.S. comparative advantage has been the abilitvtogenerate" technologygaps" - technological leads over foreign compet i tors. - often such ga ps ha ve notbeenso much i n funda men ta 1 knowledgeof tech nology and science as in the abilitytocommercia 1 ize this knowledge. American exports (includinga Sriculture) have often been cha racterizedbvountinual new product 'process developments. Elec:tronics, particularly semiconductorsand computers, provides obvious examples.

More recently, there have been assertionsthat the U.S. lead in technologyhas t:ro(icd-in t ransfers of technologyassociated with directexports. foreign investment by 11 . S. firms, andlicensing agreements withforeign firms. There havebeen claims that halting out flows of technology could reestablish the U.S. lead.

There seems little question that laggingcountries can catch up by importingtechnology. Historically, many of Japan's technicaladvances and commercial successes have beenassociatedw it h such imports. Vir tua llyall technologiestodav :1 re? rapidly diffused among industrializednations. partly through licensingarrangements, butpartly a 1s o by the ab i 1 i t vof fir ms in the a (ii';] n reei croun tries to quickly duplicate technologies developed elsewhere-aresul tof the largely SC I f-sustaining

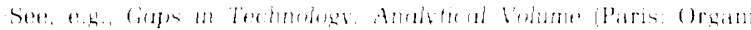

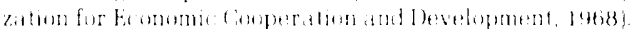

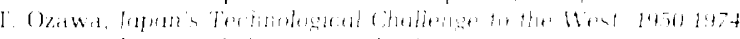

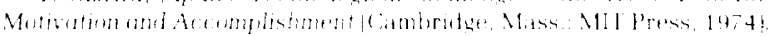


near-parity in many fields of technology and science that now exists. This observation is not meant to imply that R\&D efforts are futile, only that the benefits thus gained are likely to be shortlived, and that continuous effort is necessary to maintain them. It is difficult to safeguard purely technical advantages for long, unless coupled with stringent patent protection, closely held trade secrets, large capital requirements, or other non technical means of protection.

\section{Alternative Perspectives on Competitiveness}

Although the comparative advantage framework discussed above is commonly used in economics, international competitiveness can be approached in other ways. Some observers, for example, maintain that the United States is declining in industrial competitiveness virtually across the board-that somehow the economy is losing its vitality and ability to grow. The notion of an across-the-board loss in competitiveness is seldom defined with any precision; however, proponents of this view usually seem to refer to relative increases in productivity and level of technology in the United States as compared to other countries, For example, if the U.S. economy shows slower gains in labor (or total factor) productivity over time, this would be taken as evidence of a decline in competitiveness. Such a decline would lead to slower growth in per capita real income, again compared wit $\mathrm{h}$ other industrialized nations. The obvious example of a country losing competitiveness by this criterion is Great Britain.

Such a perspective would typically lead to public policy remedies directed at the more general dilemma-i.e., to macroeconomic policies-rather than industry-specific measures. From a purely economic point of view, sector-specific policies might be more appropriately justified by a dynamic comparative advantage analysis. This implies directing aid to sectors with strong future prospects rather than to failing industries.

Another alternative viewpoint treats market share-a common measure of performance for private corporations-as an indicator of competitiveness for nations. Markets can be defined globally, nationally, or regionally. In this view, a decline in market share is tantamount to a loss of competitiveness,

A major problem with global market share as a measure of competitiveness is that, for a country like the United States, losses in world market share are almost inevitable as other nations pro- gress economically. Starting from a lower postwar base, growth rates in many o $t$ her countries have been greater than in the United States, which has been left with a smaller part of the global economic pie. It is also possible to use market shares either $w$ i thin the United States alone or in third countries as indicators of competitiveness. If economic growth rates in other countries are higher, U.S. firms might find themselves losing share to imports at home and a $\mathrm{t}$ the same time in export markets. Even $\mathrm{i} f$ the losses in market share were restricted either to the domestic market alone or to export markets, a decline could indicate a deteriorating ability to compete with overseas producers.

\section{Technological Competitiveness}

Rather than adopting economic measures, it is possible to view competitiveness in terms of an industry's technological capabilities compared to its overseas rivals. Technology gaps and their roles in competitive advantage were mentioned above, Comparisons might be made either in terms of an industry's product offerings or its manufacturing processes.

In the case of product technologies, useful measures are difficult to find, For example, a domestic industry might lead in some products but not others, the mix shifting continuously over time. How can competitive decline be assessed in such circumstances? one can, for example, count numbers of new products or numbers of patents. By either measure, the relative position of the United States has been declining in many industries. Yet counting new products or patents is known to be a highly imperfect indicator of technological competitiveness. ${ }^{4}$

In industries that are rapidly evolving technically, such as semiconductors, it is possible to quantify technology gaps by examining the timing of new product introductions-e.g., 16-bit microprocessors. Such indicators are inevitably very narrow, as well as being retrospective rather than current or prospective, In more mature industries, technology gaps have little meaning. the introduction of new process technology for making iron or steel does not depend on technological levels so much as capital for investment, which in turn depends on expected levels of profitability. This brings us back, essentially, to comparative advantage,

W. B. Walher, Industrial Innovation and Internotonul Trading Per formance (Greenwich. Cunn.: JAI Press. 1979) 
Capital goods suppliers-firms that produce machinery and equipment used in other manufacturing industries, also provide evidence of technological capability. Examples include transfer lines for making automotive components, or lithographic equipment for fabricating integrated circuits. The products of such industries can be viewed both as endproduc ts-whose rate of technological innovation might lead or lag that of other countries-or as process innova $t$ ions that lower costs or improve product quality in the industries that use the equipment. In the la ter case, technological differences be $t$ weennations would appear as relative changes in the ability of the customer industries to compete on a cost or productivity basis, From a policystandpoint, this can be import:] $\mathrm{n}$ t, The Japanese semiconductor indus try develops and manufactures a consider-able fraction of its own processing equipment, while in this country only a few of the larger vertically integrated firms doso. Thus, improvements in the relat ive efficiency of the U.S. sem iconductorindustrydepend to a considerable extent on the a bi 1 i t i es of ad if ferent, though relat edi nd us $t r v-$ the equipment suppliers, Al thoughthereareclose a ss ocia $i$ ions betweense m i conduct or f i r ms and their suppliers, policymeasuresdirected 0111 a $\mathrm{t}$ the former might nothave the desired results.

\section{Exchange Rates}

I $n$ recent vears, exchange rates in the industrial world have beenfor the most part free to adjust to prevailing marketcondit ions. Governments dofrom time tot i me i n fluence the prices of the i $r$ currencies, but wholesaleintervention is difficul t a ndexpens ive. One conseguence of more flexible exchangerates is that domesticindus $\mathrm{r}$ ies ma $\mathrm{v}$ be pricecompeti tiveatone t i mebut not:1 nother soleIV because of exchange 1-:1 te shifts, Someobservers bel ieve: that the American steel industr became compel i t ive for a short period during the midei 1 e.1970)sasaronseguenceofasubstan t ia I readjust ment of thedollar vis-a-v is ot hercurrene ies. When such offer ts arepresent, meisurement of therempet it iveness of i motividua I industries a narelat ive priresensebeomesambiguous.

\section{Measures of Competitiveness}

The preadeding ser: $t$ in ms suggest anumber ( if possibleindicatorsof in I frnationalompetitionness:

1. Relative trends in labor productivit $t_{y}$ - A fairlsimplemel hudfor delerminingan il]- dustry's ability to compete is to compare its labor productivity over time with that of other domestic manufacturing industries. A relative decline is evidence of a possible problem, as appears to be the case in sectors such as footwear and steel.

2. Relative wage rate trends.-Industries with slackening competitiveness often show relatively falling wage levels, aga in compared to other domes tic industries, In other cases, rela $t$ ivel y rising wagesca $n$ be a couse of difficulty-e.g., if unit labor costs increase faster than in other industries. High wage rates in the U.S. steel and automobile" industries are one element in their present competitive difficulties, moreimportan $\mathrm{t}$ in s t eel because labor productivity in that industry has not increased as rapidly as in automobiles.

3 Relative profitability trends .-Declining competitiveness real' also appear as low relalive profit levels. However, it is often (ii fficult to apply such measures, part icula rly for i ndus $t r$ ies popula $t$ ed by divers $i$ fi edcompanies where profi tability and competi tiveness can va rv dramat ically for di fferent product lines. In addition, profit tability data ca $n$ be in fluencedbv differences in a coounting conven t ions and ta $x$ pol ic ies. Ja pa nese firms, for example,tendto report lower profits than Amerioan firms, partlybeca use higher deprecia tion ra tes are pe rmitted. Thev mav also be permit ted to take advantage of tax reservesnot permit ted 11 , S. firms.

4. Import penetration ratios. - Thefractionof domestic consump t ion a coou n tedfor by imports can reflect changes in cost-based compet it iveadvantage-butalso shift ing patterns of consumer demand,bo a h here and abroad. The 1 a t $t$ er is onecauseof i noreased salesofforeigncars i $\mathrm{n}$ he Un i ted Sta $t$ es. Wh ile importpenetrationrat iosaregoodindicators of compet i t iveness, part icularly i f lomg-term trends ( a i be established, thev (";11 beconfoundedbvgovernment policies (e.g. export subsidies) corporate strategies (forgoing certain markets), and variousol her farturs.

5. Process technologies,-in someindustrues,

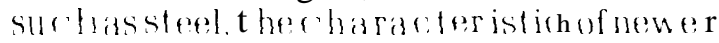
pre )('[?ss techmolog if :4; $11^{\prime}$ (' nellknown. Where?

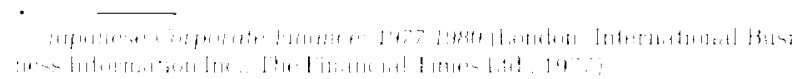


this is the case, the potential impacts on international competitiveness can be inferred-e.g., by examining the effects of the prospective technologies on production costs in various parts of the world.

6, Product technologies.-In industries such as electronics. comparative costs may be only part of a more complex competitive situation. Unique product technologies and technology gaps have been important to the past strength of U.S. industries such as electronics and aircraft: informed technical judgments are needed to evaluate their significance.

There are other possible measures of competitiveness. Some are specific to particular industries, others more general: but competitiveness can be fully understood only on a sectoral basis. Government policies and regulations affect some industries more than others. Furthermore, international competitiveness cannot be analyzed in isolation from the corporate strategies of individual firms.
Economists have offered a variety of explanations for shifts over time in comparative advantage or in competitive advantage-none very satisfactory, Models based on factor proportions, the product life cycle, or demand similarity help to understand some cases but not others. Moreover, none of the models includes the effects of conscious intervention in economic processes by exogenous agents such as governments.

Still, if policies specific to particular sectors of the economy, as well as macroeconomic and other aggregate policies are to be improved, some idea of their potential effects is required. Assessing these effects, particularly across industries, requires the use of a comparative advantage framework. In many respects, a dynamic comparative advantage analysis would be idea 1. Japan longterm economic policies are examples of attempts to develop strategies within a context of dynamic comparative advantage, strategies that are anticipatory rather than reactive. 


\section{The Economics of Industrial Policy}

A basic principle underlying public policy in a market economy is that of market failure, or government by exception; the market mechanism is preferred to government policy except when it can be shown to fail. Generally speaking, this principle is independent of the nature of the market, and holds for concentrated, oligopolistic markets as well as for those which are more competitive. The tests for market failure, and the remedies, will in fact depend on just such characteristics.

Thus, one way to begin a study of industrial policy is by examining the circumstances under which markets fail, However, market failure is a necessary but not sufficient condition for public policy, Whether government responses are warranted depends on several factors, the most important of which are the social costs of the failure.

The following sections discuss several categories of market failure, particularly those that could serve as possible rationales for industrial policy. The aim is to identify and clarify various categories of justification for government intervention in industry and to distinguish economic from political justifications,

\section{Externalities and Market Failure}

The benefits or costs to society as a whole associated with private economic activity generally differ from private benefits or costs. Therefore, market decisions based on private calculations do not necessarily yield outcomes that are socially most desirable. Such externalities often motivate public policy measures having significant effects on industry, Regulations aimed at the control of pollution or at public health and safety are examples. Such measures are discriminatory in the sense that some industries are affected more than others. Externalities have also been a rationale for government funding of R\&D because social returns to R\&D may exceed private returns.

Analyses based on externalities often point to the use of nonselective market promotion policies, such as fiscal incentives, to encourage socially desirable $R \& D$ or to discourage undesirable activities such as environmental pollution. Such measures have aggregate objectives, cutting across industrial sectors rather than being sector-specific. For example, a fiscal program to stimulate $R \& D$ in the aggregate might include tax credits for R\&D facilities, or accelerated depreciation of capital investment for facilities and equipment used for R\&D. Similarly, a fiscal program to encourage environmental improvement might include accelerated depreciation for pollution control equipment, investment tax credits for such equipment, or the use of a government bond or loan guarantee program to finance a portion of the investment, Market promotion policies of these types would have industry-specific effects, since some industries are more highly dependent on R\&D or pollute more than others, but the measures would address themselves to aggregate rather than sectorspecific objectives,

In practice, government policies in response to externalities have often been sector-specific by design - in the United States as well as in foreign countries, Direct government funding of $R \& D$, or indirect support through procurement programs, as in the U.S. semiconductor and computer industries $(\mathrm{ch}, 6)$ are cases in point. Another is emissions standards for automobiles. Whether or not the industry-specific effects of government programs in response to externalities are consciously intended, policy makers should consider these effects and their implications. Failure to do so has been one of the weaknesses of Government policies toward industry in the United States. The side-effects of policies directed at externalities have sometimes conflicted with other policy objectives, For instance, in industries such as steel or automobiles, regulatory policies have required substantial capital investments. To some extent, these have drained funds from alternative investments that might have done more to enhance productivity and competitiveness, Indeed, sideeffects of such types have often served to rally political support for counteracting industry-specific programs intended to compensate firms or industries *'injured" by Government policies.

\section{Public Goods and National Security}

Market failure also occurs in the case of "public goods. "These are goods that private firms do not produce, or do not produce in adequate quantities, usually because: 1) such goods are "nonrival" so that one person's use of them does not diminish someone else's enjoyment; or 2) they are "nonexclusive' so that those who choose not to 
pay cannot be barred from their use. National security and defense are the categories of public goods most important to industrial policy. For example, some observers argue that aid to the American steel industry is necessary because steel is vital to national security. This kind of argument, applied in other countries, is one reason for the fact that 45 percent of world steel capacity (more than 50 percent in Europe) is government-owned. 'Similar arguments are frequently made for public policies to promote semiconductor industries, on the grounds that semiconductors have critical military applications.

That the output of a particular industrial sector is vital to national security implies that social benefits exceed private benefits, and that government intervention may be needed to maintain socially desirable levels of production. Nonetheless, there are at least two steps that are necessary before concluding that government action is necessary. First, it must be demonstrated that in the absence of government action, domestic production might be inadequate to meet national security requirements. Studies of steel and semiconductor industries have been inconclusive on this point. It also must be demonstrated that in the absence of sufficient domestic production, secure sources of imports would not be available. For example, could the United States rely, if necessary, on imports of steel or semiconductor devices-either from allies or from neutral nations-at fair prices? The OTA steel study raises the possibility that if the domestic industry is allowed to decline, the United States may someday face unfair prices for steel imports, perhaps because of foreign cartels. Even if a steel cartel were judged unlikely because of the large number of foreign producers, foreign governments might halt exports to the United States to safeguard their own supplies during periods of military emergency and/or tight supplies. Given the vagaries of international economic and political conditions, and the importance of products such as steel for national defense, a risk-averse strategy might require government policies guaranteeing supplies. Such policies could include stockpiling as well as support for the domestic industry.

\section{Product Market Imperfections}

A third category of market-failure arguments for government policies is based on imperfections in markets for the products of industry. Such im-

'Technology and Steel Industry Competitiveness (Washington, D.C Office of Technology Assessment, U.S. Congress, June 1980], p. 102. perfections may take several forms-e.g., barriers to entry resulting from scale economies, product differentiation, or advertising. When imperfections of these types exist, markets may not function in socially optimal fashion. Thus, such imperfections can become an important rationale for public policies. They underlie, for example, antitrust laws in the United States.

Issues such as antitrust arise in debates about industrial policy because some people argue that aggressive pursuit of antitrust measures has put the United States at a disadvantage in international competition. According to this view, antitrust enforcement by the Department of Justice and the Federal Trade Commission has focused too narrowly on domestic markets and failed to acknowledge foreign competition. As a result, it is claimed, mergers that might enhance U.S. competitiveness have been restricted, innovation stifled, ${ }^{z}$ and suits brought seeking to break up the very firms that are mainstays of U.S. competitiveness (the ongoing Government antitrust proceedings against IBM and Western Electric are frequently brought forward as examples). Concerning mergers, chapter 5 points out that vertically integrated Japanese electronics firms, making semiconductors for their own use, may be a source of competitive advantage for that country. As the capital and R\&D costs of semiconductor production increase, economies of scale are likely to grow, making vertical integration more desirable. However, in the United States, antitrust policies could be perceived as blocks to such strategies,

\section{Capital Market Imperfections}

Imperfections in capital markets provide another possible reason for public policy. Such imperfections can take several forms, and often resemble the externality or public goods rationales discussed above. For example, capital markets may not supply funds for investments if the expected returns are too far in the future, or if social returns greatly exceed private returns.

One type of possible capital market imperfection depends simply on the size and apparent stability of the firm seeking funds. Private capital markets often appear to discriminate between large and small companies. Investors or lenders face risk and uncertain returns. Lending to large firms with established reputations and significant

\footnotetext{
Possible effects of antitrust enforcement on industrial innovation are summarized in Antitrust. Uncertuinty. and Techologeral Innowation IWashington, I.C.: Vational Arademy of Sojences. 1980).
} 
sources of internal funds gives some assurance of repayment, even though the project for which the loan was intended may fail. In contrast, lending to small firms may carry larger perceived risks of default-although this may be simply a result of poor market information about small firms, and lenders could spread their risks by lending to or investing in a number of small firms. Capital market imperfections can also stem from a preference by businesses for reinvestment of internally generated funds even given outside investment opportunities offering higher rates of return.

Alleged imperfections in capital markets resulting from better access of larger firms and established industries to external capital, or from their preferences for the reinvestment of internal funds, have sometimes led to proposals that government act as an an alternative source of financing, For example, the government might guide funds from declining industries to higher productivity sectors whose growth appeared to be limited by access to capital or by high risks, perhaps associated with new technologies,

The issue of risk introduces another type of possible capital market imperfection-failure to finance projects judged excessively risky by private lenders. All investments are inherently uncertain; the greater the uncertainty, the greater the risk and hence the higher the returns required by investors. For projects with potentially high but very uncertain returns, the cost of obtaining capital from the private capital market may be prohibitive.

Discussions of industrial policy sometimes turn to the possible need for government policies to guarantee capital availability for high-risk projects in high-technology or new-technology industries, such as semiconductors or alternative energy conversion systems. Such policies might include cofinancing or loan guarantees. Alternatively, the government could raise the potential rewards to investors by lowering the capital gains tax. Government subsidization of risk might be defended on at least two grounds: 1) that government has a greater ability to bear risk than private investors; and 2 ) that private decisionmakers may be more averse to risky investments than government decisionmakers.

A final capital market argument for public policy is based on time horizons of private investors. The OTA steel study, for example, found that new equity investments have tended to favor quick payoffs rather than the long-term investments needed to renew the technological foundation of the industry, During the past 10 years, the debt- equity ratio for the entire steel industry rose from 36 to 42 percent. ' However, the U.S. industry still has a debt-equity ratio only half that of the Japanese industry; this is a specific example of the general argument that low debt-equity ratios in U.S. industries mean that investments are evaluated primarily according to short-term profitability (debt carries fixed rate-of-return obligations while equity brings with it pressures to compete with the returns available from alternative investments), Long-term profitability is, however, more important for continuing international competitiveness. While it is difficult to generalize about the extent of any short-term bias by managements of American firms-whether because of stockholder demands or other reasons-there is a good bit of anecdotal evidence for such behavior, "Again, the policy prescription might be Government programs such as loan guarantees, support for R\&D, and selective tax credits that promote long-term projects judged to be socially desirable.

This argument for government intervention is really just the externality or public goods argument in another guise, The underlying rationale is that private estimates of returns fail to include socially desirable returns that occur at some future time. For example, socially optimal time horizons may be longer than privately optimal horizons for infrastructure or R\&D projects with long and uncertain gestation periods.

\section{Labor Market Imperfections and Adjustment Assistance}

Imperfections in the functioning of the labor market frequently serve as the justification for offsetting government policies. Such imperfections may take several forms, but the result is always the same. Wages do not adjust to equalize supply and demand for different types of laborperhaps because of labor unions, minimum wage legislation, barriers to worker relocation created by skill requirements or geography, and rigid wage differentials between industries or between workers with different skills. Lack of portable pensions is also a bar to mobility. In the presence of such imperfections, changes in demand for the products of an industry may lead to production cutbacks, layoffs, and unemployment, rather than to an adjustment in wage differentials between industries that would help maintain full employ-

\footnotetext{
Technology and Steel Industry Competitiveness, op. cit., p. 120

${ }^{\circ}$ R. H. Hayes and W. J. Abernathy. "Managing Our Way to Economic Decline." Harvard Business Review. July-August 1980, p. 67
} 
ment and reallocate labor among different industries. Productivity improvements resulting in decreased employment opportunities can have similar effects, as can international capital flowsassociated, for instance, with the establishment of overseas assembly plants.

In many countries labor market imperfections are central to pressures for government intervention in industries affected by import competition, as well as by technological unemployment or flights of capital. The latter two have generally been more important as causes of employment dislocations in the United States-whether productivity growth, movement of electronics assembly operations to Mexico or the Far East, or of textile plants from New England to the South. In this country, however, the Government has normally provided adjustment assistance only when unemployment is associated with import competition,

As an example of the rationale for such assistance, suppose that demand for the output of a domestic industry such as steel declines as a consequence of competition from lower priced imports. According to economic theory, if wages were free to fall, they would do so relative to wages in other industries where demand has not declined, The relative wage decrease in the import-affected sector should encourage workers to leave that sector for alternative jobs at higher relative wages elsewhere in the economy. In reality, such behavior seldom occurs. For example, in the American steel industry (chs. 4 and 5) wages have not declined despite import competition and falling profits. A strong union has kept wages high; incentives for workers to move to other industries have been few. Unemployment compensation and other guaranteed payments also discourage mobility,

In the absence of labor market imperfections, changes in wage differentials between industries, and in the aggregate rate of growth of wages, will guide the movement of workers from declining sectors to those that are more competitive. Although the distribution of labor would change, full employment would in principle be maintained. However, if wages do not adjust, the result will be aggregate losses in output, aggregate unemployment, and a slowdown in the movement of labor away from the import-affected industry, Therefore public policies to speed the process of adjustment may be desirable, Such policies might include relocation subsidies to workers and tax incentives for firms in other industries that hire the displaced workers.
The argument for government intervention because of labor market imperfections is based on economic efficiency and is distinct from that for intervention on equity grounds. Socially optimal allocation of resources under changing national and international market conditions may call for movement of both capital and labor from industries in relative decline to those which are more profitable. Labor market imperfections may interfere with this adjustment by distorting the price, wage, and profitability signals that guide decisions. Under these circumstances, an efficiency argument can be made for offsetting government policies. But even in the absence of such imperfections, public policies may be needed so that the costs of adjustment do not fall disproportionately on some individuals while others reap the benefits.

Again, the example of an import-affected industry such as steel or automobiles can illustrate. Shifts in international competitiveness may require the movement of labor from such an industry on efficiency grounds, Although this movement yields social benefits, it also has costs. These costs include the income lost by workers during the transition to new jobs, and any retraining and relocation costs. In the absence of public policies, the full adjustment costs are borne by the displaced workers. This is not necessarily equitable. Why should employees of firms affected by imports (or technological change or flights of capital) bear the brunt of the costs, while others-such as the consumers of cheaper foreign imports-reap the benefits? The government may well decide that a different distribution of social costs and benefits is desirable. This was one motivation for the expanded trade adjustment assistance program (see ch. 8) created by the Trade Act of 1974. In many countries income supplements, retraining and relocation grants, and aid programs for communities are used to reduce the costs paid by workers and localities when industries decline or employment opportunities are lost-whether caused by shifts in international competitiveness, technological change, or other factors. Such policies may be particularly important for industries where workers are older, unskilled, or otherwise have difficulty finding new jobs.

Efficiency and equity rationales for trade adjustment assistance are specific applications of the general principle that the costs of moving labor and capital so as to produce a net social 
gain should not fall disproportionately on particular groups. Whether the factors behind resource relocation are the result of changes in consumer demand, changes in technology, or changes in government policy-such as the scaling down of military installations or the imposition of standards for environmental control or occupational health and safety-government programs may be desirable to protect those whose jobs are affected. In the United States, however, such policies have in the past been limited to tradeaffected sectors or to a limited number of programs dealing with regional adjustment-such as the programs of the Economic Development Administration or the Department of Housing and Urban Development (ch. 8.)

Equity and efficiency rationales for government intervention are distinct, and may be in conflict. For example, adjustment programs have sometimes acted to reduce incentives for finding new jobs and themselves slowed the adjustment process. Indeed, some observers contend that the sluggish movement of labor in the United States is precisely the result of such programs-which is not an argument against adjustment policies in principle, but against those that are poorly concieved or otherwise do not function as intended. To counteract such flaws, adjustment assistance programs could be designed to increase incentives for adjustment by tying payments to socially desirable objectives such as retraining or relocation. Finally, one of the most persuasive arguments for adjustment assistance is that, in the absence of such programs, individuals who bear the costs of a socially desirable movement of resources are likely to use their political and institutional power to impede adjustment, In other words, i f the equity issue is not confronted by government policy, the result may be development of imperfections in capital, labor, and product markets that hinder rather than facilitate the movement of resources in response to shifts in corn pet i t iveness,

\section{Market Imperfections Resulting From Government Actions}

While many failures or imperfections are inherent to markets, another category consists of those that are themselves consequences of government policies, be these domestic or foreign governments, Intervention by the U.S. Government to promote or support industries such as steel or semiconductors is sometimes urged as a counter to "unfair" competition resulting from foreign government policies.

Measures to protect U.S. markets from "unfair" foreign competition have included voluntary restraint agreements (VRAS) or orderly marketing agreements (OMAS), trigger pricing, antidumping surcharges, and other remedies implicit in sections 301 and 337 of the Trade Act of 1974. These measures have not always been effective (see ch. 6). As one result-here and elsewhere-pressures can mount for alternative policy responses - eog., subsidization of industry by tax cuts or R\&D support to countervails similar programs in other countries. Imperfections created by foreign industrial policies are becoming a force for similar policies in the United States. Indeed, this is the point of departure for many discussions of industrial policy. The net result could be offsetting neomercantilist policies leaving each country worse off than it would have been if none had introduced such policies.

It is not obvious that the United States should respond to market imperfections resulting from subsidies to industries that compete with American firms, Indeed, some people argue that if foreign governments are subsidizing exports to the United States, then they are effectively subsidizing U.S. consumers. According to this view, the United States benefits from "unfair" competition, and no policy response-protectionist or otherwise-is needed. Of course the gains to the United States are not without costs and may be short-lived. As discussed in the preceding section, adjustment costs are one consequence. These costs-for moving capital and labor out of firms, regions, and industries that cannot compete against subsidized foreign producers-are often substantial. This is particularly true if capital and labor are relatively immobile. Costs of adjustment must be weighed against the benefits of subsidized imports,

Even if the net benefits outweigh the costs, a government policy response might still be warranted. At the very least, equity concerns could justify adjustment assistance. Why should some domestic interests benefit from the policies of foreign governments while others suffer? Distribution of costs and benefits should be the outcome of domestic policies rather than actions taken $b \sim$ foreign governments.

Beyond considerations of equity, there may also be long-run efficiency rationales. Suppose that in the absence of offsetting domestic policies, foreign subsidies lead to the decline of domestic 
firms, In the long run, foreign governments might use the resulting market power to cartelize or monopolize the world market, forcing up the prices of imports, Such a strategy could only be successful in industries where economies of scale or other barriers to entry prevented the reappearance of competition. For these and other reasons, predatory pricing strategies would probably not succeed. More convincing reasons for domestic policy responses to foreign subsidies focus on the loss of initiative that would result if domestic industries were allowed to passively restructure according to market signals distorted by the governments of other countries.

In addition to the distorting effects of foreign government policies, domestic government actions may create a need for compensatory policies. As noted elsewhere, policies aimed at aggregate objectives (for instance, environmental quality) often work to the disadvantage of particular industries such as steel. Evolving legal standards for product safety and reliability have likewise increased risks in some industries-e.g., chemicals. Differences in the tax treatment of various types of capital work to the advantage of some industries but not others. Interest deductions for mortgage payments in the United States favor investments in real estate over manufacturing.

Moreover, tax effects combined with rapid inflation have adversely affected investment in industry. Because the capital gains tax falls on nominal capital gains rather than real gains, investors may face taxes if they sell assets whose real value has not increased. This tends to encourage the owners of such assets simply to hold them-the lock-in effect-and works against mobility of capital. Inflation also increases the effective corporate tax rate by reducing the value of depreciation deductions based on historical costs, When public policies can be shown to distort market signals, responses ranging from their elimination to the introduction of compensating measures may be justified,

\section{Macroeconomic Rationales for Policy}

The final rationale for government intervention differs from those preceding because it is based on macroeconomic performance-measured by parameters such as price stability, aggregate levels of output and employment, or balance of payments - rather than conditions in particular industries or markets. As the market system does not always realize macroeconomic objectives on its own, government action may be required to maintain full employment or counter inflation. Such reasoning usually points to aggregate rather than industry-specific or market-specific policies, although such policies may have sector-specific effects. For example, government policies dealing with balance of payments should not be required if exchange rates can adjust freely to changing market conditions, However, foreign government interventions or lags in adjustment may call for government responses, at least temporarily. Although not industry-specific in intent, such responses would typically be industry-specific in their results-because industries that export, those that compete with imports, and those that produce goods which are not traded at all will be affected differently.

\section{Costs and Benefits of Alternative Policies}

Public policies affecting industry often carry the potential for high net costs to society, For instance, using sector-specific policies to attack aggregate problems can be inefficient-as when a declining industry is subsidized to maintain employment. Before adopting industrial policy measures, costs should be estimated both inside and outside the sectors of immediate interest, Whether choosing sector-specific policies aimed at sector-specific problems, market promotion policies, or other measures with aggregate objectives-costs and benefits of alternatives are important considerations. Even when precise evaluation is impossible, enumerating the classes of benefits and costs-which may be widely spread through society-can help to frame judgments.

To illustrate, consider the case of government intervention in manufacturing industries such as steel or automobiles. On the benefit side of the argument, major outputs can be identified that could decline or be otherwise adversely affected in the absence of government policy. The list might include:

1. The benefits of preventing decreases in domestic output and employment as a consequence of a decline in the particular industry. These losses impose only short-run costs provided alternative employment can be found for the factors of production (labor, capital) released; in other words, such costs are adjustment costs. If, however, there are regional or other barriers to factor mobility, 
then these costs may become permanent, Both short- and long-run costs can in principle be weighted to reflect distributional consequences, such as the social impact of income losses on depressed regions.

2. Prevention of losses in socially desirable R\&D as a consequence of decline.

3. Prevention of declines in domestic output necessary for national defense.

4. Prevention of loss of competition within domestic markets, including losses associated with distorted market indicators and inefficient allocation of resources,

5. Avoiding lost tax revenues, increases in unemployment compensation, and similar costs.

On the cost side of the ledger, one would have to identify the various losses that would occur as a result of government policy. This list might include:

1. Long-run efficiency losses due to misallocation of resources caused by government policy. These losses could include decreased outputs in other industries-e.g, if the sector favored by the policy bid resources away from other industries.

2. Direct costs of the policy, including costs of institutional machinery for implementing it. The calculation should consider possible cuts in other Federal programs, including distributional consequences,

3. The costs of any behavioral inefficiencies resulting from the policy. For example, government intervention to support a particular industry might create pressures for matching aid to other industries.

In principle, each of these benefits and costs should be evaluated based on alternative assumptions for future market trends, with and without the policy, and with alternative time horizons. Calculations should be made for a range of policy alternatives to determine which, if any, might be preferred,

Although this framework may seem abstract, it demonstrates that there is no prima facie case for industrial policy, especially for sector-specific policies favoring or promoting certain industries. A judicious evaluation of the many competing objectives and the many competing policy responses is needed.

\section{The Economics of Protectionism}

As discussed in chapter 6, policies intended to shield domestic industries from foreign competi- tion have seldom been effective in promoting industrial adjustment; even when effective, protectionist measures are usually rather inefficient. This section briefly reviews the effects of protection-whether by tariff or nontariff barriers. The most important nontariff barriers are quantitative restrictions on imports such as VRAs or OMAs.

In the absence of market imperfections, tariffs generally reduce aggregate economic welfare. Labor and capital employed in an industry given tariff protection will gain; but losses to consumers of the protected commodity will typically be greater, Furthermore, even when a policy response is necessary, tariffs frequently prove a second-best measure. Alternative measures can usually achieve the desired objectives at less cost to society, particularly objectives involving encouragement of domestic production in a given industry, The reason is straightforward, Tariffs change prices, and prices affect both production and consumption. A policy that works directly on production and leaves consumption unchangedsuch as a tax, subsidy, or credit policy-is more efficient than a tariff because the tariff also distorts consumption.

Quotas also tend to be second-best policies, and for the same reason-they affect both production and consumption, But quotas are often less effective than tariffs, Selective quotas-applying to certain commodities and/or certain foreign suppliers-are not always successful. If imports of one kind are restricted by quota, foreign producers may switch to a substitute. If quotas are applied to imports from one country, other countries may move in. The OMA on imports of color televisions from Japan encouraged an increase in imports from Taiwan and Korea, while also encouraging Japanese production in the United States.

Tariffs are also superior to quotas from a distributional standpoint. Tariffs, like taxes, generate revenue. The funds become available for financing other government policy measures or for offsetting other taxes.

Protection against imports by means of quotas or tariffs has been used with some frequency in recent years. In the case of U.S. industries such as apparel and footwear-where domestic producers face a cost disadvantage and market im-

For a recent example estimating the effects of tariffs or quotias on autumobile imports, see M. P. Lunch, et al., Comments of the Stuff of the Federal Trude Commission Before the Cinited Stutes Intermutumul Trude Commssion. Certum Motor Vehicies and Certum Chonsin and Bextion Therefor. (oct. 6, 1980. especially app. B 
perfections can be ruled out-protection has been justified as a short-term measure to slow the pace of decline and hence reduce adjustment costs. However, temporary protection intended to ease adjustment may become permanent. Furthermore, protection is a second-best policy compared to adjustment assistance and retraining or relocation subsidies, which do not unnecessarily raise prices to consumers,

Another rationale for temporary protection of mature or declining industries has recently been developed-an analog to the well-known infantindustry argument, This is the "senescent" industry argument, which holds that domestic producers with old, outmoded product or process technology should be protected from competition with foreign producers having more modern technology. Temporary protection, it is argued, will allow domestic firms to generate profits for modernizing their own processes and/or products. This rationale is quite different from that used to justify temporary protection because of rapid and unexpected change within the economy, The latter case-covered in trade law by "escape clause" proceedings - is clearly different from that of industries in slow decline because of longterm shifts in comparative advantage.

There are several possible pitfalls in the senescent industry argument. First, if domestic pro- ducers have been unwilling or unable to modernize or keep up with the technology employed by foreign firms, this suggests that it has been unprofitable for them to do so-e.g,, in the integrated portions of the American steel industry. Second, though a case might be made that market failure has caused the decline of domestic firms, this does not necessarily mean that protection is an appropriate policy response. Policy should be guided by benefits and costs expected in the future, not by the historical causes of decline.

Finally, if a policy to help a senescent industry does seem warranted, protection would probably not be the best remedy. Once again, protection is likely to be second-best, more costly, and less efficient than alternatives such as loan guarantees, or tax incentives for stimulating new investment. Furthermore, protection may not in fact promote modernization. Protection is only indirectly linked to capital investment, process or product innovation, and other possible strategies for increasing productivity and restoring competitiveness. While protection might raise profit levels, the profits will not necessarily be reinvested in the senescent industry, There is little evidence that trade protection in the steel or consumer electronics industries (or apparel or textiles) has worked to restore domestic competitiveness (see ch. 6), 
Legal constraints could preclude or limit the application of some kinds of policy measures directed at industrial competitiveness and economic efficiency in the United States, The possible constraints reflect not only constitutional principles, but also the traditional separation of Government and business enterprise in this country (ch. 8), The separation-more nearly an adversarial than a collaborative relationship-is deeply rooted in basic political attitudes, and has normally been perceived as healthy and desirable: it finds expression in the U.S. legal system.

The legal environment in the United States thus seeks, in many instances, to insulate Government from the private sector, both directly - as through Federal conflict of interest laws and numerous disclosure statutes, and indirectly-in antitrust and trade laws that embody fundamental presumptions against mercantilism and in favor of vigorous competition, Policy proposals of some types could raise legal issues because they would mandate precisely the behavior that the legal system presently attempts to limit or prevent,

Within the framework of the legal system, Government has, nevertheless, been granted increasing leeway to involve itself in the affairs of business and industry. The rapid growth of Federal regulation in the environmental, safety, health, and energy areas over the past 15 years is evidence of this trend. Government can certainly intercede in private trade and commerce-and in a substantial way. The basic question is: Would policy innovations be possible that could function effectively within the context of traditional Government-industry relations in the United States-as embodied in basic aspects of public law? Or, would industrial policy require new modes of interaction between the public and private sectors, and hence changes, perhaps fundamental, in that law?

A number of aspects of the legal environment for industrial policy are discussed in a general way below. The intent is to suggest topics of probable importance, the scope of industrial policy initiatives that have been suggested being too broad for examination in detail. Among these suggestions have been: tax incentives, including liberalization of business tax deductions and substan- tial tax cuts for individuals; creation of new Federal agencies: expansion of mechanisms for participation by business and labor in the activities of Government, including committees and commissions; development of programs for training, retraining, and assisting the mobility of labor; incentives for export-related manufacturing; import restraints such as surcharges and quotas: and formalized "economic planning" $[$ as in the Balanced Growth and Economic Planning Act of 1975).

\section{Constitutional Issues}

The U.S. Constitution imposes a variety of distinct restrictions on Government actions affecting private trade and commerce. Policies toward industry must conform with these-generally associated with the "Commerce Clause," delegations of congressional authority, State sovereignty, and equal opportunity.

Article I, section 8 of the Constitution-which contains the Commerce Clause-forms the basis for the Federal Government's broad powers to regulate private trade and commerce. The Constitution also ensures that Federal laws will have precedence over any inconsistent State and local laws. Over the years, the Supreme Court has continuously expanded the concept of interstate commerce: well-established guidelines now exist. The most fundamental of these allows Congress to exercise jurisdiction under the Commerce Clause whenever a commercial activity has a " substantial economic effect" on interstate commerce, Under this interpretation, even an activity taking place wholly inside one State may be within the scope of the Clause, so long as its effects extend to other States. For example, the Supreme Court has found the Commerce Clause broad enough to include the extension of Federal wage and hour protection to all workers in firms producing goods for interstate commerce.

To the extent that industrial policies would apply to major economic sectors - those that produce goods or provide services that are integrally

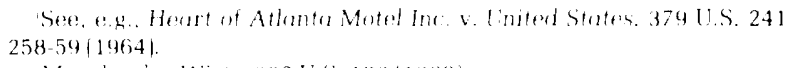


part of the flow of interstate and foreign commerce-such policies should not be materially inhibited by the Commerce Clause, Suppliers and subcontractors to these industries would also be subject to Federal regulation to the extent that they form a significant part of chains of production and distribution of products or services that are part of interstate commerce.

Article I of the Constitution also contains language that has been interpreted as permitting Congress to delegate legislative authority-for example, the day-to-day work of implementing congressional law, But the permitted delegations of authority are limited, especially to private parties rather than to Government agencies, Such restrictions would apply to committees or commissions involved with industrial policy that included private citizens within their membership, Those whose business interests could be affected would find their participation especially circumscribed,

The 10th amendment to the Constitution contains the State sovereignty provisions, which limit the extent to which the Federal Government can infringe on activities integral to the sovereignty of the States-e.g., those essential to State and local government. To the extent that a court sees industrial policy as a response to a national emergency, it would be more likely to uphold actions that might otherwise be seen as infringements on State autonomy. The courts will typically employ a balancing test: the gravity of national problems found to exist by Congress will be taken into account as a factor to be weighed, along with the nature of the State interest at stake, the extent of the interference with that interest, and the duration of the restraint.

Incorporated into the 5th amendment due process guarantee is the 14th amendment equal protection provision. The protections extend to businesses as well as individuals, and could bar programs that favor one segment of industry over another without legitimate economic or social purpose, But before a court overturned Federal economic legislation on equal protection grounds, it would have to be persuaded that the legislation was clearly without justification.

\section{Antitrust Laws}

U.S. antitrust laws seek to preserve competitive markets by broadly proscribing many forms of coordinated or collaborative activities among business enterprises. As such, they embody a fundamental public policy against the rationalization of trade, as through private "orderly marketing agreements" or similar arrangements that would tend to reduce the independent character of decisionmaking by competing firms. Given the substantial and costly risks of antitrust liability (e.g., private treble damage actions) it seems clear that the antitrust laws could represent a substantial obstacle to at least some forms of possible policy initiatives seeking increased industry wide collaboration on commercial and trade matters.

In view of the basic free enterprise policies embodied in the antitrust laws, the courts have narrowly construed explicit congressional exemptions from their application, and have sharply limited the circumstances justifying implied exemptions, Further, even where Government regulation displaces the antitrust laws, the courts have indicated that agencies can abuse their discretion in failing to consider the impact of regulatory policies on competition.

From the standpoint of industrial policy, the most important antitrust provision is section 1 of the Sherman Act, prohibiting any agreement that is "in restraint of trade among the several States or with foreign nations,"] This section has been interpreted to prohibit all manner of agreements among competitors which fix or stabilize prices, allocate territories or customers, limit market entry, regulate production, use group boycotts, or similarly restrict competition among firms at the same level of trade. Programs involving joint ventures among competing firms, including joint $R \& D$ programs, pooling of technical or marketing information, or standard setting, would thus be subject to antitrust scrutiny.

The question of antitrust restriction on $R \& D$ has recently arisen in discussions of cooperative $\mathrm{R} \& \mathrm{D}$ on generic technologies in various industries, including semiconductors. In the 1960's, the Department of Justice brought a suit under the Sherman Act alleging unlawful restraint of competition in technological $R \& D$ in the automobile industry, ${ }^{4}$ The automakers were accused of conspiring to slow the pace of technological developments aimed at meeting Federal exhaust emissions standards, Thus, joint venture and cooperative $R \& D$ programs, as well as pooling of tech-

'15 US.C.sec. 1 ( 1976), Also relevant ure the Sherman Actprovi suons, 15 L'.S.C.sec. 2 [ 1976), which prohi hi I the monopolazat ionof, or a t tempts or conspiraciestomonopolize, " any parfof the trade ur commerce u mung the several States, or with foreignnat ions, andsec: 7 of the Clay tun Act. $15 \sim^{\prime}$. S.C. sec.18 ( 1976], whuh prohibitscorporate acqu isr toons of the stock or assets uf ot her coveredcorporations " where in any line of commerceinany section of the ((inn t rv the effect uf such acquisit $10 n$ may be substa $\mathrm{n}$ tially to lessen a $\mathrm{nl}$ compet $\mathrm{i}$ toonor tend to create u monopoly."

'Inited States v. Motor Vehicles Manufacturers Associaton of the US , Inc., 1969'1'rude Cases 91, par. 72,907 (C)D. Cial.1969). 
nical and marketing information, may continue to be challenged under antitrust provisions-by the Government or by private parties, The guidelines for joint $R \& D$ recently issued by the Department of Justice, discussed below, seem unlikely to have a dramatic effect on perceptions in this area,

The potential relevance of antitrust considerations for industrial policy was illustrated during 1980 in the context of Government plans to assist the domestic automobile industry, Secretary of Transportation Goldschmidt's task force considered a variety of steps that the Government might take-including trade, tax, credit, and unemployment assistance policies, One trade policy option would have been for the administration to urge voluntary restraints on automobile imports from Japan. However, this option was judged to run the risk of antitrust litigation as an informal trade restraint agreement.

Antitrust statutes are among the more ambiguous in the United States. The Sherman Act is written in particularly general terms, and must frequently be interpreted by resort to the courts. Litigation is often prolonged and expensive; penalties can be high, including large sums in civil damages from private actions. Imprisonment may result from criminal antitrust actions. Some observers believe that uncertainties concerning antitrust enforcement, combined with such large risks, has a substantial inhibiting effect on the activities of business and industry. Others believe the activ$i$ ties inhibited to be primarily those that are clearly collusive and anticompetitive, and that present antitrust enforcement practices are necessary and effective.

Concerns of this type-related particularly to topics such as joint $R \& D$ or joint ventures for foreign trade-have recently received a good deal of attention. For example, in a message to Congress on October 31, 1979, President Carter emphasized the importance of stimulating industrial innovation, and acknowledged that antitrust laws have often been assumed to prohibit all cooperative R\&D. He directed the Justice Department to issue a set of guidelines concerning antitrust implications of cooperative research; these guidelines were published late in 1980, and seem a useful though limited step in removing ambiguity from this area of antitrust enforcement.

"Mone: Would Give (artertree dand," A utomotive News Aug 11, $1980, p 4$

"Industraa I Inn ovation Init datives Remarks A muound me a Program

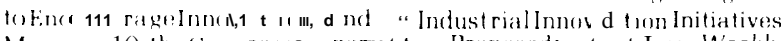
Message 1() the (ongressi ransmit tungProposedi nit lat Ives, Weekly (iompilationof PlesidentiolDeruments(), I 31.1 979. pp 2070-2071

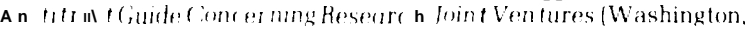
[). ( Antitrust Division. Department of Justice, November 1980|
In fact, much of the lore of antitrust is unpublished-although often enunciated in speeches by Government officials, copies of which are available from the Justice Department on request. ${ }^{8}$ Under such conditions, the private sector is likely to be wary of any participation in industrial policy initiatives which may seem to carry risk of antitrust actions.

Antitrust enforcement also extends to international trade. For example, the voluntary restraint agreements (VRAs) on imports of steeldiscussed in chapter 6-were challenged under the Sherman Act by Consumers Union, ${ }^{9}$ As a result of the VRAS, nine Japanese steel companies, plus British Steel Corp., and a number of Western European steel firms belonging to the European Coal and Steel Community, jointly agreed to reduce the amounts of steel they would export to the United States. Consumers Union charged that the President and Secretary of State lacked the authority to negotiate these agreements, and also claimed that, even assuming such authority existed, VRAs were unlawful under section 1 of the Sherman Act.

As the case progressed in the district court, Consumers Union withdrew its Sherman Act claim, leaving a state of uncertainty that still exists surrounding such voluntary private agreements. Basically, the question concerns whether or not private agreements, negotiated or induced by the Government but falling short of outright governmental compulsion, enjoy some degree of protection from antitrust attack because of the Government's involvement. Also note that, although Consumers Union brought suit against the Government (specifically, the Secretary of State), private suits might have been filed in addition. Parties directly affected by the agreements-for example, purchasers of steel claiming that VRAs raised steel prices to artificially high levelscould have brought actions under U.S. antitrust laws against the foreign steel producers that were parties to VRAs (although this might have posed jurisdictional problems).

\section{Trade Law}

The executive branch has considerable discretion in negotiating trade agreements. Nonetheless, this discretion is limited in various ways-

"For example. I. Davidow, "Unfair Competition in the U.S." (Brussels. Belgium: International Institute for the Study of Commercial (ompetition. May 5, 1980)

Consumers linion of LS. Inc. v. Rogers. 352 F. Supp. 1319 (I).I).C: 19731: Comsumers linion of UIS Inc v. Kissinger, 506 F.2d 136 (I) C. Cir 19741 . 
for example, by antitrust laws as indicated in the previous section. Other restrictions stem from international obligations the United States has assumed-e.g., under the General Agreement on Tariffs and Trade (GATT).

U.S. trade law includes a large body of treaties and executive agreements of both a bilateral and multilateral nature. Prior to 1947, American trade agreements were bilateral, However, since the appearance of GATT in 1947, most trade agreements entered into by the United States have been multilateral.,"

The basic purpose of GATT was to create a freer environment for trade among the member nations and to discourage attempts by countries to promote their own industries or to create relative disadvantages for other nations' industries. GATT attempted to meet these objectives by developing a framework for eliminating tariff discrimination among member nations, by reducing barriers to free trade other than tariffs, and by moderating tariff levels, GATT provisions represent important limitations on the kinds of policies the United States as a member nation may adopt-whether to promote domestic industries in foreign trade or to protect domestic industries against foreign competition.

However, the legal status of GATT in the United States has been unclear since its signing. GATT has never been submitted to the Senate for its "advice and consent" pursuant to article II of the Constitution. Therefore it has never been ratified as a treaty. Indeed, language in trade legislation enacted by Congress in the decade following the signing of GATT expressly withheld congressional approval or disapproval.

In April of 1979, the President's Special Trade Representative initialed the Multilateral Trade Agreements (MTAs) resulting from the Tokyo Round negotiations held under GATT. Several months later, Congress passed the 1979 Trade Act and officially approved and implemented the Agreements. Thus, the binding effect on the United States of at least the MTAs is clear-in the absence of judicial challenges to the unusual procedure of adopting separate implementing legislation to effectuate trade agreements entered into by the executive.

Major U.S. trading partners are parties to GATT and the MTAs. Accordingly, actions by the

"General Agreement on Tariffs and Trade. 55 UIN.T. 194. T.A.S No. $1700(1947)$. There have been seven rounds of trade negotiations under the auspices of GAl"I since 1947, the most recent of which wats the [okvo Ruund (1975-79).

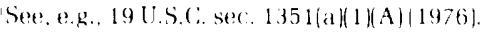

United States to assist domestic industries that are inconsistent with obligations under the Agreements-or are perceived by other signatories to be inconsistent-may be subject to diplomatic challenge under GATT. ${ }^{12}$ Moreover, since the trading partners of the United States have generally similar trade laws, violation of MTA or GATT provisions by the United States could provoke retaliation by these countries, including the implementation of both tariff and nontariff measures to restrict U.S. exports.

While the MTAs limit the policies of member governments that could act as export subsidies, they do provide leeway in such policies, Governments may promote the health and vigor of their industries in a general manner, even though such policies have an indirect impact on foreign trade. Thus, GATT does not prohibit policies aimed primarily at domestic operations, and should not pose an obstacle to industrial policies with domestic goals.' Nonetheless, the issue of when domestic subsidies begin to interfere with international trade flows has often been a matter of contention within GATT, Considerable effort went into negotiating the subsidy code in the new Agreements to try to arrive at more workable procedures,

\section{Freedom of Information Act; Government in the Sunshine Act; Federal Advisory Committee Act}

The Freedom of Information Act (FOIA) lays down comprehensive requirements for the disclosure of records kept by Government agencies. ${ }^{14}$ It makes disclosure of such information the rule, and provides the public with powerful procedural tools for enforcement. Although the FOIA embodies a basic public policy favoring open Government and public disclosure, the Act itself recognizes through a series of exemptions that not all of the Government business can be conducted in a fish bowl, Exceptions include national security matters, law enforcement investigations, and confidential business information, including trade secrets.

The breadth of FOIA'S applicability suggests that it could well apply to special Government

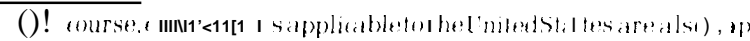

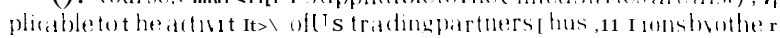

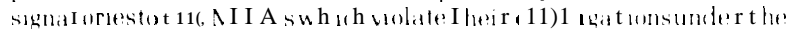

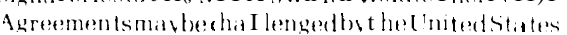

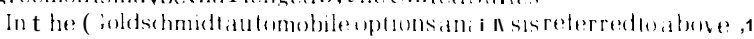

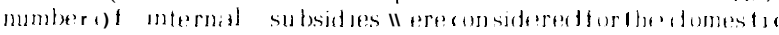
antomobilendust 5

$5 \operatorname{lis}(: \sec 552(1976)$ 
boards or corporations established for purposes of industrial policy. Thus, the scope and legal effect of the so-called "trade secrets" exception to FOIA are matters of potential importance. For example, some policy measures might call for significant submissions or exchanges of sensitive $\mathrm{t}$ ethnological, commercial, or financial datae.g., costs of production-the public disclosure of which could prejudice not only the firms involved, but also the achievement of the policy goals. [Financial harm is a basic test applied to FOIA exemptions. ) The key question would appear to be whether the exceptions, as presently embodied in the Act, would he viewed by the private sector as adequate protect ion against the disclosure of confidential information. If not, private firms would be unlikely to cooperate in the policy.

What FOIA did for agency records, the Government in the Sunshine Act does for agency meetings. Enacted in 1976, the statute requires that ". ., every portion of every meeting of an agency shall be open to public observa t ion." ") The Chrysler Corporation Loan Guarantee Board, among o the $r$ Gove rnmen $t$ bod $i$ es, has comp $1 \mathrm{i}$ ed wit $h$ the Sunshine Law'. 't The Sunshine Act does allow an agency to close its meetings undersome circumstances, including a 11 of the situations covered by FOIA exempt ions-e.g., discussions of financial data, internal personnel rules, private personal records, and information on financial inst itut ions.

The Federal Advisory Committee Act applies FOIA and Sunshine Act principles to advisory commit tees. I $\mathrm{t}$ requires that "each advisory commit tee meet ing shall be open to the public. I I t also requires that: 1 ) notice of meetings be published in the Federal Register; 2) interested persons be permitted to "a t tend, appear before, or file statements subject to reasonable regulations;" 3) minutes and other records be kept and be made available to the public.

The Sunshine Act and the Federal Advisory Committee Act raise issues similar to those of FOIA-i.e., the willingness of individuals and firms in the private sector to participate in policy initiatives that might involve disclosures of confidential in forma $t$ ion.

\section{Conflict of Interest and Financial Disclosure}

Federal conflict of interest laws and regulations, as well as financial disclosure laws,could affect the formulation and orimplementation of policies that depend on recruitment of private citizens to work for the Government. Theselaws and regulations extend to part-time as well as fulltime employment, and also to unpaid consultants. With some exceptions, they prohibit Government employees from having financial interests in Government activities: restrict the professional ac tivi ties of former Government emplovees in terms of whotheymay represent before the Government as "agen t orattorney"; prohibit Government employees fromreceiving compensation from nongovernmental sources: andprohibit Government employees from representing a client in a proceeding $\mathrm{t} o$ which the Ln $\mathrm{i}$ ted States is a party or has a direct or substantial interest.

The basic conflict of interest rule prohibits execut ive branch employeesfrompart ic i pa $\mathrm{t}$ ing in proceedings in which they have a financial interest. " The prohibition includesconsultat ion and advising, as well as decisionma $\mathrm{k}$ ing.Financia 1 interest is broadly construed to refer to interests of family and associates.

A detailed Executive order has been issued implementing the conflict of interest statutes, and two Government agencies-the Office of Personnel Management and the Office of Governmen $t$ Ethics-oversee the operation of the statutes. In addi $\mathrm{t}$ ion to these laws and regula $\mathrm{t}$ ions, under the Ethics in Government Act of 1978 many categories of Government employees must disclose detailed personal financial in forma $t$ ion.

These lawscould pose obstacles to the implementa $t$ ion of some kinds of policies because individuals in the private sector $w i$ th special expertise might either be disqualified outright or might find the prohibitions and rest rictions onerous and disruptive of their careers outside Government. There are also potential conflicts of interest when Government officials with regulatory responsibilities over industry become members of special boards, committees, or task forces relating to that same industry.

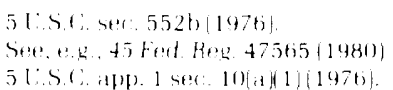




\section{Government Ownership of Patents and Technology}

If an industrial policy initiative were to involve Government stimulation or funding of R\&D and innovation, questions could arise about the interest of the Government as opposed to the private sector in any resulting inventions or other proprietary technology. Furthermore, legal restrictions on the utilization of Government-owned technology by private firms might impede the commercial development of that technology.

A number of complex and conflicting policy considerations exist in this area. First, when public funds are used to generate new technology, it seems clear that such technology should be utilized for the benefit of the public. Moreover, where the technology represents a significant advance in the state of the art, and has competitive significance, it is also clear that affording exclusive use of the technology to one firm might detract from competition in the industry. This consideration is particularly important where the technological development supported by Government would not have been commercially feasible for any one firm acting alone. On the other hand, in the absence of exclusive licensing rights, private firms might not commercialize the new technology.

Current rules governing the licensing of technology generated either by Government employees or through Government funding reflect-but do not resolve-these competing policy considerations. Thus, there is a strong general presumption favoring nonexclusive licensing. And, while provision is ostensibly made for exclusive licensing where necessary to ensure commercial development, the Government in many cases still retains the right to require sublicensing and otherwise to assure broad dissemination of the technology in a manner potentially inconsistent with a grant of exclusive rights.

At present, different Government agenciesthe Department of Energy, the National Aeronautics and Space Administration, the Department of Defense, the Environmental Protection Agencyhave different rules governing the ownership and licensing of rights to inventions or discoveries they have supported financially. Sometimes these rules are developed by the agency itself, other times they are statutory. Thus, the rights of the Government and of private firms are not set out in a unified body of law. Each agency operates under its own distinctions, its own rules or stat- utes, and its own procedures. This lack of consistency has been widely perceived as undesirable - and a potential inhibition to innovation and the commercialization of new technologies. Several bills recently introduced before Congress have sought to remedy this situation.

\section{Legal Challenges and Judicial Review}

New policy initiatives toward industry might involve new statutes, amendment or repeal of existing statutes, promulgation or amendment of executive orders or agency regulations, or combinations of these. Moreover, depending on their substance and reach, implementation might be assigned to the executive branch, existing executive or independent agencies, Government corporations, new regulatory bodies, or combinations of such entities. In turn, actions taken might include informal policy statements or guidelines, rules of general and binding applicability to individuals or businesses, or specific enforcement actions to restrain conduct inconsistent with rules and statutes. At almost any step, affected or aggrieved parties might challenge such policy initiatives in the courts. Measures intended as components of industrial policy could be subject to delaying actions as well as the threat of being struck down.

Historically, when Congress has enacted regulations significantly affecting private economic interests, it has generally provided avenues for aggrieved persons to seek judicial review. If precedent is a guide, therefore, significant aspects of new policies would likewise be subjected to judicial scrutiny. Moreover, even where Congress does not expressly provide for judicial review of an agency's action-and assuming that it does not by statute expressly preclude judicial reviewsuch review will generally be available under the Administrative Procedure Act, 'g which embodies a strong presumption in favor of judicial review of agency conduct.

Permeating the body of statutory and decisional law governing the activities of administrative agencies-as well as court review of these activities-are the often conflicting goals of: I) efficient and effective administration and implementation by Government officials of congressional objectives; and 2) the protection of private property rights from unjust or excessive governmental interference-e. g., ensuring adherence by

\footnotetext{
"5 U.S.C. sec. 500 et sea. sec. 701 et seq. (1976)
} 
the Government to constitutional and statutory guidelines.

Reflecting the great increase in Government regulation over the past 15 years, the entire area of administrative law is currently in a state of flux. Thus, while judicial challenges to new policies affecting industry might be frequent, it is difficult to do more than speculate on outcomes. However, under ordinary circumstances, the courts would probably not interfere at the preliminary stages of policy formulation. Once implementation commenced, depending on the interests affected by the policies in question, judicial challenges, including preenforcement challenges, could be expected. Whether preenforcement challenges would be entertained, and precisely at what point the courts would find that an agency's actions were "ripe" for judicial review, would depend on the availability of other means of judicial review, and the hardship of pursuing such means. In any event, it appears likely that at least some industrial policy initiatives representing substantial change from past practices would be challenged in the courts. At the least, such challenges might delay the implementation of new policy initiatives. 
Japan, France, and West Germany have evolved different approaches to industrial policy over the postwar period, As with well-developed industrial policies elsewhere, all three use a mix of policy instruments-both sectoral policies and those with aggregate objectives. The French have relied most heavily on sector-specific measures, while West Germany has stressed macroeconomic and other broad policies,

In France and Japan, which have stronger centralized bureaucracies, the direct promotion of particular industries has often been a national priority. French industrial policy has lately turned toward greater reliance on market mechanisms, an approach that West Germany has followed for many years. In Germany, the role of government intervention in the affairs of specific firms and sectors has been limited compared to both France and Japan, It is perhaps no coincidence that West Germany, with its federal government system and less centralized policymaking apparatus-in both respects the most like the United States-has emphasized sectoral measures less than Japan and France.

Any review of foreign industrial policies must keep in perspective the backdrop of rapid economic growth throughout the industrialized world that persisted from 1947 to roughly 1970. All three of these countries benefited from conditions uniquely conducive to economic expansion; under such circumstances, it is easy but potentially misleading to give too much credit to industrial policy. The critical tests for each-as for the United States-began in the 1970's. These tests will continue in the decade ahead, as the world economy grows only slowly and competition in many industrial sectors intensifies (ch. 7). Even for countries that have in the past successfully promoted industrial development, stronger competition, from more sources, presents difficult policy problems, In each of these three countries, industrial policy is being reexamined, and new approaches are under debate,

\section{The Industrial Policy of Japan}

\section{The Role of Government}

Few observers would dispute that the Japanese have successfully promoted the development of key industries during the postwar period. However, disagreement persists concerning the most critical factors in shaping industrial policy in Japan-in particular, the importance of the government role,

Observers in countries such as the United States, where Government efforts to directly promote the development of specific industries are more the exception than the rule, have at times assumed that the Japanese Government directly controls and systematically coordinates industrial policy.

While the support and guidance of the Japanese Government have clearly been important for the formulation and implementation of industrial policy, other factors have also contributed to the development of consistent and vigorous policies, Among these are the dynamism and leadership of the business community, an educated labor force incorporated into the industrial system through enterprise unions, a competent, elite bureaucratic corps, and the unusually long reign of the governing conservative Liberal Democratic Party. Furthermore, the political stability and worldwide economic expansion of the postwar periodlasting until the oil and trade crises of the 1970's-offered a climate that contributed importantly to Japan's economic development,

While much has been made of consensus and cooperation in Japan, there has been a great deal more conflict of interest and bargaining among public and private officials than may appear on the surface. Industrial policymaking in Japan, as elsewhere, is a process of conflict accommodation. What is striking about the process in Japan is the effort exerted behind the scenes by business and government leaders to informally gather information, develop a common perspective, and thus lay the groundwork for policy before final decisions are reached. Cooperation and consensus are in no sense automatic, but are carefully nurtured.

\section{Government Guidance}

While Japan's Government has traditionally played an important role in stimulating and promoting industrial development, indirect and in-

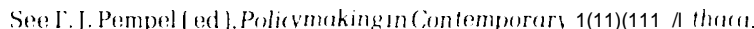
NY( iormell [ Jniversil, Press. I(177), for ancoverview of debatesonlap)a11, sep pllicumak Ing 
formal methods of guidance have generally been preferred to direct Government ownership, subsidies, or regulation. The part played by government differs from that in other countries less in the extent of intervention than in the methods used to guide and support industry. The Ministry of International Trade and Industry (MITI), which is directly responsible for industrial policy in Japan, uses different types of policies for different industries, and at various stages of development. These sector-specific measures are supplemented by macroeconomic policy and planning carried out by a number of other government agencies, including the Ministry of Finance, the Bank of Japan, the Economic Planning Agency. and the Science and Technology Agency.

In the early postwar period, five Japanese industries, including steel, were targeted as essential to a modern industrial economy. Later, attention shifted to the auto and computer industriessignaled by the development of a plan for controlling foreign investment in the motor vehicle industry in 1952, and the passage of the Electronics Industry Act in 1957. Industrial development plans and forecasts such as these are periodically reviewed and revised. The foundation of the government official position toward the electronics industry now consists of three major pieces of legislation-the 1957 Act, plus additional laws passed in 1971 and in 1978.

During the early stages of industrial policy formation, advisory panels-such as MITI's Electronics Industry Deliberation Council-collect information and build consensus among public and private officials. In addition to these official advisory groups, business committees and ad hoc political party conferences have often been formed. Keidanren, the Federation of Economic Organizations, has, for example, been instrumental in developing industrial policy initiatives for the electronics industry through its Committee on Data Processing. Sanken, the Industrial Problems Study Committee, was directly involved in advocating increased concentration in the steel industry. The Auto Industry Policy Conference was established by the Liberal Democratic Party in 1966 to deal with the imminent liberalization of trade,

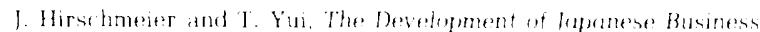

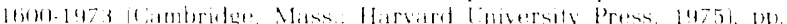

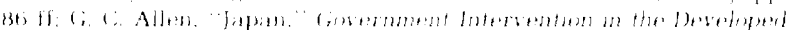
Fenomy (London C Crom Helm. 1979). p. 18.

For a general outlises of the eromomir and terthology policumaking

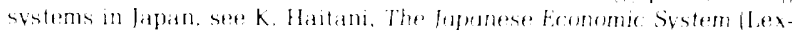
ingtun. Mass.: 1). (. Heath. 1976). and Pelicites for the Stimulation of In

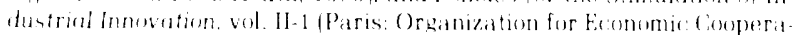
tirna and [eevelopment, 1978), (th. 5
}

In implementing industrial development plans, MITI officials have generally relied on "administrative guidance-which often has no specific statutory basis-to informally direct industries and firms. ${ }^{4}$ Bank of Japan executives similarly apply "window guidance" to the volume and direction of loans made to customers of the city banks.' Such guidance has been used to provide incentives for industrial development. to ration credit to industries and firms judged capable of rapid growth, to oversee industrial production and capacity expansion, and to encourage mergers.

To cite a few specific examples of incentives used to stimulate industrial development, the Japanese Government provided the steel industry with a set of tax and duty exemption measures during 1951 and 1952. Accelerated depreciation allowances and tax breaks have been used to promote the development of new technology in the electronics industry. MITI has also encouraged mergers: the 1957 Electronics Industry Act authorized the Ministry to guide the formation of cartels for standardizing design and rationalizing production in the computer peripherals sector; loans and tax concessions were used to encourage mergers in steel; a special tax deduction helped to promote mergers in the auto parts industry.' In addition, R\&D is stimulated through subsidies and financial incentives. MITI Agency for Industrial Science and Technology has initiated a number of long-term research projects to develop technologies such as battery-powered autos, very large-scale integrated circuits, and computer software (ch. 5). Government support is often channeled through institutions such as the Japan Electronic Computer Corp. or the Information Technology]' Promotion Agency, which receive funding from the private sector as well as loan guarantees from the government or the Japan Development Bank,

Until the early 1970's, Japan's trade policies actively promoted exports, while limiting imports of manufactures and inflows of foreign exchange. Quotas, tariffs, and commodity taxes were used to protect domestic industry. To increase exports, the Bank of Japan discounted short-term export bills at less than the market interest rate, and the Japan Development Bank and the Long-Term

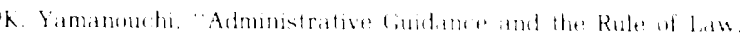
law in lopun wol. 7, 1974. 1). 22.

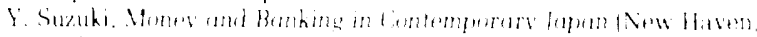

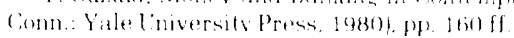

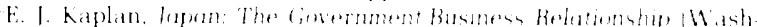

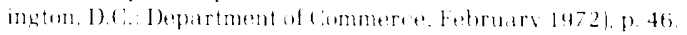

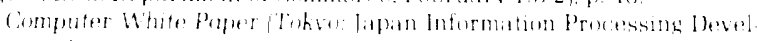
opment center, $1976 j .613$
} 
Credit Bank provided inexpensive long-term credit for export-oriented businesses, ${ }^{\mathrm{H}}$ Based on its authority under the old Foreign Investment Control Law, the Japanese Government restricted the entry of foreign firms. Though the circumstances differed, both IBM and Texas Instruments, among U.S. companies, were permitted to establish manufacturing operations in Japan only after agreeing to license patents to Japanese manufacturers.

Such blatantly protectionist policies, though formerly the norm, were substantially relaxed during the 1970's. Tariffs have been reduced to levels comparable to other industrialized nations, broad export incentives have been erased, and import quotas remain on only 27 product areas. With most trade barriers essentially dismantled, the primary obstacles remaining to hinder foreign investment and exports to Japan are less formalrestrictive interpretation of customs and product approval procedures, a complex distribution system, and government and business propensity to "buy Japan.",

\section{Effectiveness of Japanese Industrial Policy}

While Japan's Government has employed a variety of methods (many of them informal and few of them unique) to promote industrial development, it would be a mistake to assume that such efforts have always succeeded or that they have been consistently well received by business and industry. In a number of cases, Japanese firms have resisted MITI actions aimed at restricting corporate autonomy: auto parts makers opposed MITI's attempts to foster consolidation; during the mid-1960's, Sumitomo Steel refused to follow MITI guidance and limit capacity expansion; more recently, mainframe computer manufacturers have not cooperated in mergers. There have also been conflicts with other government agencies: the Ministry of Finance successfully opposed MITI efforts to establish the Japan Electronic Computer Corp. as partially governmentowned; the Fair Trade Commission was successful in resisting MITI's push to enact a "special industry development law" in the mid-1960's, but failed to block the merger that created New Japan Steel. '[) The politically powerful but uncompetitive

\footnotetext{
"I. C. Magaziner and I $\mathrm{M}$ Hout. Japanese Industrial Policy (London Policy Studies institute, 1980 l.pp 42 and 78 .

'F A. Weil and N G Glick. "Japan-Is the Market Open? A View of the? Japanese MarketDraun From U.S. Corporate Experience, Law and Policyin In ternational Business. voll 1, 1979, p 856.

Ka plan op. \{it., includes considerablediscussion of fa $I$ lures in government-business cooperation: see pp 48-67.
}

agricultural sector has received extensive government protection and subsidy at a high cost in economic efficiency. These examples show that cooperation between government and the private sector in Japan is not automatic. When it occurs, cooperation is best viewed as less the product of direct government control than the outcome of extensive but informal negotiations which result in policy that industry perceives as beneficial.

The effectiveness of Japanese industrial policy has not depended on government alone. When government actions have produced positive results, they have supported and stimulated the independent dynamism of business and industry, Increasing productive efficiency, and intense competition among firms in the domestic market, indicate the vigor and strength of Japanese industry, which is primarily privately owned and operated.

It is easy but misleading to overemphasize the contribution of the sector-specific components of Japan's industrial policy to her economic success. Broad-level indicative planning and macroeconomic policy have helped foster a stable economic climate, one conducive to industrial development. During the 1970's, for example, officials in the Ministry of Finance and the Bank of Japan contributed to industrial growth by placing high priorities on anti-inflation and exchange rate policies.

And, while Japan's past record of industrial development is impressive, a crucial question now is whether policy makers will be successful in adapting to new international and domestic conditions. MITI's current policy planning aims at adjusting to a period of lower economic growth and constraints on resources. The MITI "vision for the 1980 's" calls for ambitious efforts to revamp Japanese industry and society toward a knowledge-intensive, high-technology, resource-efficient structure. Technology as the key to economic security is at the center of the MITI strategy, "In this sense, Japan's emphasis on the electronics and information industries is based on an economic perspective more comprehensive than a simple sectoral policy.

Such a comprehensive plan will not be easy to implement. Recent experience in Japan shows that when the economy slows, conflicts of interest grow among firms and industries, particularly those in actual or potential decline-such as steel, aluminum, and shipbuilding-which compete for special assistance. In 1978, the Japanese

"Hochijunendai no Tsusho Sangyo Seisaku The Trade and Industry Policy in the $1980^{\circ}$ s). Sangyo Kozo Shingikai (Industrial Structure Coun(il). Mar. 17. 1980. p. 9 
Diet passed a law to assist such "structurally depressed" industries; but some observers have questioned the effectiveness of such aid, arguing that the plan has not succeeded in moving resources out of declining industries.

Another factor creating new difficulties for industrial policy is the internationalization of the Japanese economy. Industrial promotion policies cannot be pursued to such extremes that they jeopardize national security by provoking Japan's allies. Moreover, as the number of agencies and organizations directly concerned with industrial policy has grown, the process of policy formation has become more complicated, These factors suggest that real change will be required of public and private policy makers if Japan is to implement industrial policy appropriate to a new domestic and international climate. If the past provides an indication of the future, the Japanese Government can be expected to play a significant role in promoting the continued competitiveness of Japanese industry-but the governmental role will not be the sole determining factor.

\section{The Industrial Policy of France} The Role of Government

The French have long perceived the interplay of market forces in the economy to be chaotic and wasteful if left unregulated by government. Thus intervention has not been unique to the postwar period, but accepted as a more-or-less permanent feature of the French economy. And, to a greater extent than in many other countries, the French have used industrial policy to attempt to reach goals beyond economic development. For example, the policy of "national ";hampion" industries followed during the 1960's valued national security and prestige above economic efficiency.

Public policies in France have for many years included both protection and promotion of key industrial sectors through a wide variety of mechanisms. These mechanisms have embraced financial subsidies of many types, price controls, encouragement of mergers to increase the size and market power of French-owned corporations, export promotion, and facilitation of inward flows of technology in industries such as computers, semiconductors, and aerospace.

As is common elsewhere in Europe, there is considerable government ownership in the French economy. In fact, the sharp distinction between public and private sectors characteristic of countries such as the United States has never existed in France. Many French banks are publicly owned, and government has a strong voice in the operations of the nationalized railroads, in Air France, and in the two major oil companies -as well as exercising effective control over the two largest steel producers, (Roughly 70 percent of steel capacity is essentially nationalized.") Other publicly owned firms, such as Renault and the aircraft manufacturer Aerospatiale, carry on their activities with little direct government involvement.

The French State is highly centralized, with an elite bureaucracy that has considerable autonomy in shaping industrial policy.' As in Japan, most of the decisionmakers in both government and industry are graduates of a few prestigious schools. However, the extensive process of discussion and consensus building that precedes decisions on industrial policy in Japan is largely missing in France. Although a variety of government agencies influence policymaking, authority is remarkably concentrated, much of the actual power residing in government and semipublic financial institutions. Unlike the routine participation afforded interested parties outside the bureaucracy in Japan or West Germany, neither industry nor labor has a visible role in formulating or legitimating French industrial policy-although they can be heard through informal channels,

\section{Evolution of Industrial Policymaking in France}

Industrial policy in France since 1945 has passed through a number of stages. The exigencies of postwar redevelopment led at first to reliance on relatively formalized economic planning. But the very speed and success of redevelopment exposed shortcomings in the planning process, which since the early 1960's has been largely superseded by a more ad hoc approach,

The Gaullist period of the 1960's featured a strategy of national champions-targeted sectors intended to bring prestige as well as trade competitiveness to French industry. Largely failures -e.g., the Plan Calcul, the Concorde-the French have now turned away from highly visible national champions while remaining committed to sectoral intervention on a case-by-case basis.

\footnotetext{
Technolngy and Steel Industry Competitiveness (Washington. D.C. Office of Texthology Assessment. L.S. Congress, June 1980), p. 125

"I. Zysman. Political Strutegies for Industriul Order: Stute. Murket and Industry in France (Berkeley. Calif. : University of California Press. 1977). pp. 59-60
} 
Since 1978, government pronouncements have placed more emphasis on market forces rather than planning and intervention. There has been a shift away from price controls, as well as attempts to create more competition within the French economy.

During the 1970's, export promotion took on a greater role in industrial policy, largely because of the need to pay for high-priced imported oil. ${ }^{14}$ France's lack of energy resources also led to a strong emphasis on nuclear power generation-a technology where French industry is now among the world's leaders.

The net effects of economic planning and industrial policy in postwar France are difficult to evaluate. The government role became more systemized and more openly acknowledged concurrent with a period of rapid and steady economic expansion lasting until 1974, Much of this growth would have occurred irrespective of government actions, making it difficult to identify either positive or negative effects of industrial policy, While the French Government has failed to restore a high rate of real growth since the 1975 recession, this is a problem shared by most of the rest of the industrialized world. Despite such conspicuous failures as the Concorde-and the difficulties France has recently faced in restructuring her steel industry-many features of postwar French industrial policy have been emulated in other European countries and in the Third World.

\section{Economic Planning}

Following World War II, France adopted a system of economic planning based on 5-year projections intended to guide industrial development on a sectoral basis, This system of indicative planning-which entailed a careful laying out of public investment decisions, along with suggested directions for complementary private investments - was at first oriented toward the needs of postwar reconstruction. By 1960, indicative planning as originally conceived had been largely abandoned-in part a victim of the increasing complexity of the expanding French economy. The plan still remains-indeed the VIII plan began in 1981 - but is now largely a vehicle for discussion and information exchange within the bureaucracy and among political interests, a means of broadening perceptions and suggesting desirable policy directions. The VII plan (1976-80), for in-

${ }^{1+}$ I. G. Franku and S. Stephenson, French Fiport Behavior in Third World Markets (Washington, D.C.: Geordetown University Center for Strategic and International Studies, 1980), p. 17 stance, included a detailed outline for strengthening French science and technology. It recommended an increase in employment in the sciences, also proposals for the organization of research, as well as desirable fields of R\&D (e. g., information industries, electronic components, scientific instrumentation).

Despite the comprehensive nature of these 5year plans, even during the early postwar period the power vested in the Planning Commission-a small bureau attached to the office of the Prime Minister-was modest. As French industry redeveloped, government influence over the private sector increasingly gravitated to financial institutions-particularly the Ministry of Economy and Finance (since 1978 reorganized into two separate agencies), but also a variety of semipublic lenders such as the Credit National, plus the banks, both public and private."

During the Gaullist period of targeted support to national champion industries such as computers, these financial institutions played a major role. Agencies such as the Ministry of Industry also participate in developing strategies for industrial policy, but the importance of lending institutions in shaping industrial policy is a notable similarity among Japan, France, and West Germany, In the French case, the government influence over banks and other lenders appears to be considerably stronger than in West Germany, and at least comparable to that in Japan,

Banking in France is highly concentrated, facilitating government involvement in credit decisions; three large nationalized banks control roughly half of all funds on deposit. The Plan Calcul, for example, intended to build an internationally competitive computer firm, received more than a billion francs (roughly $\$ 200$ million) in equity investments, loans, and research subsidies-in part directly from the government, in part indirectly through government-influenced credit decisions, The Plan Calcul also illustrates the targeted approach to industrial polic adopted in France during the 1960's. Rather than systematic economic planning, this approach relied on sectoral programs that were themselves comprehensive but not necessarily closely tied to the remainder of the economy, The Plan Calcul involved the coordination of a variety of govern-

\footnotetext{
Programme \#25, Le Vil Plande Developmen t Fo onomaque et Soc ial 1976-1980(Paris, 1976), pp. 294-301.

" I Zvsman, The State as Economic Plaver (Berkelev Calif Universitwof California Press, forthoming)

J. Melitz. "I’he FrenchFinancial Svstem MechanismsandPropositoms of Reform." Conference on Pol i ticalEconomv of France. American Enterprise Institute. Washington, 1), (...Ma1 29-31,1980.
} 
ment policies, including financial tools, to support an industry judged important to national interests. Recently, as mentioned above, the French have attempted to be more flexible and more market-oriented in their sectoral programs.

\section{The Plan Calcul}

The Plan Calcul began in 1967 as the result of an agreement between the French Government and the Companie Internationale pour l'Informatique (CII). The massive and coordinated effort of the Plan Calcul was in large measure a reaction to a pair of events which reinforced the widespread perception of U.S. dominance of European computer industries. ${ }^{18}$ The two events were the acquisition of the French computer firm Machines Bull by General Electric in 1964, and the denial by the U.S. Government of an export license for the sale of a Control Data computer to the French Atomic Energy Commission in 1966. These developments catalyzed the French effort to build a strong, independent capability in computers,

CII was established by merging the two French firms with computer hardware capability that remained after the Machines Bull purchase. Implementation of the Plan Calcul depended on broad participation and cooperation within the French Government, involving institutions ranging from the Ministry of Industrial and Scientific Development to the Ministry of Defense. Coordination of their activities was the responsibility of an ad hoc body within the office of the Prime Minister, the Delegation for Information Science.

In 1975, the Plan Calcul was in essence terminated: it had been no more than marginally successful in its attempt to build a viable computer sector, although maintaining a French presence in the industry. Many reasons have been suggested for the Plan's shortcomings, including a lack of coordination with overall macroeconomic policy and an overly ambitious strategy of attempting to quickly reach technological parity with the U.S. computer industry over a broad front, rather than concentrating on more limited segments of the market, But its comprehensive outlook was nonetheless an important development in French sectoral planning. The Plan Calcul went beyond the earlier Concorde program-which had been oriented towards a single development projectto an industrywide approach, A variety of policy instruments-including fiscal incentives, man-

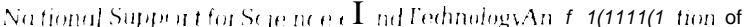

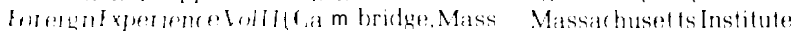

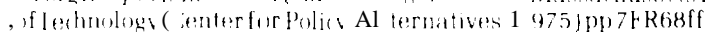

power training, and market forces-were coordinated in order to support CII and the French computer industry.

In 1976, CII merged with Honeywell-Bull-the firm that resulted when General Electric, the purchaser of Machines Bull, sold its computer business to Honeywell. This merger-again nurtured by the government-marked the end of a purely French mainframe computer firm, but not the end of sectoral involvement by the government in the industry; $\mathrm{CH} /$ Honeywell-Bull has continued to benefit from substantial government aid, and the French bureaucracy retains considerable influence over the firm's activities.

\section{Policy Instruments}

As the Plan Calcul illustrates, the French Government has used a complex and continually evolving set of economic incentives to influence and guide industry. These tools include tax benefits, outright grants, allocation of loans and credit on preferred terms, government purchases, and pricing policies, Incentives have been used selectively to encourage the private sector to undertake projects and investments that the State judges desirable.

Although the tools of French economic and industrial policy are similar to those existing in other market economies-including the United States-the French system exhibits several noteworthy features. First, while demand targets have often been formulated, in practice government incentives operate exclusively on the supply side; manipulation of taxes to influence demand has been rare. Second, incentives are positive; they do not constrain firms in the private sector but attempt to guide and encourage them by making certain activities profitable or otherwise attractive. Finally, despite the deep government involvement in many industrial sectors, short-term macroeconomic policy has not been well-coordinated with industrial policy, This appears to have been a major weakness of the French approach to policymaking, with its emphasis on sectoral measures, ${ }^{19}$

Although finance has recently been the central instrument of French industrial policy, many other tools have been employed. In the early postwar period, extensive trade barriers protected French industry and allowed it to redevelop without foreign competition. This had also been a

S. Cohen, Modern Couptolist Planning: The French Mudel (Berkeley (Galif.: Eniversity of (atifornia Press, 1977), p. 8 
prominent feature of French policies before the war. Tariff walls moved outward following the establishment of the Common Market, but France continues to restrict imports through nontariff barriers - imports of Japanese automobiles are a current example.

Support for R\&D has also had a prominent place in French industrial policy, and remains an important feature of the planning process. Nuclear power generation and integrated circuits are among the currently favored targets. ${ }^{20}$ The VIII economic plan-beginning in 1981-puts great emphasis on government support of $R \& D$ in six key sectors: electronics, energy, aerospace, marine technology, machine tools and manufacturing equipment, and biotechnology, The French propose to spend $\$ 25$ billion on the development of these industries over the 5-year course of the plan. ${ }^{2 i}$

\section{Recent Developments}

Several of the more recent shifts in French industrial policy are illustrated by government aid directed at the semiconductor industry. Rather than supporting a single national champion, Le Plan Circuits Integres is promoting several independent efforts-typically involving joint ventures with U.S. firms and aimed at transferring integrated circuit technology to the French partners. ${ }^{2}$ This splitting of the effort among several nominally competing ventures can be taken to illustrate the greater reliance on market mechanisms to which the French have turned. At the same time, given the long tradition of government intervention, and the continued existence of the apparatus and mechanisms used in the past, the move toward a market-oriented industrial policy may prove slow,

Beyond protection and promotion of high-technology growth industries such as semiconductors, the French Government has continued to intervene in sectors perceived as mature or declining, As in Japan, shipbuilding and textiles have been important to the French economy, And again as in Japan, these sectors have received aid aimed at managing decline and ameliorating some of its consequences.

Their steel industries are also important to the economies of both France and Japan, Steelmaker I'" Aims of National Research Program for 1980-1990 Outlined."

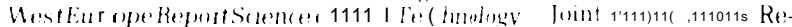
searchserviejlets 1, 896 1, Mi] r 3.1980.ppl i- 6

K l)reyfack, "France Wants Bigger Piece of Pie." Flectroncs, Oct 23. 1980, p 98

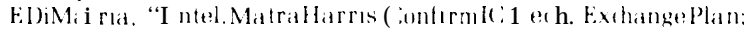
Set Itesign Subsidiarv. Elec trume Nens April 6, 190 1, p 1 in both countries have faced substantial overcapacity, although the Japanese industry is much more efficient. A task for industrial policy in France since 1978 has been to encourage and direct contraction in the steel sector. Financial aid has been provided to ease the burden of indebtedness on the three major steel groups, and policies have been designed to harmonize and rationalize production-e.g., by closing down unprofitable mills. The government intends to phase out more than 30,000 jobs by 1983 , The problems in the French steel industry have required continuing State involvement, in part because of the delicate social and regional problems created by the restructuring effort- the turn toward market mechanisms has clearly not precluded government actions in distressed industries.

\section{Effectiveness of French Industrial Policy}

A balanced view of French industrial policy should recognize its positive contributions to national economic development, but that it also has major weaknesses - and has failed in several ambitious attempts to guide the economy along particular paths. Positive incentives aimed at directing growth on a sectoral basis have often succeeded. But the isolation from market forces created by government intervention has also, in a number of instances, resulted in misallocation of capital and other resources.

Since the mid-1970's, there has been a marked shift in rhetoric concerning industrial policy in France, with government statements now emphasizing a renewed reliance on market forces. Nonetheless, as shown by the strong and continuing role of the bureaucracy in electronics and steeland also in the automobile industry, where the government engineered a recent merger between two private firms, Peugeot and Citroen-France remains a highly interventionist State, one where industrial policy is centralized to an extent unusual in a nominally free market economy.

\section{Industrial Policy in the Federal Republic of Germany}

Economic and industrial policymaking in West Germany is less centralized and less coordinated than in Japan or France. No single agency or institution such as MIT1 exists to develop and implement industrial policy. Industrial policy in West Germany is more like that in the United States than that in France, with sectoral intervention less prevalent. 
The West German economy has performed well in the postwar period, the Federal Republic being noted for consistent reliance on macroeconomic policy emphasizing price stability and export-led growth. A central theme has been the "social market economy ", - a preference for relatively unhindered price adjustments combined with social programs aimed a $\mathrm{t}$ moderating the more undesirable impacts of the free market. The role of the government has been comparatively limited - a major contribution has been to provide a stable and consistent policy environment, and an undervalued deutsche mark. "'Business-labor consensus and a liberal foreign economic policy helped to create a climate in which West German industry prospered. In recent years there has been increasing debate about the need for sectorspecific measures to promote industrial development and adaptation, but West Germany has thus far avoided a strongly sectoral approach to industrial policy.

\section{Participation in Policymaking}

The West German governing system is comparatively de-centralized. The Laender (State) governments play important roles in the Federal structure. Business and labor are relatively wellorganized, and structurally integrated into the policymaking apparatus."

Industry is represented by umbrella organizations such as the Federation of German Industry (BDI), which plays a significant role in formal and informal policy discussions with government officials. Trade associations which participate in the BDI-such as the Association of Electrical and Electronic Industries-work to promote consensus on industry-specific programs. Labor unions are likewise involved through industrywide and regional collective bargaining. Systems of codetermination and plant-level councils give workers a direct voice in the operations of factories. Labor unions are informally consulted about measures to promote industry. They also participate through organizations such as the Federal Institute of Labor, which develops programs to ease adjustment to change. At one time the "concerted action" system was also an important vehicle for labor participation-a mechanism that could be revived in the future.

1. Pinder. T. Hosumi, and W. Diebuld, Industrinl Policy and the? Inter

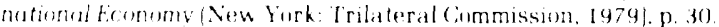

$\therefore P$. Katzenstein. Betwen Power and Plenty: Foreign Fonnome Pol icies of Advanced Industrini States fMadison. Wis.: University of Wis(onsin Press. 19781, p. 320.
Interest groups-from both business and labor-are systematically represented in policymaking, but government institutions are also important. Specialized agencies such as the cartel office (which has pursued a comparatively moderate antimonopo]y policy) and the Deutsche Bundesbank (the central bank in West Germany, which operates with considerable autonomy) provide continuity in economic policy. Although Germany's social welfare programs are the most extensive of the nations discussed in this appendix, the West German approach to industrial policy exhibits little direct government intervention compared to France or Japan.

\section{Approaches to Industrial Promotion}

Price stability, high employment, and economic growth are fundamental goals of West German industrial policy The 1967 Growth and Stability Law provides for the coordination of public and private decisions through a system of consultations between government, management, and labor, Finance plans are prepared on a 5-year basis: the Deutsche Bundesbank has a wide array of instruments to implement monetary policy. Though the Bundesbank is theoretically independent, it is bound to support the overall economic policy of the government, and in practice normally acts in close consultation with public officials.

A number of institutions-the Council of Economic Advisors, the Ministries of Finance and Economics, the Bundesbank-develop macroeconomic policies affect ing all industries; but the banks deserve special emphasis. During the high growth period through the 1960's, the Bundesbank maintained exchange rates at a level that undervalued the deutsche mark and promoted exports. More recently, the bank has emphasized stabilization.

West German banks play an additional role in industrial policy because they are allowed to hold stock in corporations, as well as making loans to them. Because bank loans are important sources of capital for West German firms, lending policies can influence business strategies. So while it would be an exaggeration to suggest that the Bundesbank or the banking community orchestrates economic and industrial policy in any centralized fashion, financial institutions do have an important part in West German industrial policy, as in France and Japan.

I he Aimsand Instrumentsof Indus trial Polic va Paras Organaza toon for ficonomic ( ioperationand l)evelopment. 1975 l. p 30 ) 
Subsidization of industry in West Germany is both direct and indirect, but is not used as widely or heavily as in many other industrialized nations. The shipbuilding industry has been given export financing assistance and tax benefits; incentives are offered to purchasers of domestically built ships. Germany's coal industry receives substantial subsidies and tax benefits, and mergers have also been encouraged. ${ }^{26}$ Generally speaking, however, manufacturing industries in West Germany have not depended on government subsidies, which have been relatively modest in size.

The West German Government also influences industry through public ownership. The government owns more than 3,000 firms, accounting for 10 percent of national income, ${ }^{27}$ The Federal and Laender governments together hold 40 percent of the stock of Volkswagen. While Volkswagen has been quite successful, Salzgitter-a steel company wholly owned by the governmenthas suffered the largest losses of any nationalized firm. Generally speaking, publicly owned firms function much like privately owned companies. There is little direct government involvement in management, nor much special assistance.

While distressed sectors such as shipbuilding, coal, and textiles have received considerable government attention, West German industrial policies have also attempted to target growth industries, ' 8 In recent years, the promotion of technological innovation, particularly in new and developing industries, has become an important element in industrial policy. Set up in 1972, the Ministry for Research and Technology (BMFT) has developed a wide variety of programs to assist both large and small firms.

Electronics companies receive $R \& D$ assistance from both the BMFT and the Ministry of Economics. The government has helped large companies such as Siemens develop advanced computer technology, and has begun an R\&D support program for very large-scale integrated circuits.")

'(; de Carmoy. "Subsidy Policies in Britan, France, and West Ger. manv: An Overview, "International Trade and Industrial Policies. S. J Warnecke, ed(New York Iolmes and Mejer, 1978). p. 50. In 1974 subsidiestot he coalind ust ry totaledIJM 1,721 millum, more than $\$ 600$ millın.

- A Wilson. "Nlal(jr StructuralDifferences of the Eromomies of the U. S., GermanvandJapan An Overview < Congressional Research Serv 1111, Librarvof (ongress Oct 31.1979, p 47.

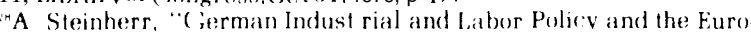
peanCommunity,' West Germunv A Europeanand Gilohal Power W.I. Kohl and (;. B \{ asevi, eds (l,exington, Mass 1). (Heath, 1980). p. 125.

'Between 1976 and 1979 the governmentreportedlyallocated $\$ 625$ million rn mat changR\&I)gran tstorompanesproducing smallcomputer svstems and peripheral equipment. The VLSI program launched on 1980 willbefunded by $\$, 300 \mathrm{~m}$ illıon $\mathrm{n}$ match ing government gran ts See Mi croelectromes In tothe 80 s(Luton, Englan i: Mackin toshPublicatons, l.td, September 197[)), pp. $51 \cdot 2$.
While the bulk of the government's assistance has gone to large companies," in recent years there has been a growing effort to assist smaller firms, of which there are more than 1,000 in electronics alone. A variety of methods are being used; for example, the government helps to support the Venture Financing Co., a corporation established in 1975 to emulate some of the features of U.S. venture capital markets.

BMFT has also setup a number of pilot projects to help smaller firms. The VDI Technology Center, for example, was established in 1976 to help small companies develop and apply microprocessor technology. The Center now has more than a hundred projects.

BMFT activities are extensive and diverse, In addition to its direct sponsorship of programs such as the VDI Technology Center, BMFT works indirectly through trade associations. It also provides some of the funding for the Fraunhofer Gesellschaft, a nonprofit society that conducts applied research useful to industry, generally on a contract basis. Substantial government funding is channeled to the Gesellschaft, the BMFT providing a core of basic support, as well as contracting or sharing costs with industry for most projects. A primary aim is to facilitate the rapid transfer of new technology to industry, There are 28 individual research institutes in the Fraunhofer Gesellschaft, each with its own facilities and a good deal of autonomy. The institutes are organized on a disciplinary basis-e. g., there are separate facilities for solid state electronics and semiconductor processing technology. Each institute has a board of directors with strong industry representation.

In addition, the West German Ministry of Economics supports 80 industrial research associations, Emphasizing R\&D assistance to smalland medium-sized firms, these are organized across disciplines to cover the range of technologies important to a particular industry.

Other distinctive features of West German industrial policy have been the use of regional development plans, and a strong focus on labor issues. A Federal-La ender committee plans re-

In 1980 . the BMFT planned to spend 7.5 percent of its 6.17 billion 1)M, fabmut $\$ 3$ billion) budget an assistance fo smaller

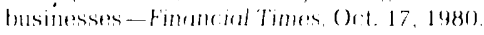

"General Scheme of the Federal Government's Research and Technology Policy for Small and Medium-Sized Firms" (1979 update), Ministrufor Research and Technology (BMF"').

"Sixth Report of the Federal Gowerment on Research. Ministry for Researehand lechologe (BMFT). 1980 .

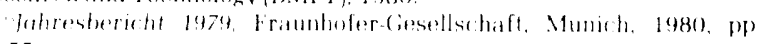
$53-55$. 
gional economic development. Sixty percent of the land area of the country is now covered by the program, which has channeled assistance to industries near the East German border and in the Saarland coal mining region, Businesses in development regions receive incentives such as taxfree grants covering 10 to 25 percent of investment costs, loans on preferred terms, and accelera ted depreciation allowances. Land acquisition assistance is also provided to firms locating or expanding facilities in designated areas, West Germany has thus developed a rather systematic approach to regional development.

The emphasis on labor concerns in West Germany is in marked contrast to countries such as Japan where enterprise unions are common. In 1974, BLIFT and the Labor and Social Affairs Ministry set up a joint program of research on workplace humanization, Stimulated by the Works Councils Act of 1972, the program reflects concern about the effects of industrial change on both skilled and unskilled workers; it aims not only to protect the health and safety of the labor force, but also to encourage organizational changes which workers themselves help to identify and implement. Oriented toward field experiments, a number of projects have focused on effects of automation and applications of computer technology.

The labor movement is strong in West Germany compared to Japan or France. Union representation on the supervisory hoards of corporations is required by law, Whether despite or because of the participation of labor in business decisionmaking as well as public policy, labor unrest in West Germany has been remarkably low, Over the most recent 5-year period for which data is avail able (1974-78), work stoppages in the Federal Republic cost, on the average, 6 working days per 100 employees per year. "The corresponding figures for other countries are: Japan, 13 days: France, 21 days; and the United States, 48 days.

A final important element of postwar West German industrial policy has been its international orientation. West Germany has had consistent trade surpluses, more than half of its exports going to other nations within the European Community (EC). The Federal Republic also carries on extensive trade with Eastern European nations. West Germany has clearly benefited from trade

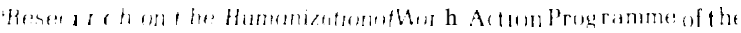

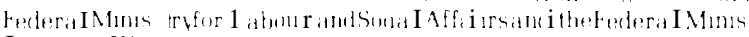

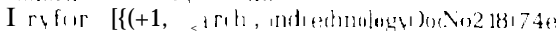

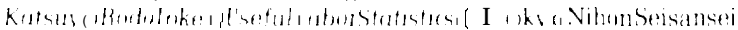

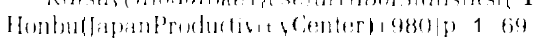

with its neighbors, and has favored EC policies aimed at reducing obstacles to free trade within the community. Less progress has been made in common EC industrial policies. An EC steel policy has been developed and superimposed on the national policies of the members of the Community, but the national policies are not always consistent with those of the EC Steel Directorate. In electronics, there has been no real Community policy. Some leaders of the West German electronics industry believe that here too a common approach-at least to problems of sudden surges in imports from abroad-may be necessary in the years ahead,

\section{New Directions in West German Industrial Policy}

A distinguishing feature of postwar German industrial policy has been its "free market" orientation. combined with extensive social programs aimed a $t$ easing the impacts of structural change on various groups, particularly labor, But while the West German Government has consistently tried to avoid strong intervention in particular industrial sectors-such as the French or Japanese emphasis on targeted industries-over the years sectoral intervention has nonetheless increased. Since the late 1960's, a number of sector-specific programs have evolved, particularly for hightechnology industries. Such policies represent a conscious attempt to meet foreign competition through expanded public support for growth industries and new technologies. Thev have been intended 1argely as supplements to macroeconomic policy.

The BNfFT programs discussed in the previous section, in particular, have been based on the proposition that government policies can and should promote positive structural adjustment. In some contrast to the industry orientation of the Ministry of Economics and its associated industrial research associations, BMFT projects emphasize development of new and key technologies such as semiconductor electronics important across industries,

Sectoral programs have been the subject of continuing controversy in the Federal Republic. Advocates of vigorous structural policy (Strukturpolitik) contend that government Support for highly competitive industries and technologies is essential if West German industry is to remain internationally strong and if structural change is

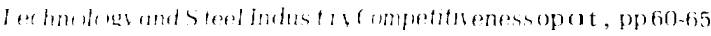


to be smoothly accommodated domestically. While they do not call for the introduction of an elaborate economic planning system on the French model, advocates of Strukturpolitik believe that government actions are justified to relieve bottlenecks and distortions in the market. Opponents worry that government support for targeted industries and technologies will lead to controls on investment and ultimately to cartels.

'F'()r a discussion of the Strukturpolitik debates, see M. Kreile, "West Germany "The Dynamics of Expansion, "Between Power and Plen ty Foreign Economic Polic ses of Advanced lndus trial Sto tes. P. Katzenstein. ed. (Madison. Was. Univers i tvof Wisconsin Press, 1 978), pp. 220-22,
This dispute has been colored by partisan and bureaucratic politics and is likely to persist in the years ahead. Fundamentally, the controversy concerns the appropriate role of the West German Government in industry and the economywhether the free market tradition needs modification in a period when technological development seems essential for maintaining competitiveness. 


\section{Index}


a ggregatepolicies. 158. (SeealsoGovernmentpolicies.)

Air Force molecular electronics program, 117

alloy specialty steel industrv. 9, 32.75

alternative fuels. 143

American Motors, 44, 147

:1 n I idumping policies. (See dumping. )

an Ii t rust po]icies, $117,155,176.184-185$

Appropriations Commit tee, House, 162

Appropriations Committee.Sena le. 162

A' \& I, 117

automobileindustrv

compet i t ive sta t us, 14-16, 31, 104-105

concent ration, 42-43

demandprojections, 140-141

domestic boundaries defined. 33-34

employment, 95

fulurecompetitiveness. 127, 143-148

andgasol ine prices, 1 18-120

and highwavconstruction, 120

Japanese experience, 15-16,95-99

markets, 43-44

product differentiation. 44

productionandsales data, 53, 92-95

productivity. 55.57

products defined, 33

and regulat ion, 44. 120-123

size, 42

sma I 1 car s trategies. 99-102

technologicalinnovation. 141-143

wages, 59,60

Banking Committee.Iouse.162

Banking Commit tee. Senate. 162

Belliaboratories, 40, 116, 117

BL, Ltd, 146

Brazil. 75, 132

Budget Committee. Senate, 162

Bureauof Industrial Economics. 163

C.AD(computer-aided design). 87

Canada. 71

capital markets. 105

andautomobile industrv. 144

and Govern men t policies. 139, 176-177

ands tee] i ndus trv. $111-112$

capitalplant. 31

capital requirement $\mathrm{t} s, 46$

a u tomobile indus trv. 101. 144

Japan ese experience. 89

semiconductor" industrv. 40.88-89, 138

steel industry. 132-133

Carter. Jimmy. 132.185

Chrvsler Corp., 43,44, 94, 101.120.146, 147

Commerce Committee. House. 162

Commerce Committee. Senate. 162

Commerce Department, 73, 156, 159, 160

compet it iveness

capital markets and, 105 conceptidefined. 25, 16(L 174

decline in, 25-26. 105-106

economir growt hand, 127. 128

findings summarized, 3-4

indicalors of. 49, 65. 17.3-174

in fluenceson.69-70

productivilyand. 54-58.61

product reliabilits and, 38

s tudwhiectivesandscope. 2,1-24

rechnologicalinnovat 1011,1 nd, o 1-65

trade balance and, $50-54$

wages and. 58-60

See also specificindustries

compu ter indusir

andantitrus tpoluces. 117

and oom $m$ un wa I ionregulat toms.1 17-1 18

competitive stat us. $41.89-90.104$

demandprojections. $134-1,35$

Japa nese experience. 89-90

marketst rurt ure.41-42

productivity. 55

products defined. 3.3

technological levels. 137

tradepatterns. 52

Seealso electronosindustrs

concent ration

a u tomobilendus trv. 42-4.1, 146-14 7

steelindustrv. 35

confl ir tof in terestlaws. 187

Congress. (See Government policites.)

consu mer elec t ron irs indus I rv

demandprojections. 1.34

importpenetration, 51, 76-77. 103

ma rket shil repa t terns. 37-38, 80-82

overseas productuon, 77-78

production rests, 79-80

productivity. 56.57

products defined. 33

resea rrh anddevelopment, 79, 115-116

and trade protectiom, 114-116

wages. 59.60

Seealso electronicsindusirs

consumption (sales)

au tomobile industrv, 14. 16. 92-95, 140-141

electrontcsindustrv. 134-135

steelindustrv. 1 1, 75-76, 103, 129

copyright policv. 117

Corporate Average Fuel Fconomv [(; AFE) standards.1 19, 122 144

costs. (See production costs.)

costs and benefitsanalysis. 180-181

Council of Economic Advisers, 154

Datsun, 99, 146

Defense Department. 88.156.163.188

demand. (See consumption.)

depreciationschedules. $113,132.139,146$

dumping 
consumer electronics, 78, 114-115

steel, 9-10, 31, 36-37, 72-73.103

trigger-price mechanism, 73, 112, 131, 179

Economic Development Agency (EDA), 112, 155

economic growth

and competitiveness, 127, 128

and steel consumption, 103

Education and Labor Committee, House, 162

electric vehicles. 143

Electronic Industries Association, 114

electronics industry

competitive status, 12-14, 31, 91-92

domestic boundaries defined, 33-34

future competitiveness, 127, 133-134, 137-140, 147-148

and Government policies, 114

technical personnel shortage, 90-91

See ULSW computer industry: consumer electronics industry: semiconductor industry

emission standards, 120- I 21

employment

automobile industry, 14, 16, 95

consumer electronics, 77

and productivity, 4, 11, 12, 26, 103

steel industry, 74-75

Energy Department, 156, 163, 188

energy policies

gasoline price controls, 118-119

and steel industry, 113-114

Energy Policy and Conservation Act, 119

Environmental Protection Agency (EPA), 120, 188

environmental regulation

and automobile industry, 120-122

and competitiveness, 17, 154

and steel industry, 10, 37, 113-114

Environment and Public Works Committee, Senate, 162

Europe

automobile industry, 141

See orso dumping

exchange rate effects. 73-74. 173

Fairchild, 82,88, 116

Federal Advisory Committee Act, 187

Federal Reserve Board, 154

Federal Trade Commission, 160

Fiat, 146

Finance Committee, Senate, 154.162

financial disclosure laws, 187

Ford Motor Co., 43,44,94, 101, 120, 122, 141, 143, 146, 147

Foreign Affairs Committee, House. 162

Foreign Relations Committee, Senate, 162

France

GDP growth, 61

industrial policy. 193-196

Freedom of Information Act (FOIA), 186-187

fuel economy, 99-101.121

Fujitsu, 90

gasoline prices, $118-120$

General Agreement on Tariffs and Trade, (GATT), 73, 186
General Electric, 79,80

General Motors, 43,44.101, 120.122, 141.146, 147

Government in the Sunshine Act. 187

Government policies

and automobile industry, 16, 44.94, 101, 118-123. 146

as causing market imperfections. 179-180

and computer industry, 117-118

costs and benefits analysis, 160, 180-181

and electronics industry, 114

French experience. 193-196

industrial policy, 7-8, 151-152, 157-158

Japanese experience, 190-193

legal constraints, 183-189

legitimate function of, 3, 26-27.180

macroindustrial policv, 8-9.20. 160-165

market failure as rationale for. 175-179

overview and evaluation. 3-7, 17-20, 109-110. 123, 152-157, 165

political context underlying, 158

prerequisites for industrial pt)licl. 159-160

research support. 116-117

and steel industry, 9-10, 37. 111-114

west German experience, 196-200

Great Britain, 61.75

gross domestic product (GDP), 61.128

gross national product (GNP). 23

ratio of exports to. 50

highway construction.” 120

Hitachi, 90

Honda. 43.99

IBhl. 40, 41, 82, 90, 114, 117, 176

ICs ( integrated circuits). (SW s ;nli(()[](i ]('1[)r In(iusl ri. ) import penetration

a u tomobile incius $t$ ry, 92-95

consumer electronics, 12.76-79

international Irade fl\{)m's. 49-54

import quotas. 181. (See (Iis $\{\mathrm{J}$ I rade p[)iiclw+, )

industrial policv. (See G(wernnleo t policies, )

in tegra ted steel indust rv, 9, 32. (SW Ils[)s I eel Indus t r!. )

integration. 40, 44.80, 88

Intel, 82

International Iron and Steel lnstitut ?. 133

International Track Commission.” 73, 115, 160, 163-164

Intersil, 88

investment st imula t i $\{$ )n. (S(?e ti] x p[)li('ies. )

Isuzu, 147

Japan

au tomobiie i ndus $\mathrm{t} r v, 15-16,57-58,95-99.141$

computer indust rv. 89-90

consumer electronics lodust rv, 77-80

c?xports GNP ra tie. 50

GDP $\operatorname{gr}\{\mathrm{w}[\mathrm{h}, 61$

industrial policies, 89. 139, 190-193

research and dew?1\{)pment, 63.64

steel pr(ducti[)n costs. 73-74, I 03

। I,SI program, 83-85

wag(? I rends. 60 
Joint Committee on Taxation, 154

Joint Economic Committee, 154, 162

Labor and Human Resources Committee, Senate, 162 labor costs, 15.97. (See also production costs.)

Labor Department, 160, 163

labor market imperfections, 177-179

Jegal issues, 183-189

]icensing fees, 64-65

Joan guarantees, 26-27, 112, 146, 155

Lockheed, 82

macroeconomic policies, 153-154. (See also Government policies. )

macroindustrial policy. [See Government policies. )

manpower, 90-91, 117, 139

manufacturing costs. (See production costs. )

market

failures, 175-180

Japanese strategies, 95,99

shares, 80-82, 155

structure, 41-42, 44

See also capital markets

Mexico, 71, 75

microcars, 143

microcomputers, 41, 136

microprocessors, 39, 87, 136-137

military research, 63-64, 116-117

minicomputers, 41

minimills, 10

Mitsubishi, 90.1.47

molecular electronics, 117

Nlostek, 88

hfotorola. 77,82,88

Multilateral Trade Agreements (MTAs), 139, 186

National Aeronautics and Space Administration, 156, 163, 188

National Highway Traffic \%]fety Administration (NHTSA), 120

National Productivity Council, 163

National Science Foundation, 156

Nippon '1'elegraph and Telephone Public Corp., 116, 139

Nissan. 122

nonintf?grated steel industry, 9, 31, 32.35

occupational safety. (See workplace health and safety. )

Office of Management and Budget, 154

Office of Science and Technology Policy, 156

OPEC, 119

Orderly Marketing Agreements, 37, 51, 76.115, 179

overseas production, 77-78

ownership of techn[dogy. 188

patent policy. 117,188

Peugot-Citr[)en, 146

prices

controls, 110

steel industry, 70-71

product differentiation, 46

a u Iomohi ] e i ndus t r\}', 16, 44, 148

Japanese automobile" industry, 15 steel industry, 34

production costs

automobile industry, 15

Japanese experience, 73-74,79-80,97.103

semiconductor industry, 39

steel industry, 35-37, 73, 129

televisions, 78

productivity y

automobile industry, 14

and competitiveness, 49, 54-58, 61

and employment, 4, 11, 12, 26, 74-75, 103

Japanese experience, 57-58,98

product market imperfections, 176

profitability

semiconductor industry, 40

steel industry, 37

protectionism. (See trade policies. )

public policy. (See Government policies. )

quality, $38,41.79, \quad 87$

quotas, 181. (See UISo trade policies. )

radios. (See consumer electronics industry; electronics industry. )

RAM [random amess memory). 54,82, 136

RCA, $65,79,80,114,138,170$

reference prices, 112

regulatory policies. [See environmental re ulation. )

reliability, 38 , 41, 77-79, 87-88

Renault, 146, 147

research and development

and antitrust laws, 176, 184-185

and competitiveness, 61-65, 171-173

consumer ele Ironics, 79, 103

ownership issue, 188

semiconductors, 40

steel industry, 35-36, 103, 132

stimulation of, 138-139, 156, 164

road construction, 120

Rockwell, 82

royalties, $64-65$

safety standards, 121. [See oIso workplace health and safety. )

Science and Technology Committee, House, 162

sectoral policies, 157. (See UJSO Government policies. )

semiconductor industry

capital requirements, 40, 88-89

captive production, 82

competitive status, 103-104

cost savings, 39

demand projections. 134

foreign competitive efforts, $82-84$

integration, 40, 88

productivity, $55-56$

product reliability, 41,87-88

products defined, 33

research and development, 40, 116-117

technological] levels, 38, 84-88, 136

trade pat terns, 51-52, 54

$\mathrm{Sec}$ also electronics industry 
Sherman Act, 184-185

Small Business Administration, 122-123

Small Business Committee, House, 162

software, 88, 90, 117, 137

Solomon, Anthony, 112

Solomon Plan, 112-113

Sony, 78, 115

South Korea, 11,51, 75, 115, 133

Steel Caucus, 162

steel industry capital plant, 31

competitive status, 9-11, 102-103

concentration, 35

demand patterns, 75-76, 129

and dumping, 31, 36-37, 72-73

employment, 74-75

and exchange rate fluctuations, 73-74

future competitiveness, 127, 129-133, 147

import penetration, 51

price behavior, 70-71

price controls, 110

production costs, $35-37$

productivity, $55,57,65$

and regulation, 113-114

sectors and products, 32, 34

and technological innovation, 35-36

Third World capacity, 133

trade protection, 111-113

wages, 59, 70, 71

Steel Tripartite Advisory Committee, 113, 159

Sumitomo Metal Industries, 36

supply and demand, (See consumption.)

Taiwan, 51, 115

tariffs, 181. (See U]so trade policies, )

tax policies

and automobile industry, 144-146

and competitiveness, 17, 153-154, 164

and research stimulation, 138-139

and stee] industry, 113, 132

technical personnel, 90-91, 117, 139

technological innovation. (See research and development.)

technological levels, 46

automobile industry, 96-97, 141-143

electronics industry, 84-88, 135-137

steel industry, 36

televisions. (See consumer electronics industry; electronics industry. )

Texas lnstrumenls, 80, 82,88, 116

Third World. 133, 141

Toshiba, 90

Toyo Kogyo, 147
Toyota, 99, 122, 146

trade adjustment assistance (TAA), 155-156, 164

Trade Agreements Act of 1979, 162-163

trade policies

automobile industry, 95, 143-144

and competitiveness, 17, 154-155

electronics industry, 114-116, 139-140

legal constraints, 185-186

protectionism, effects of, 181-182

steel industry, 9-10, 111-113, 131

Trade Policy Committee, 163

Treasury Department, 115, 154, 160

trigger-price mechanism (TPM), 73, 112, 131, 179

truck industry, (See automobile industry. )

Truman, Harry S., 110

turbocharged engines, 143

unemployment. (See employ merit.)

United Auto Workers, 143

Urban Development Administration Group, 155

U.S. Steel. 35,36

value-added, 44

value-to-weight ratio, 36, 41

VHSIC (very high-speed integrated circuit), 88, 116-117

video cassette recorders, 37, 79

video disk players, 37, 79, 138

VLSI (very large-scale integrated circuit ), 83-85,88

Volkswagen, 43,92, 99, 122, 146

Voluntary Restraint Agreements (VRAS), 111-112, 179, 185

wages

and competitiveness, 49, 58-60

Japanese experience, 60

steel industry, 70, 71, 102-103

Ways and Means Commit tee, House, 154, 162

Western Electric, 40,82, 176

West Germany

GDP growth, 61

industrial policy, 196-200

research and development, 63, 64

Westinghouse, 82

workplace health and safety

and automobile industry, 121

and product ion costs, :37

and steel indusl ry, 113-114

world car, 16, 148

Xerox, 170

Z[?nit h, 80 